\title{
The Role of Lysine Acetyltransferase Tip60 in the Murine Hippocampus
}

\author{
Dissertation \\ for the award of the degree \\ "Doctor rerum naturalium" \\ of the Georg-August-Universität Göttingen \\ within the doctoral program Genes and Development \\ of the Georg-August University School of Science (GAUSS)
}

submitted by

Inga Urban

from Hannover

Göttingen 2014 


\section{Thesis Committee}

Prof. Dr. Gregor Eichele, Genes and Behavior, Max-Planck-Institute for Biophysical Chemistry, Göttingen (Referent)

Prof. Dr. André Fischer, Laboratory for Aging and Cognitive Diseases, European Neuroscience Institute, Göttingen (Co-Referent)

Dr. Wolfgang Fischle, Chromatin Biochemistry, Max-Planck-Institute for Biophysical Chemistry, Göttingen (Co-Referent)

\section{Members of the Extended Examination Board}

Prof. Dr. Halyna Shcherbata, Gene Expression and Signaling Group, Max-Planck-Institute for Biophysical Chemistry, Göttingen

Prof. Dr. Michael Kessel, Developmental Biology, Max-Planck-Institute for Biophysical Chemistry, Göttingen

Prof. Dr. André Fiala, Molecular Neurobiology of Behavior, Schwann-Schleiden Research Centre, Göttingen

Date of oral examination: 22.07.2014 


\section{Declaration}

I hereby declare that the PhD thesis entitled "The Role of Lysine Acetyltransferase Tip60 in the Murine Hippocampus" was written independently and with no other sources and aids than quoted.

Göttingen, May 2014.

Inga Urban 



\section{Zusammenfassung}

Die Speicherung von Erinnerungen ist ein hochkomplexer Prozess, der schnelle Veränderungen bestehender Proteine, Induktion von Genexpression, de novo Proteinsynthese und die Modifizierung von neuronalen Strukturen beinhaltet. Die an diesen Prozessen beteiligte zelluläre Maschinerie war und ist Gegenstand zahlreicher Untersuchungen, die enorm zu unserem Verständnis der Gedächtnisbildung beigetragen haben. Posttranslationale Modifikationen (PTM), wie Phosphorylierung und Acetylierung, sind essentiell für die Gedächtnisbildung. Sie sind ein unerlässlicher Bestandteil von Signalkaskaden und regulieren die Zugänglichkeit von Genen für die Transkription. Durch die Beteiligung an der funktionellen und strukturellen Plastizität von Proteinen können sie sowohl die Stabilität eines Proteins als auch seine Wechselwirkungen mit anderen Proteinen regulieren. PTM sind zumeist schnell und transient, was eine hochdynamische Regulation der Protein-Funktion ermöglicht, wie sie für die Bildung neuer Gedächtnisinhalte erforderlich ist. Lysin-Acetylierung ist sowohl an der synaptischen Plastizität als auch der Gedächtnisbildung beteiligt. Diese PTM ist überwiegend in Zusammenhang mit Histon-Protein-Substraten untersucht worden und trägt zur Öffnung der Chromatinstruktur für aktive Transkription bei. Der Acetylierungszustand von Proteinen wird durch zwei Enzymklassen mit gegensätzlicher Aktivität reguliert: Lysin-Acetyltransferasen übertragen Acetylgruppen an Lysinreste von Proteinen, während Lysin-Deacetylasen diese wieder entfernen. Die vorliegende Arbeit behandelt die Rolle der Lysin-Acetyltransferase TIP60/KAT5, für die bereits zahlreiche Histon- und Nicht-Histon-Substrate identifiziert wurden. Allerdings ist die Funktion von TIP60 im Nervensystem von Säugetieren weitgehend unbekannt. Das Ziel dieser Arbeit ist es daher, erste Einblicke in die Rolle von TIP60/KAT5 im Säugerhirn zu gewinnen. Der Hippocampus wird als Zielregion gewählt, da seine Rolle bei der Kodierung neuer Erinnerungen sowohl bei Nagern als auch beim Menschen gut etabliert ist. Zu diesem Zweck wird die Deletion von Tip60 auf exzitatorische Neuronen im Hippocampus von zwei verschiedenen Mausmodellen gerichtet. Die Ergebnisse zeigen, dass ein Mangel an TIP60 zu einer konstitutiven Hochregulierung von mehreren immediate-early Genen, insbesondere in der CA1-Region, führt. Für eines dieser Gene - Npas4 - ist eine Beteiligung an der Regulation inhibitorischer Synapsen- 
bildung bekannt. Während die konditionalen Tip60-Knockout-Mäuse in den ersten Wochen nach Gendeletion zunächst normal erscheinen, bekommen sie später häufig Krampfanfälle, was einen fortschreitenden Effekt auf die synaptische Homöostase nahelegt. Die Analyse dieser Mäuse in einer Reihe von Verhaltensstudien zeigt moderate Änderungen bezüglich der Gedächtnisfunktion. Darüber hinaus wird durch die Transkriptomanalyse der CA1-Subregion des Hippocampus mittels next generation sequencing eine deutliche Veränderung in der Expression von Genen identifiziert, die an der synaptischen Funktion beteiligt sind. Die hier vorgestellten Ergebnisse geben erste Einblicke in die Funktion von TIP60 im Maus-Hippocampus und deuten auf eine Rolle in der Aufrechterhaltung der hippocampalen Netzwerkstabilität hin. 


\section{Summary}

Making new memories is a highly complex process, which involves rapid modifications of existing proteins, induction of gene expression, de novo protein synthesis, and the altering of neuronal structures. The cellular machinery involved in these processes has been the subject of numerous studies, which have contributed enormously to our understanding of memory formation. Posttranslational modifications (PTMs), such as phosphorylation and acetylation, are essential for memory formation. They are an integral part of signaling cascades and regulate the accessibility of genes for transcription. By providing functional and structural plasticity they can regulate both a protein's stability and its interactions with other proteins. PTMs tend to be rapid and transient, allowing for highly dynamic regulation of protein function as is required for the formation of new memories. Lysine acetylation is implicated in synaptic plasticity as well as memory formation. This PTM has mostly been studied with histone protein substrates and contributes to the opening of chromatin for active transcription. The acetylation state of proteins is regulated by two enzyme classes of opposing activity: lysine acetyltransferases add acetyl groups to lysine residues of proteins, while lysine deacetylases remove them. This work is focused on lysine acetyltransferase TIP60/KAT5, for which numerous histone as well as non-histone substrates have already been identified. However, its function in the mammalian nervous system is largely unknown. The aim of this thesis project is therefore to begin to elucidate the role of TIP60/KAT5 in the mammalian brain. The hippocampus is chosen as a region of interest since it has a well-established role in the encoding of new memories both in rodents and humans. Directing Tip60 deletion to excitatory neurons in the hippocampus in two different mouse models, the obtained results show that TIP60-deficiency leads to a constitutive upregulation of several immediate-early genes, predominantly restricted to the CA1 region. One of these genes Npas4 - is known to be involved in the regulation of inhibitory synapse formation. While the conditional knockout mice appear normal the first weeks after gene deletion they become prone to seizures later on, consistent with a progressive effect on synaptic homeostasis. Subjecting these mice to a series of behavioral studies reveals modest changes in memory functions. Moreover, by analyzing the transcriptome of hippocampal subregion CA1 using next generation sequencing, a marked change in the expression of genes 
involved in synaptic function is identified. The findings presented here provide first insights into the function of TIP60 in the mouse hippocampus and indicate a role in the maintenance of hippocampal network stability. 


\section{Acknowledgements}

First of all, I would like to thank Prof. Dr. Gregor Eichele for giving me the opportunity to pursue my $\mathrm{PhD}$ project in his lab.

I would like to thank my thesis committee members, Prof. Dr. André Fischer and Dr. Wolfgang Fischle for their helpful suggestions during the time this thesis project was ongoing.

Also thanks to Prof. Dr. Fischer for allowing me to perform the behavioral tests in his department. Thank you to the additional members of my examination board: Prof. Dr. Halyna Shcherbata, Prof. Dr. Michael Kessel and Prof. Dr. André Fiala for accepting my invitation to join my examination board.

Thanks to Dr. Bruno Amati for sharing his TIP60 antibody and Dr. Reinhard for the great support with antibody production. Also thanks to Prof. Yamada for providing NPAS4 antibody.

I would like to thank the former and present members of the Genes and Behavior department who have accompanied me not only during the time of my PhD thesis. A special thank you goes to Ana for teaching me the first steps in the lab as an undergraduate student and for supervising my diploma thesis. Thank you for your patience and your commitment. I feel very lucky to have had you as my supervisor. Tack so mücke Lars (Lårsch) for your constant support and the many fun moments and discussions. Many thanks to Jana for your support and help whenever needed. Many thanks also to Insa for your help and positive attitude. Also thanks to Tahereh and Vinodh for all the funny conversations and jokes that made hard days much more enjoyable. Thank you Helena for your generous help with so many different things and for being such a nice colleague. Thank you to Denise and Silvana for taking care of my mice. I would also like to thank the circadian rhythms group for their support, especially Henrik for his willingness to discuss problems. Many thanks to Susanne from the Fischer lab for helping me with the behavioral testing of my mice. 
Großer Dank gilt meinen Eltern und meiner Schwester für Eure Unterstützung während des gesamten Studiums und der Anfertigung dieser Doktorarbeit. Danke, Erik, für Deine unendliche Unterstützung während der gesamten Zeit. 


\section{Table of Contents}

ZUSAMMENFASSUNG

SUMMARY

..VII

ACKNOWLEDGEMENTS

IX

TABLE OF CONTENTS

..XI

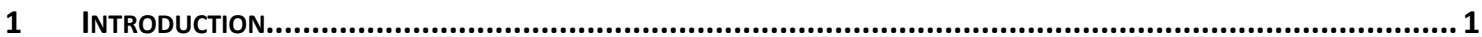

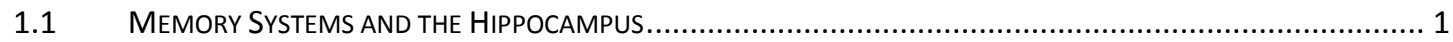

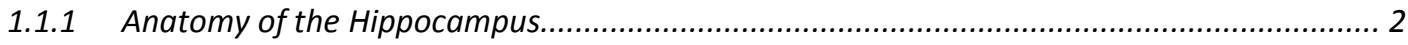

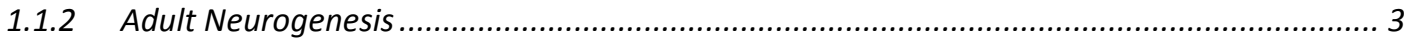

1.1.3 Hippocampal Function and Molecular Processes Involved in Memory Formation ................ 4

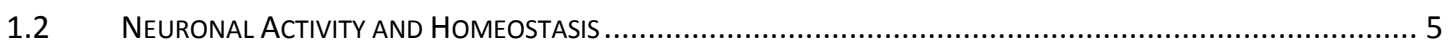

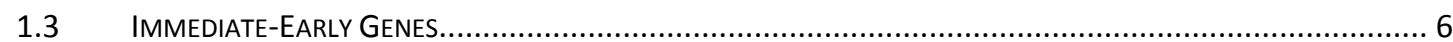

1.4 Chromatin, Transcriptional Regulation and the Role Of ACETYlation in Protein Function ............ 7

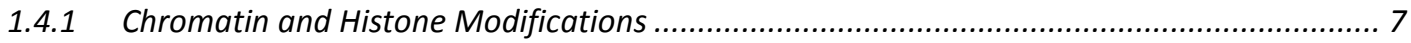

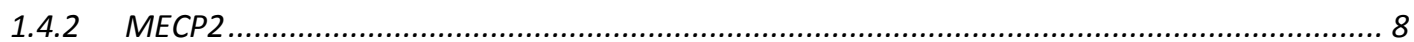

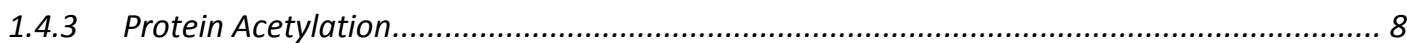

1.4.4 TIP60 is a Lysine Acetyltransferase with Pleiotropic Functions ...................................... 9

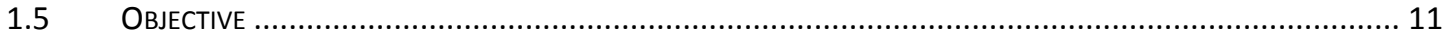

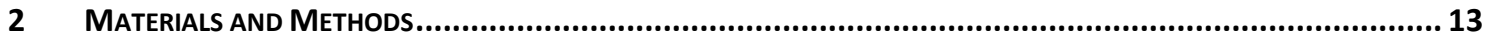

2.1 Tip60 Knockout Models ANd Their Characterization ......................................................

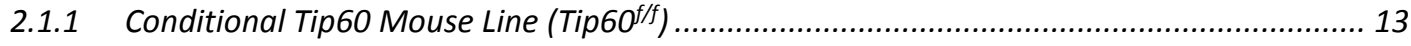

2.1.2 Constitutive Tip60 Knockout Mouse Model (CaMKCre Tip60f/f)........................................ 14

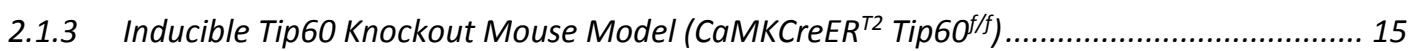

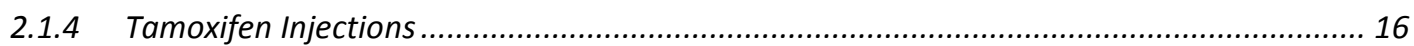

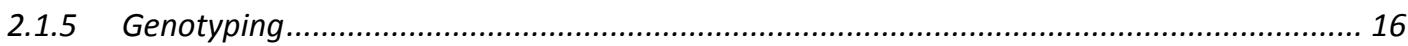

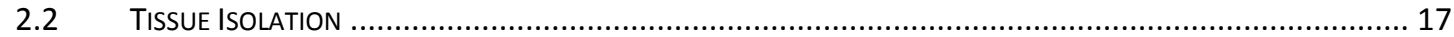

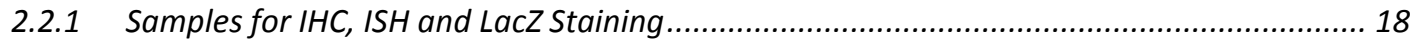

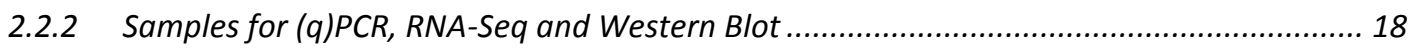

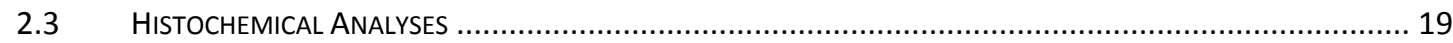

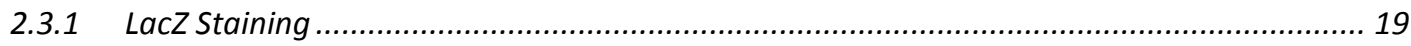

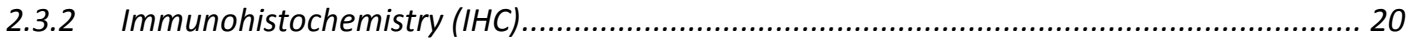




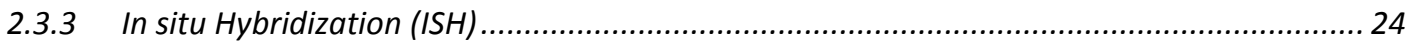

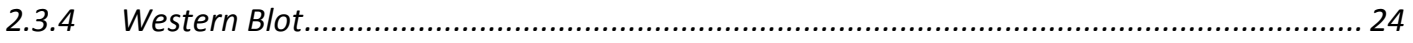

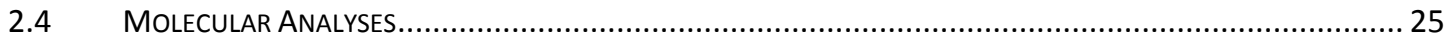

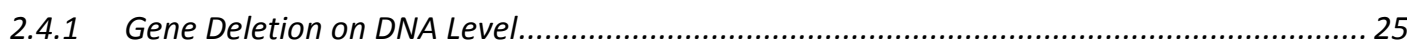

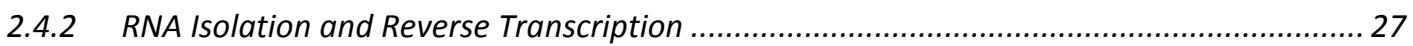

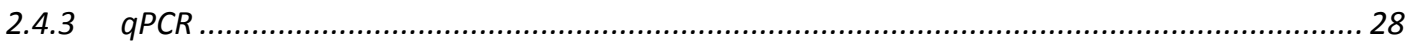

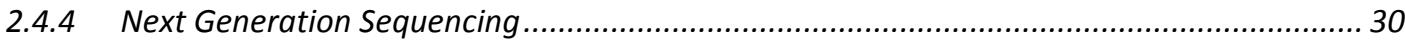

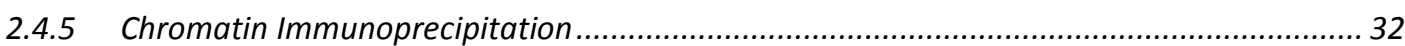

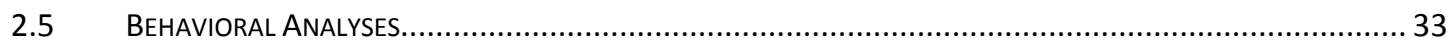

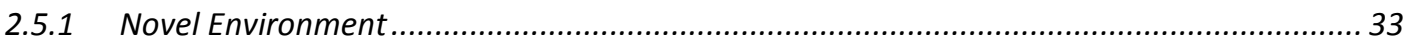

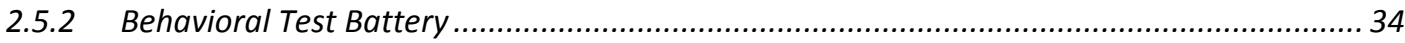

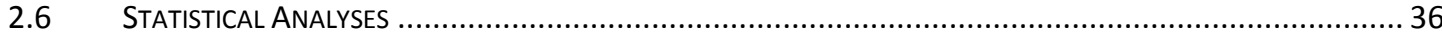

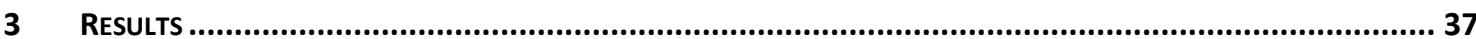

3.1 Characterization of CRE Driver Activity And Tip60 Deletion in TWo Tip60 Conditional Knockout

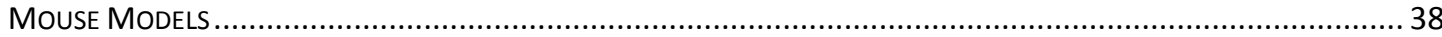

3.1.1 Characterization of the Constitutive Tip60 Knockout Model (CaMKCre Tip60 f/f) ................ 38

3.1.2 Characterization of the Inducible Tip60 Knockout Mouse Model (CaMKCreER ${ }^{T 2}$ Tip60f/f) ... 43

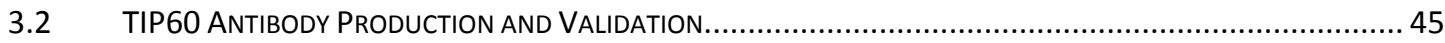

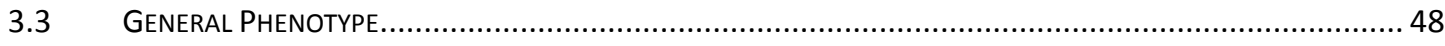

3.3.1 Constitutive Knockout Mouse Model (CaMKCre Tip60 f/f) ................................................... 48

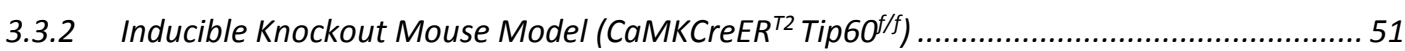

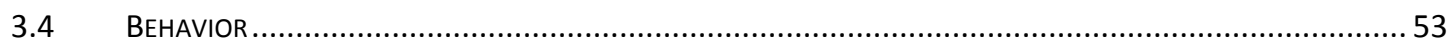

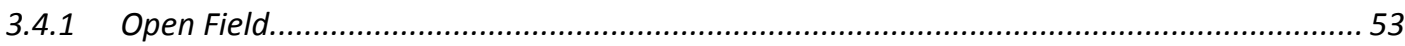

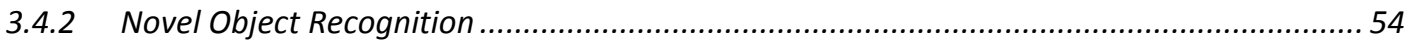

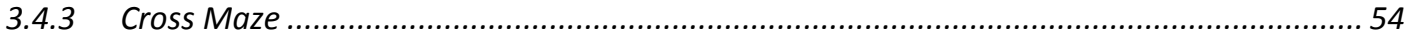

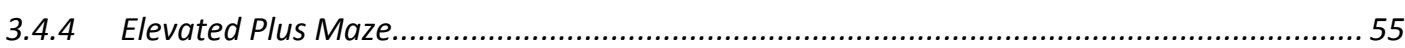

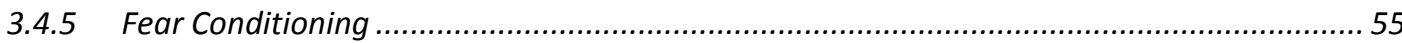

3.5 Gene EXPRESSION Changes InduCEd by A Novel ENVIRONMENT ................................................ 56

3.5.1 Immediate-Early Gene Expression Analysis by qPCR ................................................57

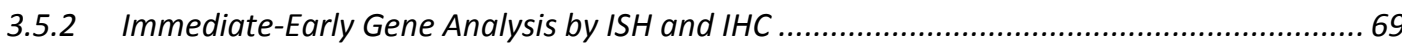

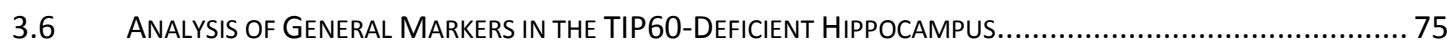

3.6.1 Neuronal, Synaptic, and Dendritic Markers ............................................................ 75

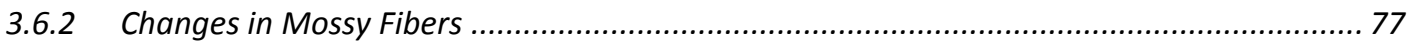

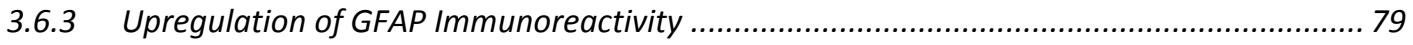

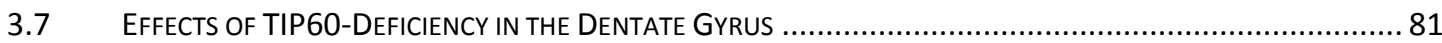


3.7.1 Non-Cell Autonomous Upregulation of Phospho-CREB in the Dentate Gyrus of CaMKCreER Tip60f/f mice

3.7.2 Upregulation of ARC and c-FOS Positive Cells in the TIP60-Deficient Dentate Gyrus.......... 83

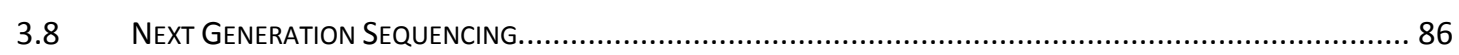

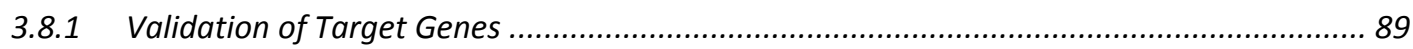

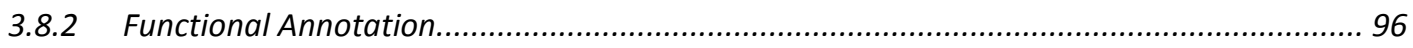

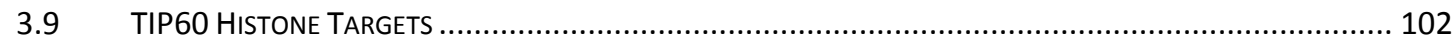

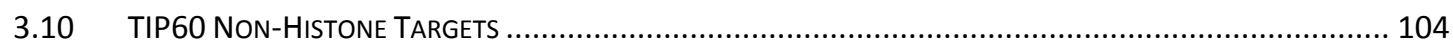

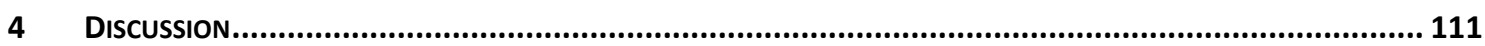

4.1 PHENOTYPES OF THE TIP60-dEFICIENT MOUSE MOdELS ....................................................... 111

4.1.1 Phenotype of the Constitutive Mouse Model (CaMKCre Tip60 $0^{f / f}$ ) ................................... 112

4.1.2 Phenotype of the Inducible Mouse Model (CaMKCreER ${ }^{T 2}$ Tip6O $\left.^{f / f}\right)$................................. 113

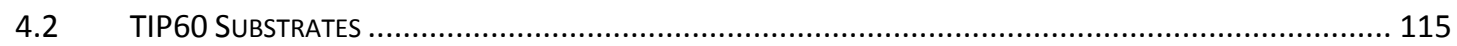

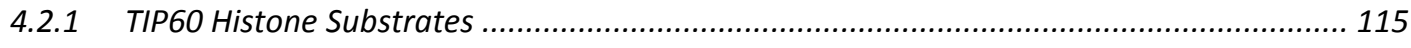

4.2.2 Potential TIP60 Non-Histone Substrates .................................................................. 116

4.3 IMPLICATIONS OF TIP60 Function In NeURONAL HOMEOSTATIC PLASTICITY....................................... 117

4.4 Widespread Changes IN Gene TRANSCRIPTION IN THE CA1 RegION .............................................. 119

4.4.1 Aberrant Regulation of Immediate-Early Genes ..................................................... 119

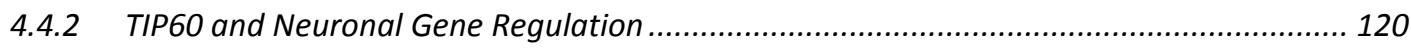

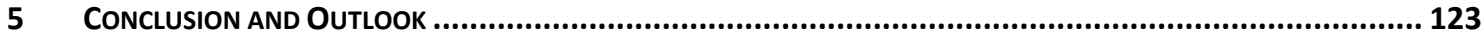

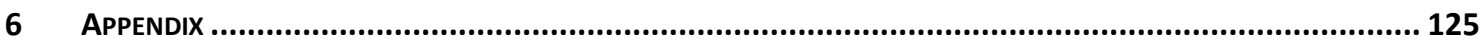

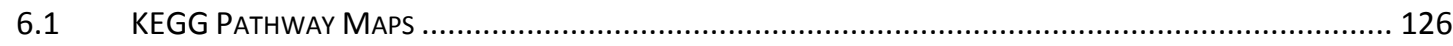

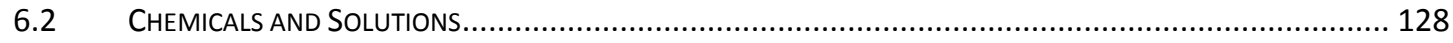

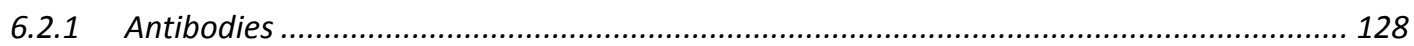

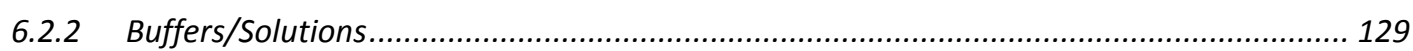

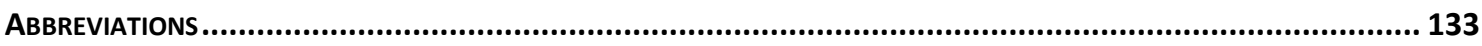

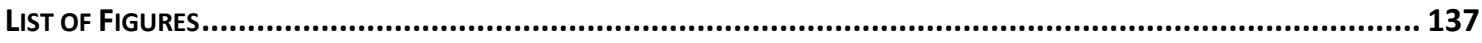

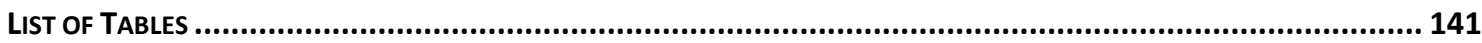

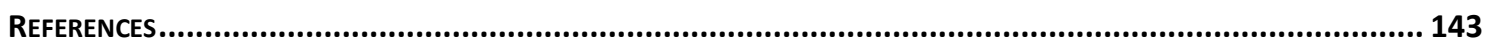





\section{Introduction}

\subsection{Memory Systems and the Hippocampus}

Our memories make up who were are. Without the recollection of our past experiences we would not be capable of having social relationships nor could we develop any advanced skills. Memories are vital since they protect us from dangers and help us to successfully adapt to changes thereby securing our survival and personal development. There are two main memory systems: the explicit/declarative memory for facts and events and the implicit/non-declarative memory for perceptual skills and motor tasks. In contrast to non-declarative memory declarative memory requires the conscious recall of information. Declarative memory, can be further divided into episodic memory and semantic memory. Episodic memory stores our personal experiences, e.g. when and where we did something. In contrast, semantic memory stores purely factual information (Squire, 2004).

The hippocampus is a brain structure that has well-established functions in learning and memory. More specifically, the hippocampus is required for explicit memory, especially episodic memory. Human patients with profound damage to the hippocampus suffer from impairment of consciously recalling episodes of their personal experiences and events. Famous patient H.M., whose hippocampal formation - together with adjacent brain areas - was partly removed in a surgery to cure his epilepsy, had lost the ability to store explicit memory (Scoville et al., 1957). His condition made it impossible to store new memories for long-term, while his memories of experiences collected prior to his surgery were mostly still intact. This form of memory deficit is referred to anterograde amnesia. However, his brain would still form implicit memories as was evident from training him motor tasks, such as a mirror tracing task (Milner, 1962). This task requires tracing a star with a pencil while observing one's hand only as a reflection in the mirror. While he significantly improved his performance on this task through several training sessions he could not consciously recall the memory of having performed and practiced this task before. The outcome of the different tests conducted with H.M. and other patients indicated that different brain regions must be involved in different kinds of 
memory. However, since the lesions of H.M. and numerous other amnesic patients were not entirely restricted to the hippocampus there was still some doubt about the exact role the hippocampus played in the observed memory impairments. Eventually, the case of patient R.B., who had a seizure-evoked lesion of the hippocampal CA1 region and also showed anterograde amnesia (Zola-Morgan et al., 1986) proved that damage to the hippocampus alone is sufficient to produce an impairment of episodic memory.

While the final storage of long-term memories takes place in the neocortex, the hippocampus is a transient place of memory storage for as long as minutes to hours up to months (McClelland et al., 1995; Squire et al., 2007). If the encoding and transfer of information to the neocortex is disrupted due to hippocampal damage, new long-term memories cannot be established.

\subsubsection{Anatomy of the Hippocampus}

The hippocampal formation is a paired brain structure located inside the medial temporal lobe. It consists of the dentate gyrus (DG) and cornu ammonis (CA) 1, 2, and 3 as well as the pre- and parasubiculum, and entorhinal cortex (EC). For simplicity, the term hippocampus will refer exclusively to the dentate gyrus and the regions CA1-3 in this thesis.

One remarkable anatomical feature of the hippocampus is the densely packed cell layers formed by the primary cells of its subregions. While the primary cells of the dentate gyrus are the granule cells, the principal cell type in the CA regions is the pyramidal neuron. The names were given in respect to the size and shape of the cell bodies.

In contrast to the mostly reciprocal connections in other cortical areas, the hippocampus has a unique anatomical organization, which is referred to as trisynaptic circuit (Amaral et al., 2006). Information is processed in a unidirectional way and enters the hippocampus through the entorhinal cortex, which is connected to the dentate gyrus via the perforant pathway (Figure 1.1). The granule cells of the dentate gyrus have unmyelinated axons, called mossy fibers, which project onto the dendrites of the pyramidal cells in the CA3 region. The axons of the CA3 neurons project to the CA1 region and are called Schaffer collaterals. The CA1 region is the output region of the hippocampus and sends the processed information to entorhinal cortex layer $\mathrm{V}$ and also to the subiculum. 


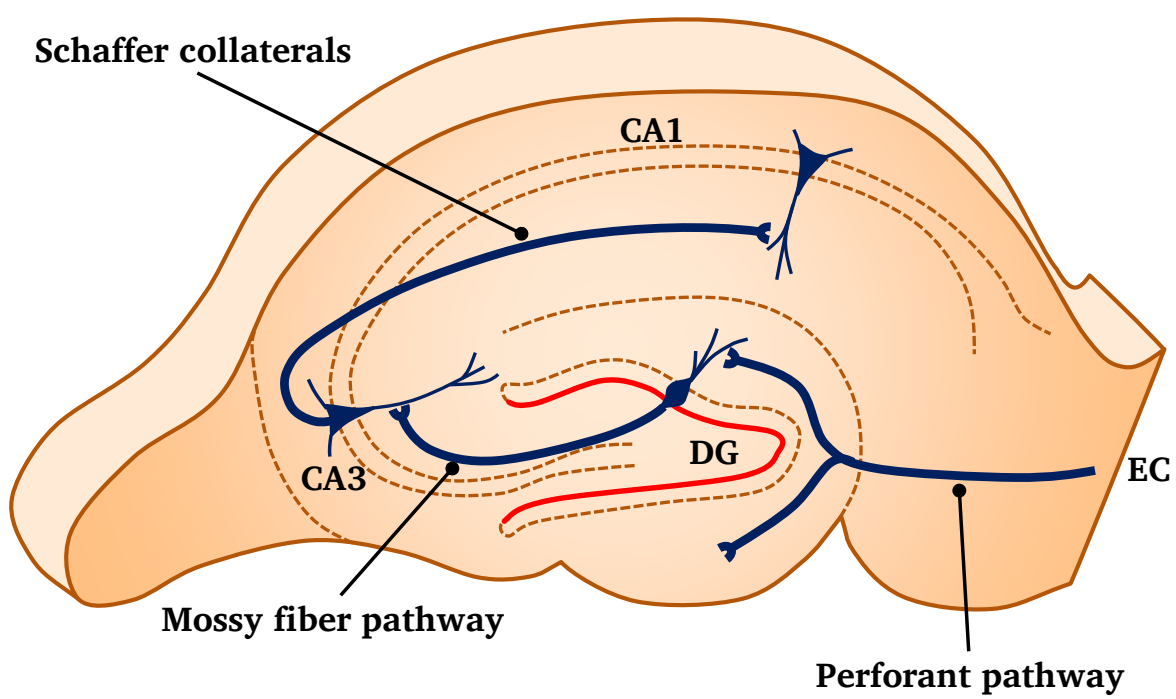

\section{Entorhinal cortex \\ Dentate gyrus \\ CA3 region \\ CA1 region}

Figure 1.1: The trisynaptic circuit of the hippocampus. The scheme illustrates the unidirectional flow of information in the mouse hippocampus from the entorhinal cortex to the CA1 region. The subgranular zone (SGZ) is shown in red. Abbreviations: $\mathrm{EC}=$ entorhinal cortex, CA1 and CA3 = cornu ammonis 1,3 , $\mathrm{DG}=$ dentate gyrus.

\subsubsection{Adult Neurogenesis}

Apart from the subventricular zone at the lateral ventricle, the hippocampus is the only region in the mammalian brain where new neurons are generated during an animal's lifetime. Adult neurogenesis does not only take place in rodents but has also been reported for the human brain (Eriksson et al., 1998). In the subgranular zone (SGZ), which lies at the border of the hilus and the granular cell layer (GCL) of the dentate gyrus (Figure 1.1), new cells are continuously born in the postnatal rodent brain. While most of these newborn cells will die before maturation a subset will either assume a glial fate or will integrate as new neurons into the already established circuitry of the granular cell layer (Ming et al., 2011). Because of the ongoing proliferative capacity of the SGZ the volume of the GCL increases over an animal's lifetime, accounting for up to $10 \%$ of the GCL population (Imayoshi et al., 2008). Functionally, the newly-generated neurons are assumed to be especially important for pattern separation (Deng et al., 2010). Moreover, decreased adult neurogenesis has been implied in diseases such as depression and dementia indicating important functions in cognitive health. In this respect, it was also shown that the proliferative rate is positively correlated with exercise. This has been shown for both patients, who increase their physical activity, as well as rodents that are 
exposed to an enriched environment (Olson et al., 2006; Yi et al., 2009; Brandt et al., 2010).

\subsubsection{Hippocampal Function and Molecular Processes Involved in Memory Formation}

New experiences have to be processed by the brain in order to be stored as memories. Already in 1904, Richard Semon postulated that this encoding of new information would result in a specific physical trace of that experience in the neurons, which he termed an "engram" (Semon, 1920). Donald Hebb postulated that only those synapses are potentiated, which are active when the postsynaptic neuron is strongly depolarized (Hebb, 1949). Thus, groups of synapses that are coordinately active and contribute together to the firing of the target postsynaptic neuron will be strengthened. This theory provided a plausible mechanism for the linking of neurons to ensembles involved in the encoding of the different environmental features of a memory. Just recently such engram-bearing cells have been identified in the hippocampus. Mice were subjected to a fear conditioning paradigm, in which they learned to associate a new context A with an aversive electrical foot shock. If reexposed to context A 24 hours later mice showed freezing behavior but not if they were placed into a different context $\mathrm{B}$, where they never received the foot shock. Ramirez et al. (2013) were able to specifically tag those cells in the dentate gyrus that were active in context A, where the foot shock was given. By artificially reactivating these cells by optogenetics in context B, a freezing behavior was triggered in the mice although they had never received a foot shock in this context. Obviously the memory of the aversive experience of the foot shock was stored in the specific subset of granule cells tagged by Ramirez et al. (2013).

On the molecular level, memories depend on persistent changes in transmission at neuronal synapses. Long-term potentiation (LTP) is considered one of the major cellular mechanisms underlying learning and memory, where repeated stimulation of a postsynaptic neuron causes an enhanced depolarization. LTP was first detected in the hippocampus of anesthetized rabbits by stimulating the perforant path (Lømo, 1966; Bliss et al., 1973). Two types of ionotropic receptors play an important role for LTP induction: the $\alpha$-amino-3-hydroxyl-5-methyl-4-isoxazole-propionate (AMPA) and the N-methyl-Daspartate (NMDA) receptor. When glutamate is released from the presynaptic neuron it binds to both of these receptors on the postsynaptic neuron. Their difference in response is the key to the regulation of LTP. The AMPA receptor will open its channel pore upon 
the binding of glutamate and thereby allow sodium ions to enter the postsynaptic neuron. If sufficient amounts of sodium ions enter the neuron, it will depolarize. Similarly, the NMDA receptor will also bind the presynaptically released glutamate. However, this is not sufficient to open its channel pore, which is obstructed by an $\mathrm{Mg}^{2+}$-ion. Only if the postsynaptic neuron depolarizes while glutamate is bound to the NMDA receptor its channel pore will open and allow calcium to enter the cell. Thereby the NMDA receptor acts as a coincidence detector as described by Hebb (Tsien, 2000). Calcium plays a pivotal role as second messenger in neuronal function. It can initiate two fundamental biochemical processes in the postsynaptic neuron, which both contribute to the strengthening of the synaptic connection: (1) posttranslational modifications, which can alter the function of already present proteins in the postsynaptic neuron as well as (2) transcription and translation, which will allow for new material to be synthesized, which is a prerequisite for the formation of long-term memory (West et al., 2011; Bading et al., 1993).

\subsection{Neuronal Activity and Homeostasis}

Neurons are electrically excitable cells and constitute the main component of the brain, including the hippocampus. They form networks and are able to exchange information via chemical or electrical signals with each other. Synapses are specialized parts of neurons, through which transmission of information occurs. An organism's interactions with the outside world trigger changes at neuronal synapses that are critical for proper cognitive function (see above). On the one hand, neurons have to be plastic, i.e. to be responsive to stimuli and to adjust their connections to other neurons accordingly, allowing for learning and memory to take place. On the other hand, neuronal function and circuitry also needs to have an overall stability in order to maintain proper functioning and efficient processing of new information. These seemingly opposing necessities become even more puzzling when one considers the longevity of neurons in the mammalian brain in contrast to the relatively short-lived life cycles of the transcripts and proteins that make up the neuron. So how do neurons handle the conflict between plasticity and stability? Recently, so-called homeostatic plasticity mechanisms have been identified, which counteract the destabilizing effects of learning-induced changes and aid in preserving overall neuronal and circuit activity (Turrigiano, 2012). One of these mechanisms is synaptic scaling, which enables a neuron to regulate its own excitability relative to network activity (Turrigiano, 2008). While direct links between disturbances in 
homeostatic plasticity and neurological disorders have not yet been fully established, there have recently been implications of a role in autism, epilepsy and Alzheimer's disease (Oberman et al., 2013; Wondolowski et al., 2013; Gleichmann et al., 2011).

\subsection{Immediate-Early Genes}

In order for a new memory to be formed, the respective external stimuli must be internalized and translated into changes on the cellular level. Stable memories are not acquired instantaneously. The transformation of a new experience into a long-term memory is a gradual process, with different and well-orchestrated steps. The induction of immediate early genes (IEGs) is one of the first steps of memory formation in the adult brain (Tischmeyer et al., 1999; Guzowski, 2002) and - interestingly - constitutes a highly conserved cellular response to external stimuli. The first IEGs were not discovered in the context of memory formation. They were viral genes, which were rapidly transcribed upon infection of a host cell. Remarkably, their transcription was independent from new protein synthesis (Watson et al., 1980). This rapid and transient transcription has later also been detected in fibroblasts and other cell lines as a response to growth factors, hormones and cytokines (Greenberg et al., 1984; Kruijer et al., 1983; Almendral et al., 1988). Eventually, IEG induction was also reported in rodents when Morgan et al. (1987) discovered that the IEG c-Fos was rapidly induced by seizures in mice. Another typical example of IEG induction in rodents is observed when the animals are exposed to a novel environment or context (VanElzakker et al., 2008; Guzowski et al., 1999). As mentioned in Section 1.1.3, Ramirez et al. (2013) could very recently show that neuronal ensembles, which are activated together during a learning experience, in which a fearful event is learned to be associated with a specific context A, are the site of storage for the respective memory trace. These engram-bearing cells were identified and tagged based on their induction of $c$-Fos, which was triggered by and specifically related to context A.

IEGs can generally be grouped into 'regulatory' and 'effector' IEGs (Lanahan et al., 1998). The first group comprises different transcription factors such as c-FOS and NPAS4, which act upstream of other target genes. The other group consists of structural proteins (e.g. ARC and HOMER1), and signaling molecules (e.g. BDNF and VGF), which have a more direct role at the synapse (Okuno, 2011). 
In summary, the following characteristics are typical for IEGs: In absence of a stimulus their expression levels are very low. Their induction is both rapid and strong. Their expression is transient, which is in part caused by a short half-life of their mRNAs (e.g. 15 min for $c-F o s)$.

While IEG expression is always independent from protein expression, the induction latency can be as fast as a few minutes (e.g. Arc and c-Fos) or take up to about one hour (e.g. Cox2). For a long time it was unclear how IEGs like Arc and c-Fos can be transcribed so rapidly after a stimulus. The rate-limiting step for de novo transcription is the recruitment of RNA Polymerase II (RNA Pol II) and the creation of the pre-initiation complex together with general transcription factors, which would not allow for such rapid transcription to take place. Recently, however, Saha et al. (2011) found that IEGs can be grouped into two different categories based on different transcriptional modalities. Rapid IEGs have RNA Pol II stalled in the vicinity of their promoters, allowing for transcription within minutes after neuronal activity. In contrast, transcription of delayed IEGs does not involve stalled Pol II and thus requires more time.

\subsection{Chromatin, Transcriptional Regulation and the Role of Acetylation in Protein Function}

The following sections are intended to give an insight into the general genomic organization of a cell and to illustrate some of the molecular mechanisms that allow for the dynamic regulation of gene transcription. This dynamic regulation is the basis for neuronal plasticity as required for learning and memory.

\subsubsection{Chromatin and Histone Modifications}

DNA is organized into higher-order structures in every cell. 147 bp of DNA are wrapped around a histone octamer, consisting of two copies of histones H2A, H2B, H3, and H4 each (Luger et al., 1997). The complex of DNA and histone proteins is called chromatin and the organization of DNA and histone proteins illustratively described as "beads on a string" (Alberts et al., 2002). Chromatin is not just a means of packaging the nearly 2 meters of DNA into the cell but it also allows for the regulation of gene transcription. Histone $\mathrm{H} 1$ is an additional histone, which is not part of the histone octamer but serves as a linker to keep the DNA in place, stabilizing the chromatin fibers. Histones possess a flexible N-terminal tail, which protrudes from the nucleosome and serves as an inte- 
grative platform for posttranslational modifications. These include methylation, phosphorylation, acetylation, or sumoylation and have been suggested to be part of a socalled histone code (Strahl et al., 2000; Jenuwein et al., 2001). By integration of the combinatorial histone tail modifications, which can be read by proteins equipped with the respective binding domains for these modifications, a distinct activity status is conferred to the respective genomic region (Musselman et al., 2012; Yun et al., 2011).

Together with DNA methylation histone modifications are a part of the epigenetic regulation that takes place within cells. By regulating the accessibility of specific genomic regions changes in gene activity and expression are possible without altering the DNA sequence of a cell. This provides cells, and especially neurons, with a remarkable plasticity while conserving their established cell identity and function (Riccio, 2010).

\subsubsection{MECP2}

In contrast to astrocytes and other somatic cells, in neurons there exists only half the normal amount of linker histone H1. At the same time, levels of Methyl CpG binding protein 2 (MECP2), which was identified as a protein tracking methylated DNA, are doubled in neurons. Therefore, it was suggested that MECP2 acts like a linker histone in neurons, regulating chromatin structure and therefore genome-wide gene expression (Skene et al., 2010). This is underlined by the approximately 20 million copies of this protein per cell, while transcription factors exist in only about $10^{4}-10^{5}$ copies (Bird, 2010).

Mutations in MECP2 cause Rett Syndrome, a congenital neurological disease, in which postnatal development is normal until 7-24 months of age but then stagnates and eventually declines (Geerts, 2008). How exactly MECP2 contributes to normal brain function has been difficult to figure out. Although MECP2 was long thought to act as a transcriptional repressor by recruiting histone deacetylases it also seems to have activating functions. Complicating matters even further, MECP2 seems to have a global function in chromatin structure specifically in neurons (Guy et al., 2011).

\subsubsection{Protein Acetylation}

As described in Section 1.4.1, histone acetylation is an epigenetic modification, which is used by cells to dynamically regulate their transcriptomes. In general, histone acetylation is correlated with active transcription (Hebbes et al., 1988). The addition of an acetyl group to a lysine of the histone tail neutralizes its positive charge, loosening the 
attraction between the histone and the negatively-charged DNA and thus opening up the chromatin for the transcription machinery (Hong et al., 1993; Lee et al., 1993). Posttranslational histone acetylation is carried out by a diverse class of enzymes collectively known as histone acetyltransferases (HATs). Since many of these enzymes also have non-histone lysine targets they are now generally referred to as lysine acetyltransferases (KATs) (Allis et al., 2007). Their actions are counteracted by lysine deacetylases (KDACs), which thus aid in regulating the acetylation status of the substrate proteins. Apart from its neutralizing effect on a lysine's positively charged amino group, acetylation can also serve as a docking site for binding of other proteins. Such proteins possess an acetyllysine binding site called bromodomain, which is found in many chromatinassociated proteins (Taverna et al., 2007). Histone acetylation is a very rapid and transient epigenetic modification and numerous studies support the view that it can aid neurons in encoding new information, which is essential for learning and memory to take place (Levenson et al., 2004; Sharma, 2010; Peleg et al., 2010).

Apart from histone proteins, the presence of posttranslational acetylation has also been identified in a multitude of non-histone proteins. In fact, numerous transcription factors are substrates for KATs and KDACs (Glozak et al., 2005). Well-characterized substrates for posttranslational protein acetylation are the tumor suppressor P53 and the oncoprotein c-MYC, which are the target of different KATs (Tang et al., 2006; Gu et al., 1997; Patel et al., 2004). KATs and KDACs are involved in many cellular processes including intracellular signal transduction, circadian rhythms and the cytoskeleton (Choudhary et al., 2009; Glozak et al., 2005). Apart from the functional implications already mentioned, posttranslational acetylation also participates in the competition between different modifications for certain residues. For example, if P53 is acetylated it cannot be ubiquitinylated, and is thereby stabilized. In the same line, acetylation has also been proposed as an opponent to phosphorylation (Kouzarides, 2000).

\subsubsection{TIP60 is a Lysine Acetyltransferase with Pleiotropic Func-}

\section{tions}

Based on their structural homologies KATs are divided into several groups, the main families being P300/CBP, GCN5/PCAF, and MYST (Lee et al., 2007). TAT-interactive protein 60kDa (TIP60/KAT5) belongs to the founding members of the MYST family of acetyltransferases (MOZ, $\underline{\text { YBF2, }}$ SAS2, TIP60), which share a 300 amino acid MYST domain containing a zinc finger and an acetyl-CoA binding motif (Avvakumov et al., 2007). 
There exist at least three Tip60 isoforms, of which Tip60 $\alpha$ contains all 14 exons and is the most studied one (Sapountzi et al., 2006). Tip60 $\beta$ lacks exon 5 (Ran et al., 2000; Sheridan et al., 2001) while a larger Tip60 isoform retains intron 1 (Legube et al., 2003). Human and mouse TIP60 $\alpha$ have nearly $100 \%$ identity and only diverge at position 175, where the serine is changed to an alanine in the human version. A schematic overview of TIP60 $\alpha$ with its functional domains is given in Figure 1.2. As evident from the figure, TIP60 also contains a chromodomain as well as a nuclear receptor (NR) box. The chromodomain binds methyl lysines and enables recruitment of TIP60 to methylated histones (Sun et al., 2009). The NR box confers the ability to interact with class I nuclear receptors (Gaughan et al., 2001). TIP60 is the catalytic subunit of the highly conserved nucleosome acetyltransferase of histone H4 (NuA4)/TIP60 complex (Doyon et al., 2004; van Attikum et al., 2005) and was first discovered as a protein interacting with the HIVprotein TAT (Kamine et al., 1996). Acting as a part of a multiprotein complex, TIP60 can acetylate histones H2A and H4 (Ikura et al., 2000). However, it also has many nonhistone targets, broadening its range of effects (Sapountzi et al., 2006). A genetic interaction screen based on an RNA interference approach in C. elegans identified Tip60 as one of several "hub" genes (Lehner et al., 2006), modifying a diversity of signaling pathways. Indeed, many studies have demonstrated that TIP60 exerts pleiotropic functions and is implicated in many different cellular processes. Most research has focused on its role in DNA damage repair and cancer (Squatrito et al., 2006). It can acetylate tumor suppressor P53 thereby modulating the decision for cell cycle arrest vs. apoptosis (Tang et al., 2006; Sykes et al., 2006). Furthermore, TIP60 has also been shown to acetylate protein kinase Ataxia telangiectasia mutated (ATM) after DNA damage (Sun et al., 2007).

Interestingly, TIP60 is suggested to play a role in Alzheimer's disease by interacting with FE65 and the intracellular part of Amyloid precursor protein (AICD) (Cao et al., 2004). In our lab TIP60 was identified as an interacting partner of core clock protein Cryptochrome1 (CRY1) and its role in the circadian clock is now well established (to be published).

In Drosophila, implications of TIP60 function in axonal transport and neuronal gene regulation have recently been reported (Lorbeck et al., 2011; Johnson et al., 2013). However, up to now, little has been known about TIP60 function in the mammalian brain. 


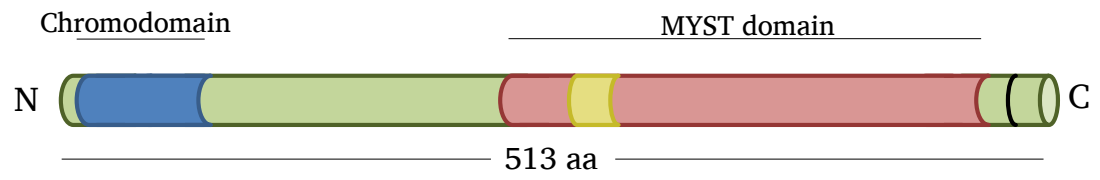

Figure 1.2: Schematic presentation of TIP60 $\alpha$ and its functional domains. Illustration of the alpha isoform of TIP60 with its chromodomain shown in blue and the MYST domain - which contains the HAT domain - shown in red. The zinc finger is depicted in yellow and the nuclear receptor (NR) box is shown in black at the C-terminal end.

\subsection{Objective}

Life-long learning is the basis for personal development, complex social interactions, and an indispensable mechanism to cope with everyday challenges. Equally important is the formation of stable long-term memories and their reliable retrieval. Disturbances in any of these processes underlie normal aging, psychiatric disorders, and neurodegenerative diseases. In order to meet with the high demands of learning and memory functions throughout life, neurons are equipped with a remarkable machinery of proteins, which constitute an essential part of the cellular repertoire serving plasticity. These include KDACs and KATs, which dynamically regulate the acetylation status of cellular proteins. However, for many of these enzymes - including TIP60 - data on the exact role and functions in the brain are still missing. TIP60 is a protein with many different functions, which include but are not restricted to histone acetylation. In order to gain first insights into TIP60 function in the mammalian brain, this project set out to investigate the role of TIP60 in the mouse hippocampus both on a molecular and behavioral level. Following a general characterization of the two mouse models used in this thesis project, data on the performance of TIP60-deficient animals in a battery of well-established behavioral tests are presented. Subsequently, results from different molecular analyses are shown, including the quantification of stimulus-induced gene regulation upon novelty exposure in the hippocampus of TIP60-deficient animals. Based on these results, the CA1 region is chosen for an unbiased approach to uncover the consequences of TIP60-deficiency on the transcriptome via next generation sequencing. Finally, changes in the acetylation status of both TIP60 histone and potential non-histone targets are presented, which may underlie some of the observed molecular effects. 



\section{Materials and Methods}

\subsection{Tip60 Knockout Models and Their Characterization}

All animal experiments were performed in compliance with the Germany Animal Welfare Law and approved by the Office for Consumer and Food Safety of the State of Lower Saxony (LAVES). The animals were kept under standard conditions with a 12 hour day/night cycle in individually ventilated cages. They received food and water ad libitum. If not explicitly stated otherwise, animals were group-housed.

The data presented in this work are from experiments conducted with both a constitutive and an inducible Tip60 knockout model, both based on the CRE-LoxP system (Feil et al., 1997; Metzger et al., 2001). In the next paragraph, both CRE driver lines, the conditional Tip60 mouse line and the resulting forebrain-specific Tip60 knockout lines will be described.

\subsubsection{Conditional Tip60 Mouse Line (Tip60 f/f)}

Since homozygous Tip60 knockout is embryonic lethal (Hu et al., 2010), the function of TIP60 in the adult organism can only be studied using conditional knockout strategies. The Tip60 conditional mouse line used in this project was created by Dr. Xunlei Zhou. LoxP sites were inserted downstream of exon 1 and upstream of exon 9 of the Tip60 gene. An overview of the Tip60 gene structure and the targeted allele is provided in Figure 2.1. When this project was started, Tip $60^{\mathrm{f} /+}$ mice were already backcrossed to N7 in the B6N background. Tip60 ${ }^{\mathrm{f} /+}$ mice were also mated with each other in order to obtain Tip $60^{\mathrm{f} / \mathrm{f}}$ animals for mating with the two CRE driver lines described in the next paragraphs. 


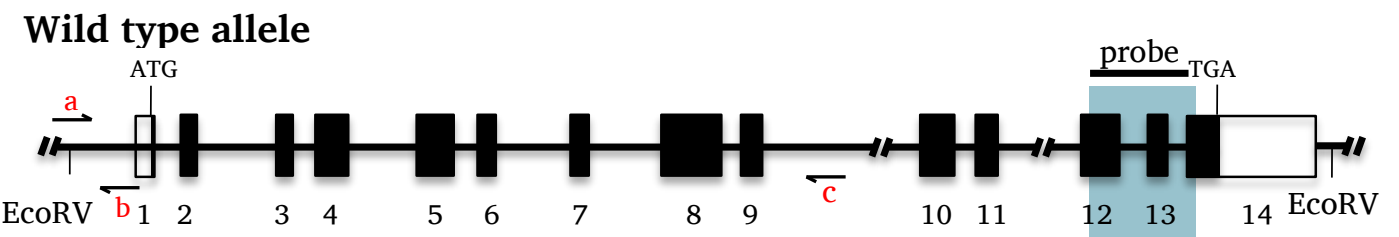

$17 \mathrm{~KB}$

Floxed allele

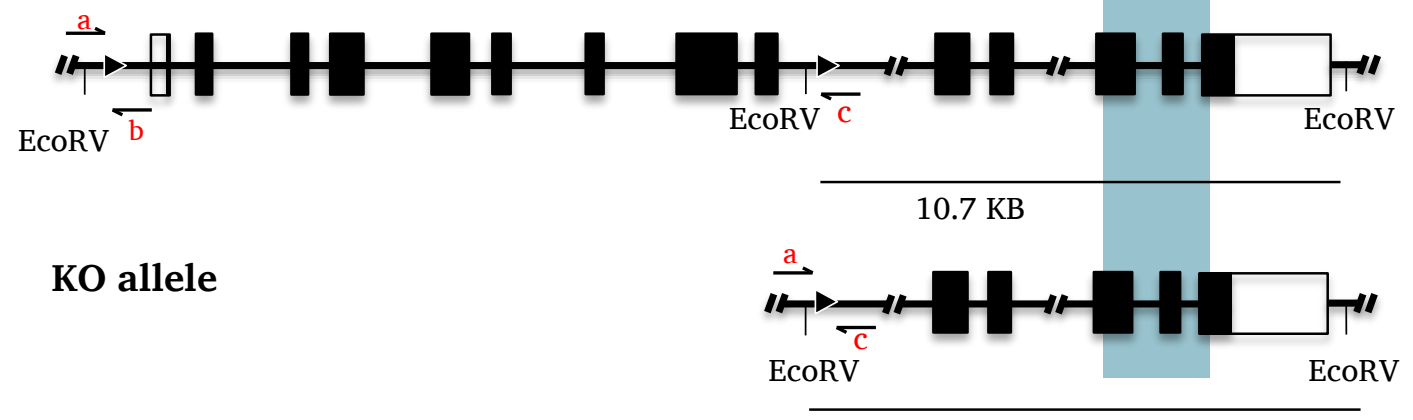

$13.5 \mathrm{~KB}$

Figure 2.1: Overview of Tip60 alleles. The Tip60 wild type, conditional ("floxed"), and deleted ("KO") alleles are depicted. LoxP sites upstream of exon 1 and downstream of exon 9 are indicated by black triangles. Positions of genotyping primers are illustrated by black arrows: $\mathrm{a}=$ LoxP1 fw, $\mathrm{b}=\mathrm{GT}$ short, $\mathrm{c}=\mathrm{LoxP} 2$ re. The probe used in Southern blot, the positions of EcoRV restriction sites as well as product fragment sizes for each Tip60 allele are illustrated.

\subsubsection{Constitutive Tip60 Knockout Mouse Model (CaMKCre Tip60 f/f)}

The constitutive Tip60 knockout mouse model was created by crossing the Tip60 $0^{\mathrm{f} / \mathrm{f}}$ conditional mouse line to a CaMKCre driver line. This driver line $\mathrm{Tg}$ (Camk2a-cre)159Kln was generated by Rüdiger Klein and is specific for excitatory neurons in the forebrain (Minichiello et al., 1999). It reportedly becomes active postnatally at around 3 weeks after birth. CaMKCre mice were generously provided by Prof. A. Stoykova and backcrossed to B6N background for more than 12 generations. Breeding within the CaMKCre colony was performed with B6N wild type animals in order to maintain the transgene in a hemizygous state. This is important since homozygosity of the transgene reportedly leads to seizures (personal communication Prof. A. Fischer).

In order to delete Tip60 postnatally from the hippocampus, the CaMKCre line was crossed to the Tip60 ${ }^{\mathrm{f} / \mathrm{f}}$ line described in Section 2.1.1. Those animals positive for the CRE transgene (CaMKCre Tip60 ${ }^{\mathrm{f} /+}$ ) were further crossed to Tip60 ${ }^{\mathrm{f} / \mathrm{f}}$ mice in order to 
obtain CaMKCre Tip60 ${ }^{\mathrm{f} / \mathrm{f}}$ mice, which were used for the experiments. Control animals used were negative for CaMKCre and with floxed Tip60 alleles (Tip60 f/f).

Unexpectedly, CaMKCre Tip60 ${ }^{\mathrm{f} / \mathrm{f}}$ mice developed health problems starting around 6 weeks of age and had a life span of less than 4 months. The observed phenotype will be described in more detail in Section 3.3.1. Due to the health problems of CaMKCre $\mathrm{Tip}^{\mathrm{f} / \mathrm{f}}$ mice only animals with one floxed Tip60 allele (CaMKCre Tip60 ${ }^{\mathrm{f} /+}$ ) were taken for matings.

For experiments, 7-8 week-old mice were taken. For ISH and IHC analyses only male mice were used while tissue of both sexes was used for qPCR and RNA-Seq analyses.

\subsubsection{Inducible Tip60 Knockout Mouse Model (CaMKCreER ${ }^{\top 2}$ Tip60 f/f)}

Since the constitutive mouse model CaMKCre Tip60 ${ }^{\mathrm{f} / \mathrm{f}}$ revealed substantial health problems after Tip60 deletion (Section 3.3.1) an inducible CRE line was obtained. The inducible CaMKCreER ${ }^{\mathrm{T} 2}$ line B6.FVB-Tg(Camk2a-cre/ERT2)2Gsc/Ieg;(EM:02125) was created by Günther Schütz (Erdmann et al., 2007) and kindly provided by the European Mouse Mutant Archive (EMMA). This line bears a bacterial artificial chromosome-derived transgene expressing the CaMKCreER ${ }^{\mathrm{T} 2}$ fusion protein under the control of the regulatory elements of the CaMKIIa gene (Erdmann et al., 2007). The line provided by EMMA contained two copies of the transgene. CRE activity can be induced by tamoxifen injections at the desired time point. The animals from this line had already been backcrossed for six generations into B6N background when obtained from EMMA. They were kept in a hemizygous state by backcrossing them to B6N wild type mice.

In order to create an inducible Tip60 knockout mouse model, CaMKCreER ${ }^{\mathrm{T} 2}$ mice were first crossed to the Tip60 ${ }^{\mathrm{f} / \mathrm{f}}$ line (Section 2.1.1) to obtain CaMKCreER ${ }^{\mathrm{T} 2} \mathrm{Tip}^{\mathrm{f} /+}$ offspring. These animals were further mated to Tip60 $60^{\mathrm{f} / \mathrm{f}}$ animals in order to obtain CaMKCreER $^{\mathrm{T} 2} \mathrm{Tip}^{\mathrm{f} / \mathrm{f}}$ mice, which were used for the experiments described in this thesis. $\mathrm{Tip}^{\mathrm{f} / \mathrm{f}}$ mice that were negative for the CaMKCreER ${ }^{\mathrm{T} 2}$ transgene were taken as control animals and will be referred to as Tip $60^{\mathrm{f} / \mathrm{f}}$. They received the same tamoxifen injections as the CaMKCreER ${ }^{\mathrm{T} 2} \mathrm{Tip}^{\mathrm{f} / \mathrm{f}}$ mice in order to rule out effects of either the injections or the tamoxifen on the characterization of the Tip60 knockout. 
Male mice were exclusively taken for all analyses except LacZ staining. Mice taken for molecular analyses were 10-11 weeks of age and sacrificed 10 days after the last tamoxifen injection if not stated otherwise.

\subsubsection{Tamoxifen Injections}

Male CaMKCreER ${ }^{\mathrm{T} 2} \mathrm{Tip}^{\mathrm{f} / \mathrm{f}}$ and Tip60 ${ }^{\mathrm{f} / \mathrm{f}}$ control mice between 8 and 12 weeks of age were intraperitoneally injected with $100 \mu \mathrm{l}$ of $20 \mathrm{mg} / \mathrm{ml}$ tamoxifen twice daily for 5 consecutive days. The tamoxifen was weighed and mixed with the appropriate volume of corn oil (Sigma) and then put on a rotator for incubation at $37^{\circ} \mathrm{C}$ for $6-7$ hours. After incubation it was stored at $4{ }^{\circ} \mathrm{C}$ protected from light and used within one week. Injections were performed by the animal caretakers.

\subsubsection{Genotyping}

\subsubsection{Biopsy Digestion}

Tail or ear biopsies were kept at $-20{ }^{\circ} \mathrm{C}$ until use. They were digested in $200 \mu$ PBND lysis buffer (6.2.2.1) and $3 \mu \mathrm{l}$ proteinase $\mathrm{K}(20 \mathrm{mg} / \mathrm{ml})$ on a thermomixer at $55{ }^{\circ} \mathrm{C}$ and $850 \mathrm{rpm}$ overnight. The temperature was raised to $85^{\circ} \mathrm{C}$ for one hour the next day in order to inactivate the enzyme. Samples were stored at $4{ }^{\circ} \mathrm{C}$ and centrifuged down before use.

\subsubsection{PCR}

PCR was performed in order to specify the genotype of the animals. $1 \mu$ of biopsy lysate was added to $24 \mu \mathrm{l}$ of PCR reaction volume and the PCR conducted using the protocol listed in Table 2.1. The primers used for the genotyping are listed in Table 2.2 and their positions are illustrated in Figure 2.1.

$10 \mu \mathrm{l}$ of each sample's PCR product was loaded onto a $1 \%$ (CaMKCre) or $2 \%$ (Tip60, CaMKCreER $^{\mathrm{T} 2}$ ) agarose gel together with a 100 bp ladder (NEB). DNA staining dye (Serva) was added 1:20000 before the gel solidified. Samples were run at $120 \mathrm{~V}$ until bands were sufficiently separated. Images of the gels were taken with a gel documentation system (intas). Representative results for all genotypes are shown in Figure 2.2. Both genotyping and gel documentation were partly done by technical staff. 
Table 2.1: PCR reactions and program used for genotyping.

\begin{tabular}{l|c|c}
\multicolumn{1}{c|}{ Reagent } & $\begin{array}{c}\text { Tip60/CaMK- } \\
\text { CreER }^{\mathrm{T2}}\end{array}$ & CaMKCre \\
\hline MilliQ $\mathrm{H}_{2} \mathrm{O}$ & 15.0 & 15.3 \\
\hline Puffer $(5 \mathrm{x})$ & 5.0 & 5.0 \\
\hline $\mathrm{MgCl} 2(25 \mathrm{mM})$ & 1.6 & 1.6 \\
\hline dNTPs $(10 \mathrm{mM})$ & 0.6 & 0.6 \\
\hline Primers $(5 \mu \mathrm{M})$ & 1.6 & 2.0 \\
\hline Taq Polymerase & 0.2 & 0.2 \\
\hline DNA lysate & 1.0 & 0.3
\end{tabular}

\begin{tabular}{c|c|c} 
Step & Temp. $\left[{ }^{\circ} \mathbf{C}\right]$ & Time $[\mathrm{min}]$ \\
\hline 1 & 94 & $04: 00$ \\
\hline 2 & 94 & $00: 30$ \\
\hline 3 & 65 & $00: 30$ \\
\hline 4 & 72 & $00: 30$ \\
\hline 5 & 72 & $10: 00$ \\
\hline 6 & 4 & $\infty$
\end{tabular} 35 cycles

Table 2.2: Primers used for genotyping.

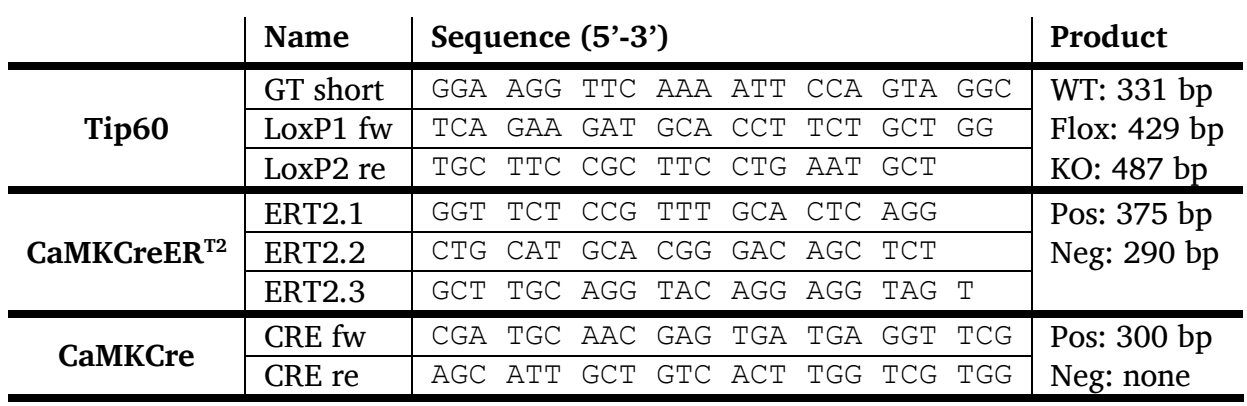
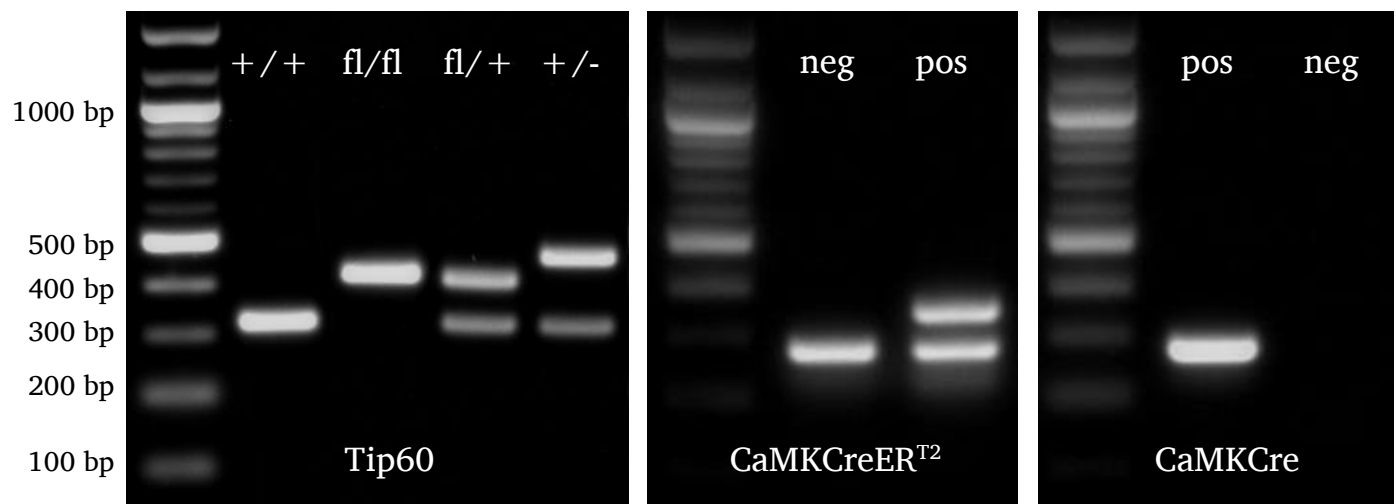

Figure 2.2 Genotyping results for Tip60, CaMKCreER ${ }^{\mathrm{T} 2}$, and CaMKCre. Representative genotyping results for Tip60 (left), CaMKCreER ${ }^{\mathrm{T} 2}$ (middle), and CaMKCre (right) are shown. Tip60 and CaMKCreER ${ }^{\mathrm{T} 2}$ PCR products were run on a $2 \%$ and CaMKCre products on a $1 \%$ agarose gel. A 100 bp ladder (NEB) was used as size marker.

\subsection{Tissue Isolation}

Animals were killed by cervical dislocation. Individuals of the constitutive Tip60 knockout line were also killed by $\mathrm{CO}_{2}$ if required. Brains were rapidly removed from the skull on a precooled metal plate that was placed on ice. The hemispheres were separated with a razor blade and immediately transferred to ice-cold 1x PBS. 


\subsubsection{Samples for IHC, ISH and LacZ Staining}

If the hemispheres were to be used for immunohistochemistry (IHC), in situ hybridization (ISH) or LacZ staining they were washed once in 1x PBS and excess liquid was removed by placing them onto a perforated metal spoon on filter paper. The hemispheres were then washed twice in cold embedding medium (Optimal Cutting Temperature, O.C.T, Sakura) in order to further remove buffer from the tissue. Custom-made, grid-lined copper chambers with walls of plexiglass - which allow to view the specimen from all sides for proper orientation - were filled with cold O.C.T.. The brain hemispheres were transferred into the chambers and properly orientated with a dissecting scope for later sectioning. The chambers with the specimen were then placed onto a metal platform in a cryobox filled with $100 \% \mathrm{EtOH}$, which had been stored at $-80{ }^{\circ} \mathrm{C}$ prior to use. Once the O.C.T. had solidified and the brains were frozen they were labeled, immediately transferred to a sealed plastic bag, and stored at $-20{ }^{\circ} \mathrm{C}$ until use.

\subsubsection{Samples for (q)PCR, RNA-Seq and Western Blot}

Hippocampi were dissected under a magnification lamp in 1x PBS on a metal plate on ice. Other brain regions were dissected directly on a cold metal plate on ice. Samples for Western blot and PCR analysis were transferred to $1.5 \mathrm{ml}$ Eppendorf tubes and flashfrozen in liquid nitrogen. These samples were stored at $-80{ }^{\circ} \mathrm{C}$ until use. Samples for qPCR and RNA sequencing (RNA-Seq) were transferred into RNALater (Ambion) and stored at $4{ }^{\circ} \mathrm{C}$ overnight. RNALater samples were transferred to $-20{ }^{\circ} \mathrm{C}$ the next day or stored at $-80{ }^{\circ} \mathrm{C}$ for long-term storage.

Microdissections of the hippocampal subregions were performed in ice-cold PBS using a binocular (Leica). First, the dentate gyrus was isolated using a $24 \mathrm{G}$ needle (Sterican, B. Braun Melsungen) as described by Hagihara et al. (2009). After this, the remaining hippocampus was entirely removed from the brain and the CA regions separated with the same needle. The CA1 region was then further divided into the dorsal and ventral part. Each hippocampal subregion was pooled from both hemispheres and transferred into a prechilled tube filled with RNALater. 


\subsection{Histochemical Analyses}

\subsubsection{LacZ Staining}

LacZ staining was performed to visualize the localization and onset of CRE driver activity in both CRE driver lines used to knock out Tip60.

The ROSA LacZ line ROSA26R (Soriano, 1999), was chosen as a reporter strain for CRE activity. In this line, a stop codon - which is flanked by LoxP sites - is upstream of the LacZ gene and inhibits its expression. Upon CRE activity the stop codon is removed and the $L a c Z$ gene is transcribed resulting in the expression of beta galactosidase. By adding $\mathrm{X}-\mathrm{Gal}$ as a substrate of beta galactosidase, which is converted to a blue precipitate in those cells where the stop codon was excised, CRE activity can be visualized.

\subsubsection{LacZ Staining of Embryos}

The CaMKCre line was mated with ROSA26R mice and the females were plug checked. Pregnant CaMKCre ROSA26R females were killed by cervical dislocation and the embryos (between $10.5-12.5 \mathrm{dpc}$ ) were removed from the uterine tissue and collected in ice-cold 1x PBS. Embryos were then released from the amniotic sac and the placenta was removed. In order to determine the genotype of the embryos, parts of the amnion were collected for genotyping.

For the staining procedure the embryos were transferred to 24 well plates. In order to transfer them between solutions without damaging the tissue, inserts with a mesh bottom were used. First, the embryos were washed in 1x PBS and then fixed in solution B at room temperature for $15 \mathrm{~min}$. After 3 washes in Solution C for $15 \mathrm{~min}$, the embryos were transferred into solution $\mathrm{D}$ with $\mathrm{X}-\mathrm{Gal}$ and incubated at $37{ }^{\circ} \mathrm{C}$ overnight and protected from light. Afterwards, embryos were washed in Solution $\mathrm{C}$ and cleared in an ascending row of glycerol and finally stored in $80 \%$ glycerol at $4{ }^{\circ} \mathrm{C}$. For composition of solutions used see appendix (6.2.2.2).

\section{Genotyping of Embryos}

Since the ROSA26R mice used for the matings were homozygous for the reporter transgene, all embryos were hemizygous for $L a c Z$ and genotyping for the gene not necessary. However, the embryos could be either positive or negative for the CRE recombinase since CaMKCre mice were always kept in a hemizygous state. Therefore, collected samples of amniotic tissue were incubated in PBND lysis buffer with proteinase $\mathrm{K}$ at 
$55^{\circ} \mathrm{C}$ overnight. The next day samples were incubated at $85^{\circ} \mathrm{C}$ for one hour to inactivate the enzyme. $1 \mu \mathrm{l}$ of lysate was used in PCR (Table 2.1) to check for the presence of the CRE-recombinase gene in embryonic tissue.

\subsubsection{LacZ Staining of Sections}

Both coronal and sagittal sections of $25 \mu \mathrm{m}$ thickness were collected and stored at $-20{ }^{\circ} \mathrm{C}$ until use. For the staining procedure the sections were thawed and then fixed in solution B for 5 min at RT using a plastic mailer. After 3 washes in solution C for 5 min staining was performed in Solution D with X-Gal at $37{ }^{\circ} \mathrm{C}$ overnight and protected from light. The next day the sections were washed in Solution $\mathrm{C}$ and $\mathrm{H}_{2} \mathrm{O}$ for $5 \mathrm{~min}$ each and then mounted with Gelmount (Biomeda). For composition of solutions see appendix (6.2.2.2).

\subsubsection{Immunohistochemistry (IHC)}

\subsubsection{Cryosectioning}

Cryosectioning was mainly performed by technical staff. Before sectioning, the O.C.T blocks of embedded brains were mounted in a Leica Cryostat and allowed to equilibrate to the chamber's temperature. Sagittal sections of $10 \mu \mathrm{m}$ thickness were taken in 6 sets. The starting point was at approximately $2.76 \mathrm{~mm}$ Bregma and verified for each animal by staining the directly preceding sections with methylene blue. Sections were transferred to superfrost glass slides (ThermoScientific) using metal masks (ISH) or no mask (IHC). In order to analyze representative sections throughout the hippocampus, six sets of sections were taken, consisting of 9-11 slides each. On each slide, sections were thus $70 \mu \mathrm{m}$ apart from each other, spanning a total of $210 \mu \mathrm{m}$. Sections were air-dried and then transferred to a slide box, sealed with isolation tape and put at $-20{ }^{\circ} \mathrm{C}$ together with a silica pouch until use. Sections intended for use in in situ hybridization were fixed and acetylated later on.

\subsubsection{Staining}

Sections were thawed for $10 \mathrm{~min}$ at room temperature. They were then fixed in $4 \%$ PFA for 20 min and washed 3 times in 1x PBS for 5 minutes. In order to increase antibody penetration, sections were further incubated in $0.25 \%$ Triton-100 and then mounted onto a plastic holder merged into 1x PBS to avoid the forming of bubbles. The slides were then put into the Sequenza rack (ThermoFisher) and $500 \mu l$ blocking reagent was added to each slide. After one hour of blocking, the slides were washed once in 1x PBS 
for $10 \mathrm{~min}$ and $240 \mu \mathrm{l}$ of antibody dilutions were added to each slide. The slides were then put at $4{ }^{\circ} \mathrm{C}$ for antibody incubation overnight. The next day, slides were washed three times in 1x PBS for 10 min and then secondary antibodies diluted in blocking reagent were added and incubated for $1 \mathrm{~h}$ at room temperature. Slides were washed again three times in 1x PBS for $10 \mathrm{~min}$ and then disassembled from the slide holder and mounted with Vectashield medium with DAPI and kept at $4{ }^{\circ} \mathrm{C}$ until use. For a list of all antibodies used see appendix (6.2.1).

\subsubsection{Quantification of Cell Numbers and Signal Intensities}

\section{Quantification of panH4ac Signal Intensity}

Cell Profiler (Jones et al., 2008) was used in order to quantify panH4ac signal in TIP60 wild type and knockout cells. One slide per CaMKCreER ${ }^{\mathrm{T} 2} \mathrm{Tip}^{\mathrm{f} / \mathrm{f}}$ animal was taken for analysis, each consisting of 4 brain sections. Composite images consisting of $3 \times 5$ images and covering the entire dorsal hippocampus in the section were taken for each channel at 20x (Leica DMI6000B, tile scan). From these composite images the CA1 region was manually cropped using ImageJ. The images were then loaded into Cell Profiler and split into the three channels (panHac, Tip60, DAPI). Cell nuclei present in the CA1 region were identified using Cell Profiler's IdentifyPrimaryObjects module with the image of the DAPI channel. The identified objects (cell nuclei) were then automatically numbered and the objects' outlines were overlaid onto the panH4ac and TIP60 channel images so that each nucleus had the same identity in each channel image. For both the panH4ac and the TIP60 channel the mean intensity of each object was measured and assigned to the respective object number (MeasureObjectIntensity). Furthermore, the mean median of each image was calculated using the MeasureImageIntensity Module. This value was subtracted from each single object value in order to correct for background signal. The corrected knockout cell values were then normalized to the corrected wild type cell values calculated correspondingly.

\section{Quantification of TIP60-positive Cells for Deletion Efficiency Analyses}

First, composite images of the dorsal hippocampus of CaMKCreER Tip60 6 f/f and CaMKCre $\operatorname{Tip}^{\mathrm{f} / \mathrm{f}}$ mice $(\mathrm{n}=4,4$ sections per animal) were taken at $20 \mathrm{x}$ magnification (Leica DMI6000B, tile scan). The images were loaded into Gimp (The GNU Image Manipulation Program) and hippocampal subregions were selected using the path tool after addition of an alpha channel. After cropping out the respective subregions, images were split into 
the single color channels and the DAPI channel images were loaded into Cell Profiler for quantification of the total cell numbers. For the CA2 region the total cell number was determined by manual counting. Cells wild type for TIP60 were quantified manually for each subregion and normalized to the total cell number.

\section{Quantification of c-FOS Positive Cells}

Image J $1.47 \mathrm{v}$ was used to quantify the number of c-FOS positive cells in the CA1 region. A schematic overview of the image processing can be found in Figure 2.3. First, the color channels were split and the greyscale versions taken for analysis. Pyramidal cells were distinguished using a watershed plugin (Watershed on graylevel images, 02.2008, Biomedical Imaging Group (BIG), EPFL Lausanne, Switzerland) on the greyscale DAPI image. Watershed options used are listed in Table 2.3. The output image was converted to a binary image. Subsequently, the greyscale image of the c-FOS signal was thresholdadjusted to selectively mark the positive cells and also converted to a binary image. The CA1 region on the binary DAPI image was selected using the polygon tool and this selection conferred to the thresholded c-FOS image. Measurements were redirected to the c-FOS binary image (Set Measurements) and Analyze Particles conducted on the binary DAPI image. This resulted in all pyramidal cells in the selected CA1 region to be recognized as separate particles and their greyscale values to be obtained from the binary cFOS image. All particles were listed in the ROI Manager and were thus individually identifiable. In order to avoid counting of signal artefacts, a cut off for the greyscale particles was set to 128 , meaning that at least half of the particle had to contain signal to be included into the analysis. 


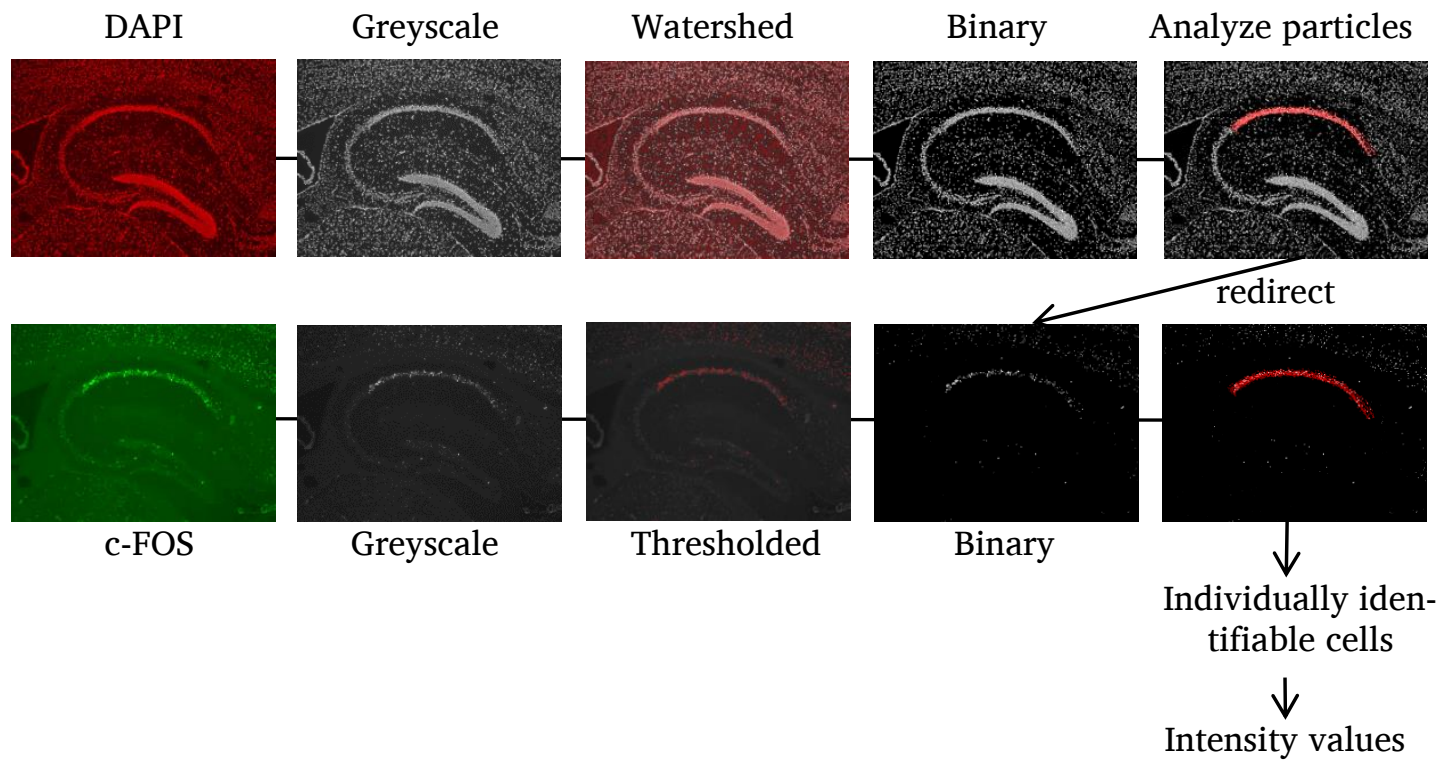

Figure 2.3: Schematic overview of image processing for c-FOS quantification in the CA1 region using ImageJ.

Table 2.3: Options set for the watershed algorithm.

\begin{tabular}{|l|l|}
\hline Gaussian blurring & Radius 1.0 \\
\hline Watershed & Bright Objects/Dark Background \\
\hline Watershed (Neighborhood) & 8-connected \\
\hline Display & Overlaid dams \\
\hline
\end{tabular}




\subsubsection{In situ Hybridization (ISH)}

In situ hybridization (ISH) was carried by technical staff, using the Tecan Genesis liquid handling platform. Details about the procedure, including probe preparation, pre-processing of tissue sections, and the ISH run have been described in detail in (Eichele et al., 2011). A list of the probes used in this thesis is shown in Table 2.4:

Table 2.4: Probes used for ISH.

\begin{tabular}{l|l|l|l|l|l|l}
$\begin{array}{l}\text { Accession } \\
\text { Number }\end{array}$ & $\begin{array}{l}\text { Gene } \\
\text { Symbol }\end{array}$ & $\begin{array}{l}\text { Seq. } \\
\text { start }\end{array}$ & $\begin{array}{l}\text { Seq. } \\
\text { end }\end{array}$ & $\begin{array}{l}\text { Forward Primer } \\
\text { (5'-3') }\end{array}$ & $\begin{array}{l}\text { Reverse Primer } \\
\text { (5'-3') }\end{array}$ & $\begin{array}{l}\text { Length } \\
\text { (bp) }\end{array}$ \\
\hline NM_153553 & Npas4 & 1636 & 2477 & $\begin{array}{l}\text { CCA GAA GCT TTG AAG } \\
\text { ACC AGT T }\end{array}$ & $\begin{array}{l}\text { CTT CGT AGG GGA } \\
\text { ATG TTG AGA C }\end{array}$ & 842 \\
\hline NM_007540 & Bdnf Ex9 & 857 & 1938 & n.a. & n.a. & 1081 \\
\hline NM_011698 & Lin7b & 12 & 525 & n.a. & n.a. & 514 \\
\hline NM_007956 & Esr1 & 1034 & 1998 & n.a. & 964 \\
\hline NM_133190 & Cacng8 & 222 & 713 & $\begin{array}{l}\text { CAT CAG CAC TGA CTA } \\
\text { CTG GCT C }\end{array}$ & $\begin{array}{l}\text { GCC GTA CGA GTA } \\
\text { GTG GTT TTT C }\end{array}$ & 492 \\
\hline NM_018801 & Syt7 & 446 & 1479 & $\begin{array}{l}\text { TGC TGG TCT CTGCAA } \\
\text { TCA TC }\end{array}$ & $\begin{array}{l}\text { GCT GAG CTT GTC } \\
\text { TTT GTC C }\end{array}$ & 1034 \\
\hline NM_018803 & Syt10 & 388 & 1149 & $\begin{array}{l}\text { CAT CTC AAG TGC TCC } \\
\text { AAC TGA A }\end{array}$ & $\begin{array}{l}\text { ATC TTTCCA TAC } \\
\text { TGT GGCTT CC }\end{array}$ & 762
\end{tabular}

\subsubsection{Western Blot}

A single hippocampus was homogenized in $150 \mu \mathrm{l} 1 \mathrm{x}$ laemmli buffer using the Beadruptor (Biolabs, speed 5, $30 \mathrm{~s}$ ). The homogenate was then quickly spun down for $10 \mathrm{~min}$ at $4{ }^{\circ} \mathrm{C}$ and the supernatant transferred to a new tube. Samples were boiled at $99^{\circ} \mathrm{C}$ for $10 \mathrm{~min}$ and cooled down before loading onto the gel. For TIP60 antibody tests $10 \%$ and for histone acetylations 4-15 \% TGX gels (Biorad) were used. Samples were run at $150 \mathrm{~V}$ for $45-60 \mathrm{~min}$ and transferred using the Turbo Blot system (Biorad) with prepacked transfer packs using the default transfer options for TGX gels. Blocking was performed with $5 \%$ Milk in $1 \mathrm{x}$ TBST for one hour and antibody incubation was overnight at $4{ }^{\circ} \mathrm{C}$ on a rotator. Washing steps were $5 \times 5 \mathrm{~min}$ in $1 \mathrm{x}$ TBST and secondary antibody was HRP-conjugated (NEB). Band detection was performed using ECL substrates (Pierce) and the ImageQuant system (GE Healthcare). Quantifications of bands were performed in the linear range using ImageJ. Western blots for quantifications of histone acetylation were performed in duplicate. 


\subsection{Molecular Analyses}

\subsubsection{Gene Deletion on DNA Level}

\subsubsection{Southern Blot}

Brain regions were dissected in ice-cold 1x PBS, frozen in liquid nitrogen and kept at $-20{ }^{\circ} \mathrm{C}$ until use. Hippocampi were homogenized with a pistil in $200 \mu \mathrm{l}$ DNA lysis buffer with $12 \mu$ proteinase K. Hindbrain samples were homogenized in $1 \mathrm{ml}$ buffer with $60 \mu \mathrm{l}$ proteinase $\mathrm{K}$. Tissue was digested at $55^{\circ} \mathrm{C}$ overnight.

The next day, phenol chloroform extraction was performed. One volume of phenol/chloroform/isoamyl alcohol (25:24:1) was added to each sample and centrifuged for $2 \mathrm{~min}$ at $14,000 \mathrm{rpm}$ at $4{ }^{\circ} \mathrm{C}$. The top layer was then transferred to a clean tube and 1 volume of chloroform added. The tube was centrifuged for $2 \mathrm{~min}$ at $14,000 \mathrm{rpm}$ at $4{ }^{\circ} \mathrm{C}$. The top layer was again transferred to a clean tube and one tenth volume of sodium acetate and one 5 th volume of cold $100 \% \mathrm{EtOH}$ added. The samples were then incubated at $-20{ }^{\circ} \mathrm{C}$ for 2 hours. Afterwards the samples were centrifuged at $14,000 \mathrm{rpm}$ at $4{ }^{\circ} \mathrm{C}$ for $30 \mathrm{~min}$ and the supernatant removed. The pellet was washed with $70 \%$ cold $\mathrm{EtOH}$ and centrifuged again at 14,000 rpm for $30 \mathrm{~min}$. The supernatant was removed and the pellet dried at room temperature and resuspended in $30 \mu \mathrm{H}_{2} \mathrm{O}$. The DNA concentration was determined with NanoDrop (ThermoScientific) and a maximum volume of $28 \mu \mathrm{l}$ used for the digestion reaction (Table 2.5):

Table 2.5: Digestion reaction for Southern blot.

\begin{tabular}{l|l} 
Reagent & Volume $[\mu \mathrm{l}]$ \\
\hline Buffer & 5.0 \\
\hline BSA & 0.5 \\
\hline EcoRV & 1 \\
\hline DNA Template & $\mathrm{x}(\max .28 \mu \mathrm{l})$
\end{tabular}

$\mathrm{H}_{2} \mathrm{O}$ was added to a total reaction volume of $50 \mu \mathrm{l}$. Samples were put at $37{ }^{\circ} \mathrm{C}$ overnight. The next day, the digestion product was loaded onto a $0.7 \%$ agarose gel (50 $\mu$ l digestion $+10 \mu \mathrm{l} 6 \mathrm{x}$ loading dye) and run at $30 \mathrm{~V}$ for approximately 29 hours. Afterwards the gel was incubated in depurination buffer on a shaker for $10 \mathrm{~min}$. The gel was then incubated in alkaline transferase buffer for $15 \mathrm{~min}$ and another $20 \mathrm{~min}$ in fresh buffer. A membrane (Hybond-XC Amersham) was cut to the appropriate size and incubated in alkaline transfer buffer together with the gel for $15 \mathrm{~min}$. It was then washed in neutralization buffer for another $15 \mathrm{~min}$ and then dried in Whatman paper. 
Table 2.6: Primer sequences for the Southern blot probe $(817 \mathrm{bp})$.

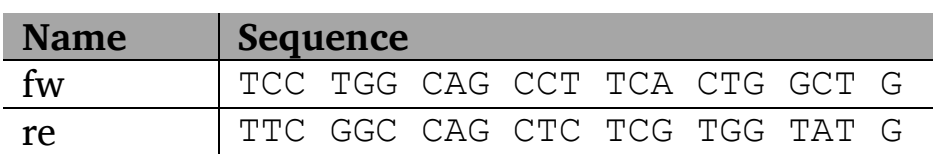

Table 2.7: PCR reaction for probe amplification for Southern blot.

\begin{tabular}{l|c}
\multicolumn{1}{c|}{ Reagent } & Volume \\
\hline $\mathrm{H}_{2} \mathrm{O}$ & 56.4 \\
\hline 10x buffer & 10.0 \\
\hline Q Solution & 20.0 \\
\hline dNTPs $[10 \mu \mathrm{M}]$ & 2.0 \\
\hline Primer Mix & 3.0 \\
\hline DNA Template & 5.0
\end{tabular}

The PCR program was the same as used for the Tip60 genotyping (Table 2.1) with the annealing temperature set to $62{ }^{\circ} \mathrm{C}$. After amplification the probe DNA was purified using a DNA purification kit (Qiagen) (Table 2.6 and Table 2.7).

The membrane was put into a hybridization-tube together with 2x SSC (ca. $200 \mathrm{ml}$ ). Prewarmed Modified Church Buffer was added $(15 \mathrm{ml})$ and the membrane incubated for 1 hour at $65{ }^{\circ} \mathrm{C}$.

\section{Probe Preparation:}

$44 \mu \mathrm{l}$ TE-Buffer $\mathrm{pH} 8.0$ were added to $230 \mathrm{ng}$ of template DNA and incubated at $95{ }^{\circ} \mathrm{C}$ for $5 \mathrm{~min}$ followed by a $15 \mathrm{~min}$ incubation on ice. $5 \mu \mathrm{l}$ 32P primer mix (Random Primer Labeling System, Rediprime II) were added and incubated for $50 \mathrm{~min}$ at $37^{\circ} \mathrm{C}$. Filter columns (Illustra ProbeQuant G-50 Micro Columns) were prepared by centrifugation at $3,000 \mathrm{rpm}$ for $2 \mathrm{~min}$. The hot probe was then loaded onto the column and centrifuged for $2 \mathrm{~min}$ at $3,000 \mathrm{rpm}$.

\section{Probe Incubation:}

The Church buffer was decanted and substituted with $15 \mathrm{ml}$ prewarmed Church buffer supplemented with the hot probe. The membrane was incubated with the probe overnight at $65{ }^{\circ} \mathrm{C}$. The next day the membrane was washed twice in prewarmed SSC buffer with SDS:

$$
\begin{aligned}
& 2 \mathrm{xSC}+0.1 \% \text { SDS } 2 \text { x } 5 \mathrm{~min} \\
& 1 \mathrm{xSS}+0.1 \% \text { SDS } 2 \text { x } 10 \mathrm{~min} \\
& 0.1 \mathrm{xSSC}+0.1 \% \text { SDS } 4 \text { x } 5 \mathrm{~min}
\end{aligned}
$$


Afterwards the membrane was put between two Whatman papers and dried for $30 \mathrm{~min}$. It was subsequently wrapped in saran foil and transferred to the developing cassette together with film (Kodak BioMAX). The film was developed after 22 hours of exposure.

\subsubsection{PCR Brain Areas}

In order to analyze Tip60 gene deletion in different brain regions of tamoxifen-induced CaMKCreER $^{\mathrm{T} 2} \mathrm{Tip}^{\mathrm{f} / \mathrm{f}}$ mice, samples from olfactory bulb, cortex, hippocampus, thalamus, hypothalamus, cerebellum, and pons/medulla were dissected on a cold plate, frozen in liquid nitrogen, and stored at $-80{ }^{\circ} \mathrm{C}$ until use.

The Allprep DNA/RNA Kit (Qiagen) was used in order to isolate DNA from the brain regions taken. Samples were transferred to $2 \mathrm{ml}$ screw cap tubes with ceramic balls on ice. After adding $600 \mu \mathrm{l}$ of RLT Plus Buffer, supplemented with beta-Mercaptoethanol, homogenization was performed using the Beadruptor (Biolabs, speed 5, 2x $30 \mathrm{~s}$ with a 30 s pause inbetween). Afterwards, samples were centrifuged at 13,000 rpm at RT and processed according to the manual's instructions. DNA was eluted in $100 \mu \mathrm{l}$ EB Buffer and concentrations measured using NanoDrop (Thermo Scientific). Samples were stored at $-20{ }^{\circ} \mathrm{C}$ until use. For PCR $50 \mathrm{ng}$ of DNA were added and the amplification performed using the Tip60 primers and the protocol listed in Section 2.1.5.2 . $10 \mu \mathrm{l}$ of each PCR product was loaded onto a $2 \%$ agarose gel and run for $1 \mathrm{~h} 20 \mathrm{~min}$ at $120 \mathrm{~V}$.

\subsubsection{RNA Isolation and Reverse Transcription}

\subsubsection{RNA Isolation}

RNA was isolated using the RNeasy Mini Kit (Qiagen) following the product's instructions. All centrifugations were carried out at maximum speed at RT. Hippocampus samples stored in RNALater (Ambion) at $-20{ }^{\circ} \mathrm{C}$ were transferred to $2 \mathrm{ml}$ tubes with screw caps filled with ceramic balls. $600 \mu \mathrm{l}$ of buffer RLT was then added and the tissue homogenized using the Beadruptor for $2 \times 30 \mathrm{~s}$ at speed 5 with a $30 \mathrm{~s}$ pause inbetween. The homogenate was then spun down for $3 \mathrm{~min}$ and the supernatant transferred to a new tube. One volume of $70 \% \mathrm{EtOH}$ was added and the samples immediately loaded onto spin columns. In order to bind the RNA to the membrane, the samples were centrifuged for $30 \mathrm{~s}$ and the flow-through discarded. This was repeated once in order to spin down the total sample volume of $1.2 \mathrm{ml}$. The membrane was then washed with $700 \mu \mathrm{l}$ of buffer RW1 and the flow-through discarded. $500 \mu \mathrm{l}$ of buffer RPE were added and the columns spun down for $30 \mathrm{~s}$ again. The column was placed into a new $2 \mathrm{ml}$ collection 
tube and spun down for $1 \mathrm{~min}$ to eliminate residual liquid. The columns were then placed into $1.5 \mathrm{ml}$ collection tubes and the RNA eluted in $30 \mu \mathrm{l}$ of $\mathrm{H}_{2} \mathrm{O}$. After one minute the samples were spun down again for 1 min and immediately put on ice. RNA concentration was measured using NanoDrop 1000. RNA was immediately used for reverse transcription or stored at $-80{ }^{\circ} \mathrm{C}$ until use.

\subsubsection{Reverse Transcription}

RNA was reverse transcribed using the Quantitect Reverse Transcription Kit (Qiagen) following the instructions provided. 1-2 $\mu \mathrm{g}$ of RNA was used and the reactions volumes scaled accordingly. For $1 \mu \mathrm{g}$ RNA, $2 \mu \mathrm{l}$ of gDNA Wipeout Buffer (7x) were mixed with template and $\mathrm{H}_{2} \mathrm{O}$ to a total volume of $14 \mu \mathrm{l}$. The samples were incubated at $42{ }^{\circ} \mathrm{C}$ for 2 min. On ice, $6 \mu \mathrm{l}$ of master mix was added, consisting of $4 \mu \mathrm{l}$ Quantiscript RT Buffer (5x), $1 \mu \mathrm{l}$ RT Primer Mix and $1 \mu \mathrm{l}$ Quantiscript Reverse Transcriptase. The samples were then incubated for $15 \mathrm{~min}$ at $42^{\circ} \mathrm{C}$ and the reaction stopped by incubating another $3 \mathrm{~min}$ at $95{ }^{\circ} \mathrm{C}$. The samples were then cooled on ice and immediately used for qPCR or stored at $-20{ }^{\circ} \mathrm{C}$ for later use.

\subsection{3 qPCR}

cDNA samples were diluted 1:20 in $\mathrm{H}_{2} \mathrm{O}$ before use in qPCR. Reaction volumes were $20 \mu$ (Table 2.8). $15 \mu$ l of mastermix were pipetted into each well and $5 \mu$ l of template was added. Each plate was spun down for $1 \mathrm{~min}$ at 1,000 rpm before being inserted into the qPCR machine (CFX96, Biorad). The program used is listed in Table 2.9. Data was analyzed using Bio-Rad CFX Manager 3.0 software. Gapdh was used for normalization using the $\Delta \Delta$ Ct method (Livak et al., 2001). All primers used in qPCR are listed in Table 2.10 .

Table 2.8: qPCR reaction mix.

\begin{tabular}{l|c} 
Reagent & Volume $[\mu \mathrm{l}]$ \\
\hline Sybr Green & 10 \\
\hline Primer Mix $(5 \mu \mathrm{M})$ & 1 \\
\hline cDNA $(1: 20)$ & 5 \\
\hline $\mathrm{H}_{2} \mathrm{O}$ & 4
\end{tabular}


Table 2.9: qPCR program.

\begin{tabular}{c|l|c|l} 
Step & Temperature $\left[{ }^{\circ} \mathrm{C}\right]$ & Time Interval [min] & Options \\
\hline 1 & 95.0 & $7: 00$ & \\
\hline 2 & 95.0 & $0: 10$ & \\
\hline 3 & 60.0 & $0: 25$ & \\
\hline 4 & 72.0 & $0: 20$ & + Plate Read \\
\hline 5 & GOTO 2,40 more times & & \\
\hline 6 & 65.0 to 95.0 , incr. $0.5{ }^{\circ} \mathrm{C}$ & $0: 05$ & + Plate Read \\
\hline & END & &
\end{tabular}

Table 2.10: Primers used in qPCR.

\begin{tabular}{|c|c|}
\hline Name & Sequence (5'-3') \\
\hline Npas4 fw & CTG AGG GGA AGT TGC TAT ACC T \\
\hline Npas4 re & GTG TTG AAT CGA CAA CGG AAA AG \\
\hline c-Fos fw & TTC CTG GCA ATA GCG TGT TC \\
\hline c-Fos re & TTC AGA CCA CCT CGA CAA TG \\
\hline Homer1 fw & CAG TTC TTC TTT GTG TTC GGG \\
\hline Homer1 re & AGA GCA AGT TTT CAT TGG GC \\
\hline cJun fw & GAA GTG ACG GAC CGT TCT ATG AC \\
\hline cJun re & GGA GGA ACG AGG CGT TGA G \\
\hline Arc fw & CAG GGG TGA GCT GAA GCC ACA A \\
\hline Arc re & TCT CAG CAG CCT TGA GAC CTG GTG \\
\hline Zif268 fw & CCT TCA ATC CTC AAG GGG AGC CGA \\
\hline Zif268 re & AAG GAC TCT GTG GTC AGG TGC TCA \\
\hline Nr4a1 fw & CCG GCT GGA GAT GCC CTG TAT TCA \\
\hline Nr4a1 re & AGG TCC ATG GTA GGC TTG CCG A \\
\hline Bdnf exon I fw & AGT TGC TTT GTC TTC TGT AGT CGC \\
\hline Bdnf exon I re & CCT GGA GAC TCA GTG TCT TA \\
\hline Bdnf exon IV fw & CAG GAG TAC ATA TCG GCC ACC A \\
\hline Bdnf exon IV re & GTA GGC CAA GTT GCC TTG TCC GT \\
\hline Lin7b fw, re & Mm_Lin7b_1_SG QuantiTect Primer (Qiagen) \\
\hline Reln fw,re & Mm_Reln_1_SG QuantiTect Primer (Qiagen) \\
\hline Gap43 fw & AGA TGG TGT CAA GCC GGA AG \\
\hline Gap43 re & CGC CTT TGA GCT TTT TCC TTG T \\
\hline Syt5 fw & TGG GCC GGA GTT ACA TAG ATA A \\
\hline Syt5 re & GGC CTA GCT GGT GTT TGT CTG \\
\hline Syt17 fw & GAC ATC AAA CCC GTT GAG TTC G \\
\hline Syt17 re & GTC ATC GGG CGT GTA GGT C \\
\hline Sst fw & ACC GGG AAA CAG GAA CTG G \\
\hline Sst re & TTG CTG GGT TCG AGT TGG C \\
\hline Syt9 fw & CTG CCA AGA TTT CAT CTA CCA CC \\
\hline Syt9 re & TCC AAG ACA CGA AAA GAG AGA CA \\
\hline Sphkap fw & GAG CGG TCC ATG AGT GAA TTA G \\
\hline Sphkap re & CAG AGG CAT GTT CCT TTA TGC T \\
\hline Sirpa fw & GCT ACC CAC AAC TGG AAT GTC \\
\hline Sirpa re & GGT TAT TTC CCT GGC GTT CTT \\
\hline Gapdh fw & CAT GGC CTT CCG TGT TCC TA \\
\hline Gapdh re & CCT GCT TCA CCA CCT TCT TGA \\
\hline Stmn3 fw & CAG CAC CGT ATC TGC CTA CAA \\
\hline Stmn3 re & GTA GAT GGT GTT CGG GTG AGG \\
\hline Dnm1 fw & AAT ATG CCG AGT TCC TGC ACT \\
\hline
\end{tabular}




\begin{tabular}{l|lllll} 
Dmn1 re & GTC TCA GCC TCG ATC TCC AG & \\
\hline Stau2 fw & CGA AGG GAG CAG TAT AAA GAA GG & \\
\hline Stau2 re & GGT TTG GGA AGC GTA GAT TCA G & \\
\hline Tip60 ex7-8 fw & GCC TGG ACG GAA GCG GAA AT & \\
\hline Tip60 ex7-8 re & CAA TGT CGT GGC TCC GGT & \\
\hline Tip60 ex9-11 fw & ACC GCA AGG GCA CCA TCT CCT TT & \\
\hline Tip60 ex9-11 re & GAG GCA GAG TCA AGA TGC AGG CCA & \\
\hline Thy1 fw & TGC TCT CAG TCT TGC AGG TG & \\
\hline Thy1 re & TGG ATG GAG TTA TCC TTG GTG TT & \\
\hline Ywhah fw & ACG AAG ATC GAA ATC TCC TCT CT & \\
\hline Ywhah re & CCG GTA GGC TTT AAC TTT CTC CA & \\
\hline Crh fw, re & Mm_Crh1_1_SG QuantiTect Primer & (Qiagen) \\
\hline Adcyap1 fw & CTG CGT GCA GAA ATG CTA CTG & \\
\hline Adcyap1 re & AGC CGT AGA GTA ATG GTG GAT AG & \\
\hline Ryr1 fw, re & Mm_Ryr1_1_SG QuantiTect Primer & (Qiagen) \\
\hline Egr2 fw, re & Mm_Egr2_1_SG QuantiTect Primer & (Qiagen) \\
\hline Esr1 fw, re & Mm_Esr1_2_SG QuantiTect Primer & (Qiagen) \\
\hline Bdnf exon IV fw (ChIP) & GGC TTC TGT GTG CGT GAA TTT & \\
\hline Bdnf exon IV re (ChIP) & AAA GTG GGT GGG AGT CCA CGA G &
\end{tabular}

\subsubsection{Next Generation Sequencing}

\subsubsection{Tissue Collection}

Mice from the inducible mouse line CAMKCreER ${ }^{\mathrm{T} 2} \mathrm{Tip} 60^{\mathrm{f} / \mathrm{f}}$ were single-caged one week before sacrifice in order to avoid any influence on immediate-early gene transcription by sequentially taking animals from the same cage. In contrast, animals from the constitutive line CaMKCre Tip60 ${ }^{\mathrm{f} / \mathrm{f}}$, which had compromised health at the time of sacrifice, were not single-caged in order to avoid further stress. All samples were collected during the animals' sleeping phase, and the time between waking up and sacrifice was equal to or less than one minute. Microdissected samples, i.e. dorsal CA1 regions, which were pooled from each animal, were handed over to the Transkriptomanalyselabor (TAL), Göttingen, for RNA extraction and sequencing.

\subsubsection{RNA Sequencing and Data Analysis}

RNA extraction was performed at the TAL using Phenol Chloroform extraction. Library preparation was performed starting from $1 \mu \mathrm{g}$ of total RNA using the TruSeq RNA Sample Preparation Kit (Illumina, RS-122-2002). Accurate quantitation of cDNA libraries was performed using the QuantiFluor ${ }^{\mathrm{TM}}$ dsDNA System (Promega). The size range of final cDNA libraries was determined applying the DNA 1000 chip on the Bioanalyzer 2100 from Agilent (280 bp). cDNA libraries were amplified and sequenced using the cBot and 
HiSeq2000 from Illumina (SR; 1x50 bp; 30 million reads per sample). Sequence images were transformed with Illumina software BaseCaller to bcl files, which were demultiplexed to fastq files with CASAVA v1.8.2. Quality check was done via fastqc (v. 0.10.0, Babraham Bioinformatics). Further details about the sample quality, including the RNA integrity number (RIN), and analysis pipeline are listed in Table 2.11 and Table 2.12:

Table 2.11: RNA-Seq data acquisition steps.

\begin{tabular}{r|l|l|l|l}
\multicolumn{1}{c|}{ Step } & Description & Tool/Script & $\begin{array}{l}\text { Non-default } \\
\text { parameters }\end{array}$ & Reference \\
\hline 1 & Quality Control & FastQC & - & $\begin{array}{l}\text { (Babraham Bioinformatics, } \\
\text { 2012) }\end{array}$ \\
\hline 2 & $\begin{array}{l}\text { Mapping to reference ge- } \\
\text { nome (GRCm37/mm9) }\end{array}$ & TopHat (v2.0.8) & $\begin{array}{l}\text {--no-cover- } \\
\text { age-search }\end{array}$ & (Trapnell et al., 2009) \\
\hline 3 & Read counting in transcripts & $\begin{array}{l}\text { bedtools } \\
\text { (bedtools cover- } \\
\text { age) }\end{array}$ & - & (Quinlan et al., 2010) \\
\hline 4 & $\begin{array}{l}\text { Detection of differential } \\
\text { gene expression }\end{array}$ & $\begin{array}{l}\text { DESeq (R-pack- } \\
\text { age) }\end{array}$ & $\begin{array}{l}\text { pairwise } \\
\text { comparisons } \\
\text { of groups }\end{array}$ & (Anders et al., 2010) \\
\hline 5 & Visualization & IGV & - & (Robinson et al., 2011)
\end{tabular}

Table 2.12: RNA-Seq sample information.

\begin{tabular}{|c|c|c|c|c|c|}
\hline Sample ID & Group & $\begin{array}{l}\text { RNA } \\
\text { quality } \\
\text { (RIN) }\end{array}$ & $\begin{array}{c}\text { Total num- } \\
\text { ber of } \\
\text { reads }\end{array}$ & $\begin{array}{l}\text { Number of } \\
\text { mapped reads }\end{array}$ & $\begin{array}{l}\text { Tophat2: align- } \\
\text { ment rate }\end{array}$ \\
\hline Sample_1155 & $\operatorname{Tip}^{\mathrm{f} / \mathrm{f}}$ & 8.6 & 35748651 & 34846631 & $97.48 \%$ \\
\hline Sample_1156 & CaMKCreER $^{\mathrm{T} 2}$ Tip60 $60^{\mathrm{f} / \mathrm{f}}$ & 8.8 & 40579081 & 39563607 & $97.50 \%$ \\
\hline Sample_1157 & Tip60 $0^{\mathrm{f} / \mathrm{f}}$ & 8.6 & 42307858 & 41203943 & $97.39 \%$ \\
\hline Sample_1158 & CaMKCreER $^{\mathrm{T} 2}$ Tip60 ${ }^{\mathrm{f} / \mathrm{f}}$ & 8.7 & 39497946 & 38815328 & $98.27 \%$ \\
\hline Sample_1159 & Tip60 $0^{\mathrm{f} / \mathrm{f}}$ & 8.6 & 41357127 & 39991490 & $96.70 \%$ \\
\hline Sample_1164 & CaMKCreER $^{\mathrm{T} 2} \mathrm{Tip}^{\mathrm{f} / \mathrm{f}}$ & 8.7 & 36535114 & 35692591 & $97.69 \%$ \\
\hline Sample_1165 & Tip60 $0^{\mathrm{f} / \mathrm{f}}$ & 8.6 & 42927766 & 41986607 & $97.81 \%$ \\
\hline Sample_1171 & CaMKCreER $^{\mathrm{T} 2} \mathrm{Tip}^{\mathrm{f} / \mathrm{f}}$ & 8.9 & 38506044 & 37565488 & $97.56 \%$ \\
\hline Sample_1173 & $\operatorname{Tip} 60^{\mathrm{f} / \mathrm{f}}$ & 8.5 & 38029985 & 37135090 & $97.65 \%$ \\
\hline Sample_1179 & CaMKCreER $^{\mathrm{T} 2} \mathrm{Tip}^{\mathrm{f} / \mathrm{f}}$ & 8.7 & 36252642 & 35233192 & $97.19 \%$ \\
\hline Sample_1181 & Tip60 $0^{\mathrm{f} / \mathrm{f}}$ & 8.7 & 41221442 & 40353048 & $97.89 \%$ \\
\hline Sample_1182 & CaMKCreER $^{\mathrm{T} 2} \mathrm{Tip}^{\mathrm{f} / \mathrm{f}}$ & 8.8 & 38585883 & 37781098 & $97.91 \%$ \\
\hline Sample_1125 & CaMKCre Tip60 f/f & 7.6 & 61855843 & 60259975 & $97.42 \%$ \\
\hline Sample_1126 & $\operatorname{Tip} 60^{\mathrm{f} / \mathrm{f}}$ & 7.6 & 76000000 & 74124395 & $97.53 \%$ \\
\hline Sample_1129 & CaMKCre Tip60 $60^{\mathrm{f} / \mathrm{f}}$ & 7.9 & 39629958 & 38630191 & $97.48 \%$ \\
\hline Sample_1130 & Tip60 $0^{\mathrm{f} / \mathrm{f}}$ & 7.6 & 53593849 & 52160629 & $97.33 \%$ \\
\hline Sample_1131 & CaMKCre Tip60 $^{\mathrm{f} / \mathrm{f}}$ & 7.9 & 61234365 & 59842035 & $97.73 \%$ \\
\hline Sample_1132 & Tip60 $0^{\mathrm{f} / \mathrm{f}}$ & 7.6 & 55175915 & 53880656 & $97.65 \%$ \\
\hline Sample_1133 & CaMKCre Tip60 f/f & 8.0 & 45833480 & 44637000 & $97.39 \%$ \\
\hline Sample_1134 & $\operatorname{Tip} 60^{\mathrm{f} / \mathrm{f}}$ & 8.0 & 52976946 & 51721840 & $97.63 \%$ \\
\hline Sample_1135 & CaMKCre Tip60 ${ }^{\mathrm{f} / \mathrm{f}}$ & 8.0 & 63805316 & 62442845 & $97.86 \%$ \\
\hline
\end{tabular}


All bioinformatical analyses of the data were performed in collaboration with Haifang Wang (CAS-MPG partner institute for Computational Biology, Shanghai institutes for Biological Sciences).

\subsubsection{Chromatin Immunoprecipitation}

For chromatin immunoprecipitation (ChIP) of microdissected hippocampal CA1 subregions, the LowCell\# ChIP Kit from Diagenode was used. Per Sample $22 \mu$ of buffer A and $11 \mu \mathrm{l}$ of magnetic beads were mixed in a $0.2 \mathrm{ml}$ tube. In order to separate the beads from the buffer after washing, the tubes were put onto a magnet (Diamag02, Diagenode) for $1 \mathrm{~min}$. After this, the supernatant was removed and another $22 \mu \mathrm{l}$ of buffer A were added. Again the tubes were left for $1 \mathrm{~min}$ on the magnet and after removal of the supernatant the beads were resuspended in $11 \mu \mathrm{l}$ buffer A. $90 \mu \mathrm{l}$ of buffer A were aliquoted into $0.2 \mathrm{ml}$ tubes and $10 \mu \mathrm{l}$ of bead solution as well as $6 \mu \mathrm{l}$ of antibody against MECP2 $2^{\mathrm{K} 464 \mathrm{ac}}$ or $3 \mu \mathrm{l}$ of IgG were added. The tubes were inserted into a $15 \mathrm{ml}$ falcon tube and placed onto a rotating wheel at $4{ }^{\circ} \mathrm{C}$ for two hours. Samples of microdissected CA1 region were homogenized in $250 \mu$ of ice-cold 1x PBS with freshly added protease inhibitors (Complete Mini, EDTA-free, Roche). Another $250 \mu \mathrm{l}$ of 1x PBS (with protease inhibitor) together with $13.5 \mu \mathrm{l}$ of $37 \%$ formaldehyde (Applichem) were added. After $15 \mathrm{~min}$ incubation on a shaker at $500 \mathrm{rpm}$ at RT $57 \mu \mathrm{l}$ of $1.25 \mathrm{M}$ glycine were added to stop the reaction. Samples were centrifuged for $10 \mathrm{~min}$ at $500 \mathrm{~g}$ at $4{ }^{\circ} \mathrm{C}$ and the supernatant was removed. The pellet was resuspended in $130 \mu \mathrm{l}$ of buffer B with protease inhibitors added and incubated on ice for $5 \mathrm{~min}$. The samples were then sonicated to shear the chromatin using a bioruptor (Diagenode). Settings were HIGH 30s on/off 25 cycles. After the shearing $870 \mu \mathrm{l}$ of buffer A (with protease inhibitor) were added. Per ChIP, $100 \mu \mathrm{l}$ of the sheared chromatin were added to the prepared bead solution and incubated on a rotating wheel at $4{ }^{\circ} \mathrm{C}$ overnight. $100 \mu \mathrm{l}$ of chromatin were kept as Input sample at $4{ }^{\circ} \mathrm{C}$ while the rest of the chromatin was frozen at $-80^{\circ} \mathrm{C}$. Beads were washed 3 times with $100 \mu \mathrm{l}$ buffer A and placed for 1 min on a magnetic rack in between. Beads were then washed once with $100 \mu \mathrm{l}$ of buffer $\mathrm{C}$, resuspended in $99 \mu$ of DNA isolation buffer (DIB) with proteinase $\mathrm{K}$ and transferred to $1.5 \mathrm{ml}$ tubes. Also $1 \mu \mathrm{l}$ of Input was added to $99 \mu \mathrm{LIB}$ and proteinase $\mathrm{K}$ in a $1.5 \mathrm{ml}$ tube. All samples were incubated at $55{ }^{\circ} \mathrm{C}$ for $15 \mathrm{~min}$ followed by an additional $15 \mathrm{~min}$ incubation at $99{ }^{\circ} \mathrm{C}$ to inactivate proteinase K. Samples were then centrifuged for $5 \mathrm{~min}$ at $14,000 \mathrm{rpm}$ at $4{ }^{\circ} \mathrm{C}$ and the supernatant transferred to a new tube. $5 \mu$ l of each sample was used in qPCR (Section 
2.4.3). Primers specific for Bdnf exon $I V$ used were the same as published by Zocchi et al. (2012).

\subsection{Behavioral Analyses}

\subsubsection{Novel Environment}

Mice were single-caged at least one week before the start of the experiment and handled daily. Home cage (HC) controls were left in the original cage until sacrifice. Animals for novel environment (NE) were taken out of their home cage and put into a new cage with a rack as a novel item for $30 \mathrm{~min}$. They were sacrificed immediately after the exploration time was up. HC and NE animals were always taken on the same day and the ratio of condition and genotype was equalized for both genotypes whenever possible. An overview of the experimental setup is illustrated in Figure 2.4.

A

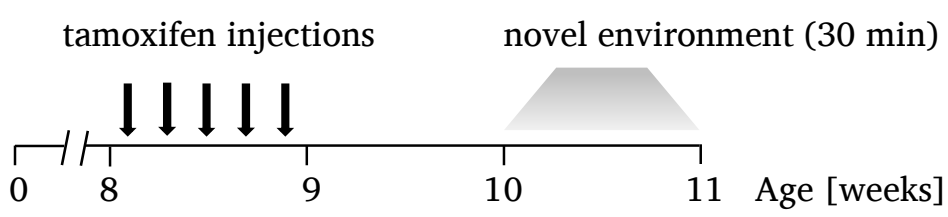

B

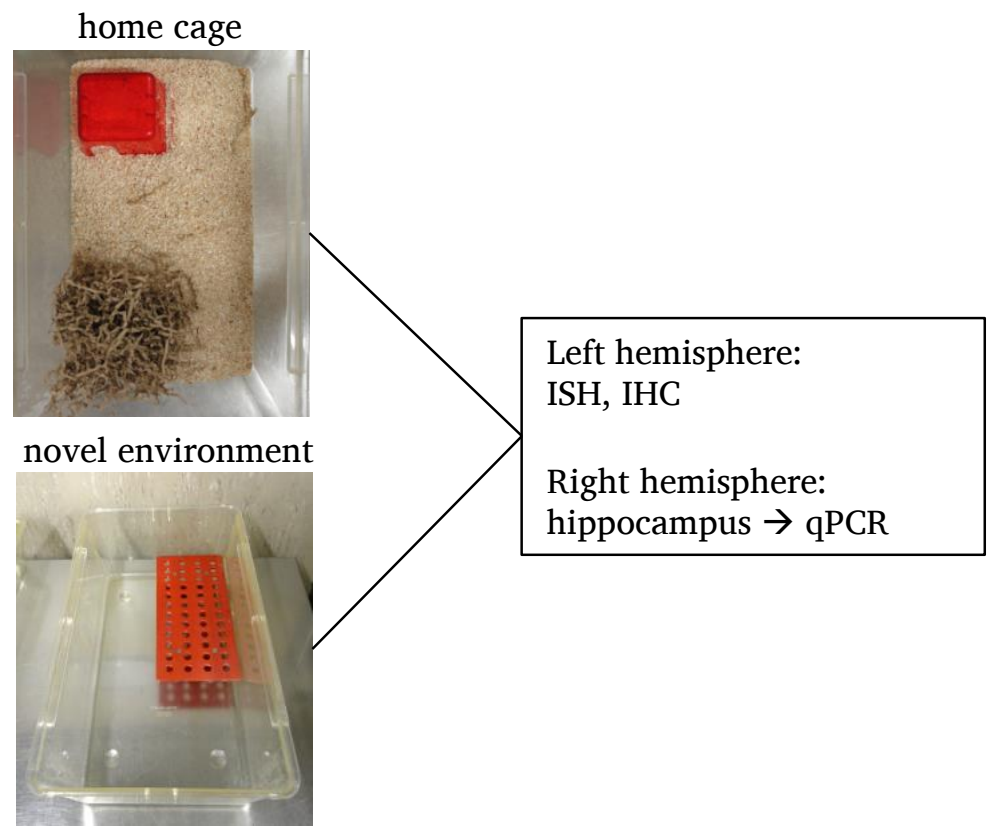

Figure 2.4 Experimental setup for the novel environment paradigm. (A) Overview of the time line for the novel environment. (B) Mice were housed in single cages (top left) at least one week before the experiment. The novel environment consisted of an empty cage without bedding and a plastic rack inside (bottom left). The tissue collected was either used for qPCR analysis or IHC/ISH. 


\subsubsection{Behavioral Test Battery}

Animals were single caged at least one week before the start of the experiments. All animals were individually tested and their behavior was analyzed using the TSE Videomot2 tracking system, Version 5.72, if not stated otherwise.

\subsubsection{Open Field}

The Open Field test allows to measure the general activity, exploratory behavior, and basal anxiety level of the mice. The animals were put into the center of a grey plastic arena ( $\mathrm{LxWxH}, 50 \times 50 \times 40 \mathrm{~cm})$, which was divided into 16 equal virtual squares. The inner 4 squares constituted the center of the box and the remaining squares the periphery. Both the activity and squares visited by the animal were recorded for $5 \mathrm{~min}$. The total distance covered, as well as the speed and occupancy of the squares in the center versus those in the periphery were calculated.

\subsubsection{Novel Object Recognition}

The Novel Object Recognition (NOR) test is used to assess recognition memory in rodents. It is based on the spontaneous tendency of the animals to spend more time exploring a novel than a familiar object (Ennaceur et al., 1988). The decision to explore the novel object is based on the comparison to existing memories of familiar objects. This test consisted of habituation, training, and two testing phases. A grey plastic box (LxWxH 50x50x40 cm) served as the testing arena. First, the mice were habituated to the test arena for $5 \mathrm{~min}$ on two consecutive days. On the following day they were introduced to two equal objects (A and A), that were placed in opposing corners of the testing arena, for 5 min (training). The next day objects A and A were exchanged by two new objects (objects $B$ and $B$ ), that were again equal to each other but markedly different from object A. The animals were allowed to explore the objects for $5 \mathrm{~min}$. After this, the animals were put back to their home cages for 5 minutes and reintroduced to the arena after one object was exchanged (objects B and C). Short-term memory assessment (STM) was performed by quantifying the number of visits to objects B and C and the time the mice spent exploring each object. 24 hours later object $\mathrm{C}$ was exchanged for object D in order to assess long-term memory (LTM) formation. Objects and the testing arena were cleaned with $70 \% \mathrm{EtOH}$ between animals and sessions. The time spent exploring each object and the number of visits were measured and the ratio of the time spent with the new object and the time spent with either the new or the old object was 
calculated. Animals that did not explore any of the two objects during a session were excluded from the analysis.

\subsubsection{Cross Maze}

The cross maze was employed in order to test spatial working memory in the mice. The test took place in a plastic arena consisting of four orthogonal arms ( $\mathrm{LxWxH}$ $30 \times 8 \times 15 \mathrm{~cm}$ ) connected via a central square ( $\mathrm{xxWxH} 8 \times 8 \times 15 \mathrm{~cm})$. The arms were transparent and had slots, in which paperboard with different geometrical patterns was inserted in order to facilitate discrimination and recognition of the different arms. Furthermore, the arms were numbered from one to four. For the test, the mice were put into the center of the maze and were then allowed to explore the arena for $10 \mathrm{~min}$. Normally, mice show preference for the arm they haven't visited for the longest. This implies that the animals will visit the four arms sequentially and will memorize the sequence of arms visited and update this list. If an impairment of spatial working memory exists the mice will have difficulty remembering which arm they visited last and this will thus result in a decreased alternation of arm entry. The readout for spatial working memory performance was thus determined as the percentage of arm entry alternation. For this, all arm entries of each animal were recorded and the sequence of arm numbers was scanned for overlapping quadrupels consisting of the four arm numbers, where each number appears exactly once (e.g. 3,4,2,1 or 1,4,3,2 but not 2,3,2,1 or $3,1,4,3)$. The alternation percentage was calculated as the percentage of actual alternations in ratio to the possible number of arm entries.

\subsubsection{Elevated Plus Maze}

The natural exploratory behavior of mice is the basis for this test, which assesses basal anxiety levels. The maze consisted of four arms (HxLxW 45x10x30 cm), which were arranged in the shape of a plus sign, inter-connected by a central platform of $10 \mathrm{~cm}^{2}$. While two arms had walls ("closed") the other two arms were without any boundaries ("open"). The arena was set $53 \mathrm{~cm}$ above the ground. In this test, the urge to explore novel environments is in conflict with the inherent aversion towards elevated and exposed areas. Therefore, mice exploring the plus maze will spend most of the time in the "closed" arms and avoid the "open" arms, which appear less safe to them. Since the animals can decide at any time whether to explore the "closed" or "open" the test reveals whether the exploratory or the fearful behavior prevails. The animals were placed into 
the center of the arena and allowed to explore the plus maze for $5 \mathrm{~min}$. Both the total number of arm entries as well as the duration of arm occupancy were measured.

\subsubsection{Fear Conditioning}

In order to compare associative learning between genotypes, fear conditioning was performed using the NIR Video Fear Conditioning System (Med Associates Inc.). The animals were placed in a sound-protected box with a metal grid floor. White noise was supplied by the system and the animals were allowed to explore the new context for $3 \mathrm{~min}$. The baseline freezing during this exploration phase was quantified using Video FreezeTM software. After the 3 min exploration, an electrical foot shock (0.7 mA, $2 \mathrm{~s})$ was delivered through the grid floor and the mice were left in the box for another $30 \mathrm{~s}$. The box and grid were cleaned with $70 \% \mathrm{EtOH}$ between mice. 24 hours later, the animals were reintroduced to the box and freezing behavior was recorded for 3 minutes. Freezing was counted by the Video FreezeTM software using a threshold of 50 and the linear detection model.

\subsection{Statistical Analyses}

GraphPad Prism Version 5.04 was used for all statistical analyses of the data. Two-tailed student's $t$-test or two-way-ANOVA with Bonferroni multiple comparison test were used to assess significant changes between groups. Error bars represent the standard error of them mean (SEM). 


\section{Results}

Two mouse models of confined TIP60-deficiency controlled by neuronal CRE drivers were created for the characterization of TIP60 function in the hippocampus. First, a model with the still widely-used constitutive CaMKCre driver was created. However, the resulting TIP60-deficient mice showed severe health problems in the form of decreased body size and weight as well as crouching. They died by 2-3 months of age. Analysis of CRE driver activity revealed that this driver was neither completely brain-specific nor inactive until postnatal stages, unlike reported by literature (Minichiello et al., 1999). In fact, the driver was active outside of the brain such as the spinal cord already during embryogenesis. Both the presence of CRE driver activity during development and the resulting health complications preceding death raised concerns of whether TIP60 function could be analyzed reliably with this mouse line. Some of the effects seen upon use of CaMKCre could be indirect, potentially masking effects of TIP60 loss in the forebrain. Moreover, the constitutive line was not suitable for behavioral analyses due to the aforementioned lack of physical fitness. However, during the time this thesis project was ongoing, an inducible CRE driver, CaMKCreER ${ }^{\mathrm{T} 2}$, became publically available. Consequently, a second, tamoxifen-inducible Tip60 knockout mouse model was established and analyzed both on molecular and behavioral levels. Despite the caveats regarding the constitutive CRE driver, having two lines with TIP60-deficiency in the forebrain allowed to compare and contrast the two models at the molecular levels. 


\subsection{Characterization of CRE Driver Activity and Tip60 Deletion in Two Tip60 Conditional Knockout Mouse Models}

\subsubsection{Characterization of the Constitutive Tip60 Knockout Model (CaMKCre Tip60}

\subsubsection{LacZ Staining}

LacZ staining was performed with the constitutive CaMKCre mouse line in order to verify correct temporal and spatial CRE activity ${ }^{1}$. CaMKCre positive animals possessing one allele of the ROSA26 CRE reporter were taken for the analysis and will be referred to as CaMKCre ROSA26. In order to assess CRE activity in the adult brain, LacZ staining of both coronal and sagittal brain sections were performed. As reported in the original publication, CRE activity was mainly restricted to the forebrain (Minichiello et al., 1999). The areas showing the most intense staining were cortex, hippocampus, and olfactory bulb (Figure 3.1). Additionally, staining was also detected in the striatum, septum, midbrain, and hypothalamus. Low level staining was detected in thalamus, pons, medulla and cerebellum. In the hippocampus CRE activity was detected in all subregions but appeared weaker in the CA2 region (Figure 3.1, bottom center). While the analysis of adult brain tissue confirmed the previously reported regional specificity of the CaMKCre driver in the adult brain, the analysis of LacZ staining in E10.5 and E12.5 embryos revealed that the CaMKCre driver is not restricted to postnatal stages. Staining was detected already at E10.5 (data not shown) and was most prominent in the neocortex and spinal cord as shown for E12.5 embryos (Figure 3.2). Interestingly, the staining intensity varied significantly between different embryos and also showed left-right asymmetric distribution in some animals. The variability in CRE activity was presumably caused by stochastic recombination in precursor cells. Once the stop codon is removed from a precursor cell, all cells derived from this precursor will lack the codon, too. Of note, wild type and CaMKCre negative embryos, which were processed at the same time, did not show any LacZ staining (data not shown), providing evidence for the specificity of

\footnotetext{
${ }^{1}$ Both the LacZ stainings of brain sections and of embryos for the constitutive mouse line were conducted as part of a student master course.
} 
the analysis. GenePaint [http://www.genepaint.org] ISH data also show expression of CaMKII $\alpha$ in the E14.5 embryo.
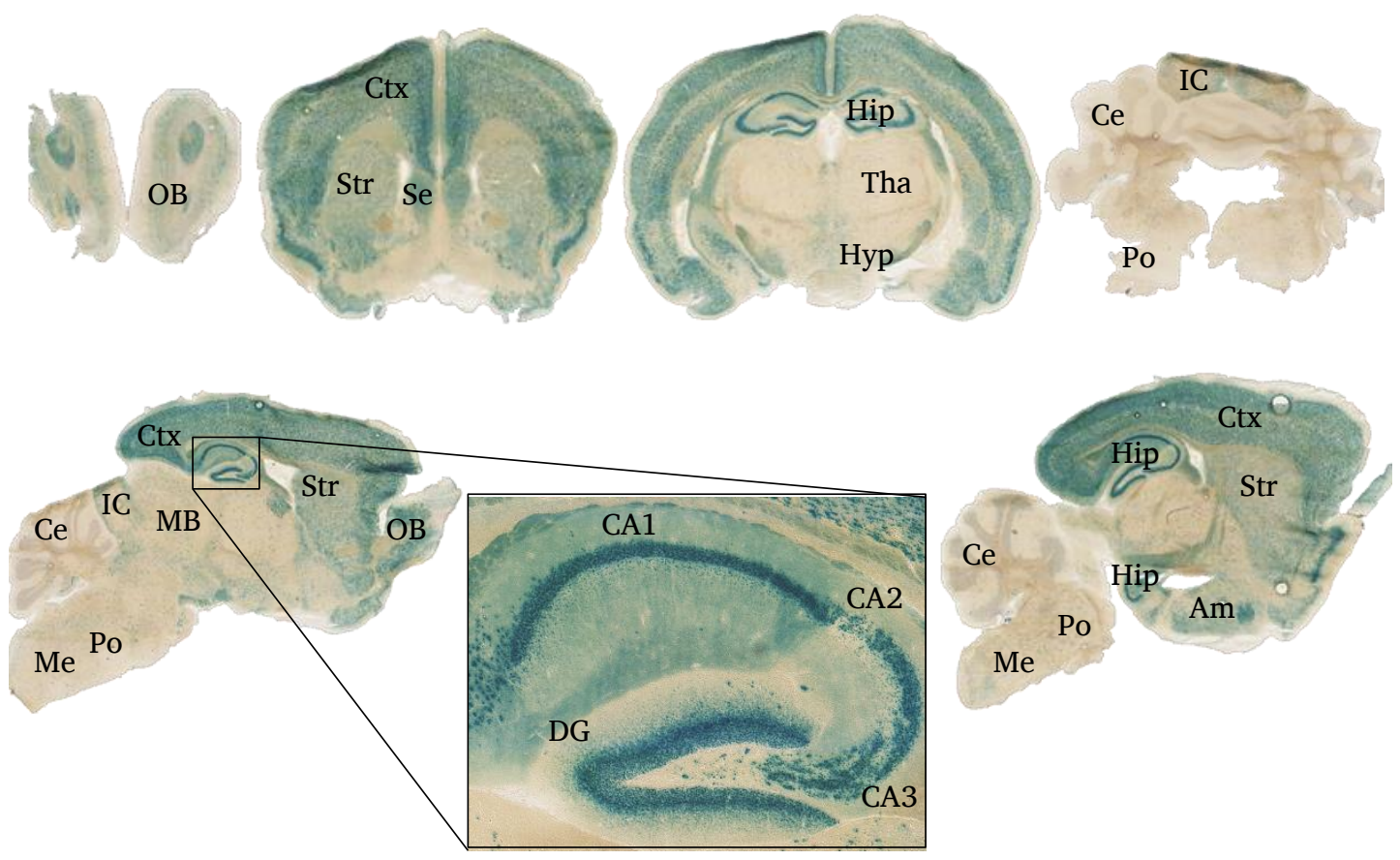

Figure 3.1: LacZ staining of brain sections of CaMKCre ROSA26 mice. Coronal and sagittal sections of 5-week-old CaMKCre ROSA26 mice show forebrain-specific CRE activity. Strong LacZ staining was detected in the olfactory bulb (OB), cortex (Ctx), and hippocampus (Hip). Moderate staining was detected in the striatum (Str), septum (Se), hypothalamus (Hyp), amygdala (Am), inferior colliculus (IC) and midbrain (MB). Staining was virtually absent from thalamus (Tha), cerebellum (Ce), pons (Po), and medulla (Me). Cryosections used were $25 \mu \mathrm{m}$ thick.
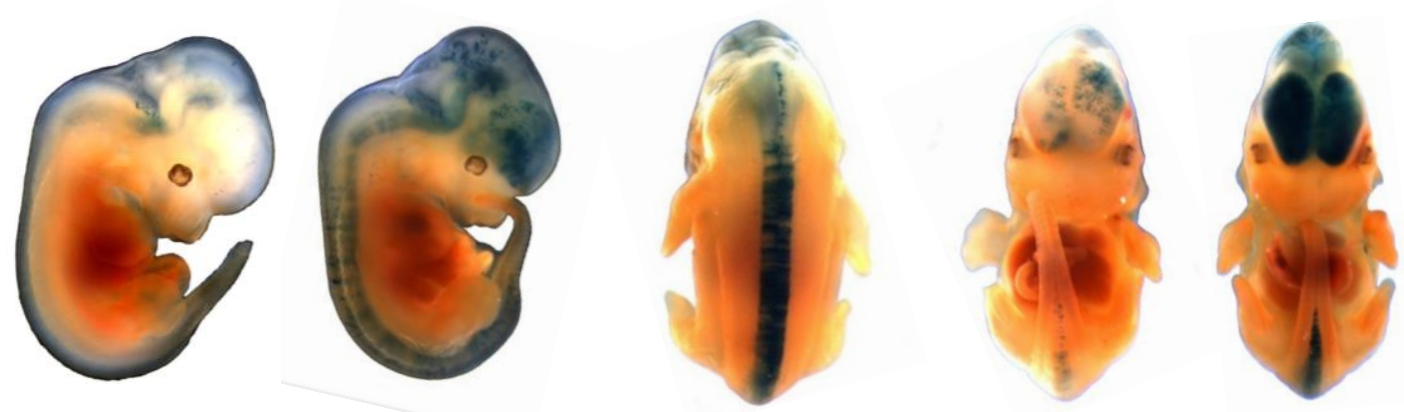

Figure 3.2: The constitutive CaMKCre driver lacks temporal and spatial specificity. LacZ staining of CaMKCre positive embryos bearing one allele of the ROSA26 CRE reporter at E12.5. Note the different degree of staining between different embryos and the asymmetrical staining in the the cortex of the embryo second from right. 


\subsubsection{Analysis of Tip60 Deletion}

Southern blot analysis of hindbrain control and hippocampus samples was performed in order to detect Tip60 deletion on the DNA level. The Tip60-specific 816 bp long probe used detected the wild type, floxed and knockout allele of Tip60 (Figure 2.1). The knockout (KO) allele was detected in the CaMKCre Tip60 ${ }^{\mathrm{f} / \mathrm{f}}$ hippocampus tissue sample but not the hindbrain sample (Figure 3.3A), consistent with the localization of CRE activity (Figure 3.1). No KO allele was detected in the hippocampus sample of a Tip60 $0^{\mathrm{f} / \mathrm{f}}$ control animal (Figure 3.3A).

In addition to detection of Tip60 deletion on the DNA level, the downregulation of Tip60 in the hippocampus of CaMKCre Tip60 $0^{\mathrm{f} / \mathrm{f}}$ animals was also examined by measuring the mRNA levels by qPCR. LoxP sites are located upstream of exon 1 and downstream of exon 9 in the conditional Tip60 allele (Figure 2.1) so that exons 1-9 will be excised by CRE while exons 10-14 remain in the genome. Quantification of Tip60 mRNA levels was performed with two primer pairs, spanning different regions of the gene. When primers hybridizing to a region spanning exons 9 to 11 were used, CaMKCre Tip60 ${ }^{\mathrm{f} / \mathrm{f}}$ animals had $51.2 \%$ less mRNA compared to control animals (Figure 3.3B, left). Since one of the LoxP sites is located downstream of exon 9, the region amplified by this primer pair only remains intact if no CRE-mediated recombination occurs and thus showed the downregulation of Tip60 transcript upon gene deletion. However, when a primer pair specific for the CRE-excised region of Tip60 was used, expression of this region was contrary to expectations - highly upregulated (34.2 fold, Figure 3.3B right). Normally, the DNA excised by CRE recombinase is degraded but in the case of the Tip60 conditional knockout mice this circular excision product appears to be maintained episomally and is hypertranscribed. Such episomal products generated by CRE-mediated gene excision have already been described elsewhere (Turlo et al., 2010).

Of note, RNA-Seq analyses have shown no enrichment of exons 1-9 in Tip60-deficient tissue samples but a downregulation equal to that of exons 10-14 (data not shown). This is most likely due to the fact that RNA-Seq involves selection of Poly(A) RNA and the absence of a hypertranscribed excision product in the sequencing data implies that it is not polyadenylated and therefore not translated into protein.

Since Tip60 gene deletion could be shown both on DNA and mRNA levels in the hippocampus, the protein levels in TIP60-deficient CaMKCre Tip60 ${ }^{\mathrm{f} / \mathrm{f}}$ mice were expected to 
A

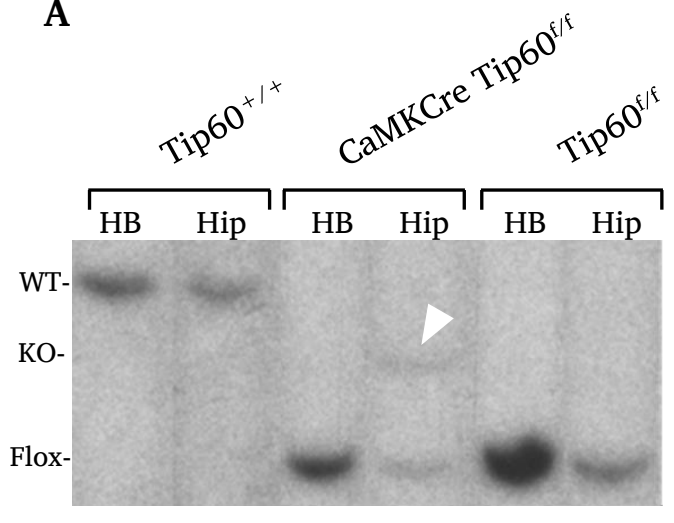

C

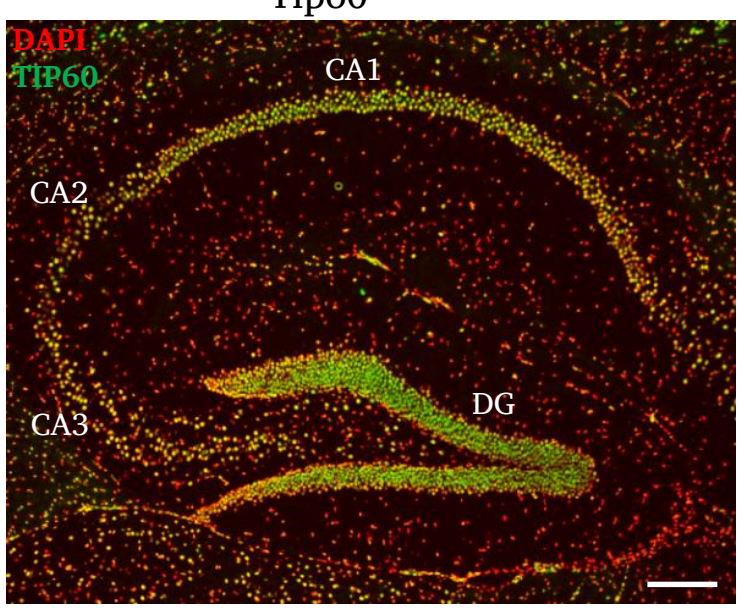

B

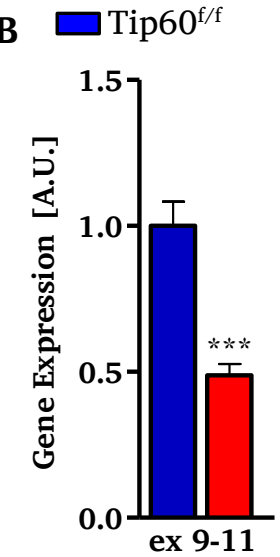

CaMKCre Tip60 $0^{\mathrm{f} / \mathrm{f}}$

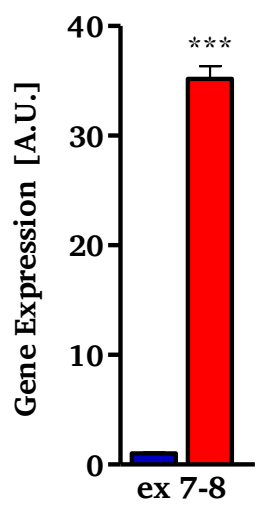

D

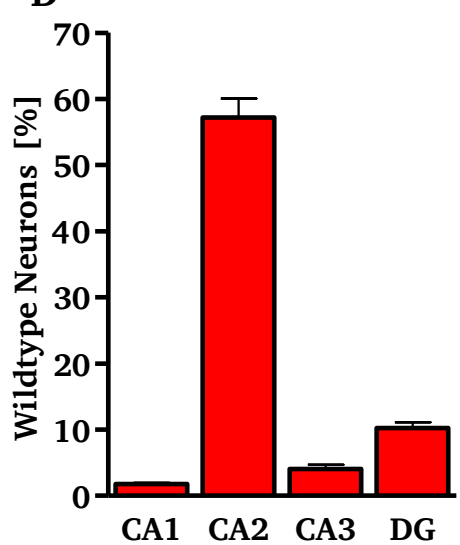

Figure 3.3: Tip60 deletion on DNA, mRNA, and protein levels. (A) Southern blot results with tissue samples from CaMKCre Tip60 ${ }^{\mathrm{f} / \mathrm{f}}$ and $\mathrm{Tip}^{\mathrm{f} / \mathrm{f}}$ (both 6 weeks of age) as well as Tip60 ${ }^{+/+}(15$ weeks) control animals. Successful excision of Tip60 was detected by the appearance of the KO band (arrowhead). HB = hindbrain, Hip = hippocampus. (B) qPCR results showing Tip60 mRNA levels in whole hippocampus samples of CaMKCre Tip60 ${ }^{\mathrm{f} / \mathrm{f}}$ and control mice at 7-9 weeks of age. Left: Results using primers spanning exons 9-11, which can only be amplified if no CREmediated recombination occurred. Right: Results using primers against exons 7-8, which amplify a part of the excised Tip60 region. Note that the excised part is hypertranscribed in CaMKCre Tip60 $0^{\mathrm{f} / \mathrm{f}}$ mice (right). $\mathrm{n}=5$ 8 per genotype. Two-tailed student's $t$-test, $* * * \mathrm{p}<0.001$. Error bars represent SEM. A.U. = arbitrary units. (C) Representative images of TIP60 immunoreactivity in the hippocampus of an 8-week-old male control and CaMKCre Tip60 ${ }^{\mathrm{f} / \mathrm{f}}$ animal. $10 \mu \mathrm{m}$ sagittal sections were incubated with antibody TIP60P4 and counterstained with DAPI. DAPI $=$ red, TIP60 = green. Scale bar represents $250 \mu \mathrm{m}$. (D) Remaining TIP60 wild type cells were counted in CaMKCre Tip60 $0^{\mathrm{f} / \mathrm{f}}$ mice $(\mathrm{n}=3$, 4 sections per animal) and normalized to DAPI positive cells in all hippocampal subregions. Percentages of residual wild type neurons (top) and of the deletion efficiencies (bottom) are shown. Error bars represent SEM.

be downregulated accordingly. One complicating circumstance with regard to the characterization of the two Tip60 conditional knockout models was the very limited amount 
of TIP60-specific antibody available for the present work. This antibody was kindly provided by Dr. Bruno Amati and was indispensable for initial characterizations of TIP60 on the protein level. Several commercial antibodies, that were claimed to be capable of detecting TIP60 in tissues, turned out to be unspecific, which could be assessed by using tissue from TIP60-deficient mice. Numerous custom antibodies produced during this thesis project never led to a reagent of the same quality as the antibody by Dr. Bruno Amati but only allowed to detect overexpressed levels of TIP60. Towards the end of the thesis project, however, a TIP60 antibody (TIP60P4) was generated by a specialized tandem-purification protocol (Section 3.2), which could detect TIP60 on brain sections. Using TIP60P4, efficient downregulation of TIP60 protein was detected in the hippocampus of CaMKCre Tip60 ${ }^{\mathrm{f} / \mathrm{f}}$ mice compared to control animals. TIP60 protein levels were visualized using immunohistochemistry (IHC) (Figure 3.3C) and quantified individually for each hippocampal subregion (see section 2.3.2.3). The deletion efficiency was highest in the CA1 region (98.2\%), followed by the CA3 region (95.9\%), the dentate gyrus (89.8 \%) and the CA2 region (42.8\%) (Figure 3.3D). The relatively low deletion efficiency in the CA2 region corresponds well with the LacZ staining showing substantially reduced CRE driver activity in CA2 compared to CA1 and CA3 (Figure 3.1). The discrepancy between the knockout percentages as quantified by qPCR and IHC are due to the fact that the CRE driver is only active in excitatory neurons but not in other neurons or in glia cells (Minichiello et al., 1999). For qPCR determination of Tip60 mRNA levels whole hippocampal tissue isolates were used containing also the mRNA of glial cells, which decrease the overall deletion efficiency. In contrast, quantification of TIP60 deletion efficiency on protein level by IHC was restricted to the primary cell layers of the hippocampal subregions. Here, glial cells could be excluded from the analysis as they are easily distinguished from neurons due to their smaller size and elliptical shape of their nuclei. As most glial cells are outside the primary cell layers the cell population included in IHC is strongly enriched for excitatory neurons, resulting in a better estimate of deletion efficiency of cells actually targeted by the CRE driver. However, it has to be noted that only sections of the dorsal hippocampus were taken for quantification and that deletion efficiency seemed to be somewhat less in the ventral hippocampus, especially in the CA3 region (data not shown). 


\subsubsection{Characterization of the Inducible Tip60 Knockout Mouse Model (CaMKCreER ${ }^{\mathrm{T} 2} \mathrm{Tip}^{\mathrm{f} / \mathrm{f}}$ )}

\subsubsection{LacZ Staining}

In addition to the constitutive CaMKCre driver, an inducible CaMKCreER ${ }^{\mathrm{T} 2}$ line was obtained and analyzed for specific CRE activity again using LacZ staining. Tamoxifen-injected CaMKCreER ${ }^{\mathrm{T} 2}$ ROSA mice showed specific localization of CRE activity to forebrain regions, including the hippocampus and cortex (Figure 3.4). In addition, moderate activity was detected in hypothalamus, amygdala, and midbrain. Weak to no staining was observed in the striatum, thalamus, olfactory bulb, cerebellum, pons, and medulla. Vehicle controls, which were injected with corn oil, showed no detectable CRE activity, confirming that the driver is not leaky. In summary, the results concurred with the published data on this driver (Erdmann et al., 2007).

\subsubsection{Analysis of Tip60 Deletion}

Tip60 deletion on the DNA level after induction with tamoxifen was analyzed in different brain regions by PCR (Figure 3.5A) using the Tip60 genotyping primers (Table 2.2). Tip60 was efficiently excised in cortex and hippocampus as shown by amplification of the KO product (Figure 3.5A). Additionally, deletion was also detected in samples of olfactory bulb, thalamus, and hypothalamus. Cerebellum and pons/medulla tissue samples served as negative control regions for CRE activity and showed - as was expected - no KO band. Next, also Tip60 mRNA levels were quantified for the inducible mouse model. As already discussed with the constitutive model, primers against the excised part of Tip60, in this case specific for the region encompassing exons 7 and 8, detected a massive upregulation of Tip60 mRNA (20.4 fold, Figure 3.5B, right). Using primers against exons 9-11, which amplify a region that remains intact only in the absence of CRE-mediated recombination, a downregulation of about $40.2 \%$ was detected in whole hippocampus samples (Figure 3.5B, left). This was very similar to the constitutive line (Figure 3.3B). As already mentioned for the constitutive line, RNA-Seq results showed no upregulation of the excised part of the Tip60 gene. This is probably due to the selection for Poly(A) RNA and indicates that no protein could be translated from the truncated transcript.

TIP60 deletion efficiency on protein level was analyzed by IHC and quantified for the different hippocampal subregions (Figure 3.6). In the CA1 region $96.4 \%$ of pyramidal 
neurons were TIP60-deficient, while deletion efficiencies for CA2, CA3 and DG were $79.9 \%, 92.8 \%$, and $98.5 \%$ respectively (Figure 3.6B). Again, these figures are comparable to those of the constitutive model (Figure 3.3D).
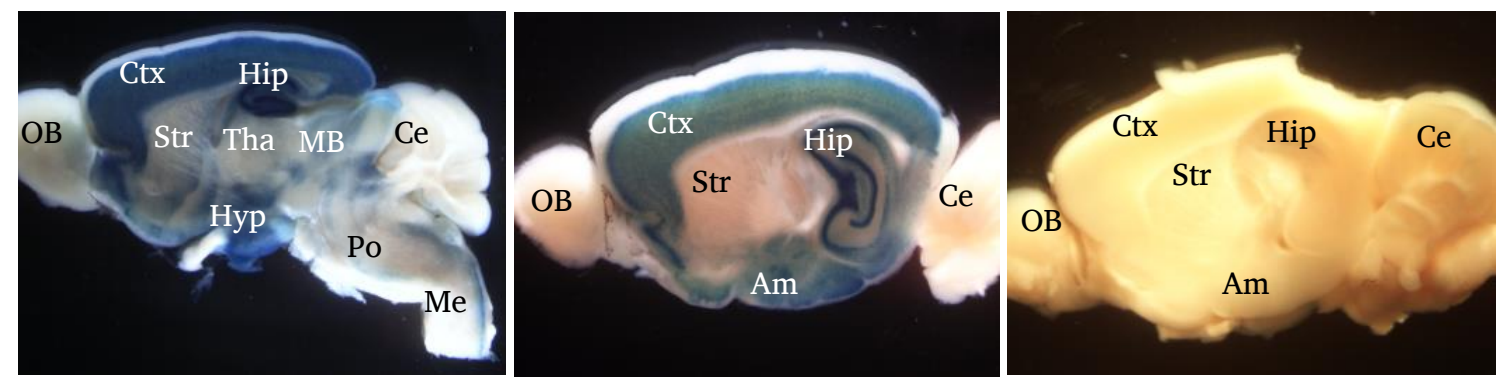

Figure 3.4: The CaMKCreER ${ }^{\mathrm{T} 2}$ driver is specific to forebrain regions and only active after tamoxifen induction. LacZ staining showing the sites of CreER ${ }^{\mathrm{T} 2}$ activity in the forebrain in ROSA26 CRE reporter mice crossed to the CaMKCreER ${ }^{\mathrm{T} 2}$ driver line upon tamoxifen injection. Brains were sectioned at different sagittal levels to visualize CRE activity throughout the brain (left, middle). Strong CRE activity is visible in the cortex (Ctx) and hippocampus (Hip). Furthermore, moderate activity can be seen in the hypothalamus (Hyp), amygdala (Am), and midbrain (MB). Weak to no staining was detected in the pons (Po), medulla (Me), cerebellum (Ce), striatum (Str), and the olfactory bulb (OB). Activity is absent in the vehicle-treated animal (right).
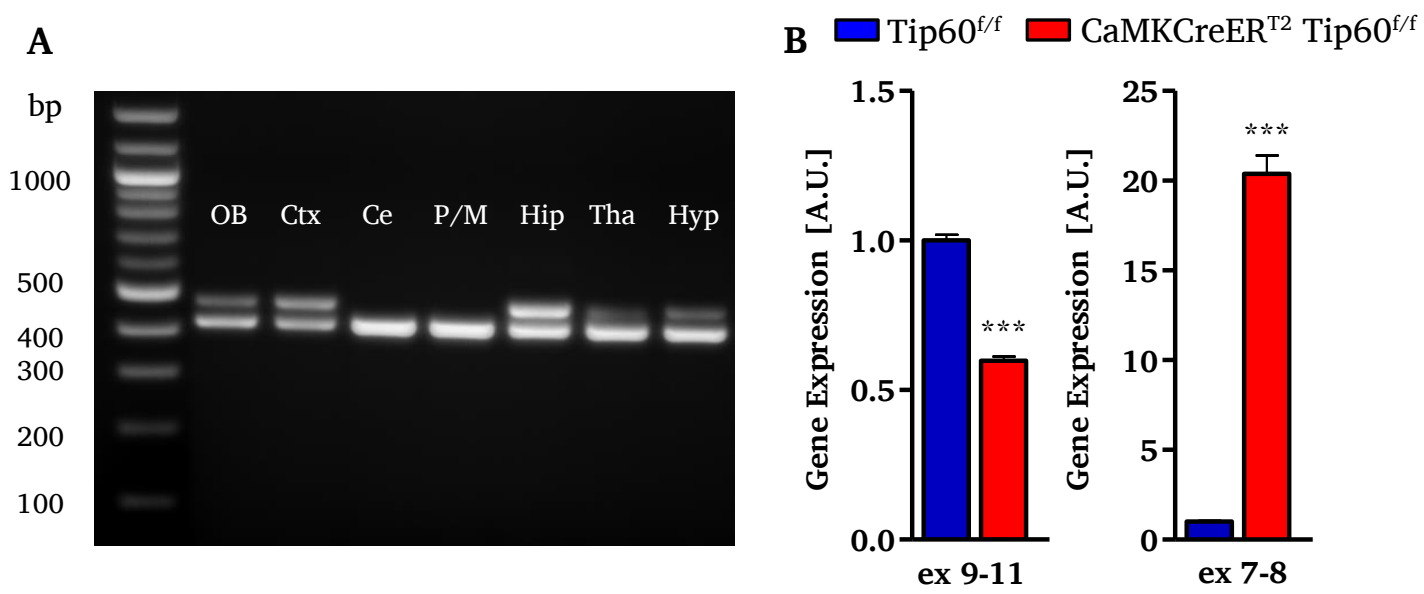

Figure 3.5 Tip60 deletion on DNA and mRNA levels. (A) PCR results from different brain regions of induced CaMKCreER ${ }^{\mathrm{T} 2} \mathrm{Tip}^{\mathrm{f} / \mathrm{f}}$ animals using primers specific for Tip60. Two PCR products were generated: the 429 bp Tip60 floxed and the 487 bp knockout allele in the case of successful Tip60 excision. (B) qPCR results showing Tip60 mRNA levels in whole hippocampus samples of CaMKCreER ${ }^{\mathrm{T} 2}$ Tip60 ${ }^{\mathrm{f} / \mathrm{f}}$ and Tip60 ${ }^{\mathrm{f} / \mathrm{f}}$ control mice 10 days after gene deletion. Left: Results using primers spanning exons 9-11, which can only be amplified if no CRE-mediated recombination occurred. Right: Results using primers against exons 7-8, which amplify a part of the excised Tip60 allele. $\mathrm{n}=17-21$ per genotype. Two-tailed student's $t$-test $* * * \mathrm{p}<0.0001$. Error bars represent SEM. A.U. = arbitrary units.

Abbreviations: $\mathrm{OB}=$ olfactory bulbs, $\mathrm{Ctx}=$ cortex, $\mathrm{Ce}=$ cerebellum, $\mathrm{P} / \mathrm{M}=$ pons/medulla, Hip $=$ Hippocampus, Tha $=$ thalamus, Hyp = Hypothalamus 
A
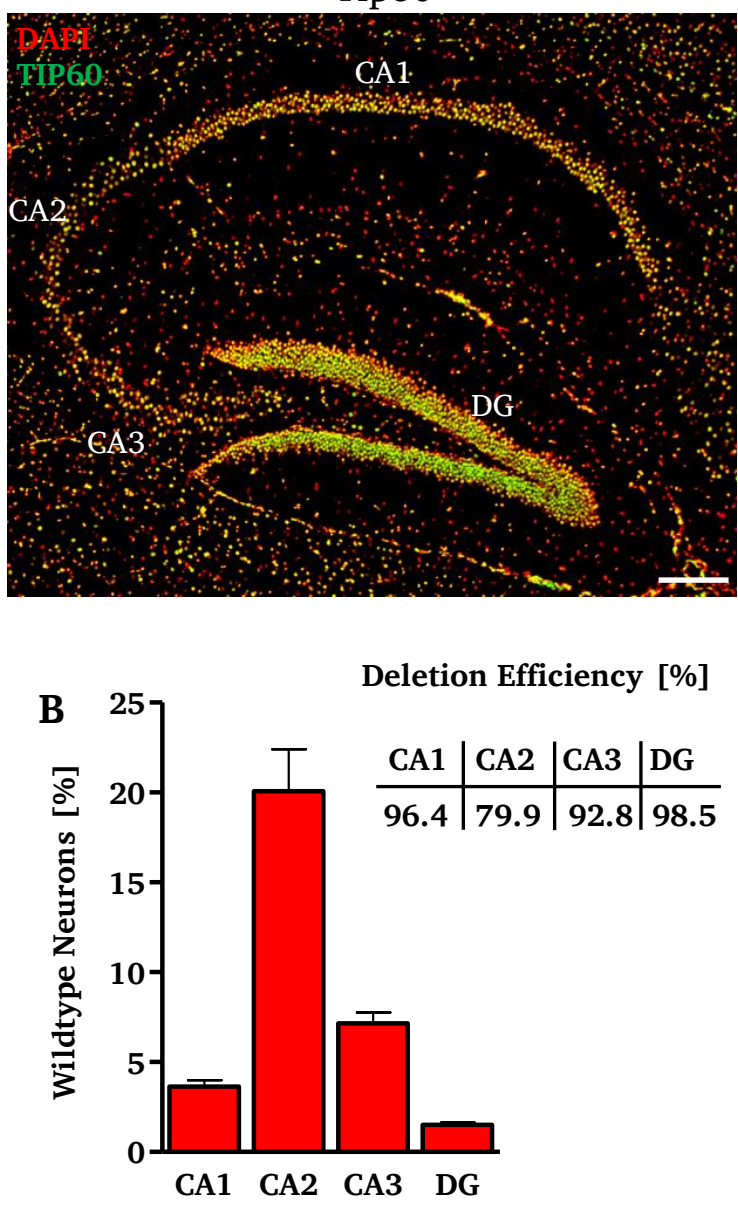

CaMKCreER $^{\mathrm{T} 2} \mathrm{Tip}^{\mathrm{f} / \mathrm{f}}$

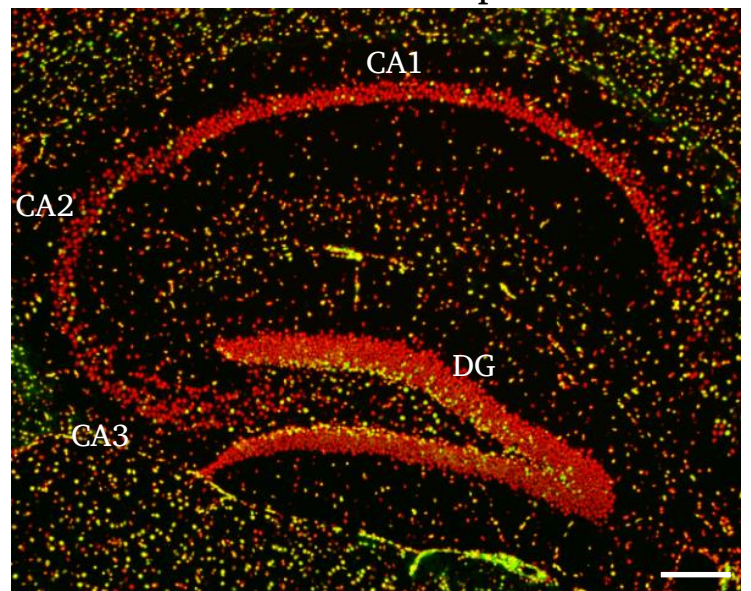

Figure 3.6: TIP60 protein levels are efficiently reduced in the dorsal hippocampus of CaMKCre$\mathbf{E R}^{\mathrm{T} 2} \mathrm{Tip}^{\mathrm{f} / \mathrm{f}}$ mice. (A) Representative images of TIP60 immunoreactivity in the hippocampus of $\mathrm{Tip}^{\mathrm{f} / \mathrm{f}}$ and CaMKCreER ${ }^{\mathrm{T} 2} \mathrm{Tip}^{\mathrm{f} / \mathrm{f}}$ mice. $10 \mu \mathrm{m}$ sagittal sections were stained with antibody TIP60P4. DAPI $=$ red, TIP60 $=$ green. Scale bar represents $250 \mu \mathrm{m}$. (B) Remaining TIP60 wild type cells were counted in CaMKCreER ${ }^{\mathrm{T} 2} \mathrm{Tip}^{\mathrm{f} / \mathrm{f}}(\mathrm{n}=4,4$ sections per animal) and normalized to DAPI positive cells in all hippocampal subregions. Percentages of wild type neurons (left) and of the deletion efficiencies (right) are shown. Error bars represent SEM.

\subsection{TIP60 Antibody Production and Validation}

Obtaining antibody that can detect TIP60 in brain samples, proved to be extremely challenging. Numerous commercial TIP60 antibodies were tested in Western blot and IHC using control and TIP60-deficient samples but none of these antibodies showed a specific signal (Table 3.1).

Importantly, many antibodies showed bands at the correct size of $\sim 60 \mathrm{kDa}$ in Western blot or nuclear staining in IHC, which had the same intensity between genotypes and could be easily mistaken for TIP60 signal if knockout samples had not been available for simultaneous testing.

A custom polyclonal antibody kindly provided by Dr. Bruno Amati, was the only antibody that would specifically detect TIP60, as tested by IHC and Western blot. This antibody will be referred to as TIP60A in subsequent paragraphs. 
Since commercial antibodies did not work and only a limited amount of TIP60A was available, immunization projects to obtain TIP60 antibody were conducted in collaboration with several well-established antibody companies. For these projects, the same peptide sequence was used as published for TIP60A (Frank et al., 2003). This peptide comprised the last 15 amino acids of the TIP60 C-terminus, CLHFTPKDWSKRGKW, and will be referred to as "CLHF". Obtaining specific antibody using the CLHF peptide failed repeatedly. Only unspecific signal was detected in both Western blot and IHC. Also the use of other published peptides for immunization did not result in an antibody specific for TIP60 (Table 3.2) (Frank et al., 2003). Of note, these antibodies could detect TIP60 protein when overexpressed in HEK cells as well as endogenous TIP60 protein in human platelet lysate (the latter kindly provided by ImmunoGlobe Antikörpertechnik $\mathrm{GmbH}$ ) so the problem appeared to be the detection of endogenous TIP60 in mouse brain samples.

In order to analyze the repeated failure of custom antibody production in more detail the location of the epitope recognized by TIP60A was determined using an epitope mapping strategy. For this, the immunization peptide CLHF was divided into 4 segments and blocking experiments were conducted both in IHC and Western blot using the truncated peptides (Figure 3.7). These experiments showed that a relevant part of the epitope was at the C-terminus of the CLHF peptide, which is also the C-terminus of the full-length protein.

Table 3.1 List of commercial TIP60 antibodies tested, that did not detect endogenous TIP60 in brain samples.

\begin{tabular}{l|l|l} 
Description & Company & Product Number \\
\hline Anti-KAT5 & Fisher Scientific & 10382070 \\
\hline TIP60 (N-17) & Santa Cruz & sc-5725X \\
\hline TIP60 (K-17) & Santa Cruz & sc-5727 \\
\hline Anti-Tip60 & Millipore & $07-038$ \\
\hline Anti-KAT5 & abcam & ab23886 \\
\hline Kat5 & Abnova & PAB18305 \\
\hline ANTI-KAT5 & Sigma & HPAO16953
\end{tabular}

Table 3.2: Peptides used for TIP60 custom antibody productions.

\begin{tabular}{c|l|c|c} 
Name & \multicolumn{1}{|c|}{ Sequence } & Position & Length (AA) \\
\hline RRNQ & RRNQDNEDEWPLAEILSVK & $17-35$ & 19 \\
\hline CRLP & CRLPVLRRNQDNEDEWPLAE & $11-30$ & 20 \\
\hline CLGT & CLGTDEDSQDSSDGIPSAPRM & $192-202$ & 21 \\
\hline CLHF & CLHFTPKDWSKRGKW & $499-513$ & 15
\end{tabular}


CLHF full-length immunization peptide: CLHFTPKDWSKRGKW

$\begin{array}{lr}\text { Peptide 1: CLHFTPKD } \\ \text { Peptide 2: } & \text { FTPKDWSK } \\ \text { Peptide 3: } & \text { KDWSKRGKW } \\ \text { Peptide 4: } & \text { SKRGKW }\end{array}$

Figure 3.7: Epitope mapping strategy for TIP60 antibody production. The four partially overlapping peptides (1-4) spanning the entire sequence of the CLHF peptide are shown. For better orientation, the first amino acid of each peptide is marked in red.

Based on the epitope mapping results, which showed that a significant part of the signal of antibody TIP60A could be blocked by peptide 4, a tandem-purification strategy was conducted in collaboration with immunoGlobe Antikörpertechnik GmbH (Himmelstadt, Germany) in order to fractionate the produced antibody of an ongoing immunization project and to obtain an antibody highly specific to peptide 4. For this, peptide CLHF was resynthesized and amidated at the $\mathrm{C}$-terminus. This amidated peptide was then used in a first purification in order to separate antibody fractions depending on their ability to detect the $\mathrm{COOH}$-terminus. The flow-through was then further purified with nonamidated peptide 4, obtaining antibody highly specific for the negatively charged Cterminus of TIP60. The purified fraction - TIP60P4 - could detect endogenous TIP60 levels on brain sections. This was validated using sections of the same Tip60 ${ }^{\mathrm{f} / \mathrm{f}}$ control and CaMKCreER ${ }^{\mathrm{T} 2} \mathrm{Tip}^{\mathrm{f} / \mathrm{f}}$ animals that had been used for IHC with TIP60A before (Figure 3.8).

In conclusion, there were presumably several reasons for the repeated failure to generate TIP60-specific antibody. One reason was that endogenous TIP60 levels in the brain appear to be very low since antibodies capable of TIP60 detection in overexpressing HEK cell lysates as well as human platelet lysate - in which TIP60 is highly expressed - were not able to detect TIP60 in brain samples. Additionally, a significant fraction of endogenous TIP60 might also be in stable complexes where the epitope is masked. Another reason is the high conservation of TIP60, which leads to strong cross-reactivity and which is especially problematic when involving proteins of much higher abundance than TIP60. 

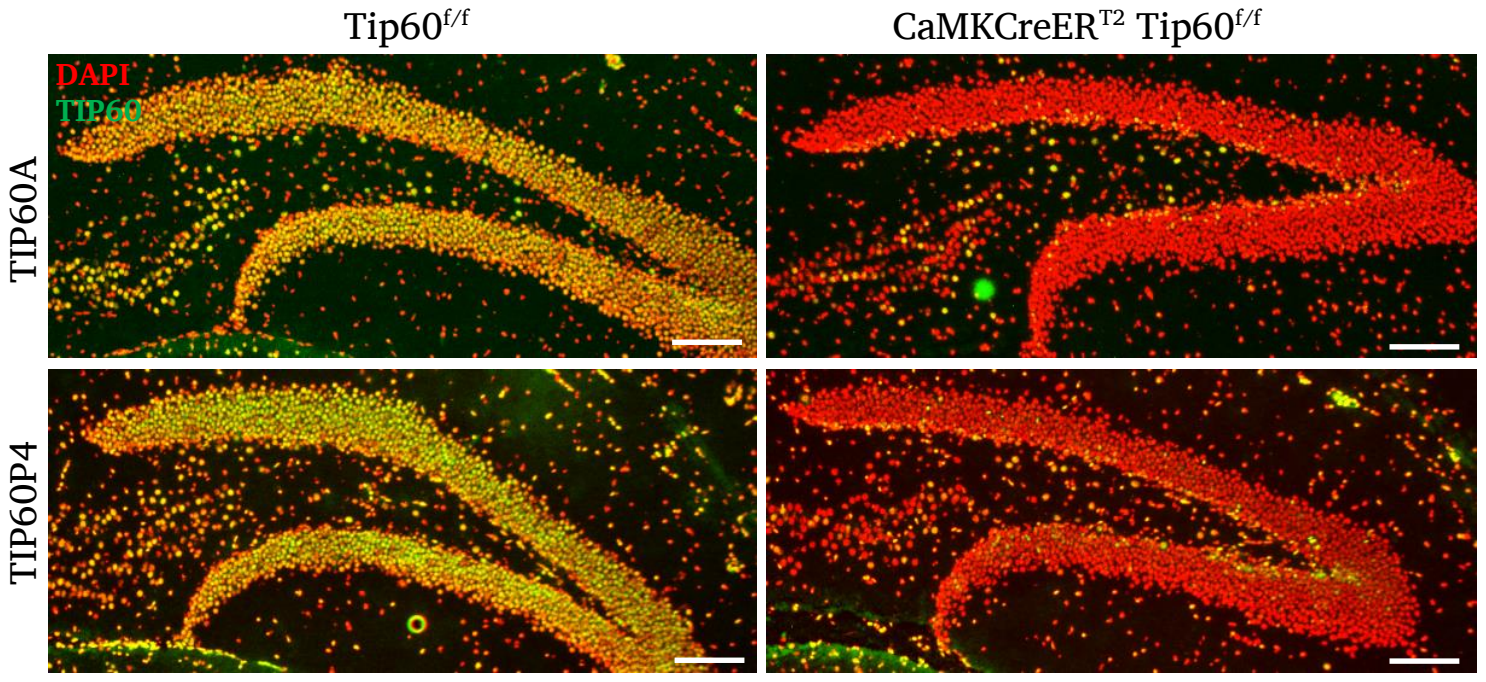

Figure 3.8: Comparison of immunoreactivity of TIP60 antibodies TIP60A and TIP60P4. TIP60 immunoreactivity using TIP60A and TIP60P4 antibodies on sections of the same Tip60 ${ }^{\mathrm{f} / \mathrm{f}}$ control and CaMKCre$\mathrm{ER}^{\mathrm{T} 2} \mathrm{Tip} 60^{\mathrm{f} / \mathrm{f}}$ animals. $10 \mu \mathrm{m}$ sagittal sections were used. DAPI $=$ red, TIP60 $=$ green. Scale bars represent $250 \mu \mathrm{m}$.

\subsection{General Phenotype}

\subsubsection{Constitutive Knockout Mouse Model (CaMKCre Tip60 f/f)}

The animals of the CaMKCre Tip60 ${ }^{\mathrm{f} / \mathrm{f}}$ constitutive knockout mouse line showed no obvious abnormalities at birth and during the first postnatal weeks. They usually appeared slightly smaller compared to their littermates at around 3 weeks of age. Definite changes concerning body size and weight, behavior, body postures, and motor function were observed from approximately 6 weeks of age onwards. Most importantly, the life span of these animals was less than 4 months and viability differed between individuals and sexes, the females being more affected than the males. This is why for all studies but qPCR and RNA-Seq analysis only male CaMKCre Tip60 ${ }^{\mathrm{f} / \mathrm{f}}$ mice were used.

The body size was markedly decreased in CaMKCre Tip60 $0^{\mathrm{f} / \mathrm{f}}$ mice of either sex at 8 weeks of age (Figure 3.9A). Their weight was also decreased in comparison to their littermate controls (Figure 3.9B). However, food intake appeared to be normal or even elevated by observation so that malnutrition can be excluded as a potential cause. CaMKCre Tip60 $60^{\mathrm{f} / \mathrm{f}}$ mice would instantly begin eating when confronted with food. In addition to the normal diet, the animals were provided with high-caloric mash. However, this did not markedly improve body growth or the health status. 
CaMKCre Tip60 ${ }^{\mathrm{f} / \mathrm{f}}$ mice tended to show nervous behavior when handled. Furthermore, with increasing age, incidences of a crouched body posture were frequently observed and the animals became increasingly apathetic (Figure 3.9C).

Motor function was assessed by placing the animals on the metal grid top of a cage. CaMKCre Tip60 ${ }^{\mathrm{f} / \mathrm{f}}$ mice showed difficulty in walking on the grid indicated by slipping in-between the metal rods. Moreover, when turning the grid upside down they quickly lost grip while their littermate controls easily held on to the grid. Once they lost contact to the grid with one of their limbs they appeared to be incapable of placing it back onto the grid. However, it cannot be excluded that the inability to hold on to the grid also involved decreased muscle strength.

Another abnormality observed with CaMKCre Tip60 ${ }^{\mathrm{f} / \mathrm{f}}$ mice was altered anxiety behavior. When put onto a table or any other elevated area CaMKCre Tip60 ${ }^{\mathrm{f} / \mathrm{f}}$ mice walked over the edge without hesitation. Eyesight appeared to be normal since the animals stretched out their forelimbs when being held closely above a surface, indicating that they saw the surface and anticipated the contact. The fact that they walked over the edges of elevated surfaces implied that they had decreased anxiety levels concerning height.

The identification of aberrant activity of the CaMKCre driver (see Section 3.1.1.1) provides a possible explanation for the observed phenotypical changes in the CaMKCre $\mathrm{Tip}^{\mathrm{f} / \mathrm{f}}$ mouse line. Presumably, the deletion of Tip60 in a subset of cells in the CNS during development caused the severe health problems and decreased viability in CaMKCre Tip $60^{\mathrm{f} / \mathrm{f}}$ animals. Furthermore, the sporadic nature of prenatal CRE activity might also explain the variability in life-span between different animals since the excision mediated by the CRE is a stochastic event affecting precursor cells at different developmental stages. 
A

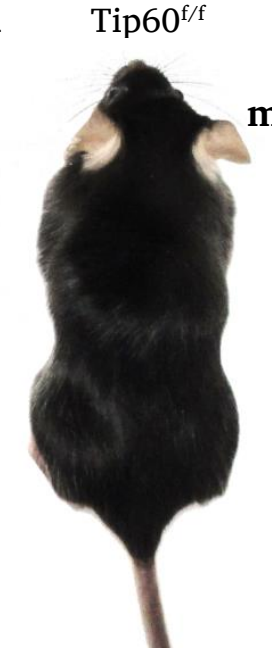

B
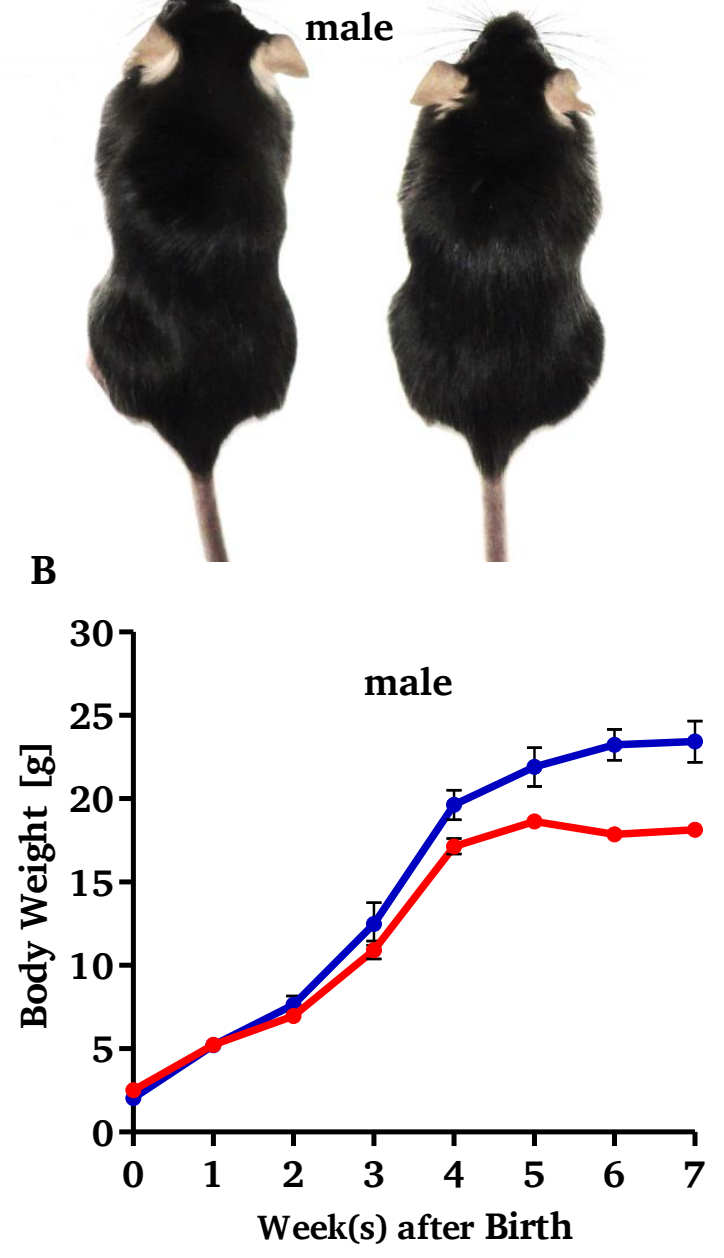

\section{CaMKCre Tip60 ${ }^{\mathrm{f} /+} \quad$ CaMKCre Tip60 $0^{\mathrm{f} / \mathrm{f}}$}

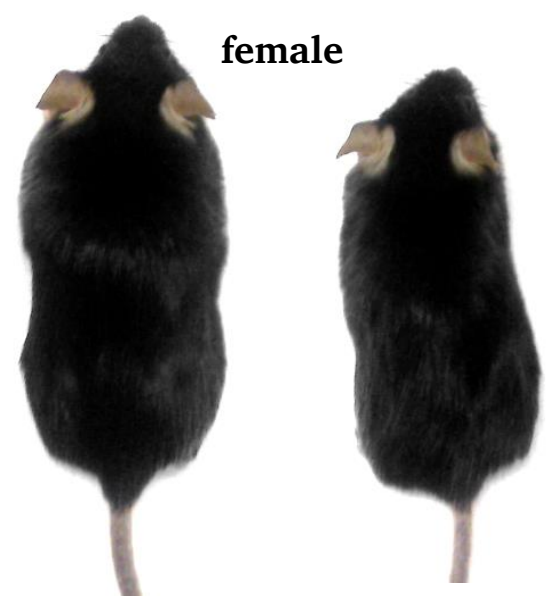

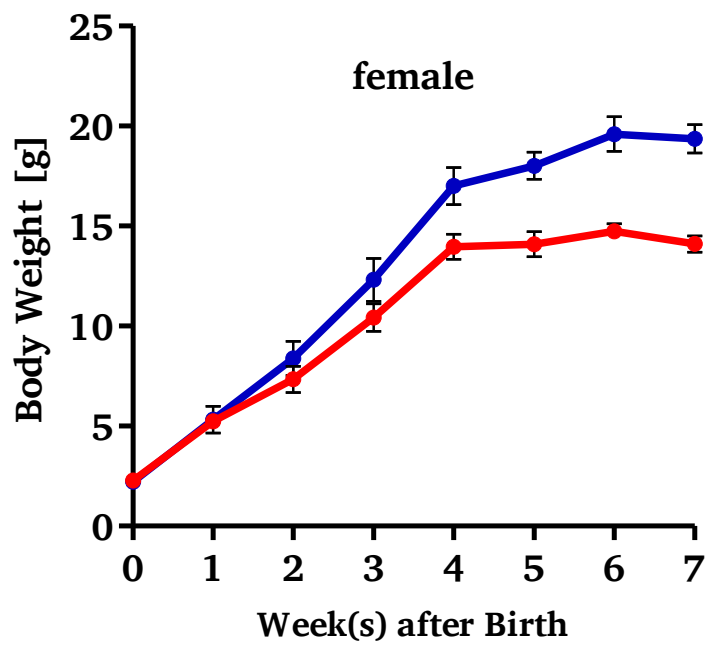

C

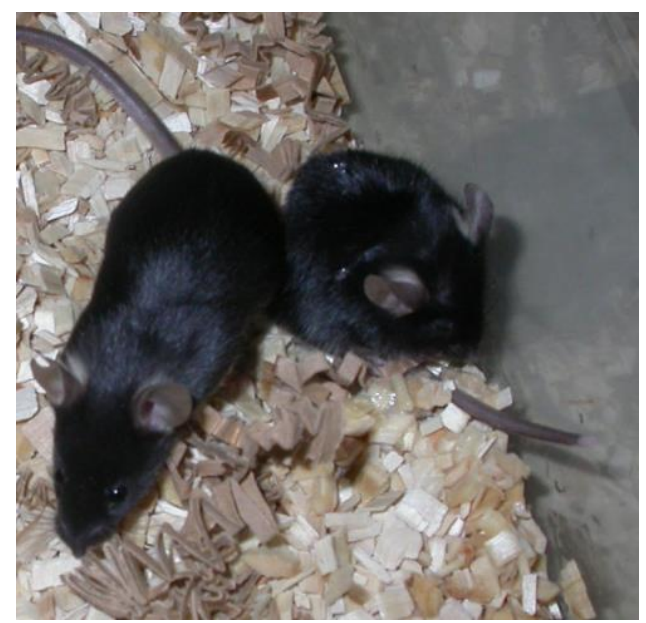

Figure 3.9: CaMKCre Tip60 $0^{\mathrm{f} / \mathrm{f}}$ mice show decreased body size and weight, as well as a crouching body posture. (A) CaMKCre Tip60 $60^{\mathrm{f} / \mathrm{f}}$ mice of either sex show decreased body size. Left: A male 8-week old TIP60-deficient CaMKCre Tip60 $0^{\mathrm{f} / \mathrm{f}}$ mouse is shown next to its littermate control. Right: A female 8-week old CaMKCre Tip60 $0^{\mathrm{f} / \mathrm{f}}$ mouse is shown next to its heterozygous littermate control. (B) Weight curves for male (left) and female (right) Tip60 $0^{\mathrm{f} / \mathrm{f}}$ and CAMKCre Tip60 $0^{\mathrm{f} / \mathrm{f}}$ animals. CaMKCre Tip60 ${ }^{\mathrm{f} / \mathrm{f}}$ mice of both sexes show decreased weight starting from 4-5 weeks onwards. $n=2-16$ per genotype and time point. Error bars represent SEM. (C) A CaMKCre Tip60 $\mathrm{f} / \mathrm{f}$ mouse (right) is shown with a littermate Tip60 $0^{\mathrm{f} / \mathrm{f}}$ control (left) at 8 weeks of age. The CaMKCre Tip $60^{\mathrm{f} / \mathrm{f}}$ animal shows typical crouching and apathetic behavior. 


\subsubsection{Inducible Knockout Mouse Model (CaMKCreER ${ }^{\mathrm{T} 2} \mathrm{Tip}^{\mathrm{f} / \mathrm{f}}$ )}

$\mathrm{CaMKCreER}^{\mathrm{T} 2} \mathrm{Tip}^{\mathrm{f} / \mathrm{f}}$ mice behaved normally and showed no overt abnormalities during the first two months after CRE induction. However, from about 3 months after TIP60 loss they became obese (Figure 3.10A, C) and showed seizures. Moreover, some of the mice became agitated and "jumpy". Both nervous behavior and seizures were most prominent in the animals that had been subjected to behavioral tests. Not only the testing stress but also being single-caged probably exacerbated the phenotype in this case. The nervous behavior upon handling by the experimenter was observed without exception for all CaMKCreER ${ }^{\mathrm{T2}} \mathrm{Tip}^{\mathrm{f} / \mathrm{f}}$ animals but in none of the Tip60 $0^{\mathrm{f} / \mathrm{f}}$ control animals after the behavioral tests were completed.

Animals that were not taken for any tests and group-housed showed variable degrees of nervous behavior. Some were extremely agitated while others were comparably calm and behaved similar to their littermate controls. In addition to the already described abnormalities, CaMKCreER ${ }^{\mathrm{T} 2} \mathrm{Tip}^{\mathrm{f} / \mathrm{f}}$ mice also showed limb clasping starting from around 3 months after Tip60 deletion (Figure 3.10B), which points to neurological defects. Clasping and body weight were analyzed weekly in CaMKCreER ${ }^{\mathrm{T} 2} \operatorname{Tip}^{\mathrm{f} / \mathrm{f}}(\mathrm{n}=11)$ and $\operatorname{Tip}^{\mathrm{f} / \mathrm{f}}(\mathrm{n}=9)$ mice by the animal caretakers and the behavior of the animals ("jumpiness" and occurrence of seizures) was noted over a time window of 6-9 months. An average of 2-3 seizures was observed per CaMKCreER ${ }^{\mathrm{T} 2} \mathrm{Tip}^{\mathrm{f} / \mathrm{f}}$ animal during the period of observation. However, since animals were not checked for seizures on a more regular basis or even continuously videotaped it is not possible to quantify the frequency of seizures. Interestingly, while the CaMKCreER ${ }^{\mathrm{T} 2} \mathrm{Tip}^{\mathrm{f} / \mathrm{f}}$ mice kept their weight constant at about $60 \mathrm{~g}$ and continued to show limb clasping, both the frequency of seizures and the nervous behavior decreased again around 4-5 months after onset.

Because the observed neurological abnormalities could have an influence on the overall constitution of the brain, the brain size was analyzed in both young and aged mice. However, no difference in comparison to control animals was found (Figure 3.10D).

Taken together, the observed abnormalities indicate that TIP60 deficiency affects neuronal homeostasis, as apparent by the occurrence of nervous behavior and seizures, and causes a progressive neurological phenotype. 

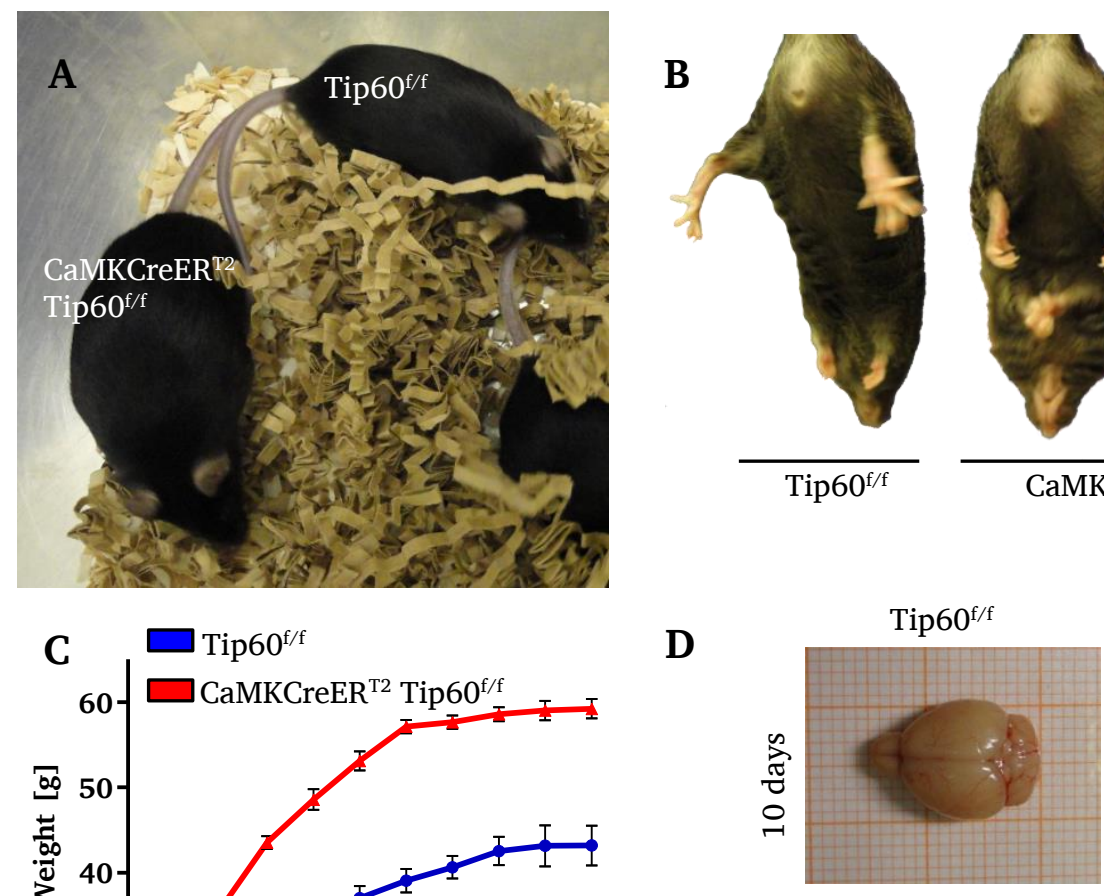

CaMKCreER $^{\mathrm{T} 2} \mathrm{Tip}^{\mathrm{f} / \mathrm{f}}$

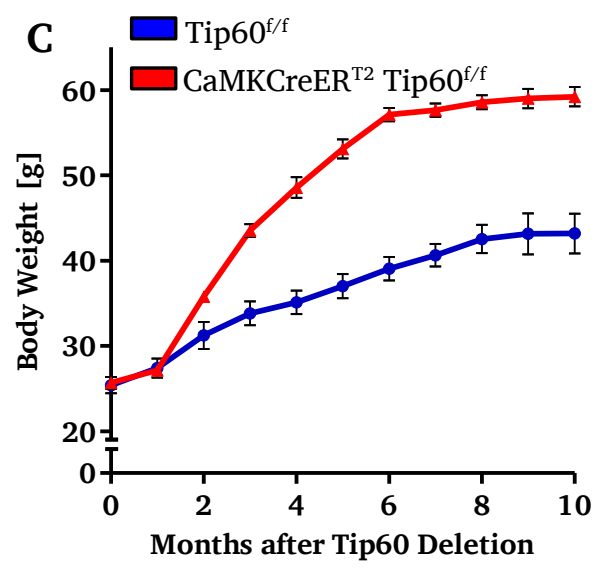

D
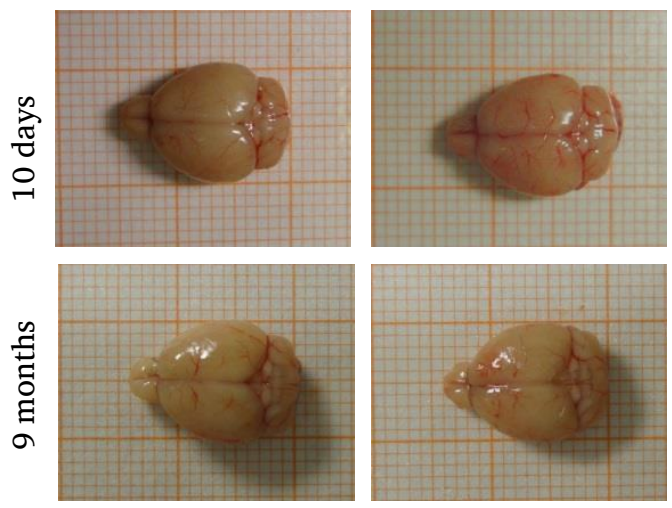

Figure 3.10: Inducible CaMKCreER ${ }^{\mathrm{T} 2} \mathrm{Tip}^{\mathrm{f} / \mathrm{f}}$ mice become obese and show limb clasping. (A) An obese CaMKCreER ${ }^{\mathrm{T} 2}$ Tip60 $0^{\mathrm{f} / \mathrm{f}}$ mouse (left) with a Tip60 ${ }^{\mathrm{f} / \mathrm{f}}$ control littermate 9 months after Tip60 gene deletion. (B) CaMKCreER ${ }^{\mathrm{T} 2} \mathrm{Tip}^{\mathrm{f} / \mathrm{f}}$ mice show limb clasping from about 3 months after Tip60 deletion onwards. While the control animal shows no limb clasping (left), the Tip60 CaMKCreER ${ }^{\mathrm{T} 2} \mathrm{Tip}^{\mathrm{f} / \mathrm{f}}$ animals show clasping four months (middle) and 9 months (right) after gene deletion. (C) Body weight curve. $n=9-11$ per genotype and time point. Error bars represent SEM. (D) Brain sizes are similar between genotypes. Representative brains of control and CaMKCreER ${ }^{\mathrm{T} 2} \mathrm{Tip}^{\mathrm{f} / \mathrm{f}}$ mice $(\mathrm{n}=3$ per genotype) are shown 10 days and 9 months after tamoxifen injections respectively. 


\subsection{Behavior}

In order to assess the consequences of TIP60-deficiency on cognitive function several standard behavioral tests were performed with the inducible CaMKCreER ${ }^{\mathrm{T} 2} \mathrm{Tip}^{\mathrm{f} / \mathrm{f}}$ model. Male CaMKCreER ${ }^{\mathrm{T} 2} \mathrm{Tip}^{\mathrm{f} / \mathrm{f}}$ and Tip60/f ${ }^{\mathrm{f} / \mathrm{f}}$ control littermates were tamoxifen-injected at 10-11 weeks of age. Since tamoxifen can influence cognitive function (Chen et al., 2002; Walf et al., 2006) the tests started 3-4 weeks after the last injection. It was shown for the CaMKCreER ${ }^{\mathrm{T} 2}$ driver that - apart from the Porsolt swim test - tamoxifen has no influence on behavior after this time (Vogt et al., 2008). Animals were singlecaged at least one week before the start of the tests.

\subsubsection{Open Field}

Possible changes in exploratory behavior and basal anxiety levels in CaMKCreER ${ }^{\mathrm{T} 2}$ Tip $60^{\mathrm{f} / \mathrm{f}}$ mice were evaluated using the open field test. Mice were placed into the open field arena for 5 min and filmed to track their paths and to calculate their speed and the distance travelled.

A

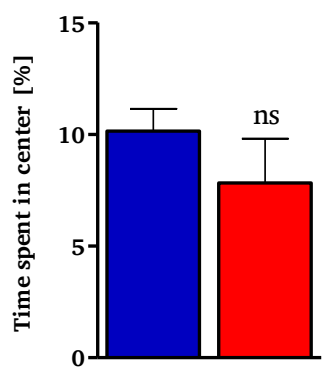

B

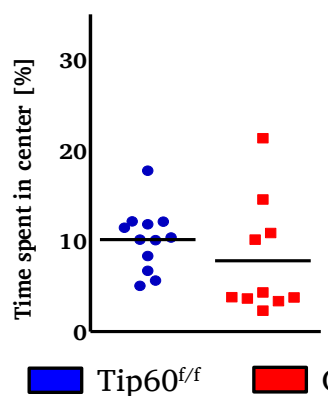

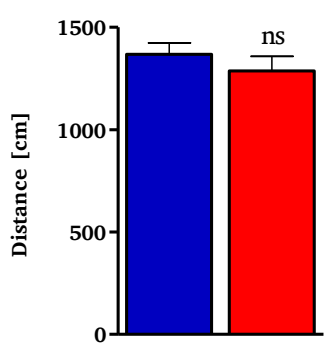

CaMKCreER $^{\mathrm{T2}} \mathrm{Tip}^{\mathrm{f} / \mathrm{f}}$
C

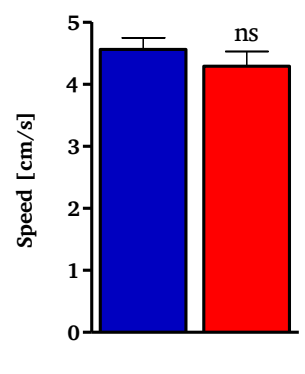

Figure 3.11: CaMKCreER ${ }^{\mathrm{T} 2} \mathrm{Tip}^{\mathrm{f} / \mathrm{f}}$ mice show comparable levels of basal anxiety in the open field test. (A) Left: Time spent in the center of the open field arena. Right: Time spent in the center, where each dot represents the test result of an individual mouse. (B), (C) There were no differences in the distance travelled or the speed between genotypes during the 5 min trial. $n=10-12$ per genotype, two-tailed student's $t$-test, ns: $\mathrm{p}>0.05,{ }^{*} \mathrm{p}<0.05$. Error bars represent SEM. A.U. = arbitrary units.

CaMKCreER $^{\mathrm{T} 2} \mathrm{Tip}^{\mathrm{f} / \mathrm{f}}$ and control animals spent a comparable amount of time in the center of the open field arena (Figure 3.11A left, $\mathrm{p}=0.37$ ), indicating normal levels of basal anxiety. The same data is also depicted as a scatter plot, showing the distribution of test results for every experimental animal (Figure 3.11A right). Neither the distance 
nor the speed covered were significantly changed, indicating normal activity levels in the TIP60-deficient animals (Figure 3.11B, C).

\subsubsection{Novel Object Recognition}

Short- and long-term memory of CaMKCreER ${ }^{\mathrm{T} 2} \mathrm{Tip}^{\mathrm{f}} \mathrm{f} / \mathrm{f}$ mice was analyzed using the novel object recognition test. When short-term memory (STM) was tested, the time spent with the novel object was significantly decreased in CaMKCreER ${ }^{\mathrm{T} 2} \mathrm{Tip}^{6} 0^{\mathrm{f} / \mathrm{f}}$ mice compared to controls (Figure 3.12, $\mathrm{p}=0.0341$ ). The number of visits of the novel object was also decreased but did not reach significance (Figure 3.12, $\mathrm{p}=0.1307$ ).

STM

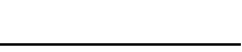

Time Spent
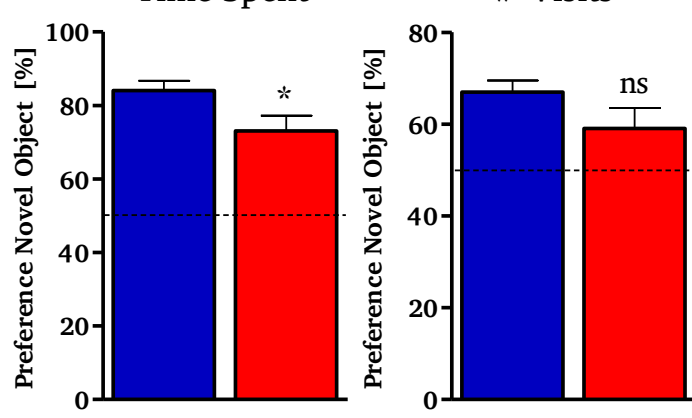

$\operatorname{Tip} 60^{\mathrm{f} / \mathrm{f}}$
LTM

Time Spent

\# Visits
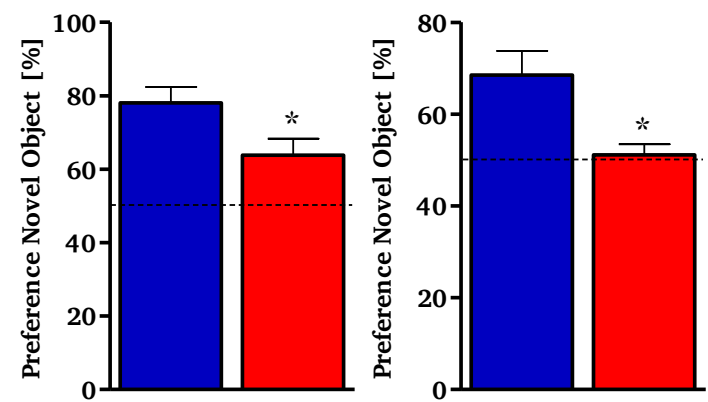

Figure 3.12: Deficits in novel object recognition in CaMKCreER ${ }^{\mathrm{T} 2} \mathrm{Tip}^{\mathrm{f} / \mathrm{f}} \mathbf{m i c e}$. CaMKCreER ${ }^{\mathrm{T} 2} \mathrm{Tip}^{\mathrm{f} / \mathrm{f}}$ and $\mathrm{Tip} 60^{\mathrm{f} / \mathrm{f}}$ control mice were tested for short- and long-term memory performance using the novel object recognition test. Preference for the novel object as time and visit ratio is shown both for STM and LTM. Chance levels are indicated by dashed lines. Abbreviations: STM = Short-term Memory, LTM = Long-Term Memory. Two-tailed student's $t$-test, ns: $\mathrm{p}>0.05,{ }^{*} \mathrm{p}<0.05 . \mathrm{n}=9-11$ per genotype. Error bars represent SEM.

In the test of long-term memory (LTM) formation the time CaMKCreER ${ }^{\mathrm{T} 2} \mathrm{Tip}^{\mathrm{f} / \mathrm{f}} \mathrm{mice}$ spent with the novel object as well as the number of visits were significantly decreased (Figure 3.12, $\mathrm{p}=0.0353$ and 0.0132). Thus, CaMKCreER ${ }^{\mathrm{T} 2} \mathrm{Tip}^{\mathrm{f} / \mathrm{f}}$ mice showed an impairment in recognition memory, the long-term memory appearing to be more affected than the short-term memory.

\subsubsection{Cross Maze}

Possible deficits in the working memory of CaMKCreER ${ }^{\mathrm{T} 2} \mathrm{Tip}^{\mathrm{f} / \mathrm{f}}$ mice were tested using the cross maze. The alternation of arms was similar between CaMKCreER ${ }^{\mathrm{T} 2} \mathrm{Tip}^{\mathrm{f} / \mathrm{f}}$ 
knockout and Tip60 ${ }^{\mathrm{f} / \mathrm{f}}$ control animals (Figure 3.13A left). Also the number of arm entries was similar between genotypes (Figure 3.13A right). The results indicate that TIP60-deficiency has no significant influence on working memory.

\subsubsection{Elevated Plus Maze}

Anxiety behavior was tested using the elevated plus maze. This test revealed the strongest phenotype in CaMKCreER ${ }^{\mathrm{T} 2} \mathrm{Tip}^{\mathrm{f} / \mathrm{f}}$ knockout mice. The relative time spent in the open arms was significantly increased (Figure 3.13B), indicating decreased anxiety in CaMKCreER $^{\mathrm{T} 2} \mathrm{Tip}^{\mathrm{f} / \mathrm{f}}$ mice. Interestingly, also the CaMKCre Tip60 ${ }^{\mathrm{f} / \mathrm{f}}$ mice appeared to be less afraid of heights (Section 3.3.1).

A

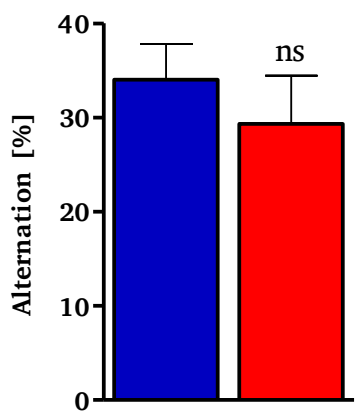

Cross Maze

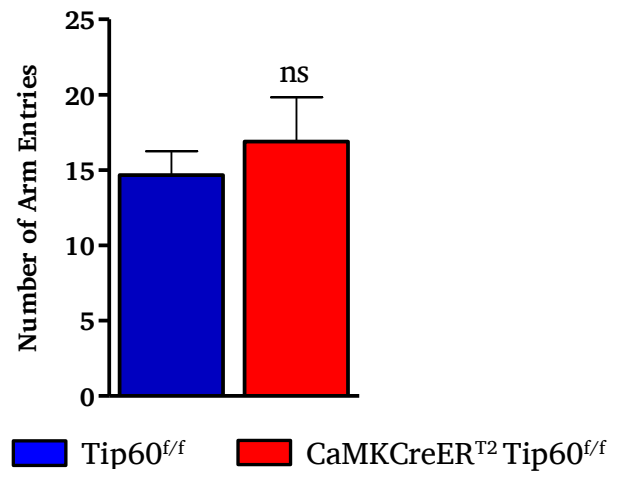

B

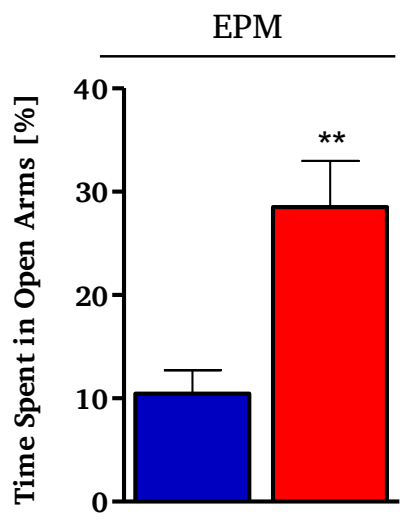

Figure 3.13: No changes in working memory but in the elevated plus maze in CaMKCreER ${ }^{\mathrm{T} 2} \mathrm{Tip}^{\mathrm{f} / \mathrm{f}}$ mice. (A) Cross maze: Successful alternation and number of arm entries performed by CaMKCreER ${ }^{\mathrm{T} 2}$ Tip60 ${ }^{\mathrm{f} / \mathrm{A}}$ mice and control animals. Two-tailed student's $t$-test, $\mathrm{ns}: \mathrm{p}>0.05 . \mathrm{n}=10-12$ per genotype. (B) Elevated plus maze (EPM): Percentage of time spent in the open arms. Two-tailed student's $t$-test, $* * \mathrm{p}<0.01 . \mathrm{n}=9-10$ per genotype. Error bars represent SEM.

\subsubsection{Fear Conditioning}

Hippocampus-dependent associative learning was measured using contextual fear conditioning. There was no significant difference between genotypes in freezing levels 24 hours after an electrical foot shock (Figure 3.14A). There was a small trend towards higher freezing levels in the CaMKCreER ${ }^{\mathrm{T2}} \mathrm{Tip}^{\mathrm{f} / \mathrm{f}}$ mice. The quantification of freezing prior to the shock showed significantly higher freezing levels in the CaMKCreER ${ }^{\mathrm{T} 2}$ Tip60 ${ }^{\mathrm{f} / \mathrm{f}}$ mice $(6.4 \%)$ compared to the controls (2.0 \%) (Figure 3.14B). Nevertheless, the percentage of freezing was within a normal range, which is why it is reasonable to assume that the measured difference did not have a relevant effect on the post-shock 
freezing. The average motion during the $2 \mathrm{~s}$ phase of the electric shock was similar between genotypes indicating comparable nociception (Figure 3.14C).

A

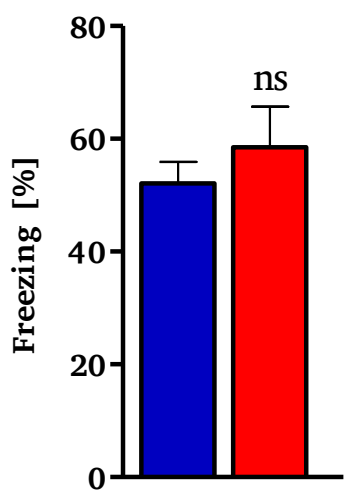

B

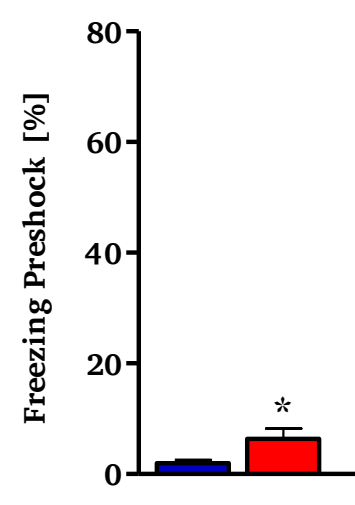

C

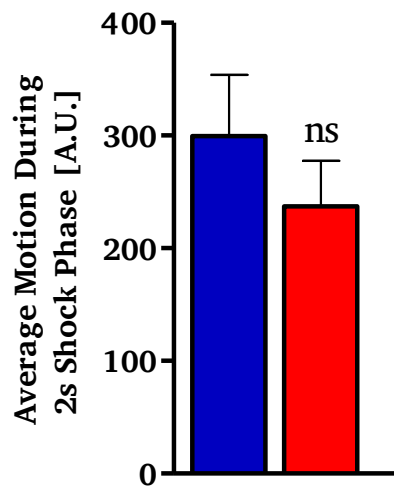

Tip60

CaMKCreER $^{\mathrm{T} 2} \mathrm{Tip}^{\mathrm{f} / \mathrm{f}}$

Figure 3.14: Fear conditioning results show no impairment of associative memory in TIP60-deficient mice. (A) The percentage of freezing 24 hours after the foot shock is similar between controls and CaMK$\mathrm{CreER}^{\mathrm{T} 2} \mathrm{Tip}^{\mathrm{f} / \mathrm{f}}$ mice. (B) Basal levels of freezing during the preshock phase are shown. (C) The average motion during the electric shock for both Tip60 $0^{\mathrm{f} / \mathrm{f}}$ controls and CaMKCreER ${ }^{\mathrm{T2}} \mathrm{Tip} 60^{\mathrm{f} / \mathrm{f}}$ mice. Two-tailed student's $t$-test, ns: $\mathrm{p}>0.05$, ${ }^{*} \mathrm{p}<0.05 . \mathrm{n}=9-12$ per genotype. Error bars represent SEM. A.U. $=$ arbitrary units.

In addition to the described tests, also hippocampus-dependent spatial learning was analyzed using the Morris water maze. However, data were not reliable due to significantly decreased swim speed in CaMKCreER ${ }^{\mathrm{T} 2} \mathrm{Tip}^{\mathrm{f} / \mathrm{f}}$ mice, which was presumably caused by the onset of obesity.

To summarize, the behavioral tests showed rather mild effects of TIP60-deficiency on cognition. The strongest phenotype in CaMKCreER ${ }^{\mathrm{T} 2} \mathrm{Tip}^{\mathrm{f} / \mathrm{f}}$ mice was detected in the elevated plus maze, which showed significantly decreased anxiety levels in TIP60-deficient animals. While working memory and associative learning appeared unchanged in CaMKCreER $^{\mathrm{T2}} \mathrm{Tip}^{\mathrm{f} / \mathrm{f}}$ mice the significant differences observed in the object recognition tests indicate a function of TIP60 in short- and long-term memory.

\subsection{Gene Expression Changes Induced by a Novel Envi-}

\section{ronment}

Acting both as a co-activator and co-repressor as well as a histone acetyltransferase, TIP60 can potentially have many different effects on gene transcription (Hlubek et al., 2001). The induction of immediate-early gene (IEG) expression offers a well-established paradigm for testing a possible role of TIP60 in IEG activation. In the brain, transcription 
levels of many IEGs, e.g. Npas4, are extremely low or even not detectable in absence of a stimulus. Placing a rodent into a novel environment has been shown to rapidly and robustly induce the transcription of numerous IEGs, including Npas4, c-Fos, and Zif268 (Hess et al., 1995; Ramamoorthi et al., 2011; Tischmeyer et al., 1999).

Thus, a novel environment paradigm was used to trigger IEG induction and to identify a possible involvement of TIP60 in IEG regulation. CaMKCreER ${ }^{\mathrm{T} 2} \mathrm{Tip}^{\mathrm{f} / \mathrm{f}}$ and $\mathrm{Tip} 60^{\mathrm{f} / \mathrm{f}}$ control animals were single-caged and handled daily at least one week before the start of the experiment. The home cage controls were kept in their cage until sacrifice while the novel environment groups were transferred to a new cage, which they were allowed to explore for $30 \mathrm{~min}$ prior to sacrifice.

Subsequently, brains were separated into both hemispheres. The whole hippocampus of the right hemisphere was isolated and the expression levels of IEGs were quantified by qPCR (Section 3.5.1). The left hemisphere was embedded and cryosectioned for ISH and IHC analysis (Section 3.5.2).

\subsubsection{Immediate-Early Gene Expression Analysis by qPCR}

Expression of several well-characterized IEGs was analyzed in whole hippocampus tissue of CaMKCreER ${ }^{\mathrm{T} 2} \mathrm{Tip}^{\mathrm{f} / \mathrm{f}}$ and Tip60 $0^{\mathrm{f} / \mathrm{f}}$ mice using qPCR. A two-way ANOVA was used to test for interaction between 'genotype' and 'condition' (home cage vs. novel environment) on IEG expression. Bonferroni multiple comparison was applied to further compare differences between genotypes under home cage and novel environment conditions. Differences in fold induction between genotypes were additionally analyzed using a two-tailed student's $t$-test.

\subsubsection{1 c-Fos}

c-Fos is one of the most-studied IEGs. Although its exact function in neurons is not well understood, it has been widely used as a marker for neuronal activity (Kaczmarek et al., 1988; Morgan et al., 1987). qPCR analysis revealed that expression of $c$-Fos was significantly increased in the CaMKCreER ${ }^{\mathrm{T} 2} \mathrm{Tip}^{\mathrm{f} / \mathrm{f}}$ animals compared to Tip60 $0^{\mathrm{f} / \mathrm{f}}$ mice both under home cage and novel environment conditions (Figure 3.15 left and Table 3.3).

Accordingly, genotype showed a highly significant effect on c-Fos expression levels $\left(F_{(1,34)}=772.75, p<0.0001\right)$. Also condition had a significant effect on $c$-Fos expression levels $\left(\mathrm{F}_{(1,34)}=116.21, \mathrm{p}<0.0001\right)$, indicating that $c$-Fos was readily induced upon novel environment exposure. However, there was no significant interaction between genotype 
c-Fos
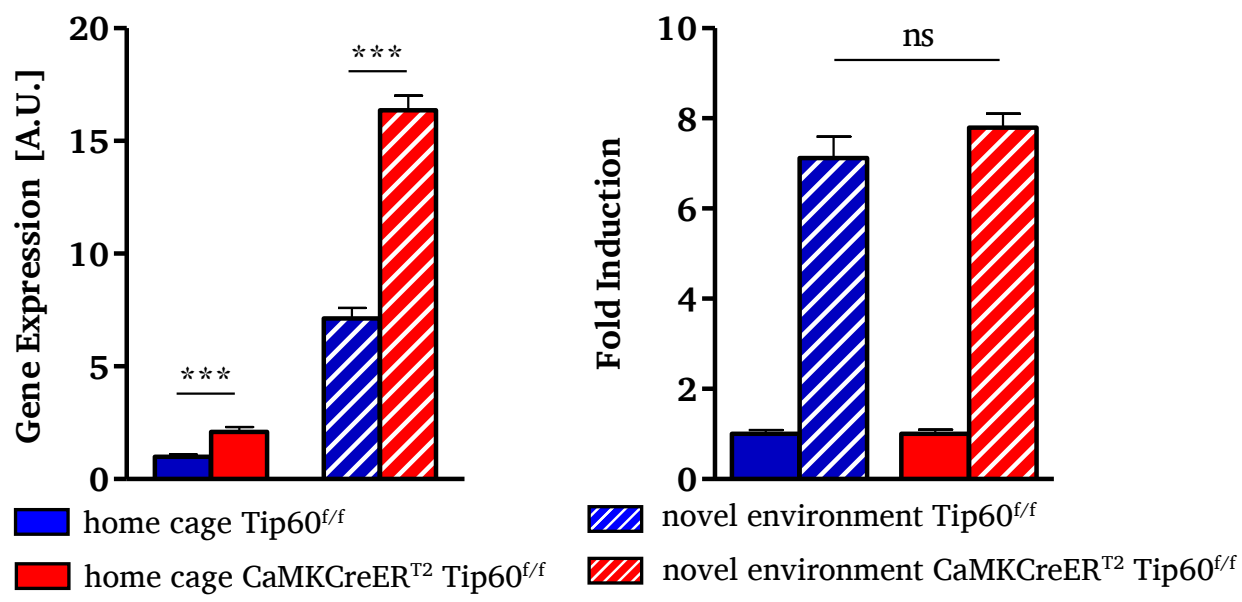

Figure 3.15: $c$-Fos expression is highly upregulated in CaMKCreER ${ }^{\mathrm{T} 2}$ Tip60 $^{\mathrm{f} / \mathrm{f}}$ mice. Left: $c$-Fos expression in CaMKCreER ${ }^{\mathrm{T} 2} \mathrm{Tip}^{\mathrm{f} / \mathrm{f}}$ and $\mathrm{Tip}^{\mathrm{f} / \mathrm{f}}$ mice both under home cage and novel environment conditions. All data was normalized to home cage Tip60 ${ }^{\mathrm{f} / \mathrm{f}}$ animals. $\mathrm{n}=9-11$ per genotype and condition; Two-wayANOVA, Bonferroni multiple comparisons (also see table below), $* * * \mathrm{p}<0.0001$. A.U. $=$ arbitrary units. Right: Fold induction upon exposure to a novel environment was similar in CaMKCreER ${ }^{\mathrm{T} 2} \mathrm{Tip}^{\mathrm{f} / \mathrm{f}}$ and Tip60 ${ }^{\mathrm{f} / \mathrm{f}}$ control animals. Two-tailed student's $t$-test, ns: $\mathrm{p}>0.05$. Error bars indicate SEM.

and condition $\left(\mathrm{F}_{(1,34)}=0.48, \mathrm{p}=0.4949\right)$, indicating that TIP60-deficiency does not influence the magnitude of IEG induction. Fold inductions upon novelty exposure were 78 fold in either genotype $(p=0.5016)$.

Table 3.3 Bonferroni multiple comparison results for c-Fos expression.

\begin{tabular}{l|c|c|c}
\multicolumn{1}{c|}{ Condition/Genotype } & Difference of means & P Value & Significance \\
\hline $\begin{array}{l}\text { home cage Tip60 } \\
\text { home cage CaMKCreER }\end{array}$ & -2.859 & $\mathrm{P}<0.0001$ & $* * *$ \\
\hline $\begin{array}{l}\text { novel environment Tip60 } \\
\text { novel environment CaMKCreER }\end{array}$ & -3.004 & $\mathrm{P}<0.0001$ & $* * *$
\end{tabular}

\subsubsection{Arc}

IEG activity-regulated cytoskeleton (Arc) is known to be rapidly transcribed upon exposure of an animal to a novel environment (Vazdarjanova et al., 2006). Under home cage conditions, differences in gene expression were not significant between genotypes, however, a trend showing increased Arc mRNA levels in CaMKCreER ${ }^{\mathrm{T} 2} \mathrm{Tip}^{\mathrm{f} / \mathrm{f}}$ mice was observed (Figure 3.16 left, Table 3.4). After exposure to a novel environment, CaMKCreER $^{\mathrm{T} 2} \mathrm{Tip}^{\mathrm{f} / \mathrm{f}}$ mice showed significantly increased Arc expression levels compared to Tip60 ${ }^{\mathrm{f} / \mathrm{f}}$ control animals (Figure 3.16 left, Table 3.4). Fold induction of Arc was more than two-fold in both CaMKCreER ${ }^{\mathrm{T} 2} \mathrm{Tip}^{\mathrm{f} / \mathrm{f}}$ and $\mathrm{Tip}^{\mathrm{f} / \mathrm{f}}$ animals after exposure to a novel environment, which is in accordance with the literature (Ramamoorthi et al., 
2011). The effect of condition was by far more significant $\left(F_{(1,36)}=103.98, p<0.0001\right)$ than the effect of genotype $\left(\mathrm{F}_{(1,36)}=6.64, \mathrm{p}=0.0142\right)$. There was no significant interaction between genotype and condition $\left(\mathrm{F}_{(1,36)}=1.03, \mathrm{p}=0.3172\right)$, despite the significant change in fold induction ( $\mathrm{p}=0.0273$ ) (Figure 3.16 right), indicating that overall response of IEG Arc expression is comparable between genotypes.

\section{Arc}
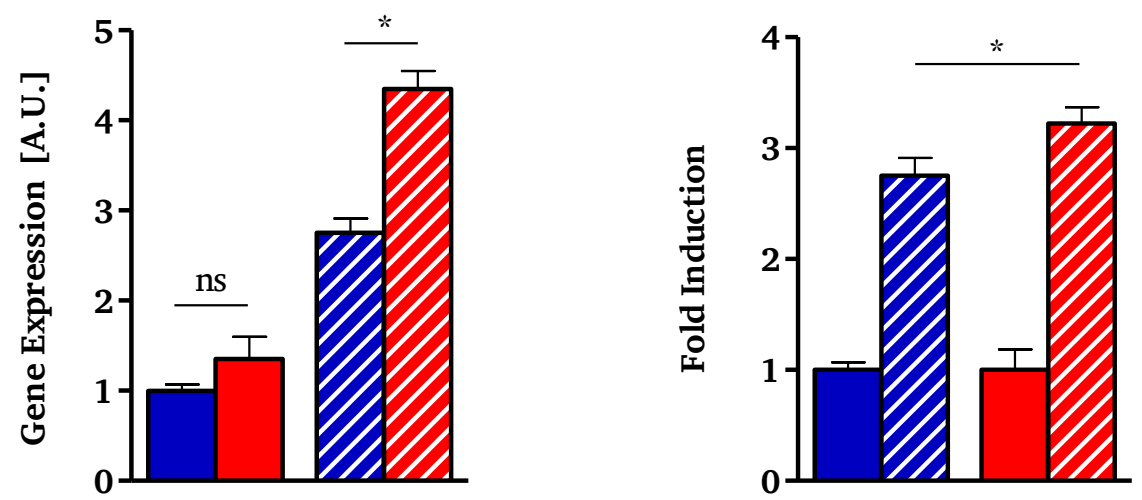

home cage Tip60 $\mathrm{f} / \mathrm{f}$

WII novel environment Tip60 ${ }^{\mathrm{f} / \mathrm{f}}$

home cage CaMKCreER ${ }^{\mathrm{T} 2} \mathrm{Tip} 60^{\mathrm{f} / \mathrm{f}}$

UIJ novel environment CaMKCreER ${ }^{\mathrm{T} 2} \mathrm{Tip}^{\mathrm{f} / \mathrm{f}}$

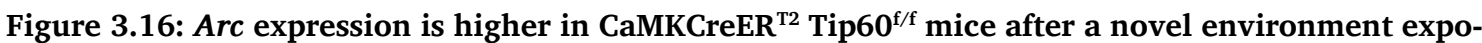
sure compared to controls. Left: Arc expression under home cage and novel environment condition in the hippocampus of CaMKCreER ${ }^{\mathrm{T} 2} \mathrm{Tip}^{\mathrm{f} / \mathrm{f}}$ and Tip60 $\mathrm{f} / \mathrm{f}$ mice. Two-way-ANOVA, Bonferroni multiple comparisons (also see table below), ${ }^{*} \mathrm{p}<0.05$. A.U. $=$ arbitrary units. Right: Fold induction of Arc was significantly higher in CaMKCreER ${ }^{\mathrm{T} 2} \mathrm{Tip}^{\mathrm{f} / \mathrm{f}}$ mice compared to Tip60 ${ }^{\mathrm{f} / \mathrm{f}}$ animals after exposure to a novel environment. Two-tailed student's $t$-test, *p $<0.05$. $\mathrm{n}=9-10$ per genotype and condition. Error bars indicate SEM.

Table 3.4: Bonferroni multiple comparison results for Arc expression.

\begin{tabular}{l|c|c|c}
\multicolumn{1}{c|}{ Condition/Genotype } & Difference of means & P Value & Significance \\
\hline $\begin{array}{l}\text { home cage Tip60 } \\
\text { home cage CaMKCreER }\end{array}$ & -0.2500 & $\mathrm{P}>0.05$ & $\mathrm{~ns}$ \\
\hline $\begin{array}{l}\text { novel environment Tip60 } \\
\text { novel environment } \text { VaMKCreER }^{\mathrm{f} / \mathrm{f}}\end{array}$ & -0.5747 & $\mathrm{P}<0.05$ & $*$
\end{tabular}

\subsubsection{Npas4}

Neuronal PAS domain protein 4 (Npas4) is a rapid IEG and has been extensively studied in recent years (Ploski et al., 2011; Bloodgood et al., 2013). It is suggested to possibly act as a master regulator of other IEGs (Ramamoorthi et al., 2011). qPCR results showed that expression of Npas4 was significantly higher in the CaMKCreER ${ }^{\mathrm{T} 2} \mathrm{Tip}^{\mathrm{f}} \mathrm{f} / \mathrm{f}$ animals 
compared to Tip60 ${ }^{\mathrm{f} / \mathrm{f}}$ mice both under home cage and novel environment conditions (Figure 3.17 left, Table 3.5). Accordingly, genotype showed a highly significant effect on Npas4 expression levels $\left(\mathrm{F}_{(1,35)}=107.45, \mathrm{p}<0.0001\right)$. Also condition had a significant effect on Npas4 expression levels $\left(\mathrm{F}_{(1,35)}=88.12, \mathrm{p}<0.0001\right)$, indicating that Npas4 is readily induced upon novel environment exposure. In both genotypes the induction was more than twofold and did not significantly differ $(\mathrm{p}=0.9548)$ (Figure 3.17 right). There was no significant interaction between genotype and condition $\left(F_{(1,35)}=0.00\right.$, $\mathrm{p}=0.9634$ ), indicating that TIP60-deficiency did not influence the extent of Npas4 induction after a novel environment stimulus (Figure 3.17 right).

\section{Npas4}
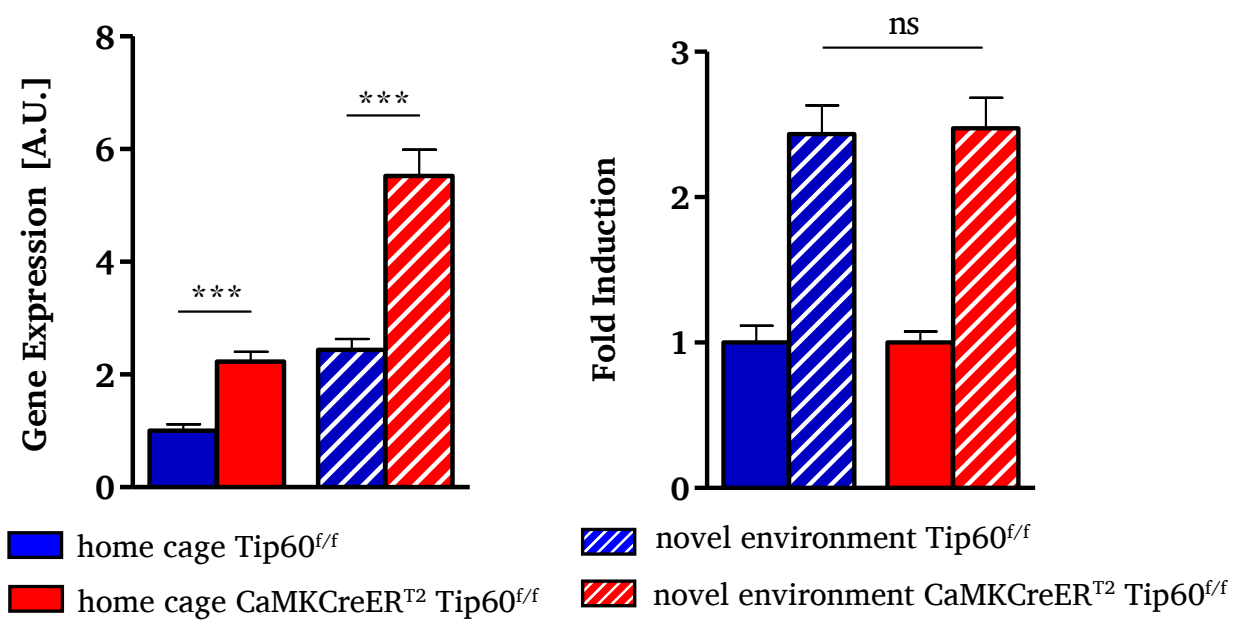

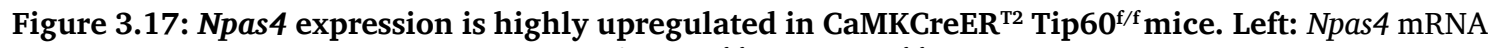
levels in the hippocampus of CaMKCreER ${ }^{\mathrm{T} 2} \mathrm{Tip}^{\mathrm{f} / \mathrm{f}}$ and $\mathrm{Tip}^{\mathrm{f} / \mathrm{f}}$ mice both under home cage and novel environment conditions. Two-way ANOVA, Bonferroni multiple comparisons (also see table below), $* * * \mathrm{p}<0.001$. A.U. = arbitrary units. Right: Fold induction of Npas4 is highly comparable between genotypes. Student's two-tailed $t$-test, ns: $\mathrm{p}>0.05 . \mathrm{n}=9-11$ per genotype and condition. Error bars represent SEM.

Table 3.5: Bonferroni multiple comparison results for Npas4 expression.

\begin{tabular}{|c|c|c|c|}
\hline Condition/Genotype & Difference of means & P Value & Significance \\
\hline $\begin{array}{l}\text { home cage Tip60 } 60^{\mathrm{f} / \mathrm{f}} \text { vs } \\
\text { home cage CaMKCreER }{ }^{\mathrm{T} 2} \mathrm{Tip}^{\mathrm{f} / \mathrm{f}}\end{array}$ & -1.310 & $\mathrm{P}<0.0001$ & $* * *$ \\
\hline $\begin{array}{l}\text { novel environment } \operatorname{Tip}^{6} 0^{\mathrm{f} / \mathrm{f}} \text { vs } \\
\text { novel environment CaMKCreER } \\
\mathrm{T} 2 \\
\mathrm{Tip}^{\mathrm{f} / \mathrm{f}}\end{array}$ & -1.298 & $\mathrm{P}<0.0001$ & $* * *$ \\
\hline
\end{tabular}




\subsubsection{Bdnf}

BDNF is a neuromodulator with pleiotropic functions on synaptic plasticity (Greenberg et al., 2009). The Bdnf gene consists of nine exons, of which only exon $I X$ is proteincoding. The other exons possess separate promoters and can be spliced to the coding exon, thereby contributing to the highly complex regulation of $B d n f$ transcription (Pruunsild et al., 2007). Bdnf exon I and exon IV are particularly interesting since they are activity-regulated and were therefore also analyzed by qPCR for differential expression in CaMKCreER ${ }^{\mathrm{T} 2} \mathrm{Tip}^{\mathrm{f} / \mathrm{f}}$ mice compared to Tip60 ${ }^{\mathrm{f} / \mathrm{f}}$ controls. Bdnf exon I expression showed a highly significant upregulation in CaMKCreER ${ }^{\mathrm{T} 2} \mathrm{Tip}^{\mathrm{f} / \mathrm{f}} \mathrm{compared}$ to Tip60 ${ }^{\mathrm{f} / \mathrm{f}}$ mice under both home cage and novel environment conditions (Figure 3.18 left, Table 3.6). Bdnf exon I levels were not increased after novel environment exposure in either genotype (Figure 3.18 right), most likely because Bdnf is a delayed IEG (Saha et al., 2011) and takes more time for effective gene induction. Two-way ANOVA analysis with Bonferroni multiple comparisons confirmed that genotype had a highly significant effect on Bdnf exon I transcription $\left(\mathrm{F}_{(1,34)}=433.76, \mathrm{p}<0000.1\right)$ while condition had no significant effect on the results $\left(\mathrm{F}_{(1,34)}=1.54, \mathrm{p}=0.2242\right)$. This indicated that the expression of Bdnf exon I was similarly upregulated in CaMKCreER ${ }^{\mathrm{T} 2} \mathrm{Tip}^{\mathrm{f} / \mathrm{f}}$ compared to Tip60 $^{\mathrm{f} / \mathrm{f}}$ control mice under both home cage and novel environment conditions (Table 3.6). No significant interaction was found between genotype and condition $\left(F_{(1,34)}=0.98\right.$, $\mathrm{p}=0.3285$ ), however, there was a significant difference in fold induction values $(\mathrm{p}=0.0456)$. This result was due to the lower Bdnf exon I expression levels in the novel environment cohort of CaMKCreER ${ }^{\mathrm{T} 2} \mathrm{Tip}^{\mathrm{f} / \mathrm{f}}$ mice compared to the home cage cohort. 


\section{Bdnf exon I}

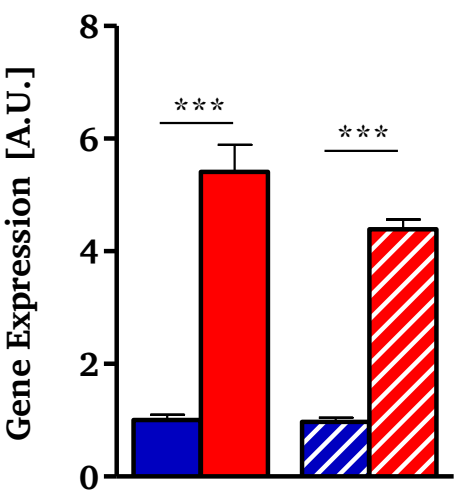

home cage Tip60 $60^{\mathrm{f} / \mathrm{f}}$

$\square$ home cage CaMKCreER ${ }^{\mathrm{T} 2} \mathrm{Tip}^{\mathrm{f} / \mathrm{f}}$

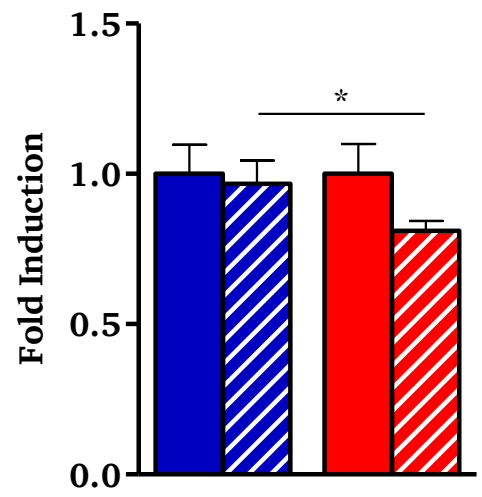

UIA novel environment Tip60 $\mathrm{f} / \mathrm{f}$

WII novel environment CaMKCreER ${ }^{\mathrm{T} 2} \mathrm{Tip}^{\mathrm{f} / \mathrm{f}}$

Figure 3.18: Bdnf exon $I$ expression is significantly upregulated in CaMKCreER ${ }^{\mathrm{T} 2} \mathrm{Tip}^{\mathrm{f}} \mathrm{C}^{\mathrm{f} / \mathrm{f}}$ mice. Left: Bdnf Exon I mRNA levels in the hippocampus of CaMKCreER ${ }^{\mathrm{T} 2}$ and Tip60 $60^{\mathrm{f} / \mathrm{f}}$ mice both under home cage and novel environment conditions. Two-way ANOVA, Bonferroni multiple comparisons (also see table below), $* * * \mathrm{p}<0.001$. A.U. = arbitrary units. Right: Fold induction of Bdnf exon I transcript in Tip60 ${ }^{\mathrm{f} / \mathrm{f}}$ and CaMK$\mathrm{CreER}^{\mathrm{T} 2} \mathrm{Tip}^{\mathrm{f} / \mathrm{f}}$ animals after exposure to a novel environment. $\mathrm{n}=9-11$ per genotype and condition. Twotailed student's $t$-test, ${ }^{*} \mathrm{p}<0.05$. Error bars represent SEM.

Table 3.6: Bonferroni multiple comparison results for Bdnf exon I expression.

\begin{tabular}{l|c|c|c}
\multicolumn{1}{c|}{ Condition/Genotype } & Difference of means & P Value & Significance \\
\hline $\begin{array}{l}\text { home cage Tip60 } \\
\text { home cage CaMKCreER }\end{array}$ & -2.427 & $\mathrm{P}<0.0001$ & $* * *$ \\
\hline $\begin{array}{l}\text { novel } \text { Tip60 }^{\mathrm{f} / \mathrm{f}} \\
\text { novel environment Tip60 }\end{array}$ & $-2 . \mathrm{f}$ vs & $\mathrm{P}<0.0001$ & $* * *$
\end{tabular}

Similarly to the changes observed for Bdnf exon $I$, expression of Bdnf exon $I V$ was also highly upregulated in CaMKCreER ${ }^{\mathrm{T} 2} \mathrm{Tip}^{\mathrm{f} / \mathrm{f}}$ mice compared to Tip60 ${ }^{\mathrm{f} / \mathrm{f}}$ controls, both under home cage and novel environment conditions (Figure 3.19 left, Table 3.7). The effect of condition was significant $\left(\mathrm{F}_{(1,35)}=6.28, \mathrm{p}=0.0170\right)$. Genotype had a very strong effect $\left(\mathrm{F}_{(1,35)}=139.41, \mathrm{p}<0.0001\right)$, showing that TIP60-deficiency leads high differences in Bdnf exon IV expression. The two-way ANOVA analysis detected no significant interaction between genotype and condition $\left(\mathrm{F}_{(1,35)}=2.14, \mathrm{p}=0.1521\right)$, indicating no overall difference in IEG induction between genotypes. However, significant changes were found when fold induction values were compared using a $t$-test $(\mathrm{p}=0.0161)$ (Figure 3.19 
right). As already mentioned, Bdnf belongs to the delayed IEGs (Saha et al., 2011), explaining the lack of high induction after 30 min of novelty exposure (Table 3.7).

\section{Bdnf exon IV}
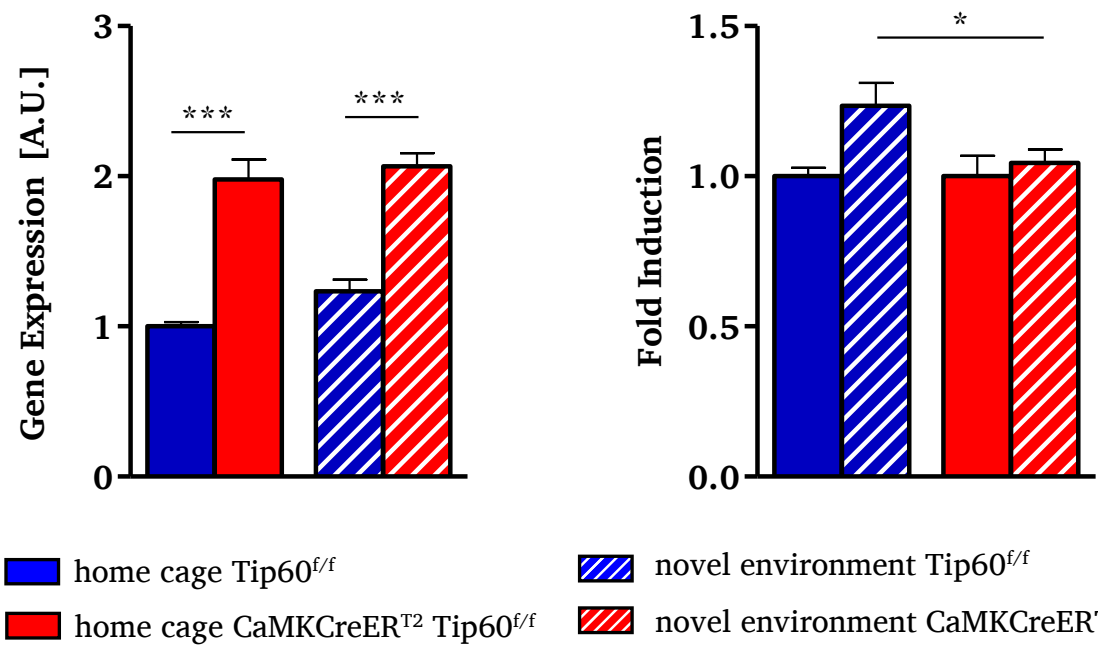

VII novel environment Tip60

UII novel environment CaMKCreERT2 Tip60 ${ }^{\mathrm{f} / \mathrm{f}}$

Figure 3.19: Bdnf exon IV expression is significantly upregulated in CaMKCreER ${ }^{\mathrm{T} 2} \mathrm{Tip}^{6} 0^{\mathrm{f} / \mathrm{f}}$ mice. Left: Bdnf exon IV expression in the hippocampus of CaMKCreER ${ }^{\mathrm{T} 2} \mathrm{Tip}^{\mathrm{f}} 0^{\mathrm{f} / \mathrm{f}}$ and Tip $60^{\mathrm{f} / \mathrm{f}}$ mice both under home cage and novel environment conditions. Two-way ANOVA, Bonferroni multiple comparisons (also see table below), ***p $<0.0001$. A.U. = arbitrary units. Right: Fold induction of Bdnf exon IV upon a novel environment exposure in Tip60 ${ }^{\mathrm{f} / \mathrm{f}}$ controls and CaMKCreER ${ }^{\mathrm{T} 2} \mathrm{Tip}^{\mathrm{f} / \mathrm{f}}$ mice. $\mathrm{n}=9-11$ per genotype and condition. Two-tailed student's $t$-test, ${ }^{*} \mathrm{p}<0.05$. Error bars represent SEM.

Table 3.7: Bonferroni multiple comparison results for Bdnf exon IV.

\begin{tabular}{l|c|c|c}
\multicolumn{1}{c|}{ Condition/Genotype } & Difference of means & P Value & Significance \\
\hline $\begin{array}{l}\text { home cage Tip60 } \\
\text { home cage CaMKCreER }\end{array}$ VS $^{\mathrm{T} 2} \mathrm{Tip60}^{\mathrm{f} / \mathrm{f}}$ & -0.9639 & $\mathrm{P}<0.0001$ & $* * *$ \\
\hline $\begin{array}{l}\text { novel environment Tip60 } \\
\text { novel environment } \text { Vs }^{\mathrm{f}}\end{array}$ & -0.7512 & $\mathrm{P}<0.0001$ & $* * *$
\end{tabular}

\subsubsection{Zif268}

Zif268/Egr1 is another rapid IEG, whose expression and induction was compared between CaMKCreER ${ }^{\mathrm{T} 2} \mathrm{Tip}^{\mathrm{f} / \mathrm{f}}$ and Tip60 ${ }^{\mathrm{f} / \mathrm{f}}$ animals. Differences in home cage levels were not significant between genotypes, while Zif268 expression was significantly higher in CaMKCreER $^{\mathrm{T} 2} \mathrm{Tip}^{\mathrm{f} / \mathrm{f}}$ compared to Tip60 ${ }^{\mathrm{f} / \mathrm{f}}$ mice under novel environment conditions (Figure 3.20 left; Table 3.8). Fold induction was approximately two-fold and similar between genotypes $(\mathrm{p}=0.3294)$. Interaction between genotype and condition was not 
significant $\left(\mathrm{F}_{(1,35)}=0.49, \mathrm{p}=0.4875\right)$, indicating that TIP60-deficiency did not influence the induction of Zif268 upon the novelty exposure. Both genotype and condition had a significant effect $\left(\mathrm{F}_{(1,35)}=15.35, \mathrm{p}=0.0004\right)$ and $\left(\mathrm{F}_{(1,35)}=129.79, \mathrm{p}<0.0001\right)$ respectively.

\section{Zif268}
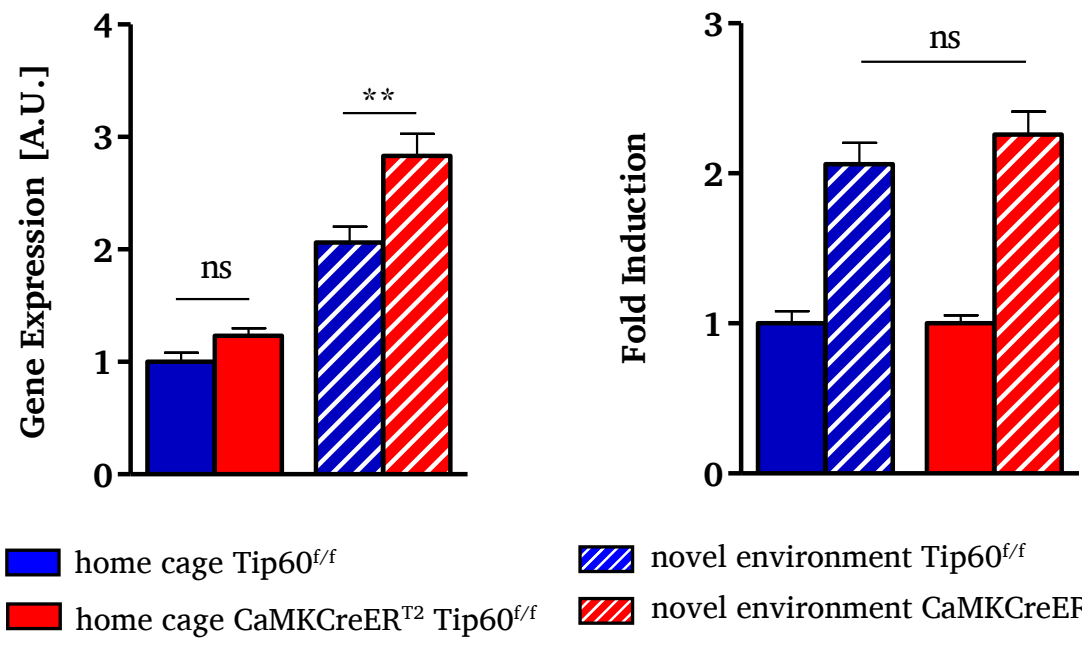

VII novel environment Tip60 $0^{\mathrm{f} / \mathrm{f}}$

ZII novel environment CaMKCreER ${ }^{\mathrm{T} 2} \mathrm{Tip}^{\mathrm{f} / \mathrm{f}}$

Figure 3.20: Basal Zif268 expression levels are significantly increased in CaMKCreER ${ }^{\mathrm{T} 2} \mathrm{Tip}^{\mathrm{f}} \mathrm{f}^{\mathrm{f}} \mathrm{mice}^{\mathrm{i}}$ after novelty exposure. Left: Expression levels of Zif268 mRNA in the hippocampus of CaMKCreER ${ }^{\mathrm{T} 2}$ $\mathrm{Tip}^{\mathrm{f} / \mathrm{f}}$ and Tip60 ${ }^{\mathrm{f} / \mathrm{f}}$ mice both under home cage and novel environment conditions. Two-way ANOVA, Bonferroni multiple comparisons (also see table below), ns: $\mathrm{p}>0.05,{ }^{*} \mathrm{p}<<0.01$. A.U. $=$ arbitrary units.. Right: Fold inductions are similar between genotypes. $n=9-11$ per genotype and condition. Two-tailed student's $t$-test, ns: $\mathrm{p}>0.05$. Error bars represent SEM.

Table 3.8: Bonferroni multiple comparison results for Zif268 expression.

\begin{tabular}{|c|c|c|c|}
\hline Condition/Genotype & Difference of means & P Value & Significance \\
\hline $\begin{array}{l}\text { home cage } \operatorname{Tip}^{\mathrm{f} / \mathrm{f}} \text { vs } \\
\text { home cage CaMKCreER }{ }^{\mathrm{T} 2} \mathrm{Tip}^{\mathrm{f} / \mathrm{f}}\end{array}$ & -0.3170 & $\mathrm{p}>0.05$ & ns \\
\hline $\begin{array}{l}\text { novel environment Tip } 60^{\mathrm{f} / \mathrm{f}} \text { vs } \\
\text { novel environment CaMKCreER }{ }^{\mathrm{T} 2} \mathrm{Tip}^{\mathrm{f} / \mathrm{f}}\end{array}$ & -0.4553 & $\mathrm{P}<0.01$ & $* *$ \\
\hline
\end{tabular}

\subsubsection{Homer1}

HOMER1 is a postsynaptic density protein, which has important functions in scaffolding of receptors. Homer1 expression was significantly upregulated in CAMKCreER ${ }^{\mathrm{T} 2} \mathrm{Tip}^{\mathrm{f} / \mathrm{f}}$ animals compared to Tip $60^{\mathrm{f} / \mathrm{f}}$ controls both under home cage and novel environment conditions (Figure 3.21 left; Table 3.9). Both genotype and condition had significant 
effects on Homer1 expression $\left(\mathrm{F}_{(1,35)}=34.02, \mathrm{p}<0.0001\right.$ and $\mathrm{F}_{(1,35)}=4.32, \mathrm{p}=0.0450$ respectively). However, there was no significant interaction found between genotype and condition, indicating that the induction of Homer1 is comparable between CaMKCreER ${ }^{\mathrm{T} 2}$ Tip60 $0^{f / f}$ and Tip60 ${ }^{f / f}$ control mice $\left(F_{(1,35)}=0.70, p=0.4084\right)$. This was confirmed by comparing the fold inductions between genotypes using a student's $t$-test $(\mathrm{p}=0.2445)$ (Figure 3.21 right).

\section{Homer1}
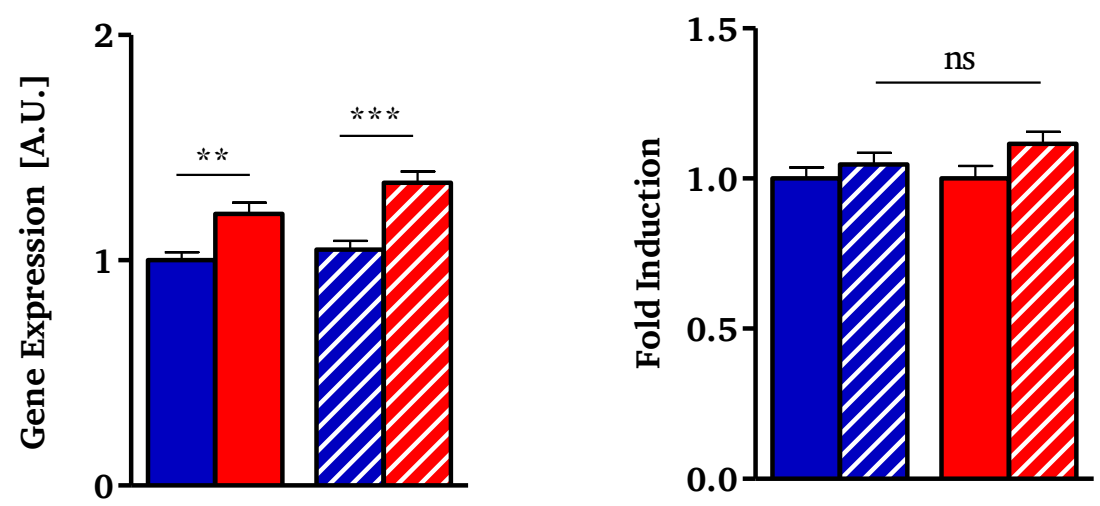

\footnotetext{
home cage Tip60 $\mathrm{f} / \mathrm{f}$

$\square$ home cage CaMKCreER ${ }^{\mathrm{T} 2} \mathrm{Tip}^{\mathrm{f} / \mathrm{f}}$
}

UII novel environment Tip60 ${ }^{\mathrm{f} / \mathrm{f}}$

UIJ novel environment CaMKCreER ${ }^{\mathrm{T} 2} \mathrm{Tip}^{\mathrm{f} / \mathrm{f}}$

Figure 3.21: Homer1 expression is significantly upregulated in CaMKCreER ${ }^{\mathrm{T} 2} \mathrm{Tip60}^{\mathrm{f} / \mathrm{f}}$ animals. Left: Homer1 mRNA expression levels in the hippocampus of CaMKCreER ${ }^{\mathrm{T} 2} \mathrm{Tip}^{\mathrm{f} / \mathrm{f}}$ and $\mathrm{Tip}^{\mathrm{f} / \mathrm{f}}$ control animals under both home cage and novel environment conditions. Two-way ANOVA, Bonferroni multiple comparisons (also see table below), $* * \mathrm{p}<0.01, * * * \mathrm{p}<0.0001$. A.U. = arbitrary units. Right: Fold inductions of Homer1 gene expression in Tip60 ${ }^{\mathrm{f} / \mathrm{f}}$ controls and CaMKCreER ${ }^{\mathrm{T} 2} \mathrm{Tip} 60^{\mathrm{f} / \mathrm{f}}$ animals upon a novel environment exposure. $\mathrm{n}=9-11$ per genotype and condition. Two-tailed student's $t$-test, $n s: \mathrm{p}>0.05$. Error bars represent SEM.

Table 3.9: Bonferroni multiple comparison results for Homer1 expression.

\begin{tabular}{l|c|c|c}
\multicolumn{1}{c|}{ Condition/Genotype } & Difference of means & P Value & Significance \\
\hline $\begin{array}{l}\text { home cage Tip60 } \\
\text { home cage CaMKCreER }\end{array}$ & -0.2690 & $\mathrm{P}<0.01$ & $* *$ \\
\hline $\begin{array}{l}\text { novel environment Tip60 } \\
\text { novel environment CaMKCreER }\end{array}$ & & & $* * *$
\end{tabular}

\subsubsection{C-Jun}

c-JUN forms the heterodimeric AP-1 early response transcription factor together with cFOS (Angel et al., 1991). c-Jun expression was higher in CaMKCreER ${ }^{\mathrm{T} 2} \mathrm{Tip}^{\mathrm{f} / \mathrm{f}} \mathrm{mice}^{-}$ compared to Tip $60^{\mathrm{f} / \mathrm{f}}$ controls under both home cage and novel environment conditions. However, the results did not reach significance (Figure 3.22 left; Table 3.10). Condition 
had a significant effect on $c$-Jun expression $\left(\mathrm{F}_{(1,36)}=15.72, \mathrm{p}=0.0003\right)$, indicating efficient induction upon the novelty stimulus. Genotype showed a mild yet still significant effect $\left(\mathrm{F}_{(1,36)}=5.44, \mathrm{p}=0.0254\right)$, indicating that expression levels are different between genotypes. The interaction between genotype and condition was not significant $\left(\mathrm{F}_{(1,36)}=0.28, \mathrm{p}=0.6013\right)$, indicating comparable gene induction for $c$-Jun. In line with this result, also the comparison of fold induction between genotypes using student's $t$ test showed no significant difference $(\mathrm{p}=0.4434)$ (Figure 3.22 right).

\section{c-Jun}

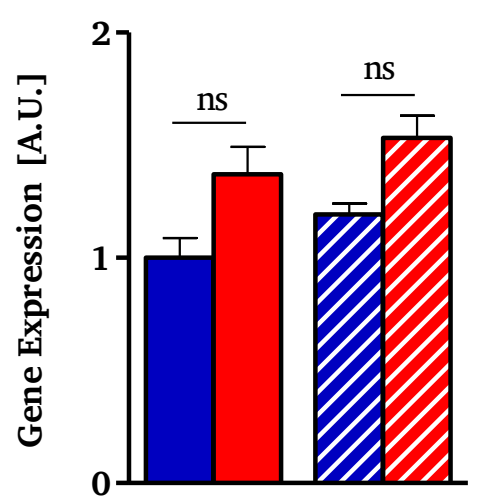

home cage Tip60 $\mathrm{f} / \mathrm{f}$

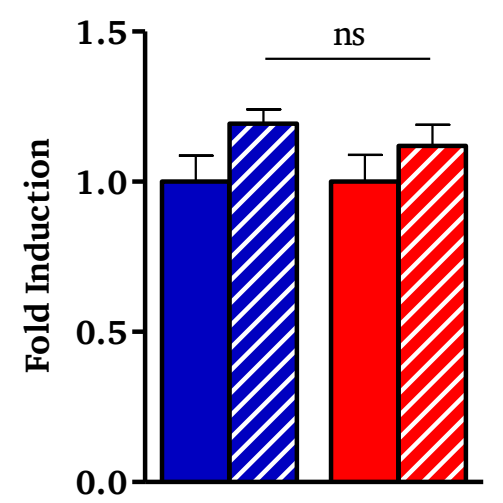

VII novel environment Tip60 ${ }^{\mathrm{f} / \mathrm{f}}$

UIJ novel environment CaMKCreER ${ }^{\mathrm{T} 2} \mathrm{Tip}^{\mathrm{f} / \mathrm{f}}$

Figure 3.22: $c$-Jun expression is not significantly changed in CaMKCreER ${ }^{\mathrm{T} 2} \mathrm{Tip}^{\mathrm{f} / \mathrm{f}}$ mice. Left: Expression levels of $c$-Jun under home cage and novel environment conditions in the hippocampus of Tip $60^{\mathrm{f} / \mathrm{f}}$ control and CaMKCreER ${ }^{\mathrm{T} 2} \mathrm{Tip}^{\mathrm{f} / \mathrm{f}}$ mice. Two-way ANOVA, Bonferroni multiple comparisons (also see table below), ns: $\mathrm{p}>0.05$. A.U. = arbitrary units. Right: Fold induction of $c$-Jun expression in Tip60 ${ }^{\mathrm{f} / \mathrm{f}}$ control and CaMKCreER ${ }^{\mathrm{T} 2} \mathrm{Tip}^{\mathrm{f} / \mathrm{f}}$ mice after novelty exposure. $\mathrm{n}=9-11$ per genotype and condition. Two-tailed student's t-test, ns: $\mathrm{p}>0.05$. Error bars represent SEM.

Table 3.10: Bonferroni multiple comparison results for c-Jun.

\begin{tabular}{|c|c|c|c|}
\hline Condition/Genotype & Difference of means & P Value & Significance \\
\hline $\begin{array}{l}\text { home cage Tip60 } 60^{\mathrm{f} / \mathrm{f}} \text { vs } \\
\text { home cage CaMKCreER }{ }^{\mathrm{T}} \mathrm{Tip}^{\mathrm{f} / \mathrm{f}}\end{array}$ & -0.2883 & $P>0.05$ & ns \\
\hline 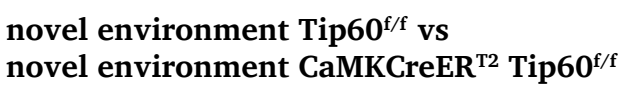 & -0.1820 & $\mathrm{P}>0.05$ & ns \\
\hline
\end{tabular}

\subsubsection{Nr4a1}

Nuclear Receptor Subfamily 4 Group A Member 1 (Nr4a1/Nur77) is a zinc-finger containing IEG (Davis et al., 1993). Expression levels of Nr4a1 were significantly upregulated in CaMKCreER ${ }^{\mathrm{T} 2} \mathrm{Tip}^{\mathrm{f} / \mathrm{f}}$ mice compared to Tip60 ${ }^{\mathrm{f} / \mathrm{f}}$ controls under both home cage and novel environment conditions (Figure 3.23 left; Table 3.11). Accordingly, genotype 
had a highly significant effect $\left(\mathrm{F}_{(1,35)}=93.89, \mathrm{p}<0.0001\right)$. Also condition had a strong effect on Nr4a1 expression $\left(\mathrm{F}_{(1,35)}=30.26, \mathrm{p}<0.0001\right)$, indicating efficient induction upon the novelty stimulus. The interaction between genotype and condition was not significant $\left(\mathrm{F}_{(1,35)}=0.005, \mathrm{p}=0.9433\right)$, indicating equal gene induction for Nr4a1. In line with this result, also the comparison of fold induction between genotypes using student's $t$-test showed no significant difference $(\mathrm{p}=0.9121)$ (Figure 3.23 right).

\section{$\operatorname{Nr4a1}$}
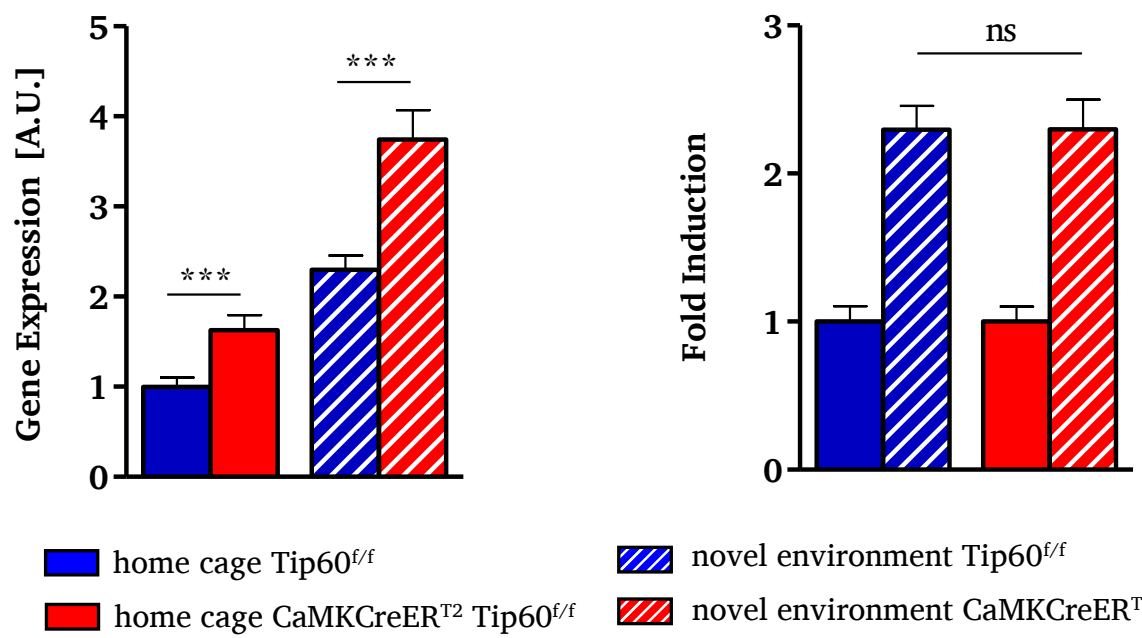

Figure 3.23: $\mathrm{Nr4a1}$ is significantly upregulated in CaMKCreER ${ }^{\mathrm{T} 2} \mathrm{Tip}^{\mathrm{f}} \mathrm{f} / \mathrm{f}$ animals under home cage conditions. Left: Expression levels of Nr4a1 under home cage and novel environment conditions in the hippocampus of Tip60 ${ }^{\mathrm{f} / \mathrm{f}}$ control and CaMKCreER ${ }^{\mathrm{T} 2} \mathrm{Tip}^{\mathrm{f} / \mathrm{f}}$ mice. Two-way ANOVA, Bonferroni multiple comparisons (also see table below), ${ }^{* * *}$ p $<0.0001$. A.U. = arbitrary units. Right: Fold induction of $N r 4 a 1$ mRNA in CaMKCreER ${ }^{\mathrm{T} 2} \mathrm{Tip}^{\mathrm{f} / \mathrm{f}}$ and Tip60 ${ }^{\mathrm{f} / \mathrm{f}}$ mice after a novelty exposure. $\mathrm{n}=9-11$ per genotype and condition. Two-tailed student's $t$-test, ns: $\mathrm{p}>0.05$. Error bars represent SEM.

Table 3.11: Bonferroni multiple comparison results for $\mathrm{Nr4a1}$ expression.

\begin{tabular}{l|c|c|c}
\multicolumn{1}{c|}{ Condition/Genotype } & Difference of means & P Value & Significance \\
\hline $\begin{array}{l}\text { home cage Tip60 } \\
\text { home cage CaMKCreER }\end{array}$ & -1.233 & $\mathrm{P}<0.0001$ & $* * *$ \\
\hline $\begin{array}{l}\text { novel environment Tip60 } \\
\text { novel environment CaMKCreER }\end{array}$ & -1.215 & $\mathrm{P}<0.0001$ & $* * *$ \\
\end{tabular}




\subsubsection{IEG Expression in the Constitutive Knockout Mouse Model}

Although CaMKCre Tip60 $0^{\mathrm{f} / \mathrm{f}}$ mice were not suitable for testing in a novel environment paradigm due to early lethality and apathy, it was possible to determine whether IEGs were upregulated at basal levels as they were in the CaMKCreER ${ }^{\mathrm{T} 2} \mathrm{Tip}^{\mathrm{f}} \mathrm{f}^{\mathrm{f}}$ mice. There- $^{-}$ fore, hippocampal expression of IEGs was analyzed in CaMKCre Tip60 $0^{\mathrm{f} / \mathrm{f}}$ mice, which were group-housed with littermate controls, at 7-8 weeks of age (Figure 3.24). Indeed, all IEGs tested were also found to be upregulated in the CaMKCre Tip60 $0^{\mathrm{f} / \mathrm{f}}$ mouse line, however, for most genes significance was not reached due to relatively high variability in expression. Interestingly, Bdnf exon $I$ and exon $I V$ showed even higher upregulation than in the inducible line (compare Figure 3.18 and Figure 3.19). Bdnf exon I was significantly upregulated by 14.9 fold $(\mathrm{p}<0.0001)$ while Bdnf exon IV was significantly upregulated by 3.3 fold $(\mathrm{p}<0.0001)$.
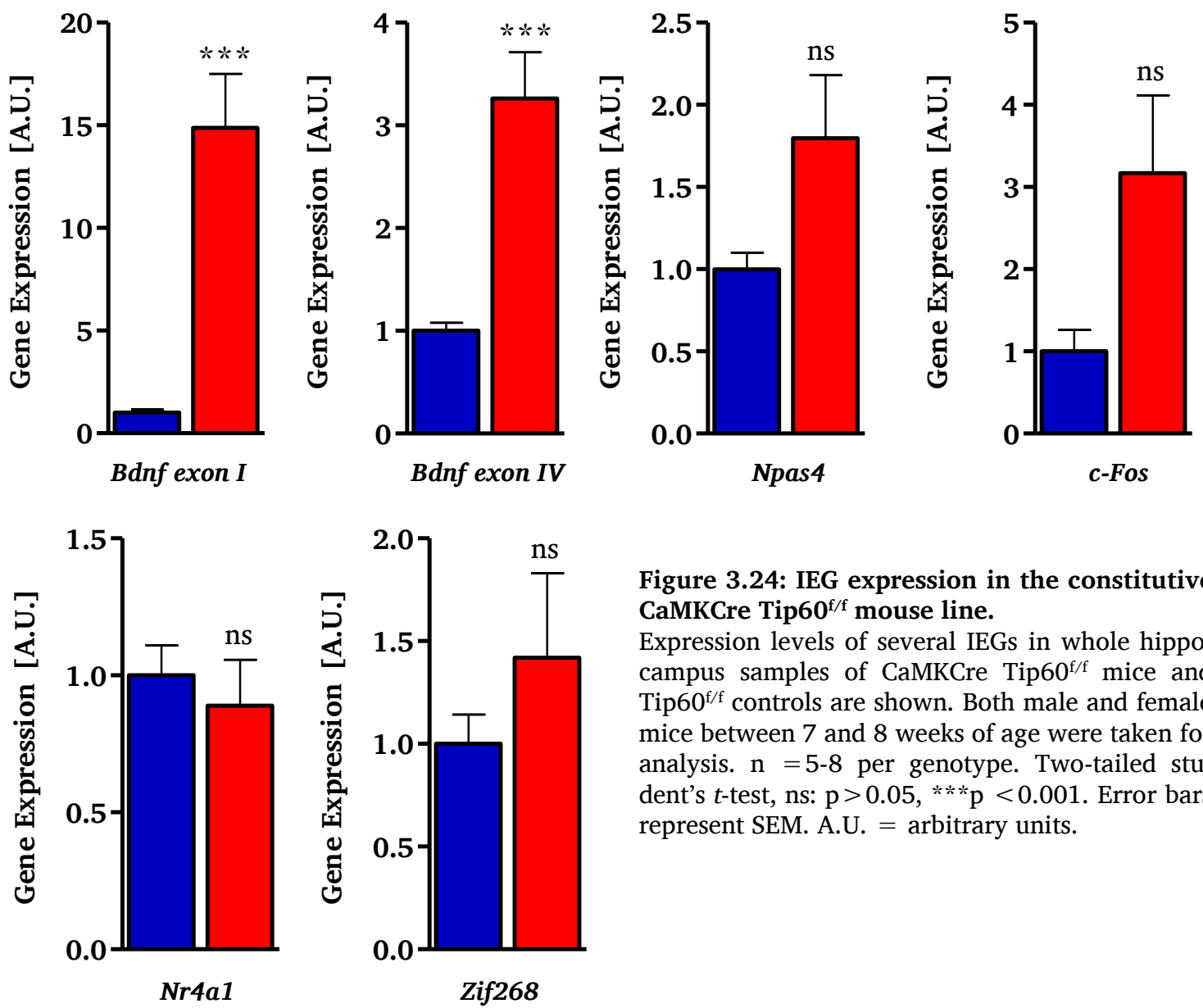

Figure 3.24: IEG expression in the constitutive CaMKCre Tip60 ${ }^{\mathrm{f} / \mathrm{f}}$ mouse line.

Expression levels of several IEGs in whole hippocampus samples of CaMKCre Tip60 ${ }^{\mathrm{f} / \mathrm{f}}$ mice and Tip $60^{\mathrm{f} / \mathrm{f}}$ controls are shown. Both male and female mice between 7 and 8 weeks of age were taken for analysis. $\mathrm{n}=5-8$ per genotype. Two-tailed student's $t$-test, ns: $\mathrm{p}>0.05,{ }^{* * * \mathrm{p}}<0.001$. Error bars represent SEM. A.U. = arbitrary units. 
Npas4 levels were upregulated by 1.7 fold $(\mathrm{p}=0.1324)$ while $c$-Fos levels were increased by 3.2 fold $(\mathrm{p}=0.0763)$ but neither of them reached significance due to large standard deviations. Nr4a1 expression levels were not upregulated in CaMKCre Tip60 $/ \mathrm{f} / \mathrm{mice}$ but instead showed a slight reduction $(\mathrm{p}=0.3935)$.

Summing up the data presented in this section, all IEGs analyzed were to some extent upregulated in TIP60-deficient mice. This was also confirmed by the analysis of hippocampal samples from the constitutive mouse line albeit high variation in expression levels. Of note, expression of Bdnf exons $I$ and $I V$ was more strongly upregulated in the constitutive than in the inducible mouse line. In addition to the increase at basal levels in the CaMKCreER ${ }^{\mathrm{T} 2} \mathrm{Tip}^{\mathrm{f} / \mathrm{f}}$ mice, there was a further upregulation of IEG expression when these mice were placed into a novel environment. However, the relative increase of IEG expression from home cage to novel environment was generally not different between controls and TIP60-deficient mice. Viewed from this perspective of transcriptional regulation, the absence of TIP60 derepressed IEGs - without exception under both conditions. Formally, TIP60 is a repressor of IEG expression.

\subsubsection{Immediate-Early Gene Analysis by ISH and IHC}

In order to characterize the upregulation of IEGs in the hippocampus of CaMKCreER ${ }^{\mathrm{T2}}$ Tip $60^{\mathrm{f} / \mathrm{f}}$ mice at cellular levels, ISH and IHC were performed on brain sections of animals from either home cage or novel environment conditions. Most changes were highly specific and localized to the pyramidal neurons of the CA1 region.

\subsubsection{1 c-FOS}

The mRNA levels of $c$-Fos were significantly upregulated in the hippocampus of CaMK$\mathrm{CreER}^{\mathrm{T} 2} \mathrm{Tip}^{\mathrm{f} / \mathrm{f}}$ mice and highly elevated in the hippocampus of CaMKCre Tip60 ${ }^{\mathrm{f} / \mathrm{f}}$ mice (Figure 3.15, Figure 3.24). Therefore, c-FOS protein levels and the distribution of c-FOSpositive cells were analyzed in sections of home cage and novel environment controls of either genotype. The IHC results agreed with the qPCR analyses, showing strong upregulation of c-FOS immunoreactivity in the TIP60-deficient hippocampus (Figure 3.25A). Interestingly, c-FOS immunoreactivity showed a high specificity for the CA1 region in CaMKCreER ${ }^{\mathrm{T} 2} \mathrm{Tip}^{\mathrm{f} / \mathrm{f}}$ animals (Figure 3.25A). Therefore, the number of c-FOS positive cells in the CA1 region was quantified in CaMKCreER ${ }^{\mathrm{T} 2} \mathrm{Tip}^{\mathrm{f} / \mathrm{f}}$ and Tip60 ${ }^{\mathrm{f} / \mathrm{f}}$ mice of both home cage and novel environment condition. In accordance with the qPCR results the number of c-FOS positive cells was significantly increased in CaMKCreER ${ }^{\mathrm{T2}}$ 
A

$\mathrm{TIP}^{\mathrm{f} / \mathrm{f}}$

CaMKCreER $^{\mathrm{T} 2} \mathrm{TIP}^{\mathrm{f} / \mathrm{f}}$
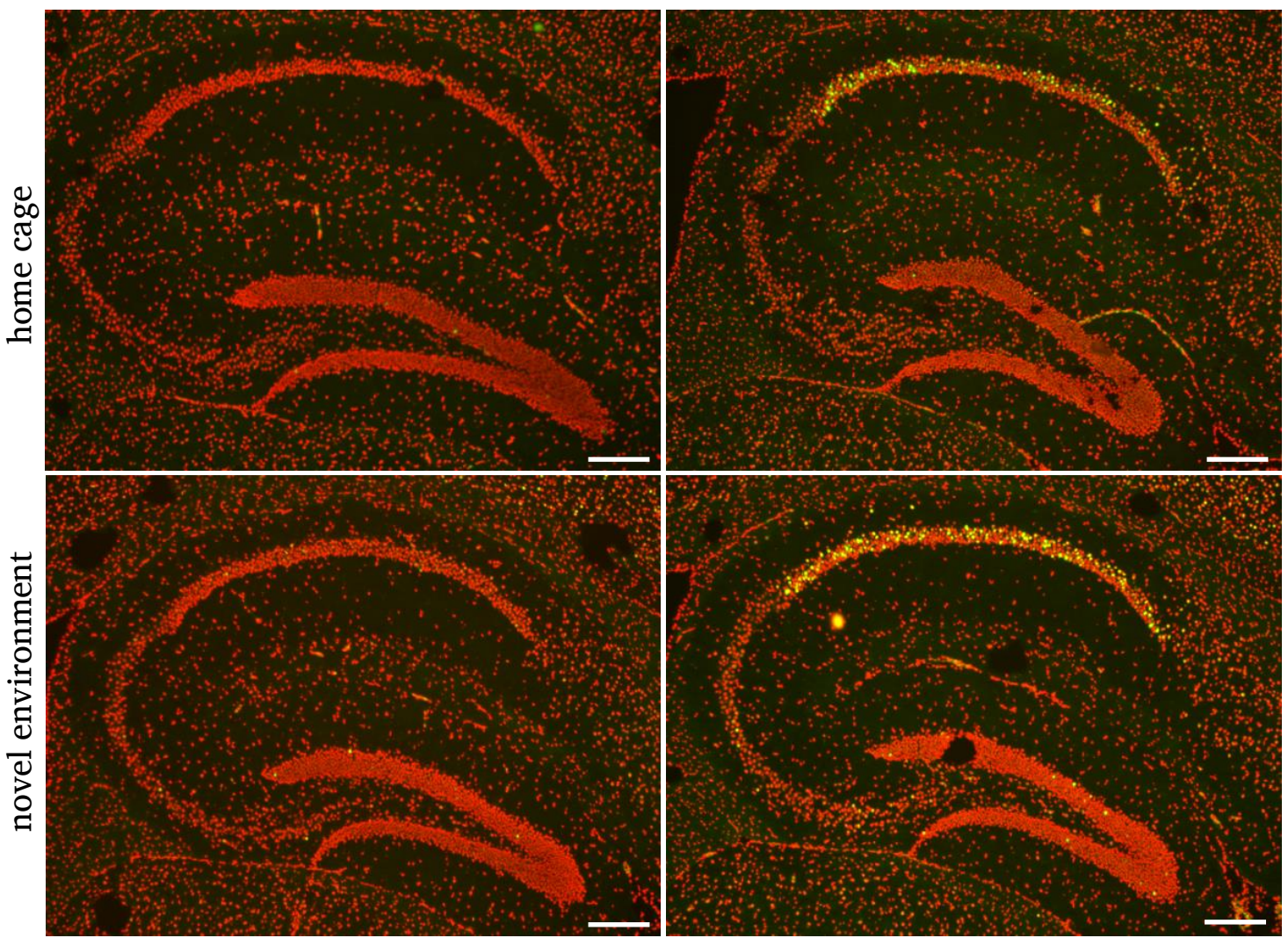

B

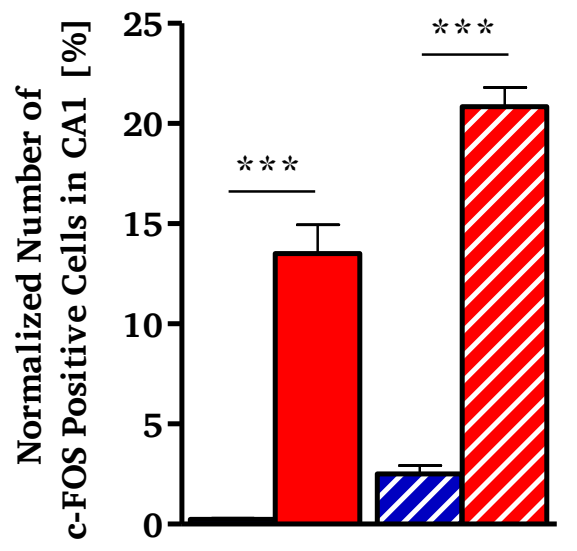

Figure 3.25: The number of c-FOS positive cells is significantly upregulated in the CA1 region of CaMKCreER $^{\mathrm{T} 2} \mathrm{Tip60}^{\mathrm{f} / \mathrm{f}}$ mice. (A) Hippocampus sections of CAMKCreER ${ }^{\mathrm{T} 2} \mathrm{Tip}^{\mathrm{f} / \mathrm{f}}$ and Tip60 ${ }^{\mathrm{f} / \mathrm{f}}$ mice both under home cage and novel environment conditions stained with antibody specific for c-FOS. Red = DAPI, green $=\mathrm{c}$-FOS, $10 \mu \mathrm{m}$ sagittal sections. Scale bars represent $250 \mu \mathrm{m}$. (B) Quantification of c-FOS positive cells in the CA1 region. $n=3-5$ per genotype and condition. The number of c-FOS positive cells was normalized to the number of DAPI positive cells. Two-way ANOVA, Bonferroni multiple comparisons, $* * * \mathrm{p}<0.0001$. Error bars represent SEM.

UII novel environment Tip60 $\mathrm{f} / \mathrm{f}$

WII novel environment CaMKCreER ${ }^{\mathrm{T} 2} \mathrm{Tip}^{\mathrm{f} / \mathrm{f}}$

$\operatorname{Tip}^{\mathrm{f} / \mathrm{f}}$ mice both under home cage and novel environment conditions (Figure 3.25B). Further analysis of protein levels in naïve CaMKCreER ${ }^{\mathrm{T} 2} \mathrm{Tip}^{\mathrm{f} / \mathrm{f}}$ animals showed that c- 

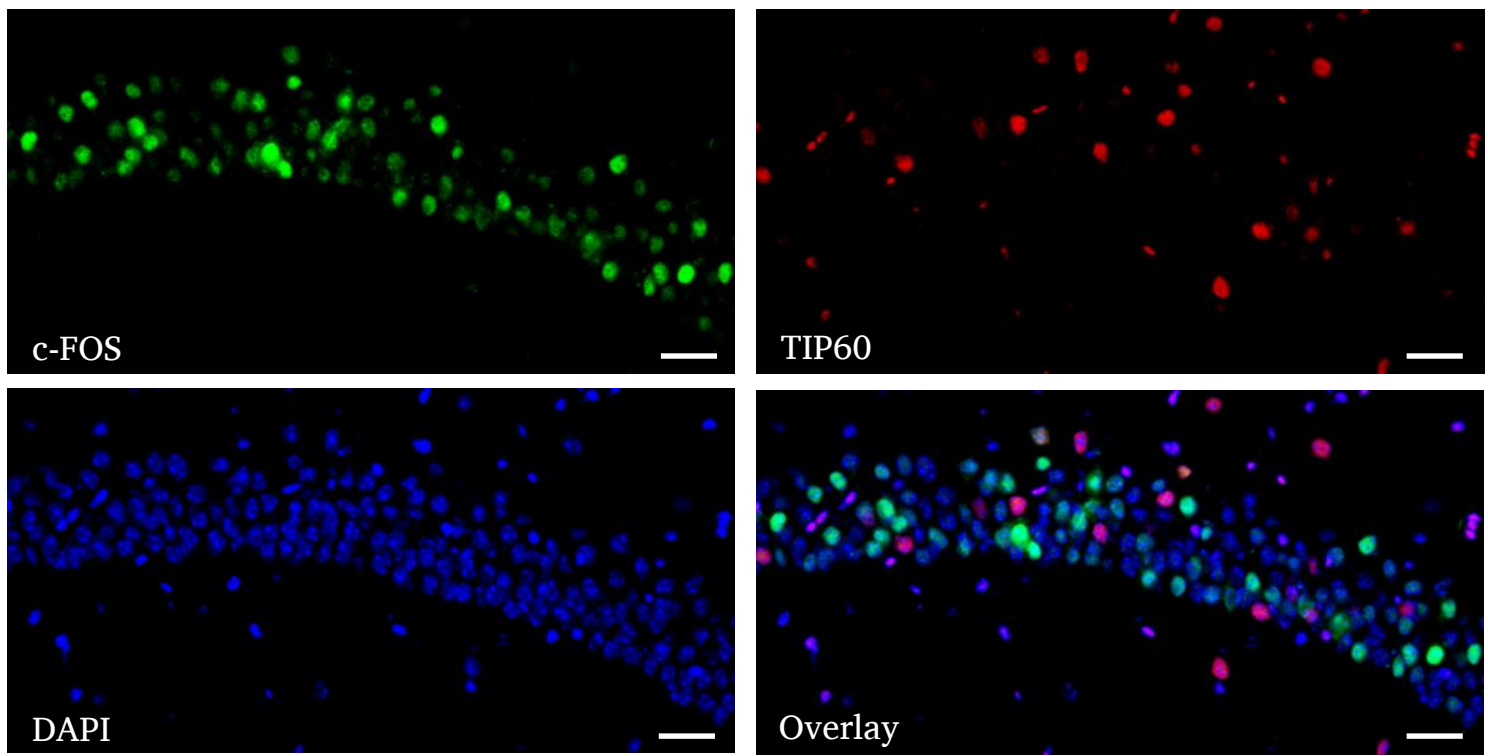

Figure 3.26: c-FOS positive cells in the CA1 region of CaMKCreER ${ }^{\mathrm{T} 2} \mathrm{Tip}^{\mathrm{f} / \mathrm{f}}$ mice are negative for TIP60. Representative images from an IHC double labeling experiment with c-FOS and TIP60P4 antibodies using cryosections of CaMKCreER ${ }^{\mathrm{T} 2} \mathrm{Tip}^{\mathrm{f} / \mathrm{f}}$ animals. c-FOS positive cells in the CA1 region are TIP60-deficient as shown by lack of overlay with TIP60 immunoreactivity. $10 \mu \mathrm{m}$ sagittal sections were used, $\mathrm{n}=4,4$ sections per animal. Scale bars represent $50 \mu \mathrm{m}$.

FOS was instantly upregulated in the CA1 region ( 3 days after the last tamoxifen injection was the earliest time point checked) and remained upregulated 3-4 months after CRE induction (data not shown).

Since the CaMKCreER ${ }^{\mathrm{T} 2}$ driver is not $100 \%$ effective in the dorsal CA1 region (Figure 3.6B) some of the c-FOS positive cells in the CaMKCreER ${ }^{\mathrm{T} 2} \mathrm{Tip}^{\mathrm{f} / \mathrm{f}}$ mice could potentially be wild type cells and the upregulation of c-FOS would then be a non-cell autonomous response to the TIP60 mutant cells in the neighborhood. Therefore, a double labeling experiment with TIP60P4 antibody was conducted. The results showed that those cells with upregulated c-FOS levels were also TIP60-deficient cells (Figure 3.26). By contrast, cells expressing TIP60 did not show upregulation of c-FOS. This strongly indicates a cell-autonomous effect of TIP60-deficiency on the pyramidal neurons of the CA1 region.

\subsubsection{Npas4}

In addition to c-Fos, also Npas4 was significantly upregulated in CaMKCreER ${ }^{\mathrm{T} 2} \mathrm{Tip}^{\mathrm{f} / \mathrm{f}}$ mice compared to Tip60 $60^{\mathrm{f} / \mathrm{f}}$ animals both under home cage and novel environment conditions (Figure 3.17). Therefore, the localization of Npas4 expression as well as protein distribution were further analyzed by ISH and IHC respectively. Confirming the qPCR 


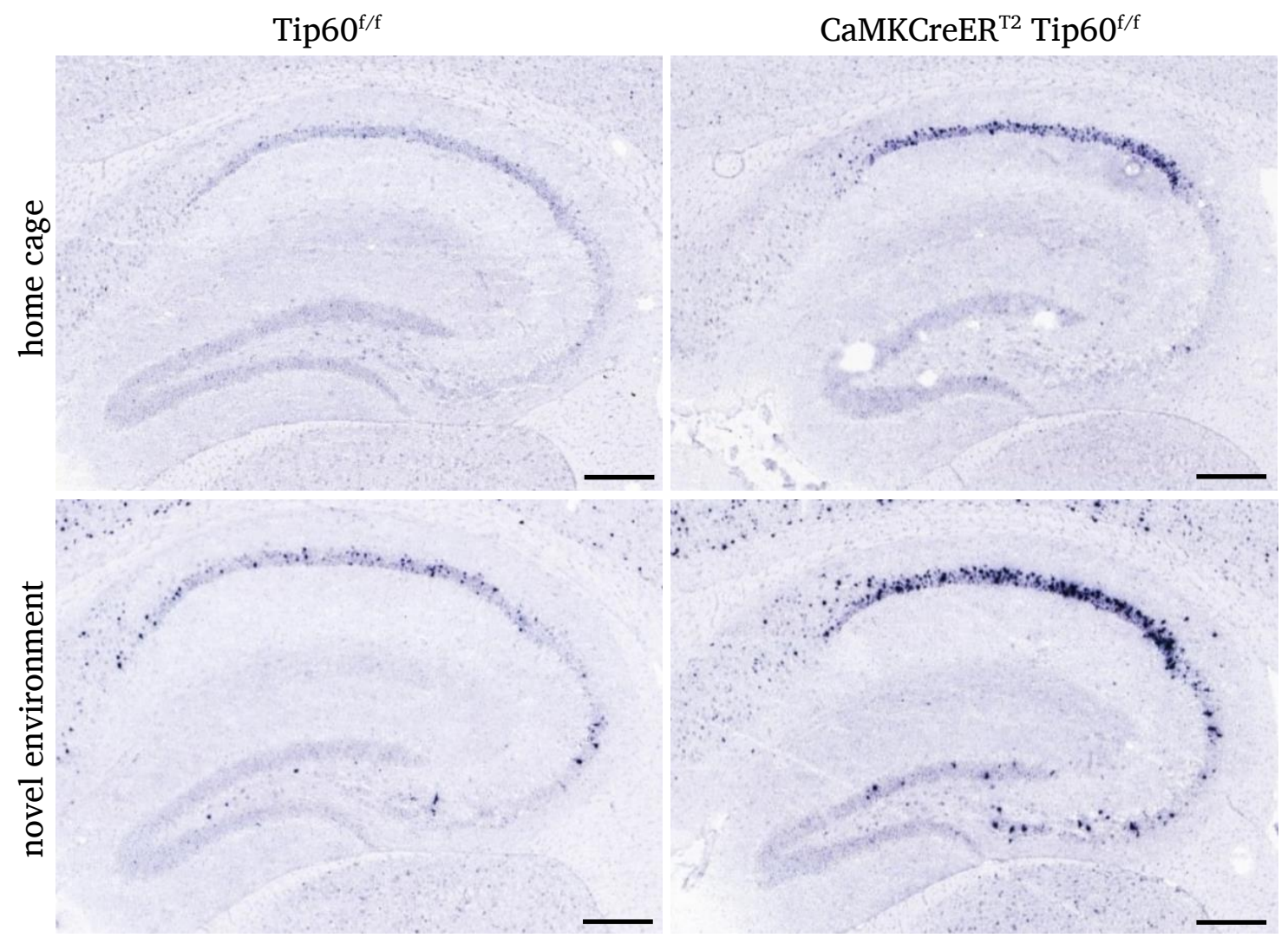

Figure 3.27: Npas4 mRNA is upregulated in the CA1 region of CaMKCreER ${ }^{\mathrm{T} 2} \mathrm{Tip}^{\mathrm{f}} \mathbf{\mathrm { f } / \mathrm { f }}$ mice. In situ staining of brain sections from in CaMKCreER ${ }^{\mathrm{T} 2} \mathrm{Tip}^{\mathrm{f} / \mathrm{f}}$ mice and Tip60 ${ }^{\mathrm{f} / \mathrm{f}}$ controls both under home cage and novel environment conditions with probe specific for Npas4. ISH was performed on $10 \mu \mathrm{m}$ sagittal sections ( $n=3-5$ per genotype and condition, 4 sections per animal). Scale bars represent $250 \mu \mathrm{m}$.

results, Npas4 expression was strongly upregulated in the hippocampus of CaMKCreER ${ }^{\mathrm{T} 2}$ Tip $60^{\mathrm{f} / \mathrm{f}}$ mice compared to controls both under home cage and novel environment condition (Figure 3.27). Moreover, as was the case for c-FOS, the upregulation of Npas4 was highly localized to the CA1 region of the TIP60-deficient hippocampus. The upregulation of Npas4 implied that there were higher calcium levels in at least a subset of CA1 pyramidal neurons in CaMKCreER ${ }^{\mathrm{T} 2} \mathrm{Tip}^{\mathrm{f} / \mathrm{f}}$ mice since Npas4 is exclusively induced by depolarization (Ramamoorthi et al., 2011). Also the detected upregulation of Npas4 levels in Tip60 ${ }^{\mathrm{f} / \mathrm{f}}$ controls after the exposure to the novel environment by qPCR (see Figure 3.17) is evident in the ISH data. Using IHC, also NPAS4 protein levels were analyzed in hippocampal sections. The results confirmed that also NPAS4 protein is upregulated specifically in the CA1 region of the TIP60-deficient hippocampus, although the upregulation at protein levels appeared to be more restrictive (Figure 3.28). Of note, NPAS4 is normally not expressed in wild type mice under home cage conditions (Bloodgood et al., 2013). 

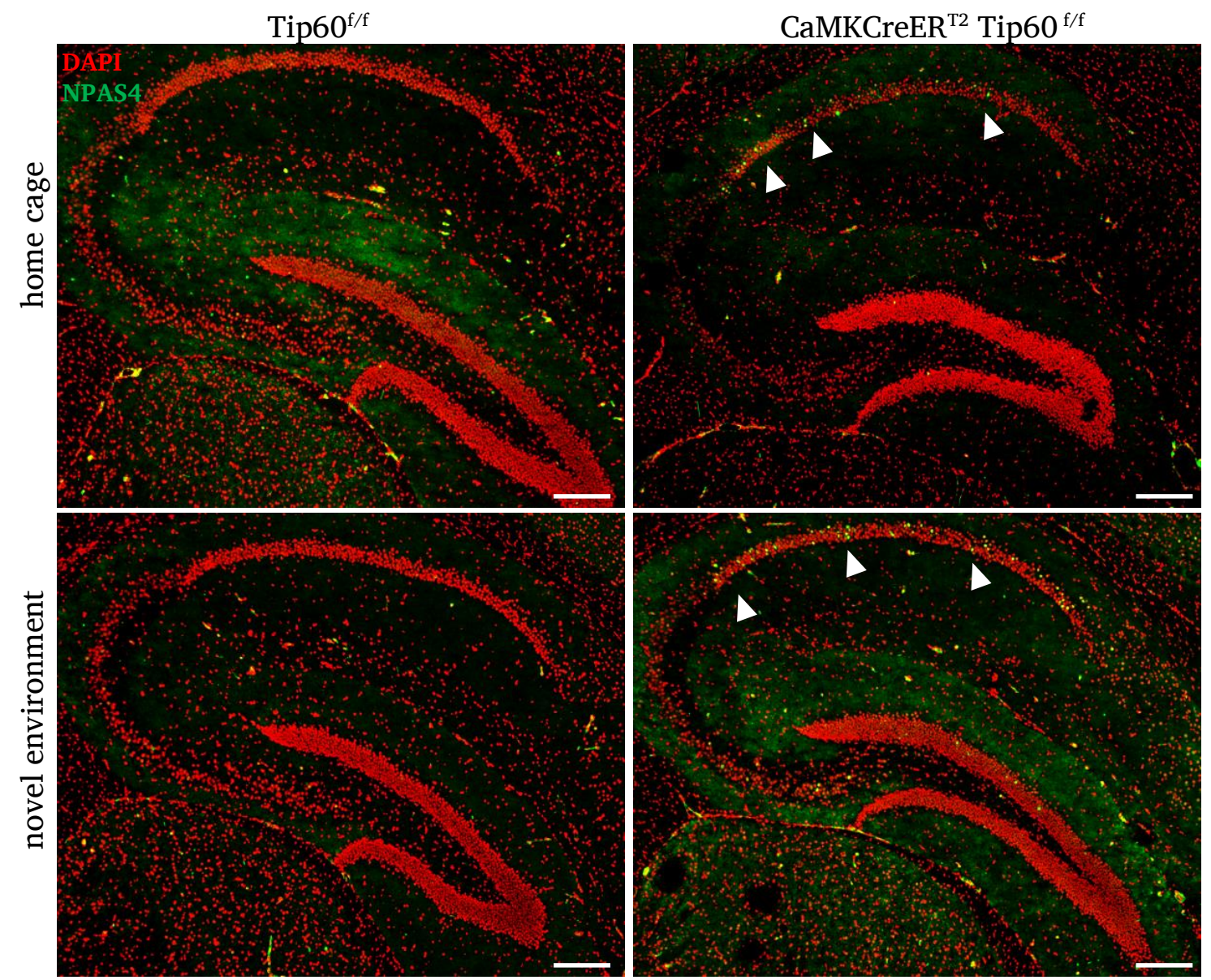

Figure 3.28: NPAS4 protein is upregulated in the CA1 region of CaMKCreER ${ }^{\mathrm{T} 2} \mathrm{Tip60}^{\mathrm{t} / \mathrm{f}}$ mice. IHC results with brain sections from CaMKCreER ${ }^{\mathrm{T} 2} \mathrm{Tip} 60^{\mathrm{f} / \mathrm{f}}$ and Tip $60^{\mathrm{f} / \mathrm{f}}$ mice both under home cage and novel environment conditions using NPAS4-specific antibody. NPAS4 signal in the hippocampus of CaMKCreER ${ }^{\mathrm{T} 2}$ $\mathrm{Tip}^{\mathrm{ff} / \mathrm{f}}$ mice is mainly localized to the CA1 region (white arrowheads). IHC was performed on $10 \mu \mathrm{m}$ sagittal sections ( $n=3-5$ per genotype and condition, 4 sections per animal). DAPI $=$ red, NPAS4 $=$ green. Scale bars represent $250 \mu \mathrm{m}$. 


\subsubsection{Bdnf}

Due to the high upregulation of Bdnf exons $I$ and $I V$ in both TIP60-deficiency mouse models (see Figure 3.18, Figure 3.19, and Figure 3.24) and the strong implication of this gene in synaptic plasticity, Bdnf expression was visualized by ISH using a probe specific for the coding exon of the Bdnf gene. As described earlier Bdnf exons I and IV are both non-coding and always spliced to exon IX, which is the coding exon. Thus, by using a probe specific to exon IX, total $B d n f$ transcript levels were visualized in this experiment. Again, previous qPCR results were confirmed since Bdnf was strongly upregulated in CaMKCreER ${ }^{\mathrm{T} 2} \mathrm{Tip}^{\mathrm{f} / \mathrm{f}}$ animals compared to Tip60 ${ }^{\mathrm{f} / \mathrm{f}}$ control mice under both home cage and novel environment conditions (Figure 3.29). Compared to other IEGs analyzed, the upregulation was not restricted to the CA1 region and strongest in the dentate gyrus. In addition, scattered cells were observed in the CA1 region.

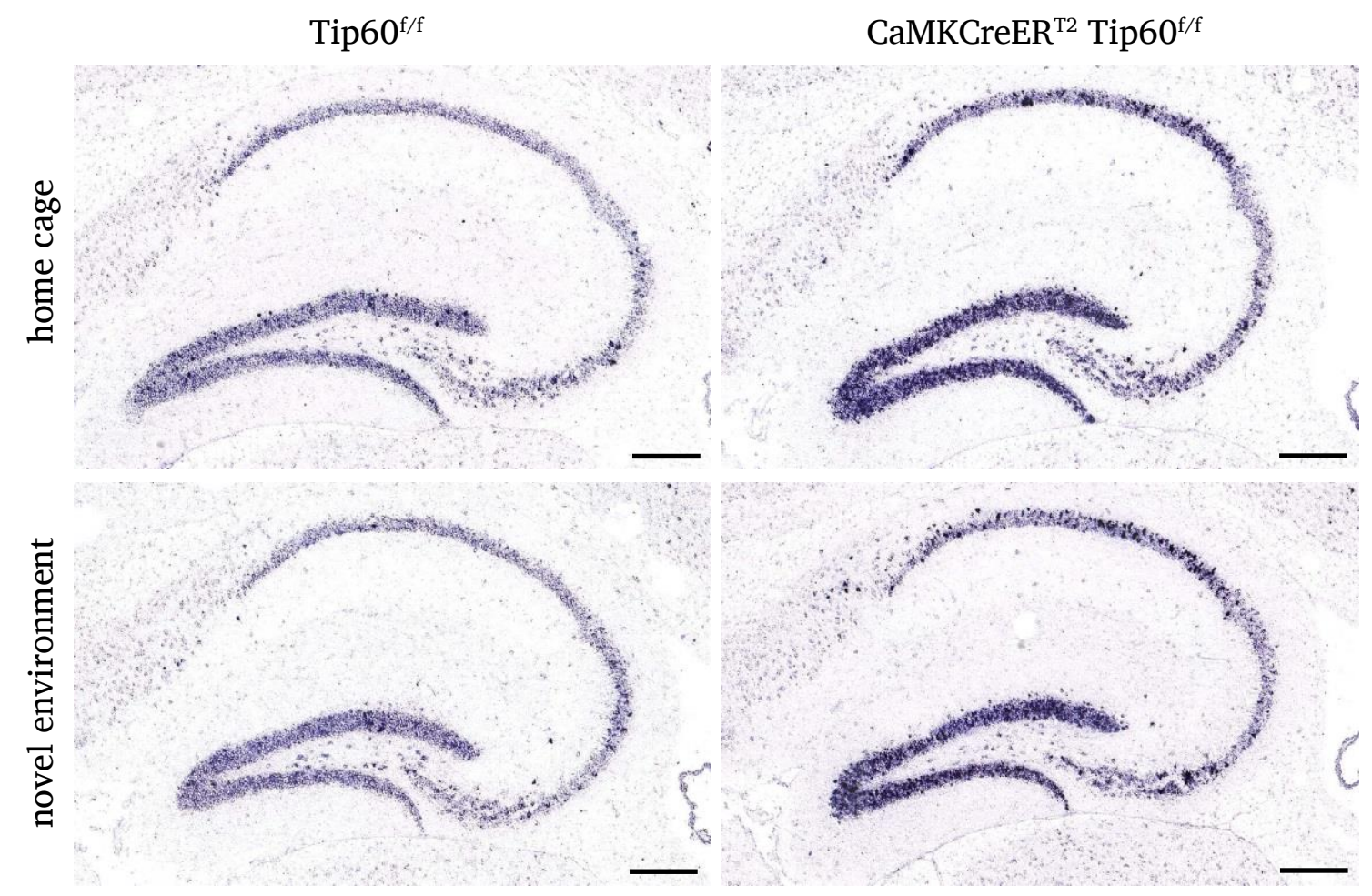

Figure 3.29: Bdnf exon IX is upregulated in CaMKCreER ${ }^{\mathrm{T} 2} \mathrm{Tip}^{\mathrm{f}} \mathrm{Co}^{\mathrm{f} / \mathrm{f}} \mathrm{mice}$. In situ staining of brain sections from CaMKCreER ${ }^{\mathrm{T} 2} \mathrm{Tip}^{\mathrm{f} / \mathrm{f}}$ and Tip60 $60^{\mathrm{f} / \mathrm{f}}$ mice under both home cage and novel environment conditions using probe specific for the coding exon of Bdnf. ISH was performed on $10 \mu \mathrm{m}$ sagittal sections $(\mathrm{n}=3-5 \mathrm{per}$ genotype and condition, 4 sections per animal). Scale bars represent $250 \mu \mathrm{m}$. 
Taken together, the ISH and IHC experiments confirmed the results of the qPCR analyses and also demonstrated that IEG upregulation is highly localized to the TIP60-deficient CA1 region for the genes analyzed. Moreover, it could also be shown that the upregulation of c-Fos and Npas4 is also present on the protein level albeit in the case of NPAS4 to a lesser degree than that seen for the corresponding transcript indicating an influence of posttranscriptional regulation.

\subsection{Analysis of General Markers in the TIP60-Deficient Hippocampus}

\subsubsection{Neuronal, Synaptic, and Dendritic Markers}

In order to investigate potential general morphological alterations in the hippocampus of CaMKCreER ${ }^{\mathrm{T} 2} \mathrm{Tip}^{\mathrm{f}} 0^{\mathrm{f} / \mathrm{f}}$ mice, IHC for neuronal as well as synaptic and dendritic marker proteins was performed (Figure 3.30). Neuronal nuclei (NeuN) immunoreactivity showed comparable neuronal populations and distribution in the hippocampus (Figure 3.30 top). Presynaptic marker Synaptophysin (SYP) and dendritic marker Microtubuleassociated protein 2 (MAP2) showed similar distributions and intensities (Figure 3.30 center and bottom). 

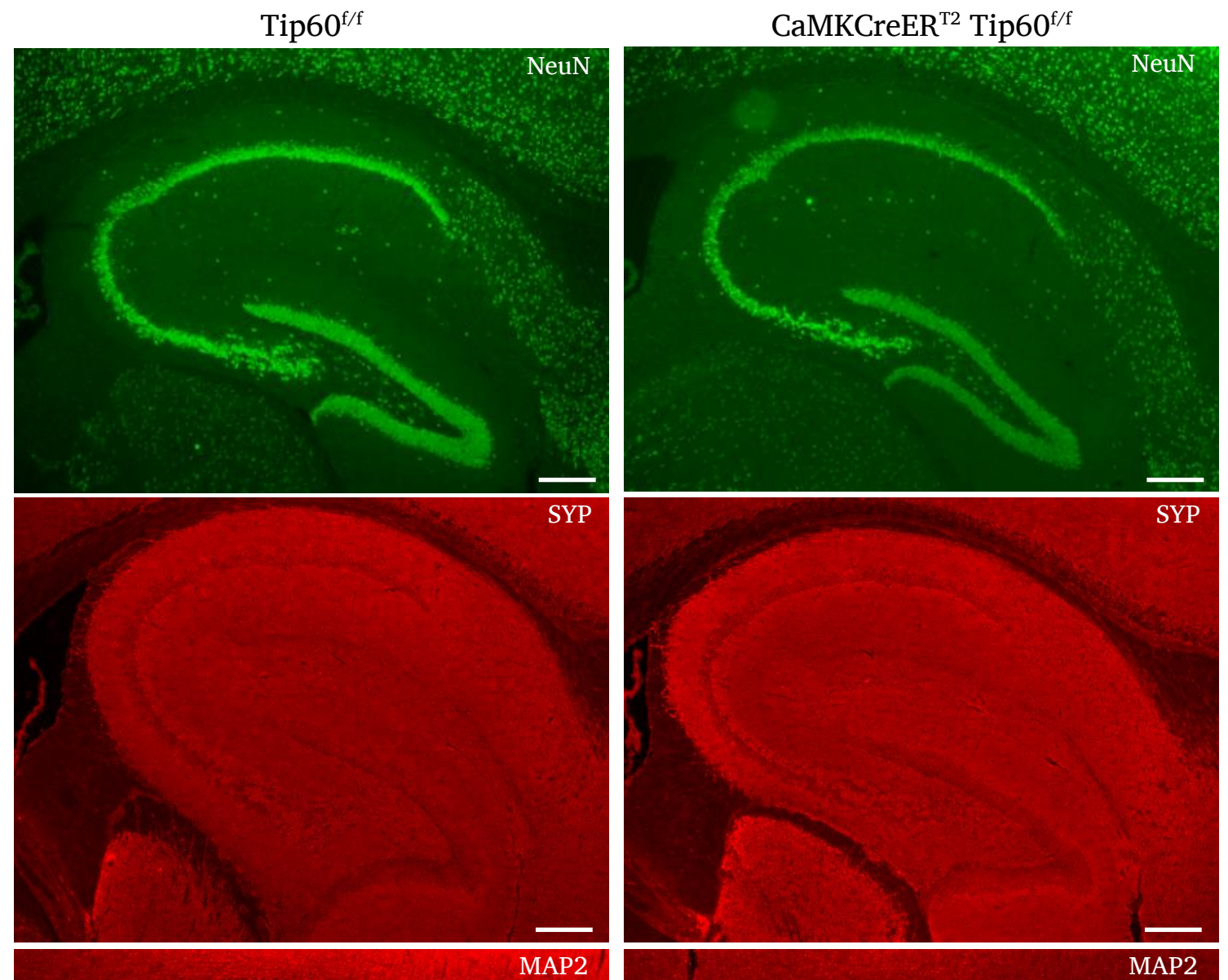

MAP2
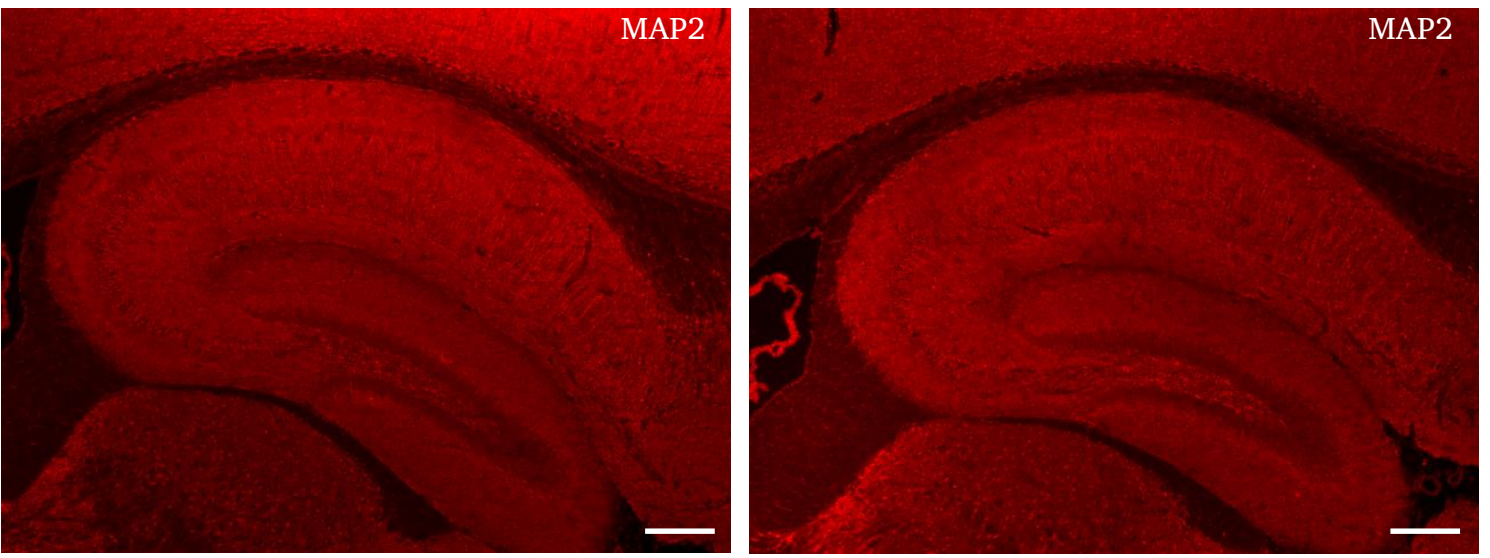

Figure 3.30: Comparison of several general markers in the hippocampus of CaMKCreER ${ }^{\mathrm{T} 2} \mathrm{Tip}^{\mathrm{f} / \mathrm{f}}$ and Tip60 ${ }^{\mathrm{f} / \mathrm{f}}$ control mice. Neuronal marker Neuronal Nuclei (NeuN), presynaptic marker Synaptophysin 1 (SYP), and dendritic marker microtubule-associated protein 2 (MAP2) gave similar signal intensity using sections of both genotypes. IHC was performed on $10 \mu \mathrm{m}$ sagittal sections. Representative images were taken ( $\mathrm{n}=4$ per genotype, 4 sections per animal). Scale bars represent $250 \mu \mathrm{m}$. 


\subsubsection{Changes in Mossy Fibers}

Synaptoporin (SPO, also known as Synaptophysin II) is a synaptic vesicle protein, which is highly enriched in the mossy fibers of the hippocampus (Fykse et al., 1993). It shares high homology with synaptophysin I, which is more uniformly expressed. Presynaptic SPO is required for the formation of so-called thorny excrescences (TEs), which are predominantly found on the dendrites of hippocampal CA3 pyramidal cells (Amaral et al., 1981). TEs serve as the postsynaptic target for the mossy-fiber terminals of the granule cells of the dentate gyrus and have recently been implied in homeostatic plasticity (Lee et al., 2013).

Since SPO is a broadly used marker for mossy fiber terminals, SPO immunoreactivity was analyzed by IHC and found to be downregulated in both TIP60-deficiency mouse lines (Figure 3.31). In CaMKCreER ${ }^{\mathrm{T} 2} \mathrm{Tip}^{\mathrm{f} / \mathrm{f}}$ mice (Figure 3.31B) decreased SPO signal intensity could be observed especially in the infrapyramidal layer and the hilar region. By contrast, signal intensity was similar in the mossy fibers near the CA3/CA2 boundary. In the constitutive mouse model (Figure 3.31D) the intensity of SPO immunoreactivity in all regions of the mossy fiber projection area appeared to be downregulated compared to Tip60 $0^{\mathrm{f} / \mathrm{f}}$ controls.

The decrease in SPO immunoreactivity found in the TIP60-deficient mice implied a decrease in synaptic contact between the granule cells of the dentate gyrus and the pyramidal neurons of the CA3 region (Grabs et al., 1994). 

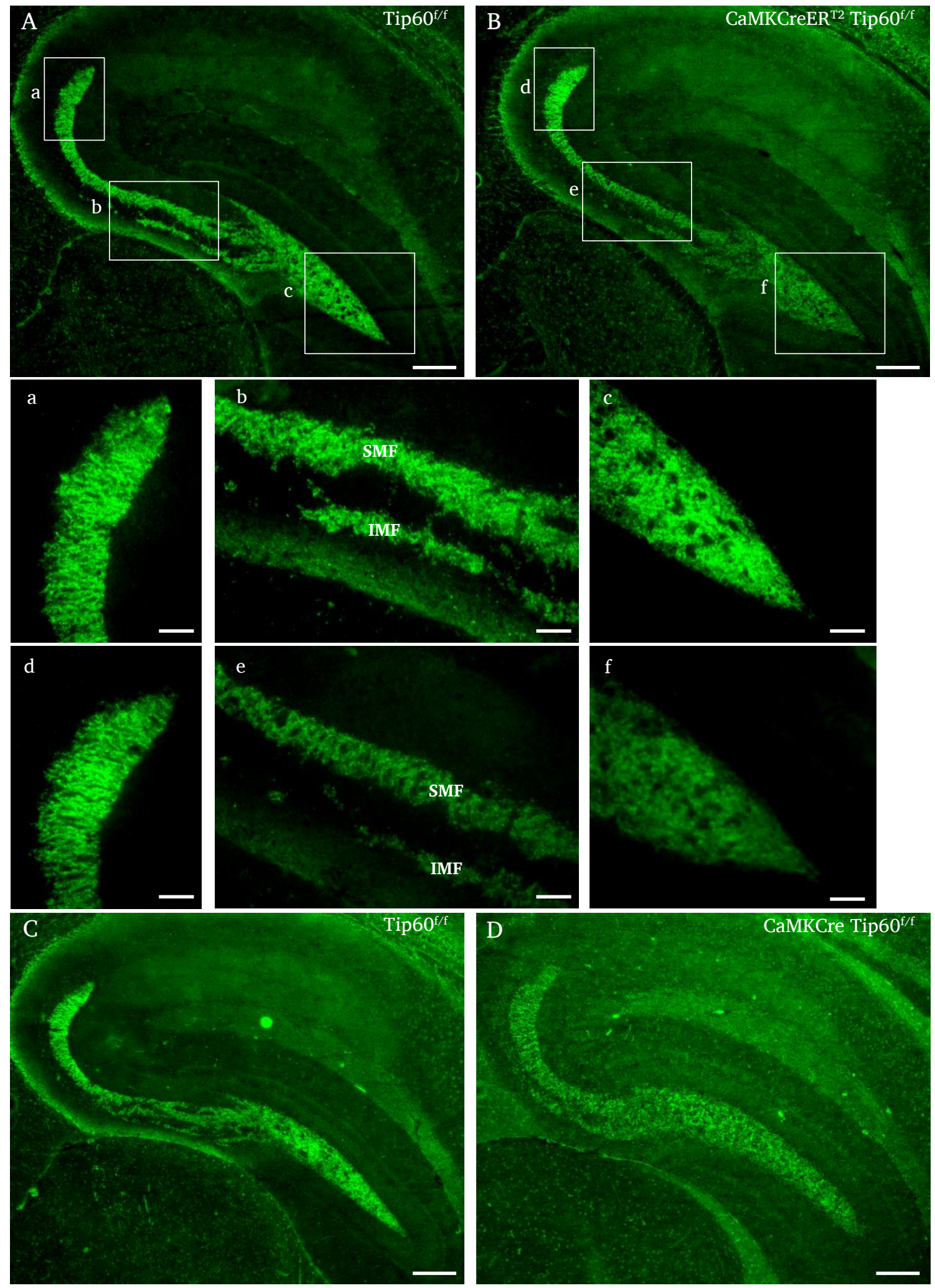

Figure 3.31: Presynaptic marker Synaptoporin (SPO) is reduced in the mossy fibers of the TIP60deficient hippocampus. Immunohistochemistry was performed on sections of both the inducible $(A, B)$ and the constitutive (C,D) line. Different regions of mossy fiber projection are shown at 20x magnification in Tip60 ${ }^{\mathrm{f} / \mathrm{f}}$ controls $(\mathrm{a}, \mathrm{b}, \mathrm{c})$ and CaMKCreER ${ }^{\mathrm{T} 2} \mathrm{Tip}^{\mathrm{f} / \mathrm{f}}$ animals (d,e,f). In the constitutive mouse model SPO signal was equally decreased in all regions of the mossy fiber projections (D, 5x). $10 \mu \mathrm{m}$ thick sagittal sections were analyzed (constitutive line: $n=3$, inducible line: $n=4$ per genotype; 4 sections per animal). Abbreviations: SMF = suprapyramidal mossy fibers; IMF = infrapyramidal mossy fibers. Scale bars represent $250 \mu \mathrm{m}$ for images taken at $5 \mathrm{x}$ and $50 \mu \mathrm{m}$ for images taken at 20x magnification (insets). 


\subsubsection{Upregulation of GFAP Immunoreactivity}

The brain consists to approximately equal amounts of neurons and glial cells. Glial cells provide support and protection for neurons and comprise of 3 different types: astrocytes, oligodendrocytes, and microglia (Parpura et al., 2012). The CaMKCre and CaMKCreER ${ }^{\mathrm{T} 2}$ drivers used in this study are not active in glial cells since CaMKII $\alpha$ is not expressed therein. Consequently, glial cells always retain both Tip60 alleles in CaMKCre Tip60 ${ }^{\mathrm{f} / \mathrm{f}}$ and CaMKCreER ${ }^{\mathrm{T} 2} \mathrm{Tip}^{\mathrm{f} / \mathrm{f}}$ mice. However, the existence of TIP60-deficient neurons could have potential effects on glial cells since neurons and glial cells are functionally connected (Araque et al., 2010; Hansson et al., 2003). That is why astrocyte marker Glial Fibrillary Acidic Protein (GFAP) was used to compare the amount and distribution of astrocytes in the hippocampus of the two TIP60-deficiency models relative to Tip60 ${ }^{\mathrm{f} / \mathrm{f}}$ control mice.

Intensity of GFAP immunoreactivity was comparable between CaMKCreER ${ }^{\mathrm{T} 2} \mathrm{Tip}^{\mathrm{f} / \mathrm{f}}$ and Tip60 ${ }^{\mathrm{f} / \mathrm{f}}$ mice (Figure 3.32 top). However, CaMKCre Tip60 ${ }^{\mathrm{f} / \mathrm{f}}$ mice showed highly upregulated GFAP signal in the stratum radiatum and stratum oriens of the CA1 region as well as the region of mossy fiber terminals situated in the stratum lucidum (Figure 3.32 bottom). Presumably, the increase in GFAP suggests a form of pathologic changes in the constitutive line, which could be one of the reasons for brain malfunction. 
$\operatorname{Tip} 60^{\mathrm{f} / \mathrm{f}}$

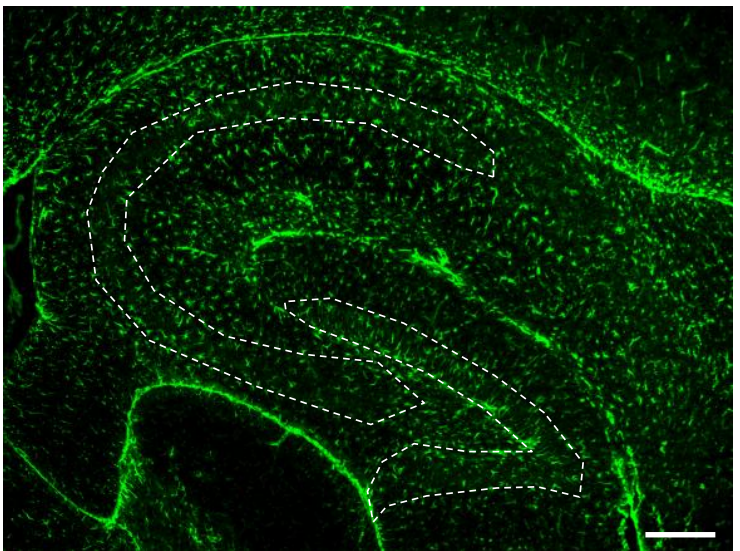

$\operatorname{Tip} 60^{\mathrm{f} / \mathrm{f}}$

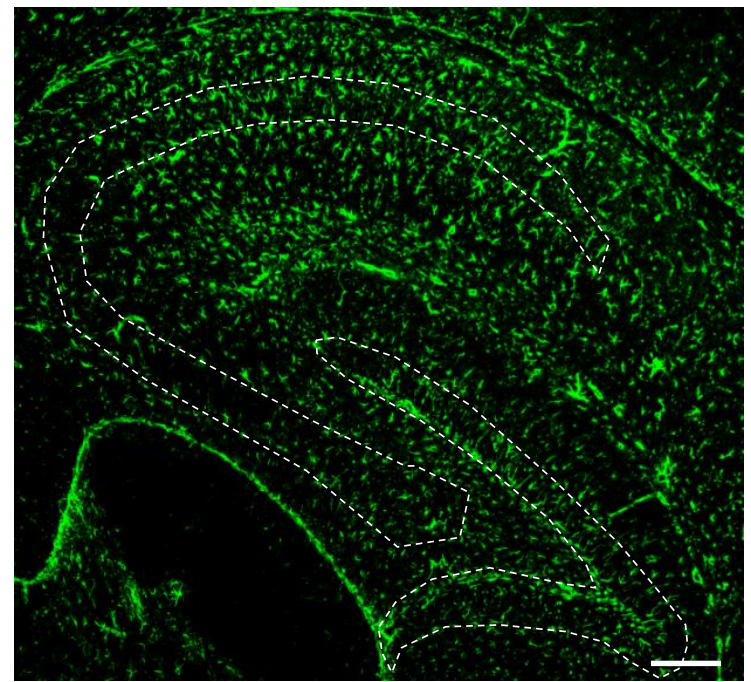

CaMKCreER ${ }^{\mathrm{T} 2} \mathrm{Tip}^{\mathrm{f} / \mathrm{f}}$

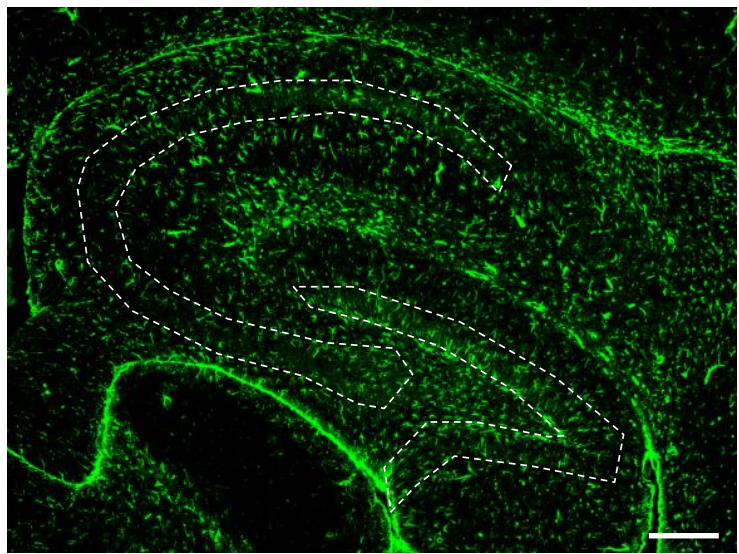

CaMKCre Tip60 $0^{\mathrm{f} / \mathrm{f}}$

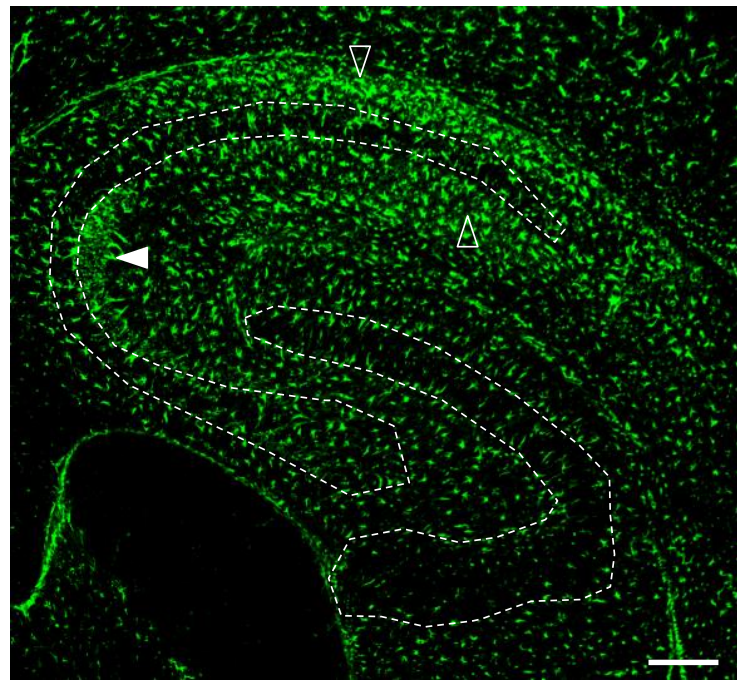

Figure 3.32: GFAP immunoreactivity is increased in the hippocampus of CaMKCre Tip60 ${ }^{\mathrm{f} / \mathrm{f}} \mathrm{mice}$. GFAP immunoreactivity in the hippocampus of CaMKCreER ${ }^{\mathrm{T} 2} \mathrm{Tip}^{\mathrm{f} / \mathrm{f}}$ and Tip60 ${ }^{\mathrm{f} / \mathrm{f}}$ mice (top) and in CaMKCre Tip60 ${ }^{\mathrm{f} / \mathrm{f}}$ and $\mathrm{Tip}^{\mathrm{f} / \mathrm{f}}$ mice (bottom). Note the increase of GFAP immunoreactivity in the stratum lucidum (filled arrowhead) and stratum radiatum as well as stratum oriens of the CA1 region (open arrowheads) in CaMKCre Tip60 $/ \mathrm{f}$ mice. $10 \mu \mathrm{m}$ sagittal sections were used. $\mathrm{n}=3-4$ per genotype, 4 sections per animal. Scale bars represent $250 \mu \mathrm{m}$. 


\subsection{Effects of TIP60-Deficiency in the Dentate Gyrus}

\subsubsection{Non-Cell Autonomous Upregulation of Phospho-CREB in the Dentate Gyrus of CaMKCreER ${ }^{\mathrm{T} 2} \mathrm{Tip}^{\mathrm{f} / \mathrm{f}}$ mice}

cAMP response element-binding protein (CREB) is a transcription factor, which is activated by phosphorylation at serine 133 in response to neuronal depolarization. Subsequently, it activates its target genes through binding to their cAMP response elements (Shaywitz et al., 1999). Since $c$-Fos is a well-known phospho-CREB (pCREB) target gene (Sheng et al., 1990) and is highly upregulated in the TIP60-deficient hippocampus, this led to the assumption that pCREB levels might by elevated in the TIP60-deficiency mouse models. Up to now, several protein kinases phosphorylating CREB at S133 have been identified, including protein kinase A (PKA). Gavaravarapu et al. (2000) reported that TIP60 inhibits CREB activation by PKA. This would suggest that TIP60-deficiency leads to increased CREB activation and could provide a possible explanation for the increased levels of IEGs observed in the hippocampus of CaMKCreER ${ }^{\mathrm{T} 2} \mathrm{Tip}^{6} 0^{\mathrm{f} / \mathrm{f}}$ mice. CREB phosphorylation was therefore analyzed in hippocampal sections of CaMKCreER ${ }^{\mathrm{T} 2}$ $\mathrm{Tip}^{\mathrm{f} / \mathrm{f}}$ and Tip60 $0^{\mathrm{f} / \mathrm{f}}$ control animals. Due to the strong upregulation of $c$-Fos in the CA1 region in CaMKCreER ${ }^{\mathrm{T} 2} \mathrm{Tip}^{\mathrm{f} / \mathrm{f}}$ mice, localization of pCREB was expected to be similar. However, no upregulation of pCREB was found in the CA1 region of CaMKCreER ${ }^{\mathrm{T} 2}$ Tip60 ${ }^{\mathrm{f} / \mathrm{f}}$ animals (data not shown). Instead, a striking increase in the number of positive cells was observed in the dentate gyrus (Figure 3.33A). Therefore, the number of pCREBpositive cells was quantified in the dentate gyrus of CaMKCreER ${ }^{\mathrm{T} 2} \mathrm{Tip}^{\mathrm{f}} \mathrm{f} / \mathrm{f}$ and $\mathrm{Tip} 60^{\mathrm{f} / \mathrm{f}}$ animals. While the volume of the GCL was similar between genotypes, the number of pCREB-positive cells was significantly upregulated in the TIP60-deficient animals (Figure 3.33B). pCREB is normally localized to the subgranular zone (SGZ) of the dentate gyrus, which is a site of adult neurogenesis in the brain as described in Section 1.1.2. New cells are born and among them are neurons that increase the cell number in the granular cell layer of the dentate gyrus during the animal's lifetime. As noted before, the activity of the CRE driver used in this thesis project is restricted to excitatory neurons and is completely absent in cells of the SGZ. Thus, the stem cells of the SGZ remain wild type for TIP60 and changes in pCREB expression must be an indirect response to the TIP60-deficiency within the granular cell layer of the dentate gyrus. IHC double labeling experiments with pCREB-specific antibody and TIP60P4 confirmed that pCREB positive 
cells are indeed wild type for TIP60 (Figure 3.33C). Hence the observed increase in CREB phosphorylation is very likely a non-cell autonomous effect of TIP60-deficiency.

A

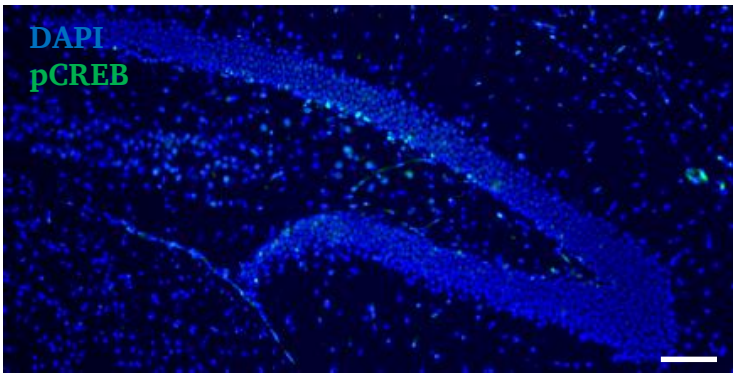

CaMKCreER $^{\mathrm{T} 2} \mathrm{Tip}^{\mathrm{f} / \mathrm{f}}$
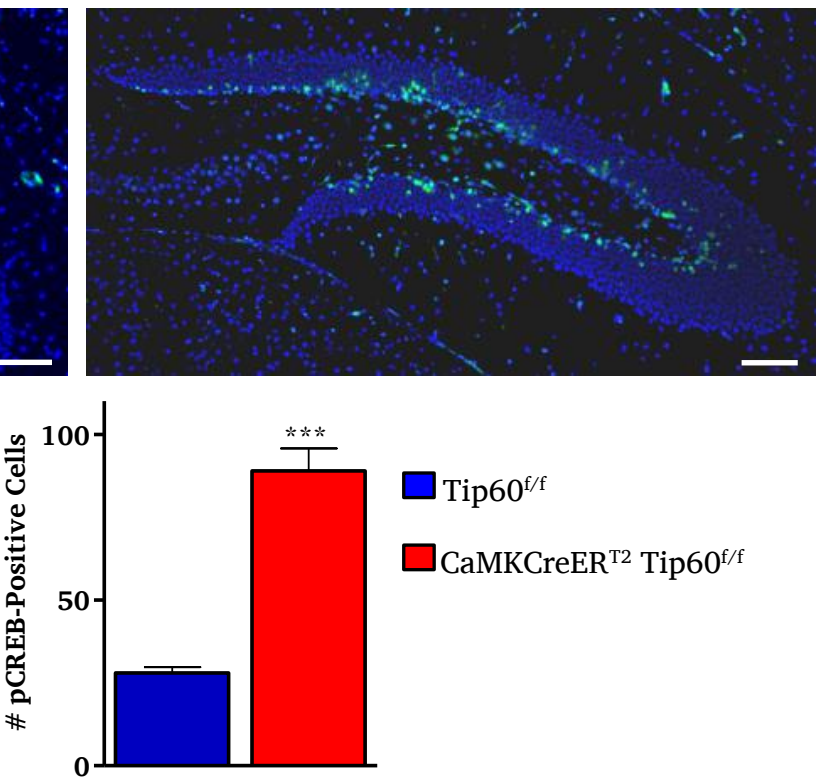

$\square$ Tip60 $0^{\mathrm{f} / \mathrm{f}}$

$\square$ CaMKCreER $^{\text {T2 }}$ Tip60 $^{\mathrm{f} / \mathrm{f}}$

C
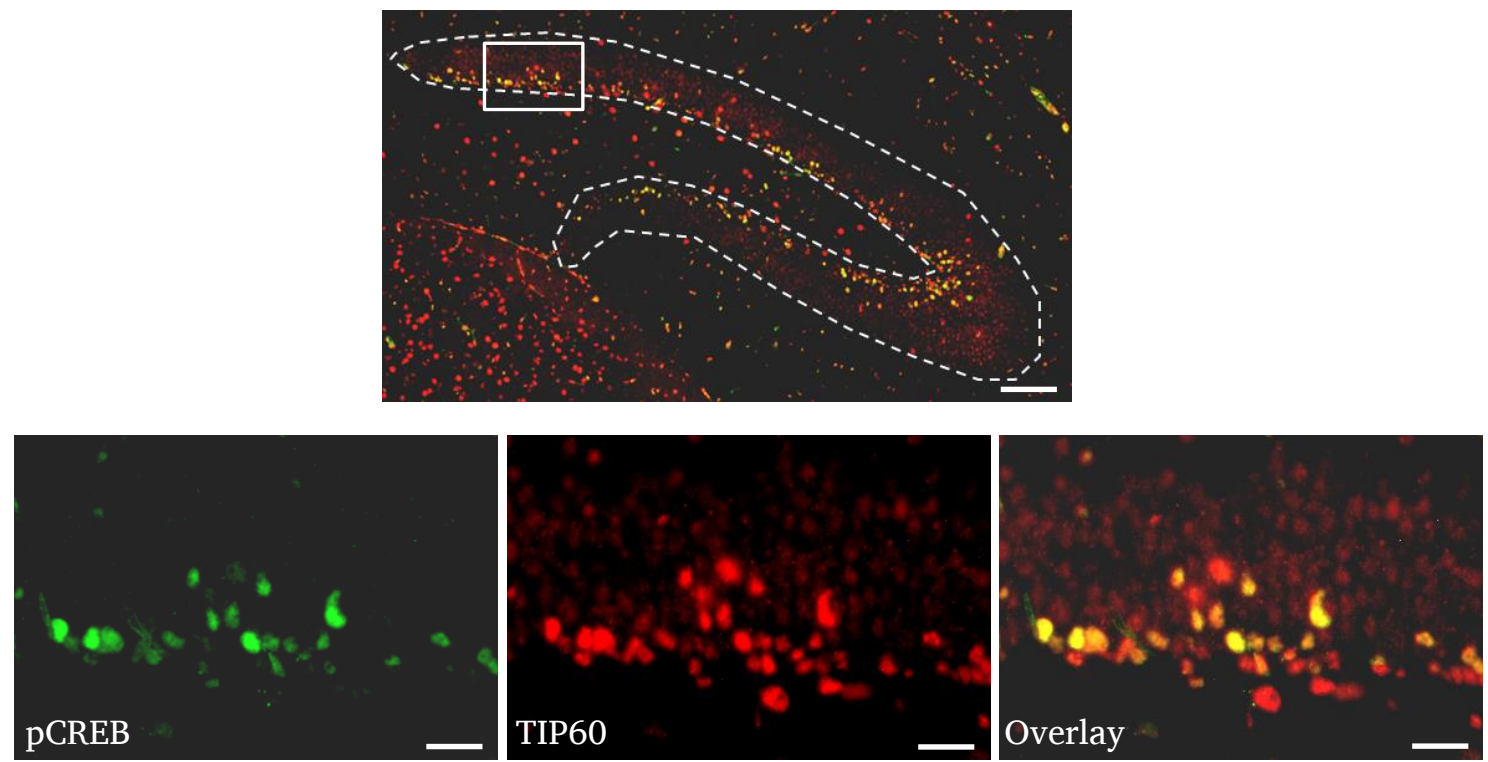

Figure 3.33: The number of pCREB positive cells is increased in the dentate gyrus of CaMKCreER

Tip60 $/ \mathrm{f}$ mice. (A) Representative images of IHC performed with pCREB specific antibody on sections of CaMKCreER $^{\mathrm{T} 2} \mathrm{Tip}^{\mathrm{f} / \mathrm{f}}$ and Tip60 $0^{\mathrm{f} / \mathrm{f}}$ control mice. (B) Left: the volumes of the granular cell layer of Tip60 $0^{\mathrm{f} / \mathrm{f}}$ control and CaMKCreER ${ }^{\mathrm{T} 2} \mathrm{Tip}^{\mathrm{f} / \mathrm{f}}$ mice are similar. Two-tailed student's $t$-test, ns: $\mathrm{p}>0.05$. Right: Quantification of pCREB-positive cells in the dentate gyrus. $n=4$ per genotype, 4 sections per animal. Two-tailed student's $t$-test $* * * \mathrm{p}<0.0001$. Error bars represent SEM. (C) Double labeling with TIP60P4 antibody and antibody against pCREB. Inserts show higher magnification of the indicated area. The overlay of pCREB (green) and TIP60 signal (red) in a subset of TIP60-positive cells is apparent from the yellow signal. IHC was performed on $10 \mu \mathrm{m}$ sagittal sections. Scale bars represent $100 \mu \mathrm{m}$ for overview images and $50 \mu \mathrm{m}$ for inserts. 


\subsubsection{Upregulation of ARC and C-FOS Positive Cells in the TIP60-Deficient Dentate Gyrus}

While the most striking changes in hippocampal IEG expression in TIP60-deficient mice were localized to the CA1 region (Figure 3.25 and Figure 3.28), an increase in the number of c-FOS and ARC-positive cells was discovered in the TIP60-deficient dentate gyrus of CaMKCreER ${ }^{\mathrm{T} 2} \mathrm{Tip}^{\mathrm{f} / \mathrm{f}}$ mice (Figure 3.34A). These cells appeared to be scattered all over the granular cell layer (GCL). Quantification of cells labeled for ARC or c-FOS as well as the subset of cells labeled for both proteins were quantified in the dentate gyrus of both CaMKCreER ${ }^{\mathrm{T2}} \mathrm{Tip}^{\mathrm{f} / \mathrm{f}}$ and Tip60 $60^{\mathrm{f} / \mathrm{f}}$ animals and showed a significant upregulation in the TIP60-deficient animals (Figure 3.34B). IHC double labeling of ARC and TIP60 showed that ARC-positive cells are TIP60-negative (Figure 3.35). The upregulation of C-FOS and ARC-positive cells indicated altered activity levels in a subset of granule cells in the TIP60-deficient dentate gyrus. It remains to be seen, whether these represent a consistent group of cells or whether activity levels are generally more unsteady in the TIP60-deficient GCL. 
A
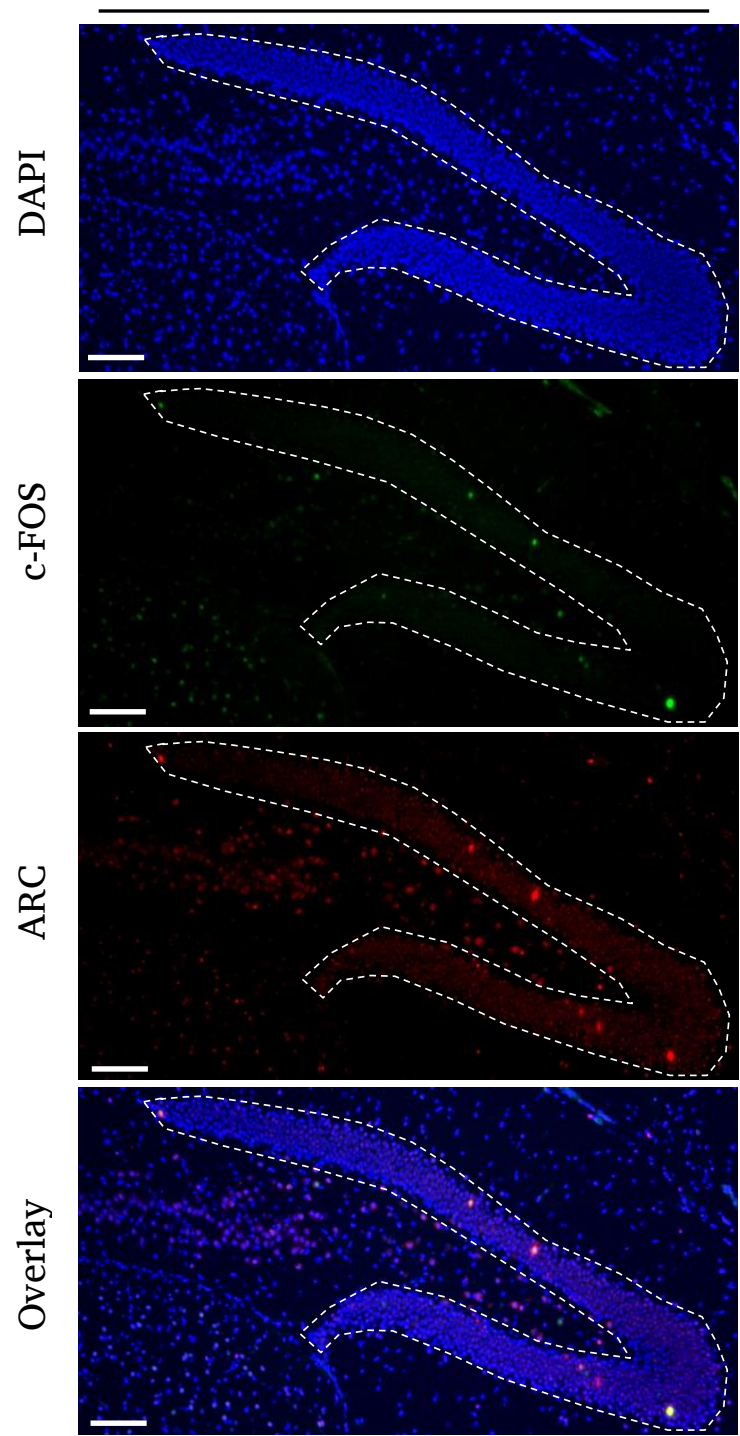

CaMKCreER $^{\mathrm{T} 2} \mathrm{Tip}^{\mathrm{f} / \mathrm{f}}$
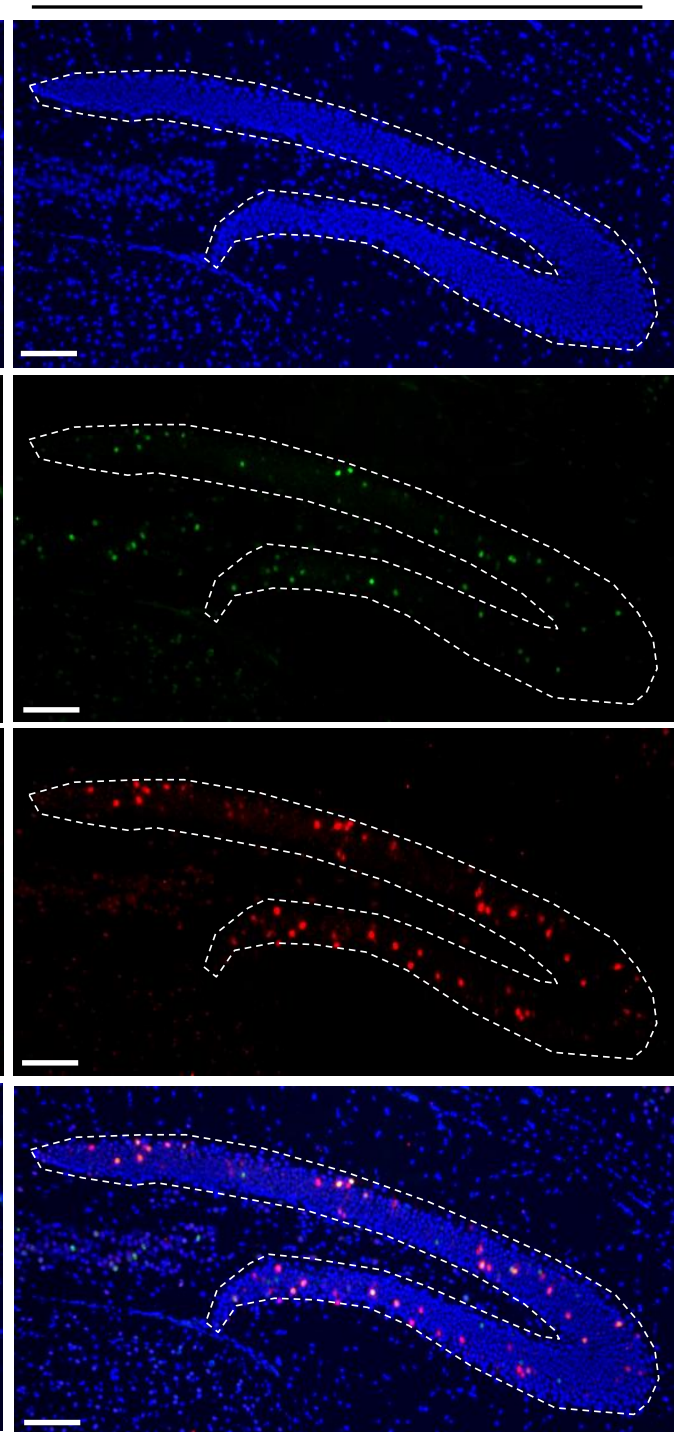

B

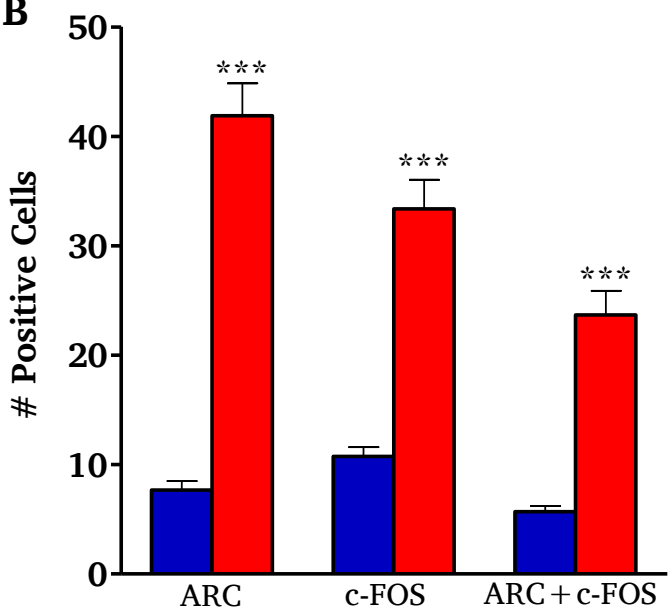

Figure 3.34: The number of ARC and c-FOS positive cells is increased in the TIP60-deficient dentate gyrus. (A) Cells positive for c-FOS or ARC in the dentate gyrus were visualized by a double labeling IHC experiment using specific antibodies. The granular cell layer of the dentate gyrus is marked by dashed lines (B) Quantification of c-FOS and ARCpositive cells on $10 \mu \mathrm{m}$ thick sections of the dentate gyrus in Tip60 $0^{\mathrm{f} / \mathrm{f}}$ control and CaMKCreER ${ }^{\mathrm{T} 2} \mathrm{Tip}^{\mathrm{f} / \mathrm{f}}$ animals ( $\mathrm{n}=4$ per genotype, 4 sections per animal). The average number of positive cells per section is shown. One-tailed student's $t$-test, ${ }^{* * *} \mathrm{p}<0.0001$. Scale bars represent $100 \mu \mathrm{m}$. Error bars represent SEM. 

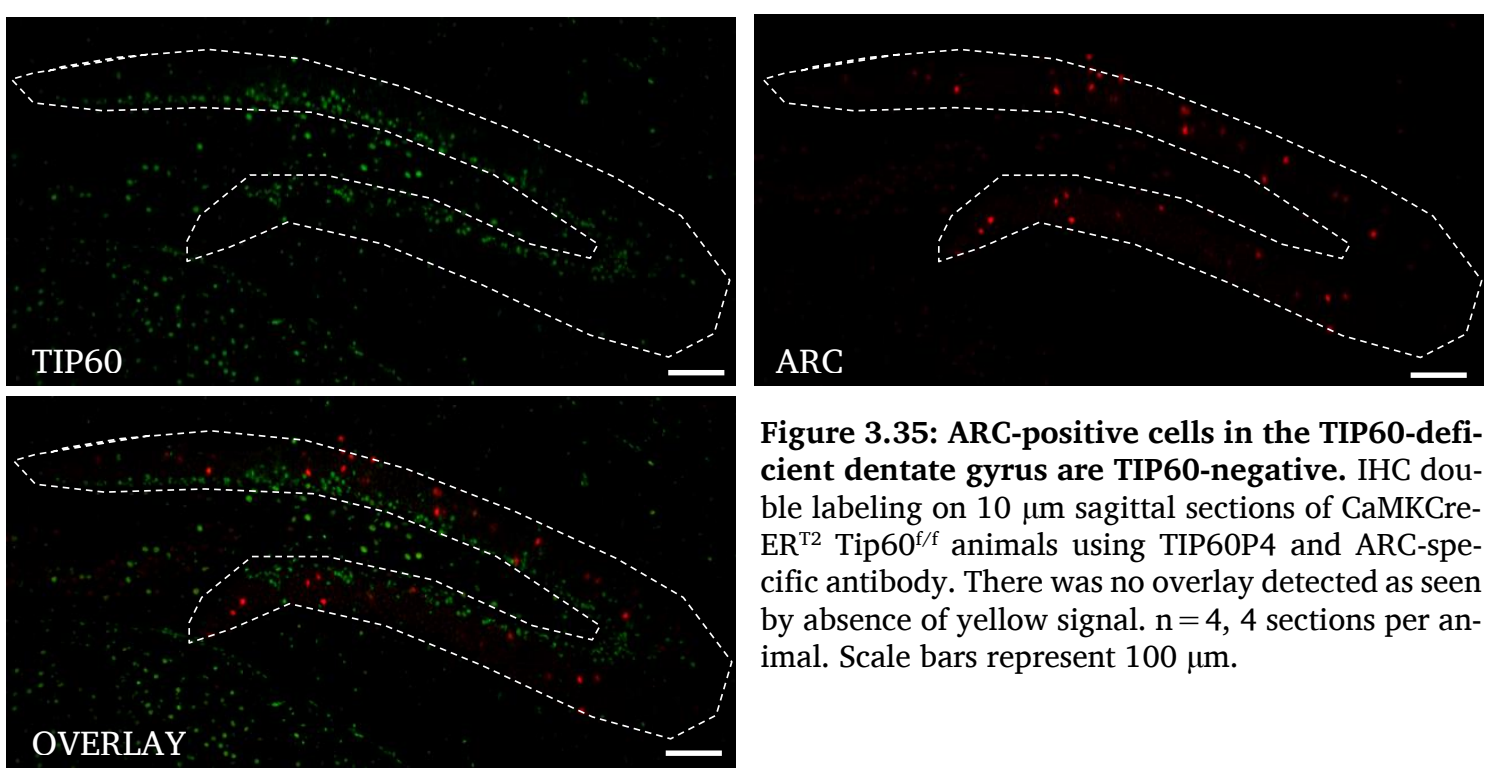

Figure 3.35: ARC-positive cells in the TIP60-deficient dentate gyrus are TIP60-negative. IHC double labeling on $10 \mu \mathrm{m}$ sagittal sections of CaMKCre$\mathrm{ER}^{\mathrm{T} 2} \mathrm{Tip}^{\mathrm{f} / \mathrm{f}}$ animals using TIP60P4 and ARC-specific antibody. There was no overlay detected as seen by absence of yellow signal. $n=4,4$ sections per animal. Scale bars represent $100 \mu \mathrm{m}$. 


\subsection{Next Generation Sequencing}

In order to assess transcriptional changes in the absence of TIP60 in an unbiased manner, next generation sequencing (NGS) was performed. The hippocampus is a very heterogeneous brain structure due to its different subregions and cell types. Hence, performing RNA-Seq on whole hippocampal tissue could possibly obscure individual subregional changes. Due to the strong upregulation of IEGs identified in the dorsal CA1 region of the CAMKCreER ${ }^{\mathrm{T} 2} \mathrm{Tip}^{\mathrm{f} / \mathrm{f}}$ mouse line, this part of the hippocampus was therefore chosen for whole transcriptome analysis. An important long-term aim is to identify direct targets of TIP60 and to filter out indirect effects as efficiently as possible. That is why RNA-Seq was performed on samples from both the constitutive and the inducible mouse lines, assuming that the overlap between the two lines would provide the most reliable TIP60-regulated candidate genes.

In CaMKCre Tip60 ${ }^{\mathrm{f} / \mathrm{f}}$ mice expression of a total of 8,438 genes was changed while in CaMKCreER $^{\mathrm{T} 2} \mathrm{Tip}^{\mathrm{f} / \mathrm{f}}$ mice a total of 7,054 genes were found to have significantly changed expression levels (Figure 3.36A) $(\mathrm{q}<0.01)$. Indeed, there was a major overlap of 4,541 genes found to be significantly dysregulated in both mouse lines as illustrated by the VENN diagram in Figure 3.36A. These genes were similarly up- and downregulated in both TIP60-deficiency models. The higher number of differentially expressed genes in the constitutive line can possibly be explained by the longer presence of TIP60deficiency due to the constitutive CRE driver and by indirect effects due the observed health problems.

The heat map in Figure 3.36B gives an overview of the changes in gene expression in both mouse lines. Unlike the situation for the IEGs, there were now both up- and downregulated genes identified. A total of 1,745 genes with a $\log _{2}$-transformed fold change $\log _{2} \mathrm{FC}>0.5$ and $\mathrm{q}<0.01$ were mapped.

Histograms of $\log _{2}$-transformed fold changes are shown in Figure 3.37A and B for both the inducible and the constitutive mouse line. Also the overlap between transcripts dysregulated in both mouse lines is shown. Note, that in comparison to the inducible mouse line (Figure 3.37A), the larger variance in the histogram in Figure 3.37B indicates stronger dysregulation of more transcripts in the constitutive mouse line. 
A

constitutive inducible

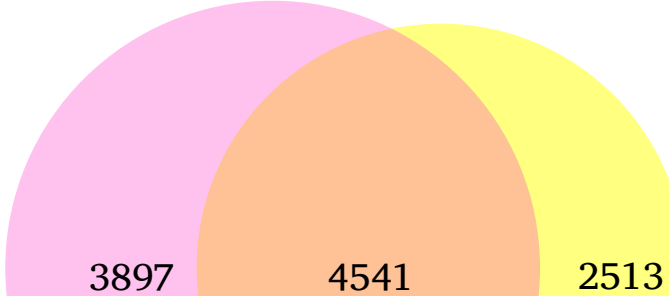

B

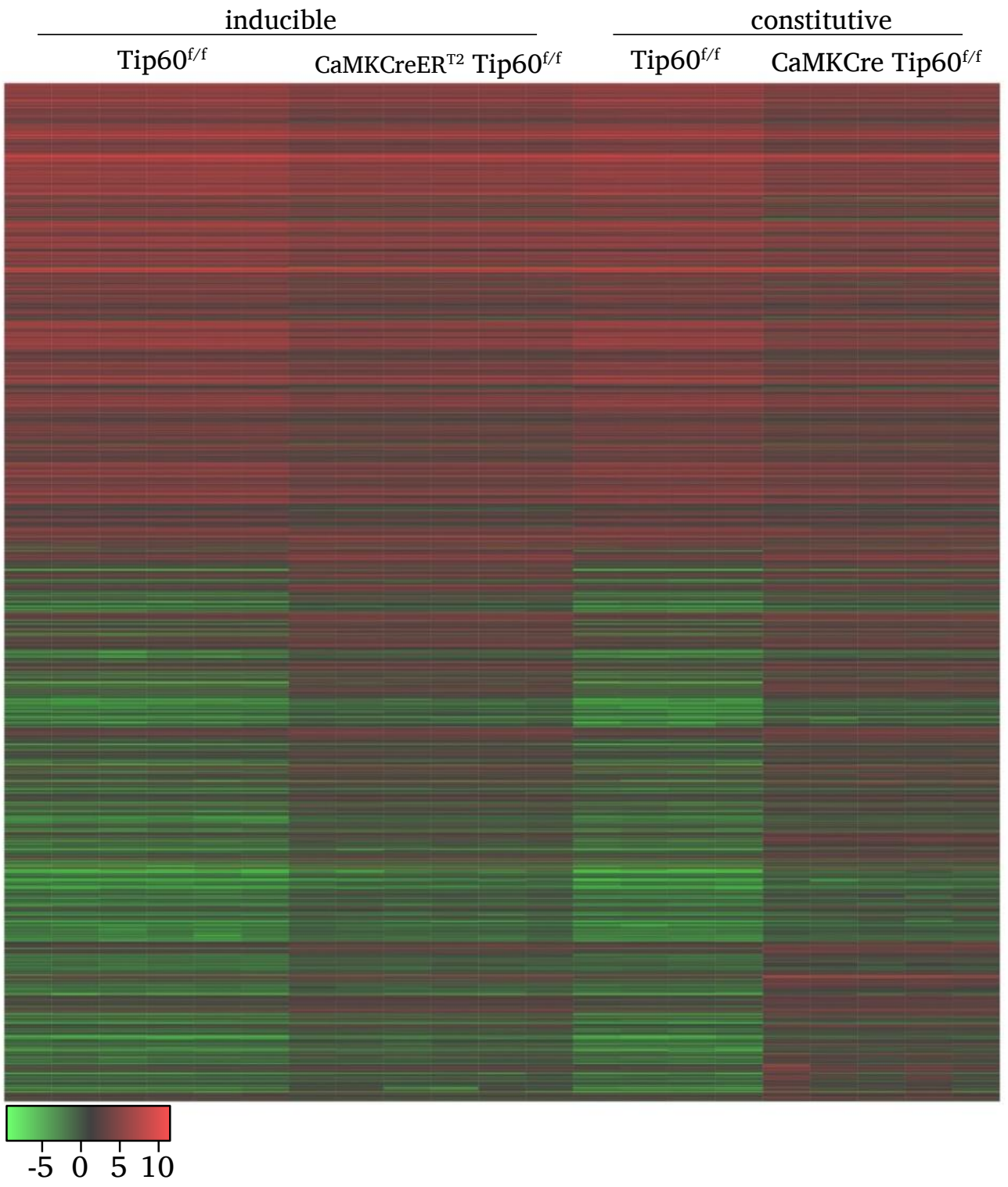

Figure 3.36: Heatmap and Venn diagram of RNA-Seq results from dorsal CA1 region. (A) Venn diagram illustrating the significant overlap of the differentially expressed genes between the inducible and constitutive TIP60-deficiency mouse lines (Fisher's exact test p-value $<2.2 \mathrm{E}-16$ ). (B) The heatmap represents the expression pattern of consistently affected genes in both TIP60-deficiency mouse lines. The RNAseq read number was normalized to RPKM. Criteria were $\mathrm{q}<0.01$ and $\log _{2}$-transformed fold changes larger than 0.5 in both mouse lines. Inducible mouse line $n=6$, constitutive mouse line $n=4-5$ per genotype. 
A

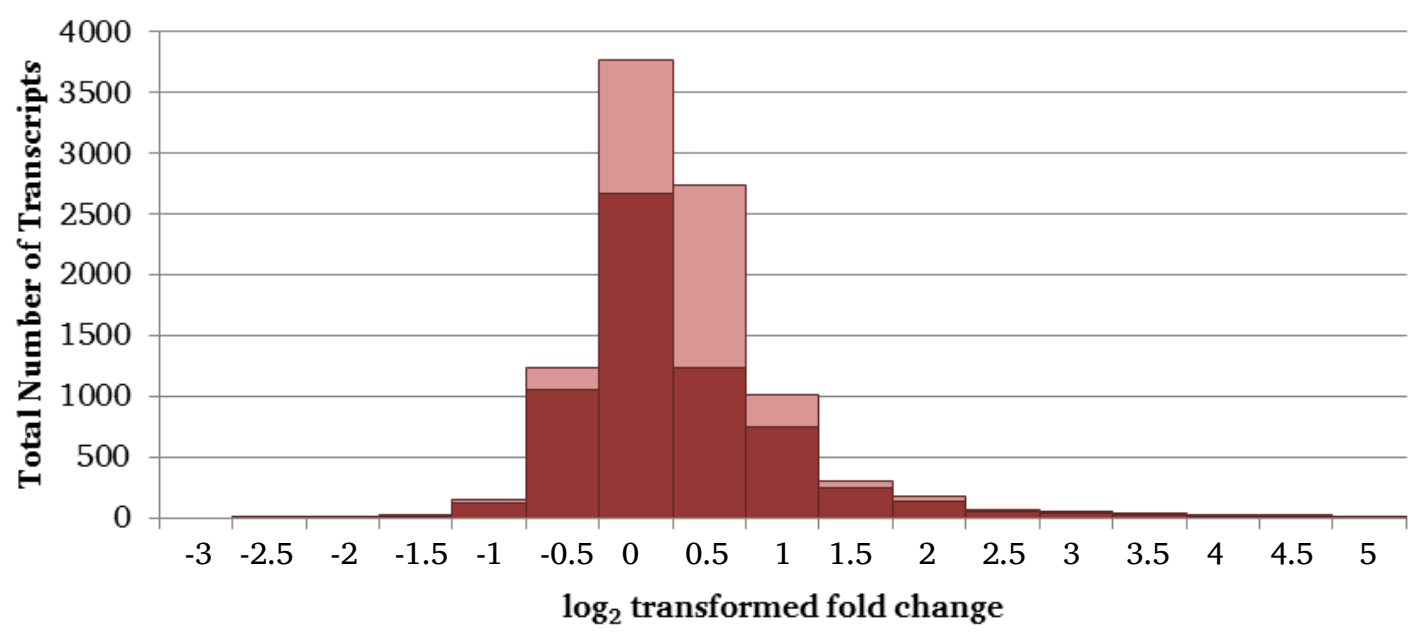

inducible mouse line $\quad \square$ overlap

B

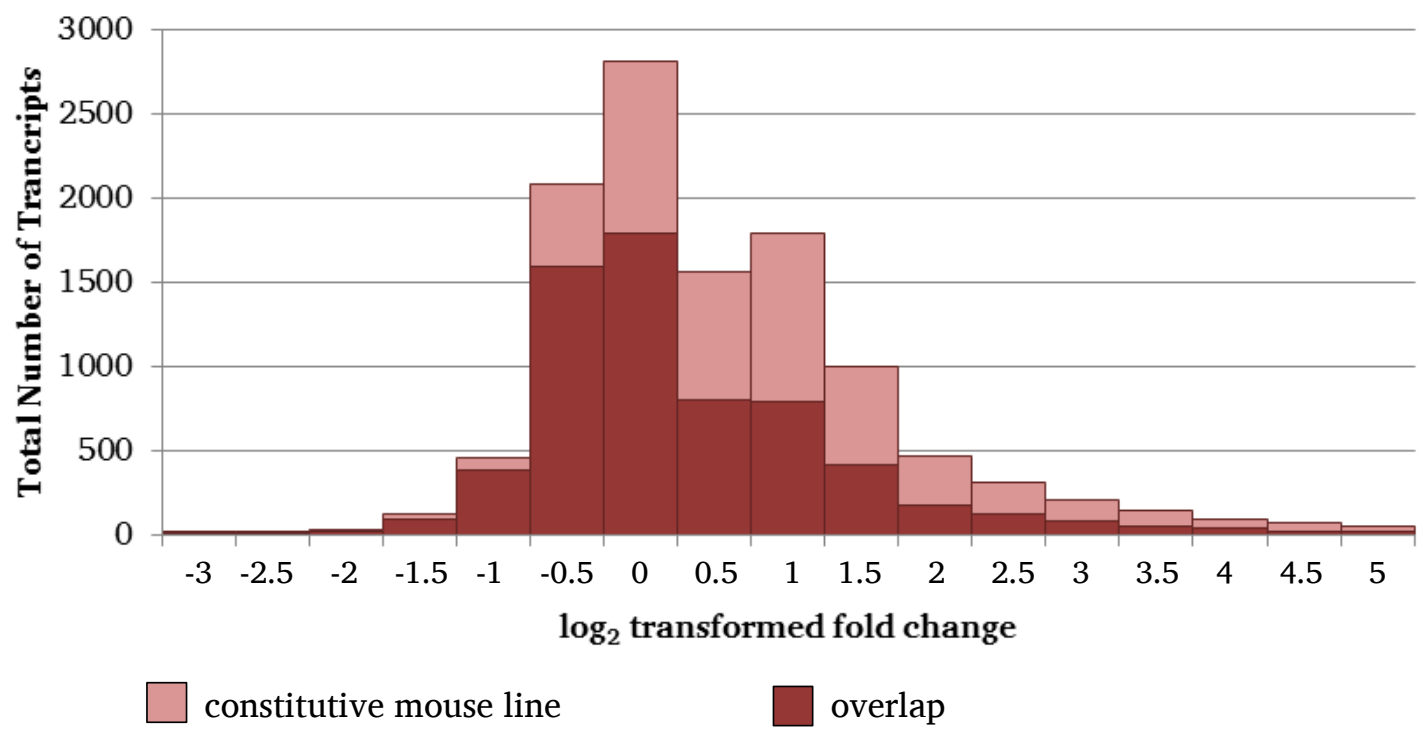

Figure 3.37: Histograms of $\log _{2}$-transformed fold changes in gene expression. (A) Distribution of $\log _{2^{-}}$ transformed fold changes of the inducible mouse line. The overlap shows the fraction that is also found in the significant overlap of the two mouse lines. (B) Distribution of $\log _{2}$-transformed fold changes of the constitutive mouse line. The overlap shows the fraction that is also found in the significant overlap of the two mouse lines. 


\subsubsection{Validation of Target Genes}

This section is organized into two parts. In the first part, expression of previously identified IEGs, which were constitutively upregulated in the TIP60-deficient hippocampus, will be compared to the RNA-Seq data. In the second part, validations of selected novel candidate genes identified by RNA-Seq will be shown by qPCR and by ISH. The validation experiments of both parts confirmed the reliability of the RNA-Seq transcriptome analysis.

\subsubsection{Confirmation of IEG Upregulation in the Dorsal Hippocampus of TIP60- deficient mice}

Comparing the changes in IEG expression obtained by RNA-Seq to previous results obtained by qPCR and ISH/IHC analyses there was a similar upregulation of Npas4, c-Fos, and Bdnf exons I and IV in both mouse lines (Table 3.12). Results for other IEGs also showed good consistence with previous quantifications using whole hippocampus preparations as expression levels of Nr4a1, Arc, and Zif268 were increased in the dorsal CA1 region of CaMKCreER ${ }^{\mathrm{T} 2} \mathrm{Tip}^{\mathrm{f} / \mathrm{f}}$ mice (Table 3.12). The rather modest upregulation of Bdnf exon $I$ and $I V$ in comparison to qPCR results (see Section 3.5.1) was most likely due to the different hippocampal regions used. The ISH analysis of Bdnf exon IX expression showed that the strongest upregulation of $B d n f$ was in the TIP60-deficient dentate gyrus (see Section 3.5.2.3), a region included in the whole hippocampal samples used for qPCR analysis. In contrast, for RNA-Seq microdissected dorsal CA1 region was taken. Here, the upregulation of $B d n f$ exon $I X$ as visualized by ISH was modest and this thus affected the magnitude of the fold change detected. Interestingly, some IEGs previously not analyzed by qPCR in the constitutive mouse line were downregulated as assessed by NGS and thus showed a different regulation than was observed for the inducible mouse line. These included Arc and Homer1 (Table 3.12). 
Table 3.12: RNA-Seq results for selected genes validated in Section 3.8.1.

\begin{tabular}{|c|c|c|c|c|c|c|}
\hline & Inducible & IKCreER & ip60 ${ }^{f / f}$ line & Constitut & aMKCre & p60 $60^{\mathrm{f} / \mathrm{f}}$ line \\
\hline Gene name & $\begin{array}{l}\log _{2} \mathrm{FC} \\
(\mathrm{WT} / \mathrm{KO})\end{array}$ & $\begin{array}{l}\text { Fold } \\
\text { change }\end{array}$ & q value & $\begin{array}{l}\log _{2} \mathrm{FC} \\
(\mathrm{WT} / \mathrm{KO})\end{array}$ & $\begin{array}{l}\text { Fold } \\
\text { change }\end{array}$ & q value \\
\hline$F_{O S}{ }^{\mathrm{a}}$ & 2.28 & 4.86 & $7.78 \mathrm{E}-43$ & 1.41 & 2.67 & 0.001 \\
\hline $\operatorname{Npas}^{\mathrm{a}}$ & 1.41 & 2.66 & $2.41 \mathrm{E}-59$ & 0.55 & 1.46 & $3.02 \mathrm{E}-8$ \\
\hline Bdnf exon $I^{\mathrm{a}}$ & 0.48 & 1.39 & $6.36 \mathrm{E}-08$ & 0.82 & 1.76 & $9.11 \mathrm{E}-17$ \\
\hline Bdnf exon $I V^{\mathrm{a}}$ & 0.40 & 1.32 & $6.12 \mathrm{E}-06$ & 0.68 & 1.60 & $2.84 \mathrm{E}-18$ \\
\hline$N r 4 a 1^{\mathrm{a}}$ & 0.97 & 1.95 & $2.18 \mathrm{E}-37$ & -0.70 & 0.62 & 0.0006 \\
\hline$A r c^{\mathbf{a}}$ & 0.57 & 1.48 & 0.0001 & -1.06 & 0.48 & 0.0004 \\
\hline Zif268/Egr1 $^{\mathrm{a}}$ & 0.40 & 1.32 & 0.0005 & -1.04 & 0.49 & 0.0005 \\
\hline Homer $1^{\text {a }}$ & 0.20 & 1.15 & 0.002 & -0.56 & 0.68 & 0.002 \\
\hline $\operatorname{Lin}^{2} b^{b}$ & -1.66 & 0.32 & $1.51 \mathrm{E}-118$ & -1.93 & 0.26 & $3.12 \mathrm{E}-88$ \\
\hline$E s r 1^{\mathrm{b}}$ & 3.41 & 10.61 & $8.28 \mathrm{E}-107$ & 1.15 & 2.21 & $2.76 \mathrm{E}-07$ \\
\hline Syt7 $\mathbf{b}$ & -1.05 & 0.48 & $1.44 \mathrm{E}-150$ & -1.22 & 0.43 & $2.69 \mathrm{E}-89$ \\
\hline Syt10 & 1.90 & 3.74 & $6.37 \mathrm{E}-61$ & 1.60 & 3.02 & $6.55 \mathrm{E}-23$ \\
\hline Cacng8b & -0.76 & 0.59 & $4.36 \mathrm{E}-41$ & -1.34 & 0.40 & $4.55 \mathrm{E}-75$ \\
\hline
\end{tabular}

Fold change values are shown in bold for easier comparison. Superscripts after gene names indicate: $\mathrm{a}=$ genes previously analyzed by qPCR, b $=$ novel genes validated by ISH. $\log 2 \mathrm{FC}=\log 2$-transformed fold change.

\subsubsection{Validation of Novel Candidate Genes identified by NGS}

\section{qPCR Analyses}

Due to time restrictions, validation of novel NGS candidate genes with qPCR focused on the RNA-Seq samples from the inducible mouse line. Genes selected for validations had a $\log _{2}$ transformed fold change $\left(\log _{2} \mathrm{FC}\right)$ of at least 0.5 and were chosen based on their possible significance for the observed phenotype. The validations showed high consistency with the changes detected by RNA-Seq (Table 3.13).

Table 3.13: Validation of RNA-Seq fold changes by qPCR.

\begin{tabular}{c|c|c} 
Gene Name & Fold Change qPCR & Fold Change RNA-Seq \\
\hline Lin7b & 0.37 & 0.32 \\
\hline Reln & 1.79 & 1.56 \\
\hline Gap43 & 0.92 & 0.71 \\
\hline Syt5 & 0.53 & 0.43 \\
\hline Syt17 & 0.69 & 0.57 \\
\hline Sst & 1.99 & 1.84 \\
\hline Syt9 & 2.77 & 7.58 \\
\hline Sphkap & 0.50 & 0.45
\end{tabular}




\begin{tabular}{c|c|c} 
Sirpa & 0.24 & 0.65 \\
\hline Stmn 3 & 0.25 & 0.64 \\
\hline Dnm1 & 0.61 & 0.54 \\
\hline Stau2 & 0.76 & 0.60 \\
\hline Thy1 & 0.63 & 0.54 \\
\hline Ywhah & 0.71 & 0.58 \\
\hline Crh & 2.82 & 2.79 \\
\hline Adcyap1 & 1.15 & 5.76 \\
\hline Ryr1 & 1.56 & 3.02 \\
\hline Egr2 & 1.56 & 7.30 \\
\hline Esr1 & 7.99 & 10.61
\end{tabular}

Expression of several genes, whose expression was significantly changed in CaMKCreER ${ }^{\mathrm{T} 2} \mathrm{Tip}^{\mathrm{f} / \mathrm{f}}$ mice in RNA-Seq analysis, were validated using qPCR. The same samples as for RNA-Seq were used.

\section{ISH Analyses}

Validation of RNA-Seq results by ISH was conducted with either the inducible TIP60deficiency mouse line alone or with both mouse lines in order to analyze the reproducibility of molecular changes and to map the changes at cellular resolution. Performing ISH with probes against RNA-Seq candidate genes did not only allow to validate the RNA-Seq results in the dorsal CA1 region but simultaneously also allowed to assess the changes in expression of a particular gene in the other hippocampal regions. Here, genes implied in synaptic function with marked changes in expression were selected as well as Esr1, which showed extremely high upregulation in CaMKCreER ${ }^{\mathrm{T} 2} \mathrm{Tip}^{\mathrm{f} / \mathrm{f}}$ mice.

\section{Esr1}

Estrogen receptor alpha (Esr1) is important for hippocampal learning (Bean et al., 2014; Han et al., 2013) and was 10-fold upregulated in CaMKCreER ${ }^{\mathrm{T} 2} \mathrm{Tip}^{\mathrm{f} / \mathrm{f}}$ animals compared to Tip60 $0^{\mathrm{f} / \mathrm{f}}$ control mice. While it was also significantly upregulated in CaMKCre Tip60 $0^{\mathrm{f} / \mathrm{f}}$ mice compared to Tip60 ${ }^{\mathrm{f} / \mathrm{f}}$ controls the increase in gene expression was only twofold (Table 3.12). For validation of these RNA-Seq results ISH was performed with sections from both TIP60-deficiency mouse lines. The ISH confirmed the strong upregulation of Esr1 in the CA1 region of CaMKCreER ${ }^{\mathrm{T} 2} \mathrm{Tip}^{\mathrm{f} / \mathrm{f}}$ mice (Figure 3.38, top right) and the lack of such high upregulation in CaMKCre Tip60 $60^{\mathrm{f} / \mathrm{f}}$ mice (Figure 3.38 bottom 
$\operatorname{Tip} 60^{\mathrm{f} / \mathrm{f}}$

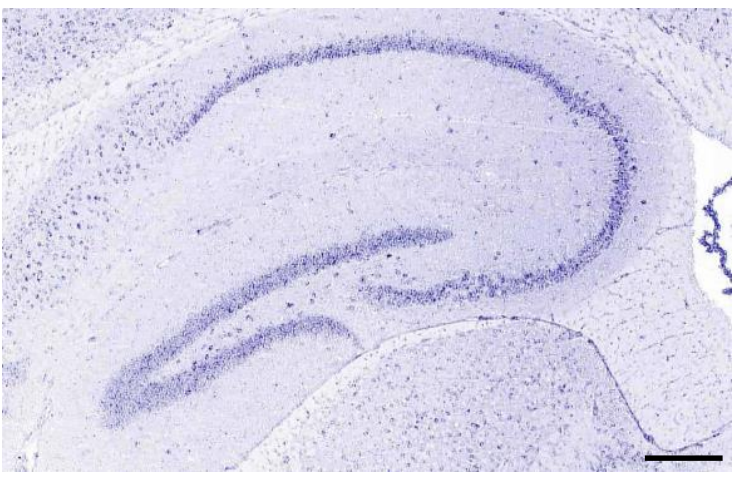

$\operatorname{Tip} 60^{\mathrm{f} / \mathrm{f}}$

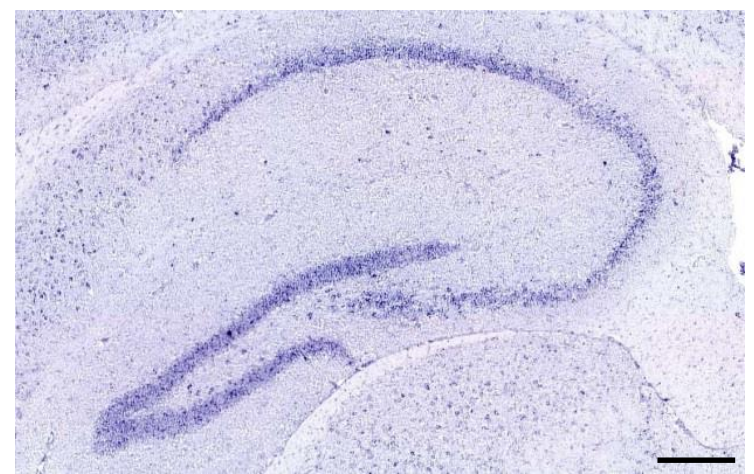

CaMKCreER $^{\mathrm{T} 2} \mathrm{Tip}^{\mathrm{f} / \mathrm{f}}$

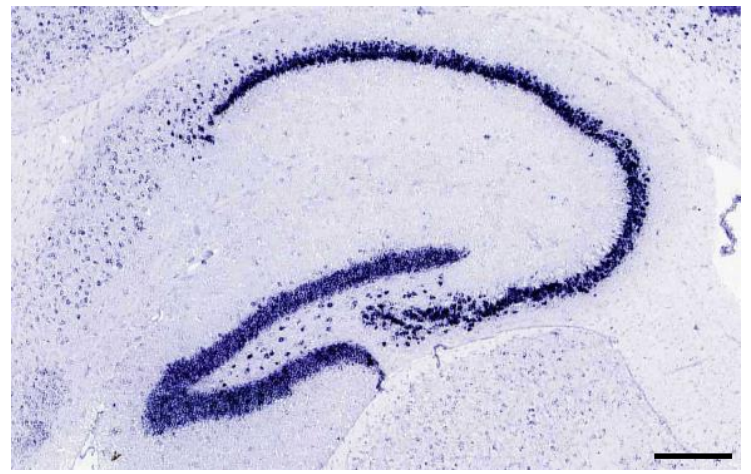

CaMKCre Tip60 f/f

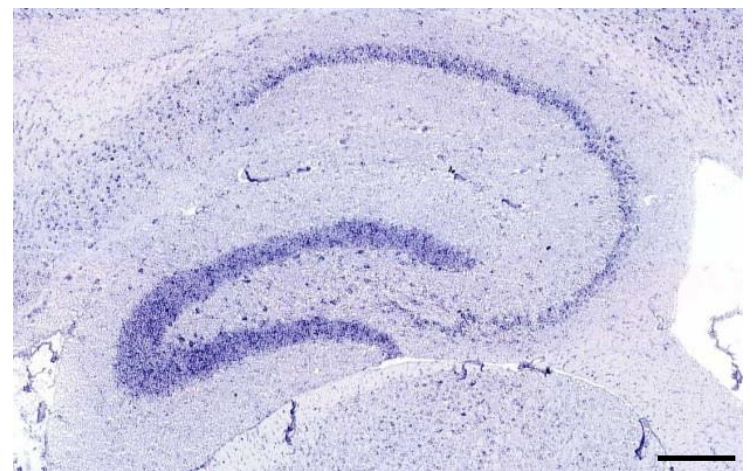

Figure 3.38: Esr1 is strongly upregulated in the hippocampus of CaMKCreER ${ }^{\mathrm{T} 2} \mathrm{Tip60}^{\mathrm{f} / \mathrm{f}}$ mice. Representative ISH results of CaMKCreER ${ }^{\mathrm{T} 2} \mathrm{Tip}^{\mathrm{f} / \mathrm{f}}$ and Tip60 $0^{\mathrm{f} / \mathrm{f}}$ mice $(\mathrm{n}=4$ per genotype) as well as CaMKCre Tip60 ${ }^{\mathrm{f} / \mathrm{f}}$ mice and controls $(\mathrm{n}=3-4$ per genotype). ISH with Esr1 specific probe was performed on $10 \mu \mathrm{m}$ thick sagittal sections. Scale bars represent $250 \mu \mathrm{m}$.

right). Moreover, the ISH analysis revealed that Esr1 is highly upregulated in all hippocampal subregions in CaMKCreER ${ }^{\mathrm{T} 2} \mathrm{Tip}^{\mathrm{f} / \mathrm{f}}$ mice. While TIP60 has been reported to be necessary for Esr1 target gene activation (Jeong et al., 2011) there is no evidence that it is involved in the transcriptional regulation of the Esr1 gene itself so it remains unclear what causes Esr1 upregulation in the CaMKCreER ${ }^{\mathrm{T} 2} \mathrm{Tip}^{\mathrm{f} / \mathrm{f}}$ hippocampus.

\section{Lin7b (Mals-2, Veli2)}

Lin-7 Homolog B (LIN7B) is a protein enriched in brain synapses, where it is localized to the postsynaptic density (PSD) (Jo et al., 1999). Lin7b was found to be significantly downregulated in both TIP60-deficiency mouse models in the RNA-Seq analysis (Table 3.12). This result was confirmed by ISH using sections of the inducible mouse line, which revealed strong downregulation of Lin $7 b$ in all hippocampal subregions as well as cortex (Figure 3.39) 

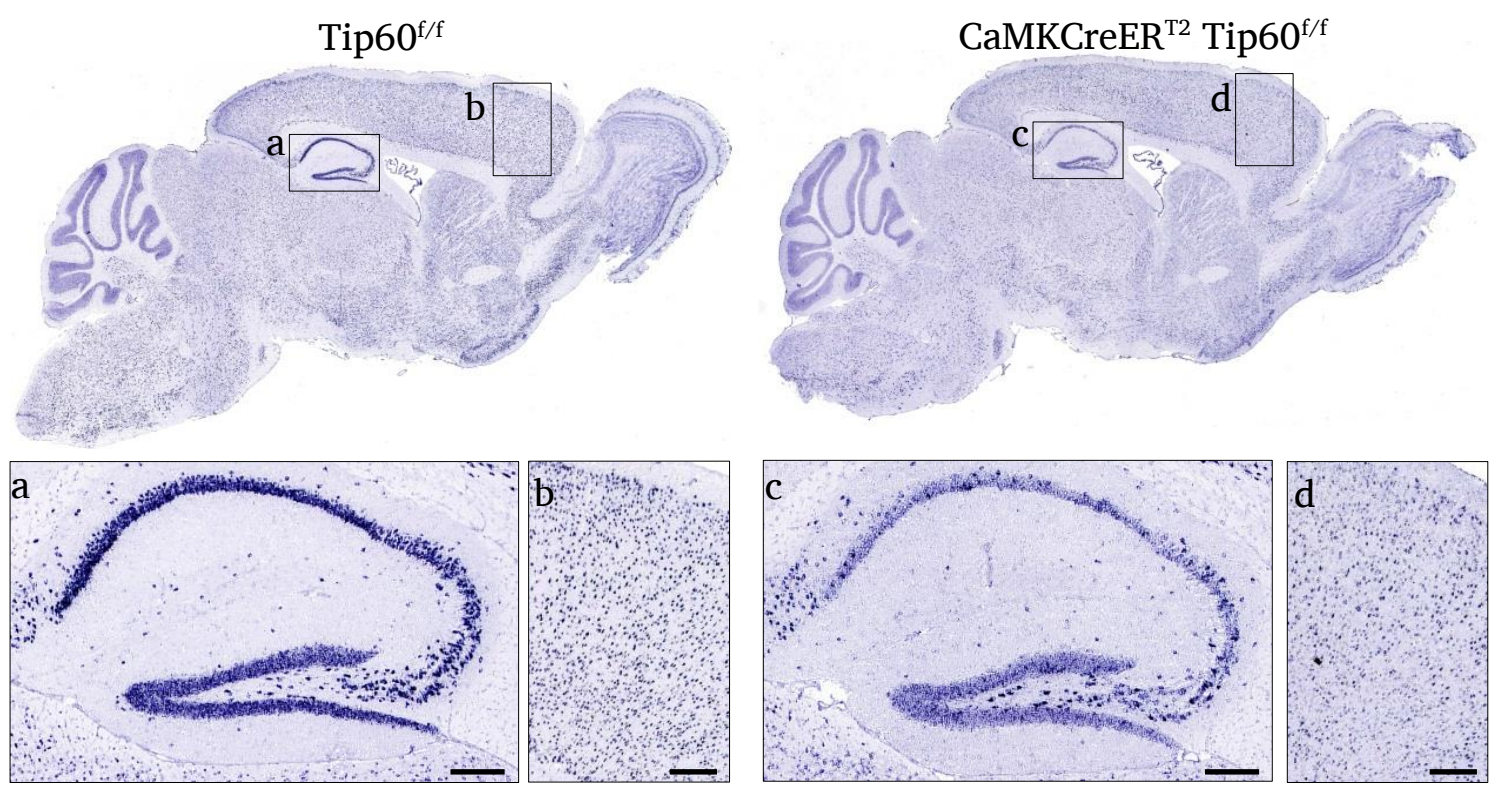

Figure 3.39: $\operatorname{Lin} 7 b$ is downregulated in the hippocampus and cortex of CaMKCreER ${ }^{\mathrm{T} 2} \mathrm{Tip}^{\mathrm{f}} \mathrm{C}^{\mathrm{f} / \mathrm{f}} \mathrm{mice}^{\mathrm{i}}$. Representative ISH images show downregulation of $\operatorname{Lin} 7 \mathrm{~b}$ expression in the brain of CaMKCreER ${ }^{\mathrm{T} 2} \mathrm{Tip}^{\mathrm{f}} \mathrm{O}^{\mathrm{f} / \mathrm{f}}$ mice (right) compared to control animals (left). Inserts of the hippocampus (a,c) and cortex(b,d) are shown at higher magnification. The signal intensity is strongly reduced in CaMKCreER ${ }^{\mathrm{T} 2} \mathrm{Tip} 60^{\mathrm{f} / \mathrm{f}}$ mice in both the hippocampus (c) and the cortex (d) compared to Tip60 ${ }^{\mathrm{f} / \mathrm{f}}$ controls (a) and (b). Lin $7 \mathrm{~b}$-specific probe was used in ISH on $10 \mu \mathrm{m}$ thick sagittal sections. $\mathrm{n}=4$ per genotype. Scale bars represent $250 \mu \mathrm{m}$.

\section{Syt7 and Syt10}

RNA-Seq results indicated that several synaptotagmins, which are involved in exocytosis, were significantly dysregulated in the dorsal CA1 region of CaMKCreER ${ }^{\mathrm{T} 2} \mathrm{Tip}^{\mathrm{f} / \mathrm{f}}$ mice. Consequently, ISH was used to examine changes in expression at the cellular level for two members of this family of membrane-trafficking proteins. Synaptotagmin 7 (Syt7) was significantly downregulated in CaMKCreER ${ }^{\mathrm{T} 2} \mathrm{Tip}^{\mathrm{f} / \mathrm{f}}$ mice (Figure 3.40 top). Its expression levels were especially low in the CA1 and CA3 region of the TIP60-deficient hippocampus. Downregulation was also visible in the dentate gyrus albeit to a lesser extent. Synaptotagmin 10 (Syt10) was significantly upregulated in the CA1 region of the CaMKCreER ${ }^{\mathrm{T2}} \mathrm{Tip}^{\mathrm{f} / \mathrm{f}}$ mice (Figure 3.40 bottom). It was identified as an IEG in the rat brain by differential expression in brain exposed and unexposed to kainic acid (Babity et al., 1997). Analysis of Syt10 transcript showed scarce distribution of cells with highly upregulated expression in the CA1 region of CaMKCreER ${ }^{\mathrm{T} 2} \mathrm{Tip}^{\mathrm{f} / \mathrm{f}}$ animals compared to Tip60 ${ }^{\mathrm{f} / \mathrm{f}}$ controls. In contrast, expression was downregulated in the dentate gyrus. 


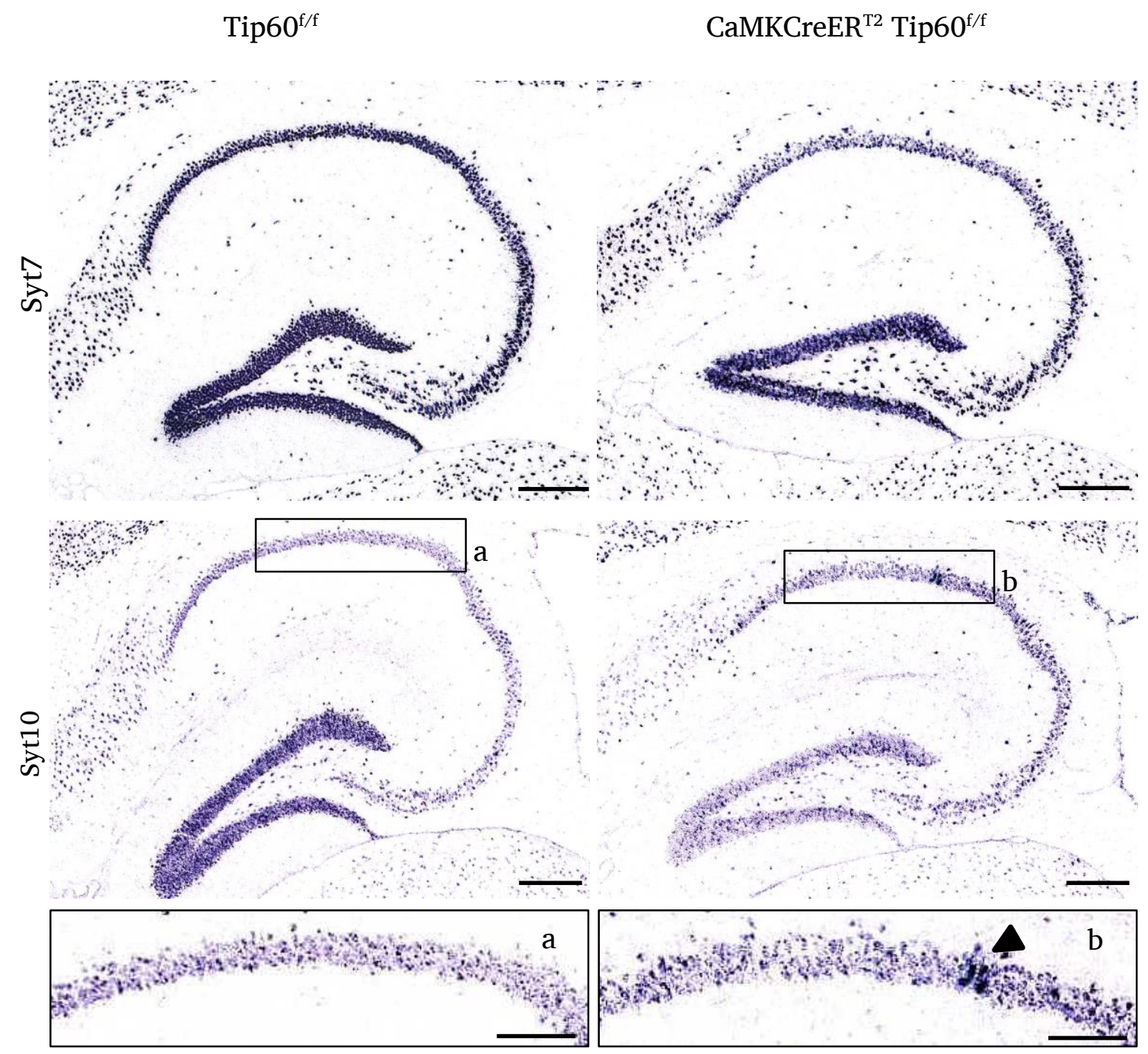

Figure 3.40: Syt7 and Syt10 mRNA levels are significantly changed in the hippocampus of CaMKCreER $^{\mathrm{T2}} \mathrm{Tip}^{\mathrm{f} / \mathrm{f}}$ mice. Expression of Syt7 (top) and Syt10 (bottom) in the hippocampus of CaMKCreER ${ }^{\mathrm{T} 2}$ Tip60 $0^{\mathrm{f} / \mathrm{f}}$ animals and Tip60 ${ }^{\mathrm{f} / \mathrm{f}}$ controls using ISH with gene-specific probes. Inserts (a,b) show Syt10 mRNA signal the CA1 region at higher magnification. Scarce distribution of cells with highly upregulated Syt10 levels are visible in CaMKCreER ${ }^{\mathrm{T} 2} \mathrm{Tip}^{\mathrm{f} / \mathrm{f}}$ animals compared to Tip60 $0^{\mathrm{f} / \mathrm{f}}$ controls (a, b; black arrowhead). $\mathrm{n}=1$ per genotype, $10 \mu \mathrm{m}$ thick sagittal sections were used for ISH analysis. Scale bars represent $250 \mu \mathrm{m}$ or $500 \mu \mathrm{m}(\mathrm{a}, \mathrm{b})$.

\section{Cacng8}

Expression of calcium channel voltage-dependent gamma subunit 8 (Cacng8) was significantly downregulated in the CA1 region CaMKCreER ${ }^{\mathrm{T} 2} \mathrm{Tip}^{\mathrm{f} / \mathrm{f}}$ mice (Table 3.12). This was confirmed by ISH analysis (Figure 3.41). Additionally, the ISH data revealed that Cacgn8 expression was massively downregulated in the dentate gyrus and in the other CA regions. The protein encoded by this gene is a type I transmembrane AMPA receptor regulatory protein (TARP). TARPs regulate both trafficking and channel gating 

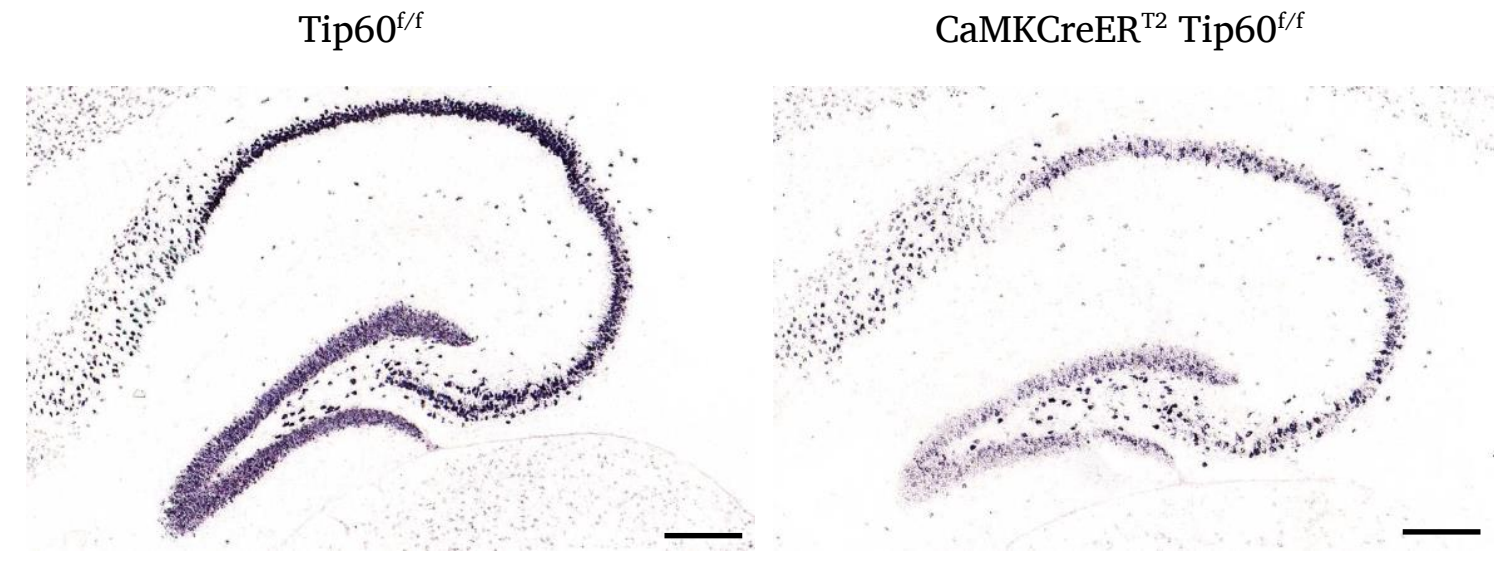

Figure 3.41: Cacng8 is significantly downregulated in all hippocampal subregions of CaMKCreER ${ }^{\mathrm{T} 2}$ Tip60 ${ }^{\mathrm{f} / \mathrm{f}}$ mice. Expression of Cacng8 mRNA in the hippocampus of CaMKCreER ${ }^{\mathrm{T2}} \mathrm{Tip}^{\mathrm{f}} \mathrm{0}^{\mathrm{f} / \mathrm{f}}$ and Tip60 $\mathrm{f}^{\mathrm{ff}}$ mice detected by ISH with Cacng8 specific probe. Cells positive for Cacng8 expression are scarcely distributed throughout the hippocampal subregions of CaMKCreER ${ }^{\mathrm{T} 2} \mathrm{Tip} 60^{\mathrm{f} / \mathrm{f}}$ mice while expression is ubiquitous in the Tip60 $0^{\mathrm{f} / \mathrm{f}}$ control animal. $10 \mu \mathrm{m}$ thick sagittal sections were used. $\mathrm{n}=1$ per genotype. Scale bars represent $250 \mu \mathrm{m}$.

of the AMPA receptors thereby contributing significantly to the functional plasticity of the synapse (Sager et al., 2009). 


\subsubsection{Functional Annotation}

\subsubsection{GO Groups}

Functional annotation was performed with the differentially regulated genes of each of the two TIP60-deficiency models using DAVID (the Database for Annotation, Visualization and Integrated Discovery) (Dennis et al., 2003). In an attempt to identify the core processes that TIP60 participates in, functional annotation was also performed with the overlapping genes between the two mouse lines.

Figure 3.42 provides an overview of up- and downregulated gene ontology (GO) terms found with the overlapping genes of both mouse models, followed by tables listing the GO terms found in the overlap of the two lines as well as for each mouse line separately (Table 3.14, Table 3.15, and Table 3.16). Functional annotation clustering was performed in order to filter out redundant GO terms.

Since there existed a high overlap of genes dysregulated in the two TIP60-deficient mouse lines (see Figure 3.36A) also the functional analysis was expected to show a significant overlap of GO terms. Indeed, the upregulated GO terms identified for CaMKCre$\mathrm{ER}^{\mathrm{T} 2} \mathrm{Tip} 60^{\mathrm{f} / \mathrm{f}}$ mice (Table 3.16) were the same as for the overlapping genes of both mouse lines (Table 3.14). These included response to DNA damage stimulus and cell cycle, which can be explained by the well-known functions of TIP60 in DNA repair. Among those GO terms identified as upregulated in CaMKCre Tip60 ${ }^{\mathrm{f} / \mathrm{f}}$ mice (Table 3.15) but not present in the list of overlapping terms were defense response and positive regulation of immune system process, indicating the existence of injury or damage in the TIP60-deficient hippocampus as already suggested by an increase in GFAP immunoreactivity (Figure 3.32). A significant number of downregulated GO terms listed for the inducible mouse line was also listed in the overlap of the both mouse lines. At the same time, these included the most interesting GO terms identified in the functional analysis with respect to the observed molecular and phenotypical changes in TIP60-deficient mice. The terms were ion transport, ion binding, ion channel activity, and cell-cell-adhesion (Figure 3.42B). Moreover, the GO terms downregulated in the overlapping genes also included the term synaptic vesicle. These findings underlined the assumption of changes in synaptic plasticity and cell signaling in the TIP60-deficient CA1 region. 
A

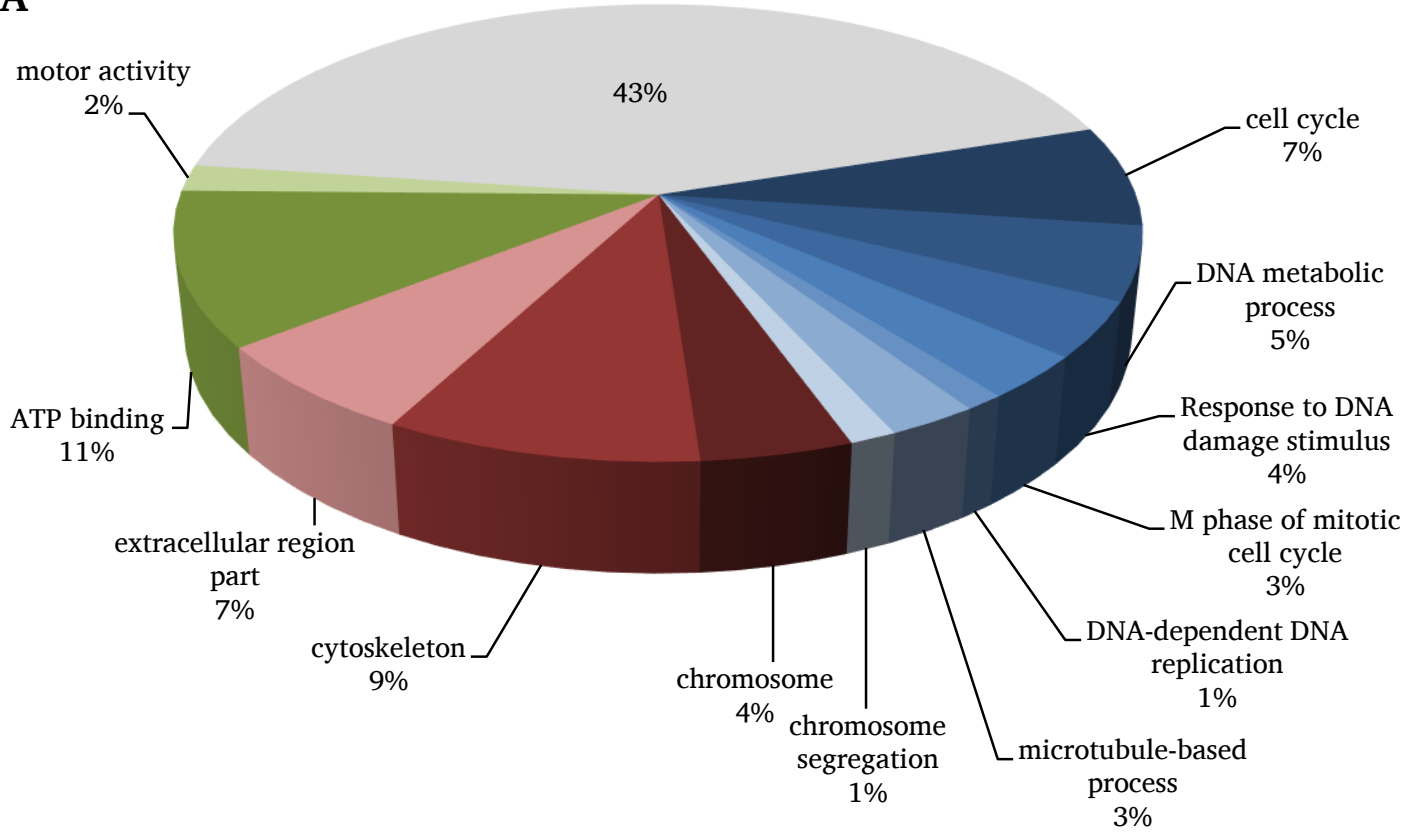

Biological process

Cellular compartment

B

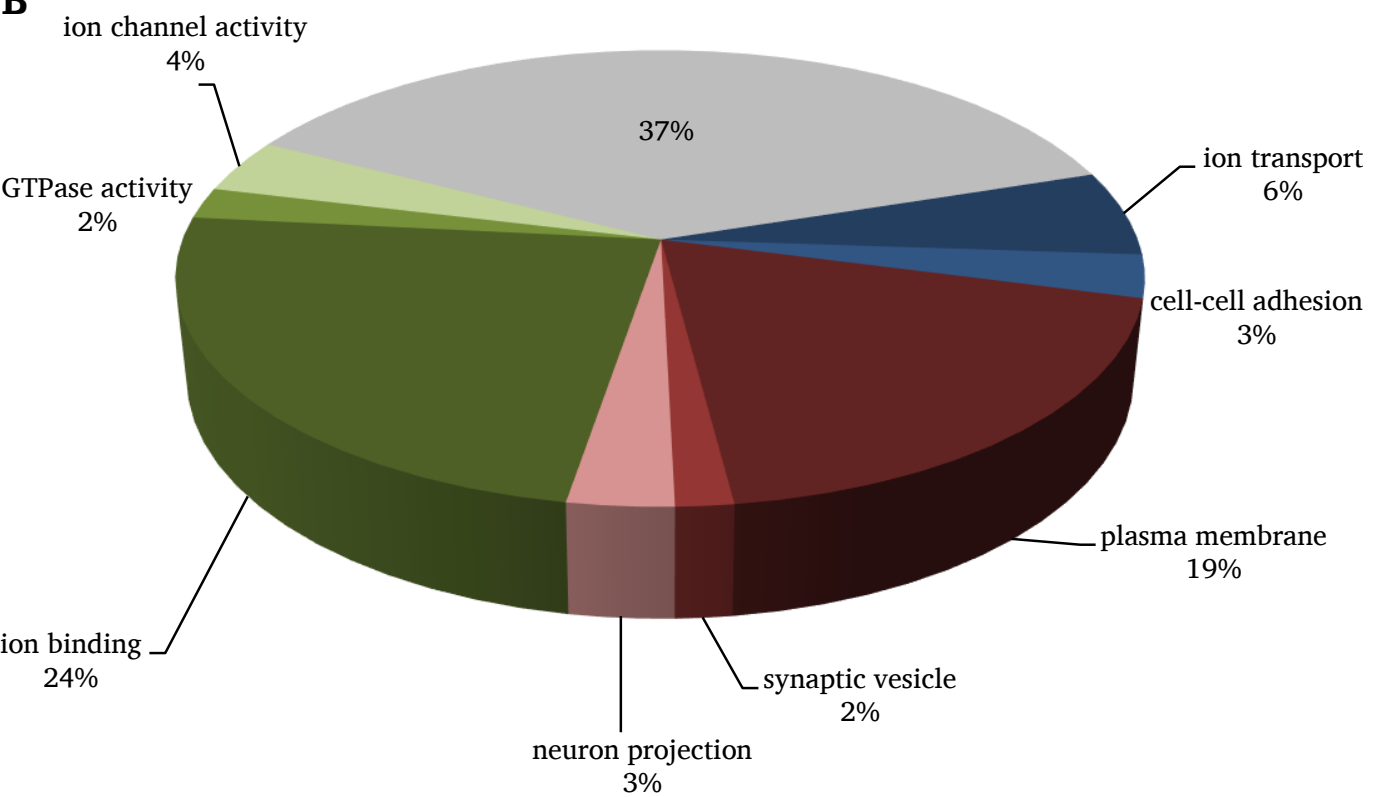

Figure 3.42 GO terms identified for the significantly overlapping genes of both TIP60-deficiency mouse lines. (A) GO term categories of significantly overlapping genes upregulated in both mouse lines are shown. (B) GO term categories of significantly overlapping genes downregulated in both mouse lines. Fractions are color-coded depending on their role in biological process (blue), cellular compartment (red) or molecular function (green). 
KEGG pathway analysis with the significantly overlapping genes of the two TIP60-deficiency mouse lines gave only DNA replication as significant output, while there were no downregulated pathways identified (Table 3.14). However, separate analysis of the two mouse lines both listed gap junction and MAPK signaling pathway as significantly downregulated pathways (Table 3.15 and Table 3.16). Since the overlap did not give a significant result, there are obviously numerous genes belonging to these pathways that differ between the two TIP60-deficiency models (see Figure 6.1 and Figure 6.2).

Table 3.14: GO-Term and KEGG analysis for the overlapping genes of the inducible and the constitutive TIP60-deficiency mouse line.

\begin{tabular}{|c|c|c|c|c|c|c|c|}
\hline & Category & Term & Count & $\%$ & p-value & $\begin{array}{c}\text { Fold } \\
\text { Enrichment }\end{array}$ & FDR \\
\hline \multirow{13}{*}{ 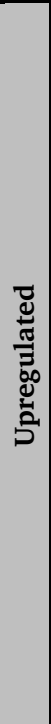 } & GOTERM_BP_FAT & GO:0007049 cell cycle & 69 & 7.2 & $8.51 \mathrm{E}-13$ & 2.6 & $1.49 \mathrm{E}-09$ \\
\hline & GOTERM_BP_FAT & $\begin{array}{l}\text { GO:0006974 response to DNA dam- } \\
\text { age stimulus }\end{array}$ & 38 & 3.9 & 3.49E-09 & 3.0 & $6.12 \mathrm{E}-06$ \\
\hline & GOTERM_BP_FAT & GO:0006259 DNA metabolic process & 50 & 5.2 & 3.51E-10 & 2.7 & 6.12E-06 \\
\hline & GOTERM_BP_FAT & $\begin{array}{l}\text { GO:0000087 M phase of mitotic cell } \\
\text { cycle }\end{array}$ & 30 & 3.1 & $6.29 \mathrm{E}-09$ & 3.5 & $1.10 \mathrm{E}-05$ \\
\hline & GOTERM_BP_FAT & $\begin{array}{l}\text { GO:0006261 DNA-dependent DNA } \\
\text { replication }\end{array}$ & 11 & 1.1 & $1.22 \mathrm{E}-06$ & 7.4 & 0.002 \\
\hline & GOTERM_BP_FAT & $\begin{array}{l}\text { GO:0007059 chromosome segrega- } \\
\text { tion }\end{array}$ & 13 & 1.3 & $1.81 \mathrm{E}-05$ & 4.6 & 0.032 \\
\hline & GOTERM_BP_FAT & $\begin{array}{l}\text { GO:0007017 microtubule-based pro- } \\
\text { cess }\end{array}$ & 25 & 2.6 & $1.78 \mathrm{E}-05$ & 2.7 & 0.032 \\
\hline & GOTERM_CC_FAT & GO:0005856 cytoskeleton & 87 & 9.0 & $4.74 \mathrm{E}-08$ & 1.8 & $6.50 \mathrm{E}-05$ \\
\hline & GOTERM_CC_FAT & GO:0005694 chromosome & 42 & 4.4 & $3.61 \mathrm{E}-08$ & 2.6 & $4.94 \mathrm{E}-05$ \\
\hline & GOTERM_CC_FAT & GO:0044421 extracellular region part & 63 & 6.5 & $10.4 \mathrm{E}-06$ & 1.9 & 0.001 \\
\hline & GOTERM_MF_FAT & GO:0005524 ATP binding & 105 & 10.9 & 7.62E-09 & 1.7 & $1.14 \mathrm{E}-05$ \\
\hline & GOTERM_MF_FAT & GO:0003774 motor activity & 18 & 1.9 & $5.51 \mathrm{E}-05$ & 3.1 & 0.082 \\
\hline & KEGG_PATHWAY & mmu03030:DNA replication & 10 & 0.8 & $8.84 \mathrm{E}-05$ & 5.1 & 0.107 \\
\hline
\end{tabular}

\begin{tabular}{|c|l|l|c|c|c|c|c|}
\cline { 2 - 8 } \multicolumn{1}{c|}{ Category } & \multicolumn{1}{c|}{ Term } & Count & $\%$ & p-value & $\begin{array}{c}\text { Fold } \\
\text { Enrichment }\end{array}$ & FDR \\
\hline & GOTERM_BP_FAT & GO:0006811 ion transport & 44 & 6.1 & $2.09 \mathrm{E}-05$ & 2.0 & 0.035 \\
\hline & GOTERM_BP_FAT & GO:0016337 cell-cell adhesion & 22 & 3.0 & $1.45 \mathrm{E}-05$ & 3.0 & 0.024 \\
\hline & & & & & & \\
\hline \\
\cline { 2 - 8 } \\
\end{tabular}

Differentially expressed genes taken for analysis had $\mathrm{q}<0.01$ and $\log _{2} \mathrm{FC}>0.5$. Cut-off for enriched terms: FDR $<0.1$. 
Table 3.15: GO-Term and KEGG analysis for the constitutive CaMKCre Tip60 ${ }^{\mathrm{f} / \mathrm{f}}$ mouse line.

\begin{tabular}{|c|c|c|c|c|c|c|}
\hline Category & Term & Count & $\%$ & p-value & \begin{tabular}{c|c|} 
Fold \\
Enrichment
\end{tabular} & FDR \\
\hline GOTERM_BP_FAT & GO:0006952 defense response & 143 & 5.0 & 3.83E-19 & 2.1 & 7.15E-16 \\
\hline GOTERM_BP_FAT & $\begin{array}{l}\text { GO:0002684 positive regulation of } \\
\text { immune system process }\end{array}$ & 81 & 2.8 & 8.06E-17 & 2.6 & $2.11 \mathrm{E}-13$ \\
\hline GOTERM_BP_FAT & GO:0001775 cell activation & 90 & 3.1 & $3.73 \mathrm{E}-16$ & 2.4 & $6.22 \mathrm{E}-13$ \\
\hline GOTERM_BP_FAT & $\begin{array}{l}\text { GO:0001817 regulation of cytokine } \\
\text { production }\end{array}$ & 60 & 2.1 & $1.11 \mathrm{E}-14$ & 2.8 & 2.07E-11 \\
\hline GOTERM_BP_FAT & GO:0007155 cell adhesion & 154 & 5.3 & $7.11 \mathrm{E}-14$ & 1.8 & $1.33 \mathrm{E}-10$ \\
\hline GOTERM_BP_FAT & GO:0010941 regulation of cell death & 147 & 5.1 & $1.78 \mathrm{E}-11$ & 1.7 & $3.31 \mathrm{E}-08$ \\
\hline GOTERM_BP_FAT & GO:0060429 epithelium development & 81 & 2.8 & $1.50 \mathrm{E}-09$ & 2.0 & $2.80 \mathrm{E}-06$ \\
\hline GOTERM_BP_FAT & $\begin{array}{l}\text { GO:0001944 vasculature develop- } \\
\text { ment }\end{array}$ & 75 & 2.6 & $5.42 \mathrm{E}-09$ & 2.0 & $1.01 \mathrm{E}-05$ \\
\hline GOTERM_BP_FAT & GO:0048732 gland development & 63 & 2.2 & $7.28 \mathrm{E}-09$ & 2.1 & $1.36 \mathrm{E}-05$ \\
\hline GOTERM_BP_FAT & $\begin{array}{l}\text { GO:0002520 immune system devel- } \\
\text { opment }\end{array}$ & 83 & 2.9 & $2.01 \mathrm{E}-08$ & 1.8 & 3.74E-05 \\
\hline GOTERM_BP_FAT & $\begin{array}{l}\text { GO:0032680 regulation of tumor ne- } \\
\text { crosis factor production }\end{array}$ & 18 & 0.6 & 2.33E-08 & 4.4 & 4.35E-05 \\
\hline GOTERM_BP_FAT & $\begin{array}{l}\text { GO:0009891 positive regulation of bi- } \\
\text { osynthetic process }\end{array}$ & 132 & 4.6 & $1.30 \mathrm{E}-07$ & 1.5 & $2.42 \mathrm{E}-04$ \\
\hline GOTERM_BP_FAT & GO:0042330 taxis & 39 & 1.4 & $3.30 \mathrm{E}-07$ & 2.3 & $6.15 \mathrm{E}-04$ \\
\hline GOTERM_BP_FAT & GO:0035295 tube development & 72 & 2.5 & $6.98 \mathrm{E}-07$ & 1.8 & $1.30 \mathrm{E}-03$ \\
\hline GOTERM_BP_FAT & GO:0016477 cell migration & 65 & 2.3 & $3.32 \mathrm{E}-06$ & 1.8 & $6.19 \mathrm{E}-03$ \\
\hline GOTERM_BP_FAT & GO:0007049 cell cycle & 135 & 4.7 & 5.37E-06 & 1.4 & 1.00E-02 \\
\hline GOTERM_BP_FAT & $\begin{array}{l}\text { GO:0042325 regulation of phosphor- } \\
\text { ylation }\end{array}$ & 74 & 2.6 & $6.81 \mathrm{E}-06$ & 1.7 & 1.27E-02 \\
\hline GOTERM_BP_FAT & $\begin{array}{l}\text { GO:0048568 embryonic organ devel- } \\
\text { opment }\end{array}$ & 64 & 2.2 & 7.95E-06 & 1.7 & $1.48 \mathrm{E}-02$ \\
\hline GOTERM_BP_FAT & $\begin{array}{l}\text { GO:0010627 regulation of protein ki- } \\
\text { nase cascade }\end{array}$ & 45 & 1.6 & $2.10 \mathrm{E}-05$ & 1.9 & 3.93E-02 \\
\hline GOTERM_CC_FAT & GO:0044421 extracellular region part & 222 & 7.7 & $2.55 \mathrm{E}-24$ & 1.9 & $3.71 \mathrm{E}-21$ \\
\hline GOTERM_CC_FAT & GO:0009986 cell surface & 108 & 3.7 & $4.17 \mathrm{E}-19$ & 2.4 & $6.05 \mathrm{E}-16$ \\
\hline GOTERM_CC_FAT & GO:0005886 plasma membrane & 575 & 19.9 & $1.77 \mathrm{E}-16$ & 1.3 & $3.22 \mathrm{E}-13$ \\
\hline GOTERM_CC_FAT & GO:0043235 receptor complex & 28 & 1.0 & 4.05E-05 & 2.3 & $5.88 \mathrm{E}-02$ \\
\hline GOTERM_MF_FAT & GO:0019955 cytokine binding & 43 & 1.5 & $2.25 \mathrm{E}-13$ & 3.3 & $3.69 \mathrm{E}-10$ \\
\hline GOTERM_MF_FAT & GO:0019838 growth factor binding & 37 & 1.3 & $2.02 \mathrm{E}-12$ & 3.5 & 3.30E-09 \\
\hline GOTERM_MF_FAT & GO:0005125 cytokine activity & 48 & 1.7 & $5.25 \mathrm{E}-05$ & 1.8 & 8.59E-02 \\
\hline KEGG_PATHWAY & $\begin{array}{l}\text { mmu04060:Cytokine-cytokine recep- } \\
\text { tor interaction }\end{array}$ & 90 & 3.1 & $2.12 \mathrm{E}-15$ & 2.3 & $2.61 \mathrm{E}-12$ \\
\hline KEGG_PATHWAY & mmu04512:ECM-receptor interaction & 38 & 1.3 & $6.85 \mathrm{E}-10$ & 2.8 & 8.47E-07 \\
\hline KEGG_PATHWAY & mmu04510:Focal adhesion & 60 & 2.1 & 6.79E-07 & 1.9 & $8.40 \mathrm{E}-04$ \\
\hline KEGG_PATHWAY & mmu04640:Hematopoietic cell lineage & 33 & 1.1 & $8.28 \mathrm{E}-07$ & 2.4 & $1.02 \mathrm{E}-03$ \\
\hline KEGG_PATHWAY & $\begin{array}{l}\text { mmu04514:Cell adhesion molecules } \\
\text { (CAMs) }\end{array}$ & 49 & 1.7 & $1.87 \mathrm{E}-06$ & 2.0 & $2.31 \mathrm{E}-03$ \\
\hline KEGG_PATHWAY & $\begin{array}{l}\text { mmu04620:Toll-like receptor signaling } \\
\text { pathway }\end{array}$ & 35 & 1.2 & $5.85 \mathrm{E}-06$ & 2.2 & 7.23E-03 \\
\hline KEGG_PATHWAY & mmu04940:Type I diabetes mellitus & 25 & 0.9 & $1.96 \mathrm{E}-05$ & 2.5 & $2.42 \mathrm{E}-02$ \\
\hline KEGG_PATHWAY & $\begin{array}{l}\text { mmu04610:Complement and coagula- } \\
\text { tion cascades }\end{array}$ & 28 & 1.0 & 2.02E-05 & 2.3 & $2.50 \mathrm{E}-02$ \\
\hline KEGG_PATHWAY & $\begin{array}{l}\text { mmu05322:Systemic lupus erythema- } \\
\text { tosus }\end{array}$ & 34 & 1.2 & 4.11E-05 & 2.0 & $5.08 \mathrm{E}-02$ \\
\hline KEGG_PATHWAY & $\begin{array}{l}\text { mmu04621:NOD-like receptor signal- } \\
\text { ing pathway }\end{array}$ & 24 & 0.8 & 4.78E-05 & 2.4 & $5.90 \mathrm{E}-02$ \\
\hline
\end{tabular}




\begin{tabular}{|c|c|c|c|c|c|c|}
\hline Category & Term & Count & $\%$ & p-value & $\begin{array}{c}\text { Fold } \\
\text { Enrichment }\end{array}$ & FDR \\
\hline GOTERM_BP_FAT & $\begin{array}{l}\text { GO:0019226 transmission of nerve } \\
\text { impulse }\end{array}$ & 48 & 2.5 & 3.00E-09 & 2.6 & $5.34 \mathrm{E}-06$ \\
\hline GOTERM_BP_FAT & GO:0006811 ion transport & 105 & 5.5 & 6.39E-09 & 1.8 & $1.14 \mathrm{E}-05$ \\
\hline GOTERM_BP_FAT & $\begin{array}{l}\text { GO:0031644 regulation of neurologi- } \\
\text { cal system process }\end{array}$ & 29 & 1.5 & $1.05 \mathrm{E}-07$ & 3.1 & $1.87 \mathrm{E}-04$ \\
\hline GOTERM_BP_FAT & $\begin{array}{l}\text { GO:0031175 neuron projection devel- } \\
\text { opment }\end{array}$ & 43 & 2.3 & $1.99 \mathrm{E}-07$ & 2.4 & $3.55 \mathrm{E}-04$ \\
\hline GOTERM_BP_FAT & GO:0016337 cell-cell adhesion & 44 & 2.3 & $7.10 \mathrm{E}-07$ & 2.2 & $1.27 \mathrm{E}-03$ \\
\hline GOTERM_BP_FAT & GO:0048666 neuron development & 49 & 2.6 & $3.52 \mathrm{E}-06$ & 2.0 & $6.28 \mathrm{E}-03$ \\
\hline GOTERM_BP_FAT & GO:0030534 adult behavior & 23 & 1.2 & $5.44 \mathrm{E}-06$ & 3.0 & 9.70E-03 \\
\hline GOTERM_BP_FAT & $\begin{array}{ll}\text { GO:0006793 phosphorus metabolic } \\
\text { process }\end{array}$ & 106 & 5.6 & $4.20 \mathrm{E}-05$ & 1.5 & 7.47E-02 \\
\hline GOTERM_CC_FAT & GO:0045202 synapse & 80 & 4.2 & $1.21 \mathrm{E}-17$ & 2.8 & $1.71 \mathrm{E}-14$ \\
\hline GOTERM_CC_FAT & GO:0030054 cell junction & 81 & 4.3 & $9.84 \mathrm{E}-09$ & 1.9 & $1.39 \mathrm{E}-05$ \\
\hline GOTERM_CC_FAT & GO:0005624 membrane fraction & 84 & 4.4 & $4.12 \mathrm{E}-08$ & 1.8 & $5.80 \mathrm{E}-05$ \\
\hline GOTERM_CC_FAT & GO:0005856 cytoskeleton & 145 & 7.6 & $3.12 \mathrm{E}-06$ & 1.4 & 4.39E-03 \\
\hline GOTERM_CC_FAT & GO:0005874 microtubule & 44 & 2.3 & 7.23E-06 & 2.1 & $1.02 \mathrm{E}-02$ \\
\hline GOTERM_CC_FAT & GO:0008021 synaptic vesicle & 19 & 1.0 & $1.94 \mathrm{E}-05$ & 3.1 & $2.74 \mathrm{E}-02$ \\
\hline GOTERM_MF_FAT & GO:0043167 ion binding & 442 & 23.3 & $8.29 \mathrm{E}-13$ & 1.3 & $1.30 \mathrm{E}-09$ \\
\hline GOTERM_MF_FAT & GO:0005216 ion channel activity & 68 & 3.6 & $1.48 \mathrm{E}-10$ & 2.3 & 2.32E-07 \\
\hline GOTERM_MF_FAT & $\begin{array}{l}\text { GO:0042165 neurotransmitter bind- } \\
\text { ing }\end{array}$ & 22 & 1.2 & $9.02 \mathrm{E}-06$ & 3.0 & $1.41 \mathrm{E}-02$ \\
\hline GOTERM_MF_FAT & GO:0016917 $\sim$ GABA receptor activity & 12 & 0.6 & $1.92 \mathrm{E}-05$ & 4.7 & $3.00 \mathrm{E}-02$ \\
\hline KEGG_PATHWAY & $\begin{array}{l}\text { mmu04080:Neuroactive ligand-recep- } \\
\text { tor interaction }\end{array}$ & 50 & 2.6 & 2.39E-08 & 2.3 & $2.89 \mathrm{E}-05$ \\
\hline KEGG_PATHWAY & mmu04360:Axon guidance & 31 & 1.6 & $1.92 \mathrm{E}-07$ & 2.8 & $2.32 \mathrm{E}-04$ \\
\hline KEGG_PATHWAY & mmu04020:Calcium signaling pathway & 38 & 2.0 & $6.78 \mathrm{E}-07$ & 2.4 & $8.20 \mathrm{E}-04$ \\
\hline KEGG_PATHWAY & mmu04540:Gap junction & 23 & 1.2 & $1.17 \mathrm{E}-06$ & 3.2 & $1.42 \mathrm{E}-03$ \\
\hline KEGG_PATHWAY & mmu04010:MAPK signaling pathway & 45 & 2.4 & $4.91 \mathrm{E}-06$ & 2.0 & $5.94 \mathrm{E}-03$ \\
\hline KEGG_PATHWAY & $\begin{array}{l}\text { mmu04810:Regulation of actin cyto- } \\
\text { skeleton }\end{array}$ & 37 & 1.9 & 3.77E-05 & 2.0 & 4.55E-02 \\
\hline
\end{tabular}

Differentially expressed genes taken for analysis had $\mathrm{q}<0.01$ and $\log _{2} \mathrm{FC}>0.5$. Cut-off for enriched terms: FDR $<0.1$. 
Table 3.16: GO-Term and KEGG-Pathway analysis of the inducible CaMKCreER ${ }^{\mathrm{T} 2} \mathrm{TIP}^{\mathrm{T}}$-deficiency line.

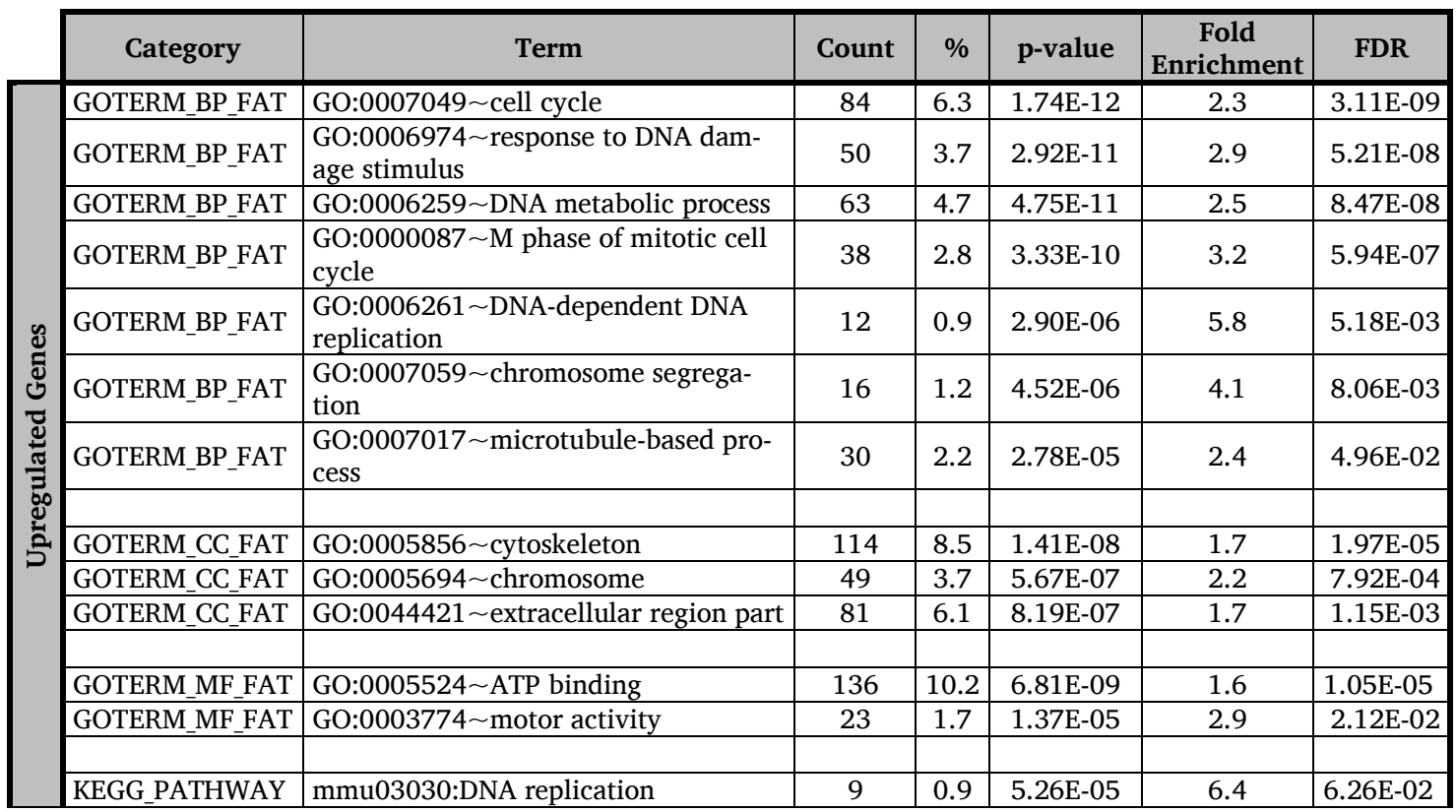

\begin{tabular}{|c|c|c|c|c|c|c|c|}
\hline & Category & Term & Count & $\%$ & p-value & $\begin{array}{c}\text { Fold } \\
\text { Enrichment }\end{array}$ & FDR \\
\hline \multirow{9}{*}{ 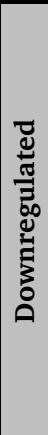 } & GOTERM_BP_FAT & GO:0006811 ion transport & 60 & 6.1 & 7.68E-07 & 2.0 & $1.32 \mathrm{E}-03$ \\
\hline & GOTERM_BP_FAT & GO:0016337 cell-cell adhesion & 28 & 2.9 & $3.21 \mathrm{E}-06$ & 2.8 & $5.52 \mathrm{E}-03$ \\
\hline & GOTERM_BP_FAT & GO:0030182 neuron differentiation & 36 & 3.7 & $4.72 \mathrm{E}-05$ & 2.1 & $8.13 \mathrm{E}-02$ \\
\hline & GOTERM_BP_FAT & GO:0048666 neuron development & 29 & 3.0 & $5.79 \mathrm{E}-05$ & 2.3 & $9.96 \mathrm{E}-02$ \\
\hline & GOTERM_CC_FAT & GO:0005886 plasma membrane & 192 & 19.6 & $1.82 \mathrm{E}-08$ & 1.4 & $2.48 \mathrm{E}-05$ \\
\hline & GOTERM MF FAT & GO:0043167 ion binding & 228 & 23.3 & 8.98E-08 & 1.3 & 1.33E-04 \\
\hline & GOTERM_MF_FAT & GO:0005216 ion channel activity & 38 & 3.9 & $3.81 \mathrm{E}-07$ & 2.5 & $5.65 \mathrm{E}-04$ \\
\hline & KEGG_PATHWAY & mmu04540:Gap junction & 14 & 1.4 & $2.51 \mathrm{E}-05$ & 4.1 & $2.29 \mathrm{E}-02$ \\
\hline & KEGG_PATHWAY & mmu04010:MAPK signaling pathway & 26 & 2.7 & 3.33E-05 & 2.5 & 3.88E-02 \\
\hline
\end{tabular}

Differentially expressed genes taken for analysis had $\mathrm{q}<0.01$ and $\log _{2} \mathrm{FC}>0.5$. Cut-off for enriched terms: FDR $<0.1$. 


\subsection{TIP60 Histone Targets}

While recombinant TIP60 can acetylate free histones H2A, H3, and H4 in vitro (Kimura et al., 1998; Yamamoto et al., 1997), it is only able to acetylate nucleosomal histones when in a stable multiprotein complex. The TIP60 complex can acetylate histones H2A and H4, and - albeit to a lesser degree - also H3 (Ikura et al., 2000). In order to quantify changes in acetylation levels in TIP60-deficient hippocampus, Western blot was performed with samples of CaMKCreER ${ }^{\mathrm{T} 2} \mathrm{Tip}^{\mathrm{f} / \mathrm{f}}$ and control mice (Figure 3.43). Due to TIP60's known role in histone acetylation, a downregulation of the examined histone targets was expected. Except for H3K14 acetylation, which showed a trend towards higher levels in CaMKCreER ${ }^{\mathrm{T} 2} \mathrm{Tip}^{\mathrm{f} / \mathrm{f}}$ mice, all histone acetylations analyzed indeed showed a trend towards decreased levels in the CaMKCreER ${ }^{\mathrm{T} 2} \mathrm{Tip}^{\mathrm{f}} \mathrm{f} / \mathrm{f}$ mice. However, only the downregulation of H4K5ac by $39 \%$ reached significance $(p=0.0102)$. H4K6ac was downregulated by $19.5 \%(\mathrm{p}=0.3422)$, H4K12ac by $28 \%(\mathrm{p}=0.1258)$, and H4K8ac by $8.6 \%(p=0.6710)$ but neither of them reached significance. H3K14ac was upregulated by $30.3 \%(\mathrm{p}=0.1224)$.

Quantification of histone acetylation levels in Western blot provided an overall estimation of changes in histone acetylation due to TIP60-deficiency but could not provide an
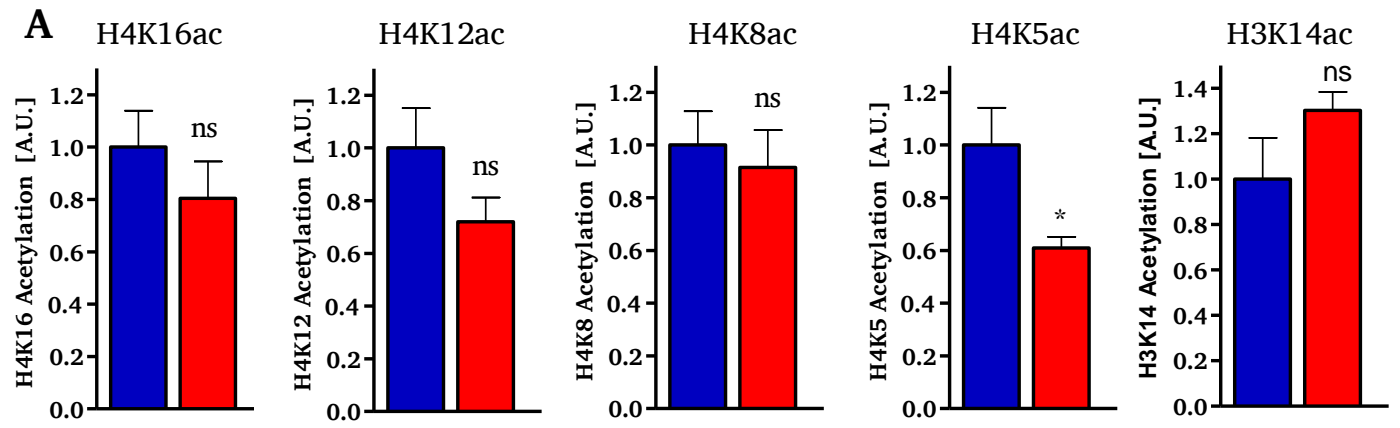

$\square \operatorname{Tip} 60^{\mathrm{f} / \mathrm{f}}$

CaMKCreER ${ }^{\mathrm{T} 2} \mathrm{Tip} 60^{\mathrm{f} / \mathrm{f}}$
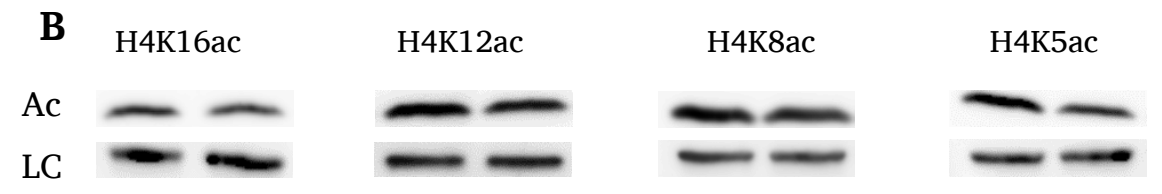

H3K14ac

Figure 3.43: Histone acetylation levels in CaMKCreER ${ }^{\mathrm{T} 2} \operatorname{Tip}^{\mathrm{f} / \mathrm{f}}$ hippocampus samples. Western blot results of histone acetylation levels in whole hippocampus samples of Tip60 ${ }^{\mathrm{f} / \mathrm{f}}$ control and CaMKCreER ${ }^{\mathrm{T} 2}$ Tip60 ${ }^{\mathrm{f} / \mathrm{f}}$ mice ( $\mathrm{n}=4-5$ per genotype). (A) Quantifications of H4K16, H4K12, H4K8, H4K5 and H3K14 acetylation are shown. Two-tailed student's $t$-test, ns: $\mathrm{p}>0.05$, ${ }^{*} \mathrm{p}<0.05$. (B) Representative bands used for quantifications are shown underneath the respective bar graphs. Abbreviations: Ac $=$ Histone acetylation, LC = loading control (Actin for all but H4K12ac (Gapdh)). Error bars represent SEM. A.U. = arbitrary units. 
A

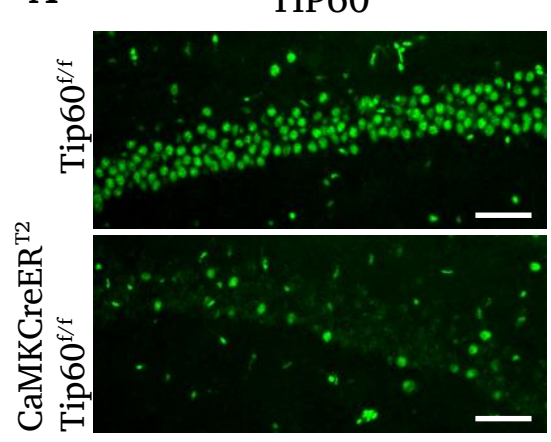

panH4ac

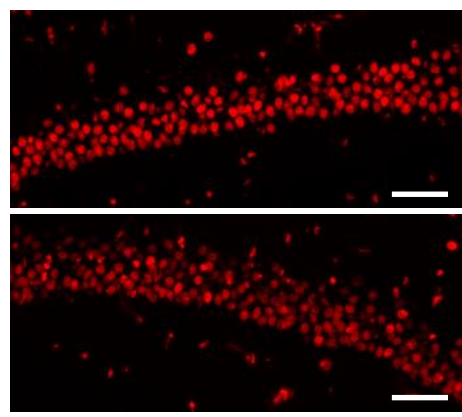

Overlay

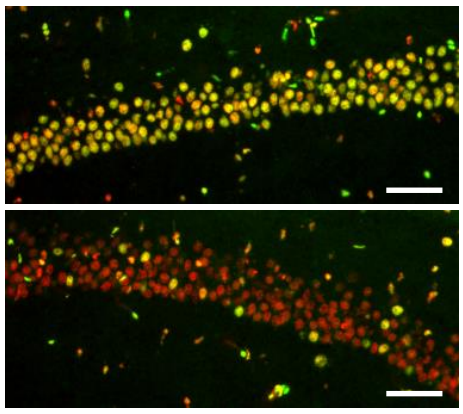

B
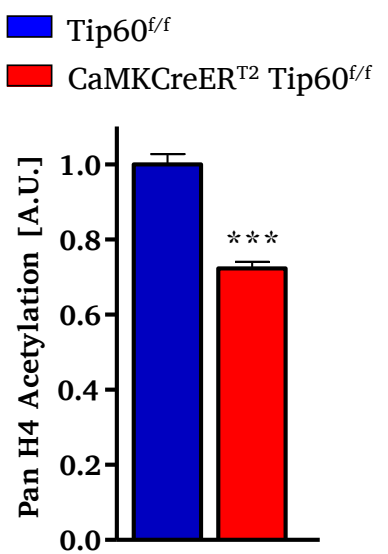

Figure 3.44: PanH4 acetylation is downregulated in TIP60-deficient cells the CA1 region. (A) Representative images of TIP60 and panH4ac signal in the CA1 region of CaMKCreER ${ }^{\mathrm{T} 2} \mathrm{Tip}^{\mathrm{f} / \mathrm{f}}$ and Tip60 ${ }^{\mathrm{f} / \mathrm{f}}$ control animals are shown. Scale bars represent $50 \mu \mathrm{m}$. (B) Quantification of pan histone $\mathrm{H} 4$ acetylation signal intensities in TIP60-deficient and wild type cells in the dorsal CA1 region of CaMK$\mathrm{CreER}^{\mathrm{T} 2} \mathrm{Tip}^{\mathrm{f} / \mathrm{f}}$ mice in IHC $(\mathrm{n}=4,4$ sections per animal). Two-tailed student's $t$-test, ${ }^{* * *} \mathrm{p}<0.0001$. Error bars represent SEM. A.U. $=$ arbitrary units.

accurate estimation of changes between TIP60-deficient and wild type neurons due to contamination with glial cells and residual wild type neurons. In order to assess the effect of the Tip60 knockout on histone acetylation more accurately, IHC double labeling was performed in the CA1 region of CaMKCreER ${ }^{\mathrm{T} 2} \mathrm{Tip}^{\mathrm{f} / \mathrm{f}}$ mice using TIP60P4 and panH4ac antibodies. The CA1 region was chosen since this region was also taken for RNA-Seq analysis, thereby allowing to possibly correlate the two data modalities. The IHC double labeling allowed to quantify signal intensities between directly neighboring TIP60-deficient and wild type cells in the same sections. Since H4 is the main histone target of TIP60, the double labeling allowed to assess the in vivo effect of Tip60 loss on the acetylation of this histone. As expected, panH4 acetylation levels were significantly downregulated by $27.7 \%$ in TIP60-deficient cells compared to wild type cells (Figure $3.44)$.

The downregulation of panH4 acetylation demonstrated that TIP60-deficiency in a particular neuron directly translated into a reduction of acetylation of a bona fide TIP60 target. That panH4 is still acetylated, albeit lower levels, suggested a redundancy by other HATs. 


\subsection{TIP60 Non-Histone Targets}

Numerous TIP60 non-histone targets have been identified, among them p53 and ATM (Tang et al., 2006; Sun et al., 2007). TIP60 shares many histone as well as non-histone substrates with acetyltransferase P300 (Xiao et al., 2014; Ogryzko et al., 1996; Kimura et al., 1998). These two proteins appear to act together very closely since TIP60 is also acetylated by P300 (Col et al., 2005). Furthermore, SIRT1 is a counteracting deacetylase for both TIP60 and P300 (Wang et al., 2010; Bouras et al., 2005). Recently, P300 and SIRT1 have been shown to regulate the acetylation status of MECP2 and thereby the transcriptional level of Bdnf exon IV expression (Zocchi, 2012). Upon acetylation at K464 by P300 - and to a lesser degree also by CBP - MECP2 binds to Bdnf exon IV, inhibiting its transcription. When SIRT1 deacetylates MECP2 it is released from the DNA and transcription of $B d n f$ exon $I V$ is upregulated. Since $B d n f$ exon $I V$ was significantly upregulated in both Tip60 conditional knockout mouse models used in this work, the acetylation status of MECP2 was analyzed using a commercially available antibody against MECP2 $2^{\mathrm{K} 464 \mathrm{ac}}$. IHC analyses of CaMKCreER ${ }^{\mathrm{T2}} \mathrm{Tip}^{\mathrm{f} / \mathrm{f}}$ and CaMKCre Tip60 ${ }^{\mathrm{f} / \mathrm{f}}$ mice revealed a downregulation of MECP2 $2^{\mathrm{K} 464}$ acetylation levels in the hippocampus of TIP60-deficient animals (Figure 3.46 and Figure 3.48). In order to exclude that the overall abundancy of MECP2 was decreased, IHC was also performed with a pan-MECP2 antibody on sections of CaMKCreER ${ }^{\mathrm{T} 2} \mathrm{Tip}^{\mathrm{f} / \mathrm{f}}$ and Tip60 ${ }^{\mathrm{f} / \mathrm{f}}$ animals (Figure 3.47). However, staining intensity was similar between genotypes demonstrating that MECP2 is hypoacetylated in the TIP60-deficient hippocampus. Since Zocchi et al. (2012) reported that MECP2 is a substrate of the acetyltransferase P300, the overall levels of P300 were analyzed using IHC in order to exclude a decrease in P300 levels as a cause of hypoacetylation of MECP2. Staining intensities appeared similar between genotypes (Figure 3.50). P300 is known to have numerous acetylation sites, among which K1499 is especially critical for its enzymatic activity (Thompson et al., 2004). The acetylation status of $\mathrm{P} 300^{\mathrm{K} 1499}$ was thus analyzed in sections of the hippocampus by IHC. Downregulation of the acetylation of K1499 acetylation of P300 was apparent in TIP60-deficient animals of both mouse models when compared to control animals (Figure 3.49 and Figure 3.51). Of note, the antibody used to detect acetylation of $\mathrm{P} 300^{\mathrm{K} 1499}$ cannot distinguish between the acetylation of P300 at K1499 and the acetylation of CBP at K1535 due to complete conservation of this region. 


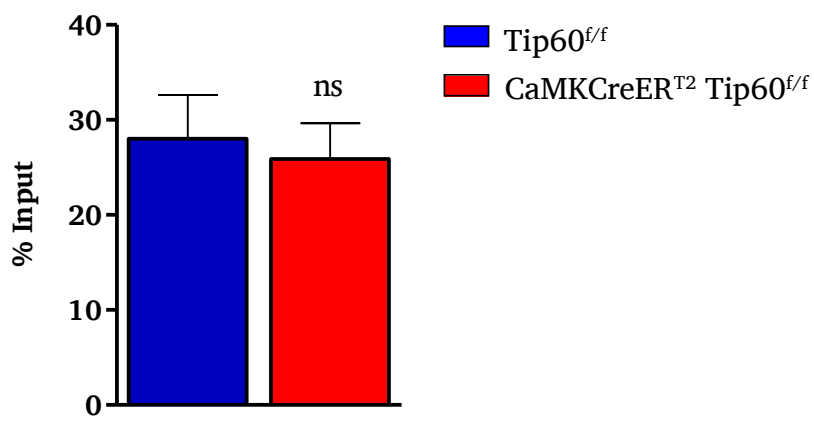

Figure 3.45: Binding of MECP2 ${ }^{\mathrm{K} 464 \mathrm{ac}}$ at Bdnf exon IV is comparable between CaMKCreER ${ }^{\mathrm{T} 2}$ $\mathrm{Tip60}^{\mathrm{f} / \mathrm{f}}$ and Tip60 ${ }^{\mathrm{f} / \mathrm{f}}$ mice. ChIP results of MECP2 ${ }^{\mathrm{K} 464 a c}$ binding to Bdnf exon IV using microdissected hippocampal CA1 region of CaMKCreER ${ }^{\mathrm{T} 2} \mathrm{Tip} 60^{\mathrm{f} / \mathrm{f}}$ and Tip60 $0^{\mathrm{f} / \mathrm{f}}$ mice. Graph shows percent input enrichment. Two-tailed student's $t$-test, ns: $\mathrm{p}>0.5, \mathrm{n}=3$ per genotype. Error bars represent SEM.

Chromatin immunoprecipitation (ChIP) was performed in order to assess whether the hypoacetylation of MECP2 led to the upregulation of Bdnf exon IV detected by qPCR and RNA-Seq. The CA1 region of CaMKCreER ${ }^{\mathrm{T} 2} \mathrm{Tip}^{\mathrm{f} / \mathrm{f}}$ and Tip60 $0^{\mathrm{f} / \mathrm{f}}$ mice was taken for ChIP analysis. However, no significant changes in MECP2 $2^{\mathrm{K} 464 a \mathrm{a}}$ occupation of Bdnf exon IV were detected (Figure 3.45). IgG levels were $<0.5 \%$ of the input for either genotype.

Extensive bioinformatical analyses were performed in collaboration with Haifang Wang in order to compare MECP2 targets identified in microarray and RNA-Seq experiments published by other groups (Skene, 2010; Chahrour et al., 2008) with the significantly changed genes in TIP60-deficient CA1 region. However, promising candidate genes have not been identified so far.

In summary, MECP2 and P300 are hypoacetylated in TIP60-deficient hippocampus and possibly contribute to the broad transcriptional changes identified by NGS analysis. However, the exact molecular consequences, if any, of this hypoacetylation of MECP2 have yet to be elucidated. 
$\operatorname{Tip} 60^{\mathrm{f} / \mathrm{f}}$
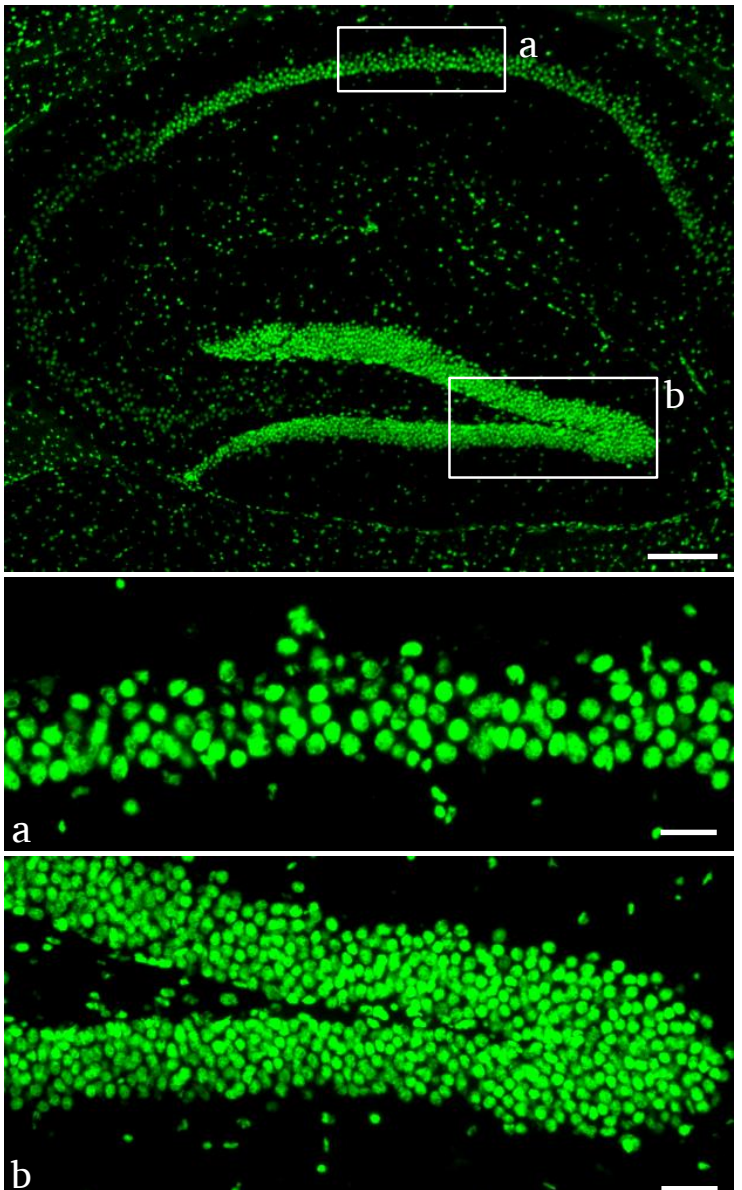

Figure 3.46: Acetylation of MECP2 is decreased in the hippocampus of CaMKCreER ${ }^{\mathrm{T} 2} \mathrm{Tip}^{\mathrm{ff} / \mathrm{f}}$ mice Overview images of MECP2 $2^{\mathrm{K} 464 a \mathrm{c}}$ immunoreactivity in the hippocampus of Tip $60^{\mathrm{f} / \mathrm{f}}$ control and CaMKCreER ${ }^{\mathrm{T} 2}$

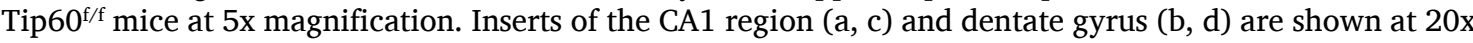
magnification. $10 \mu \mathrm{m}$ sagittal sections, $\mathrm{n}=4$ per genotype, 4 sections per animal. Scale bars represent 250 $\mu \mathrm{m}$ for $5 \mathrm{x}$ and $50 \mu \mathrm{m}$ for $20 \mathrm{x}$ magnifications.

$\operatorname{Tip} 60^{\mathrm{f} / \mathrm{f}}$

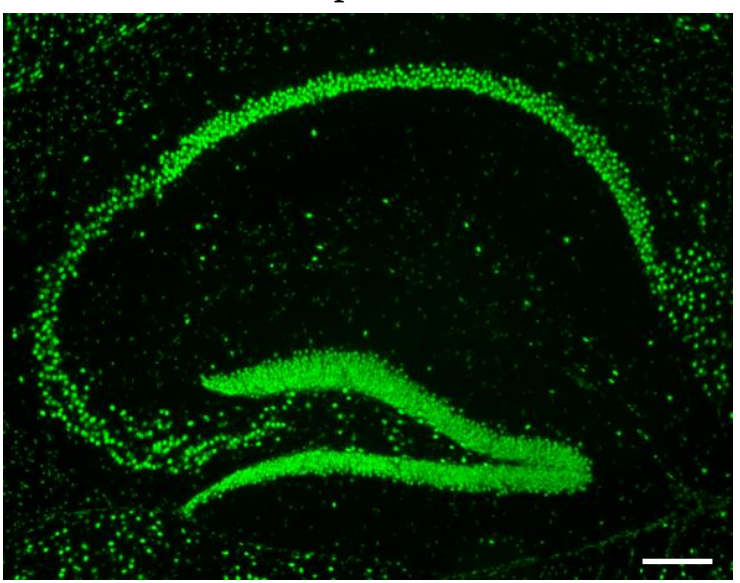

CaMKCreER $^{\mathrm{T} 2} \mathrm{Tip}^{\mathrm{f} / \mathrm{f}}$

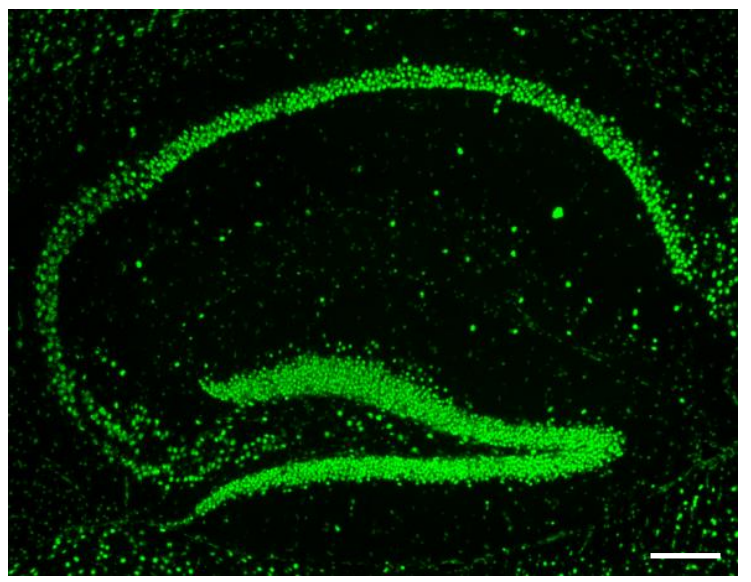

Figure 3.47: MECP2 staining intensities are comparable between CaMKCreER ${ }^{\mathrm{T} 2} \mathrm{Tip}^{\mathrm{f} / \mathrm{f}}$ and $\mathrm{Tip60} \mathrm{0}^{\mathrm{f} / \mathrm{f}}$ control mice. MECP2 immunoreactivity in the hippocampus of Tip60 $0^{\mathrm{f} / \mathrm{f}}$ and CaMKCreER $\mathrm{R}^{\mathrm{T} 2} \mathrm{Tip} 60^{\mathrm{f} / \mathrm{f}}$ animals. $10 \mu \mathrm{m}$ sagittal sections, $\mathrm{n}=4$ per genotype, 4 sections per animal. Scale bar represents $250 \mu \mathrm{m}$. 
$\operatorname{Tip} 60^{\mathrm{f} / \mathrm{f}}$
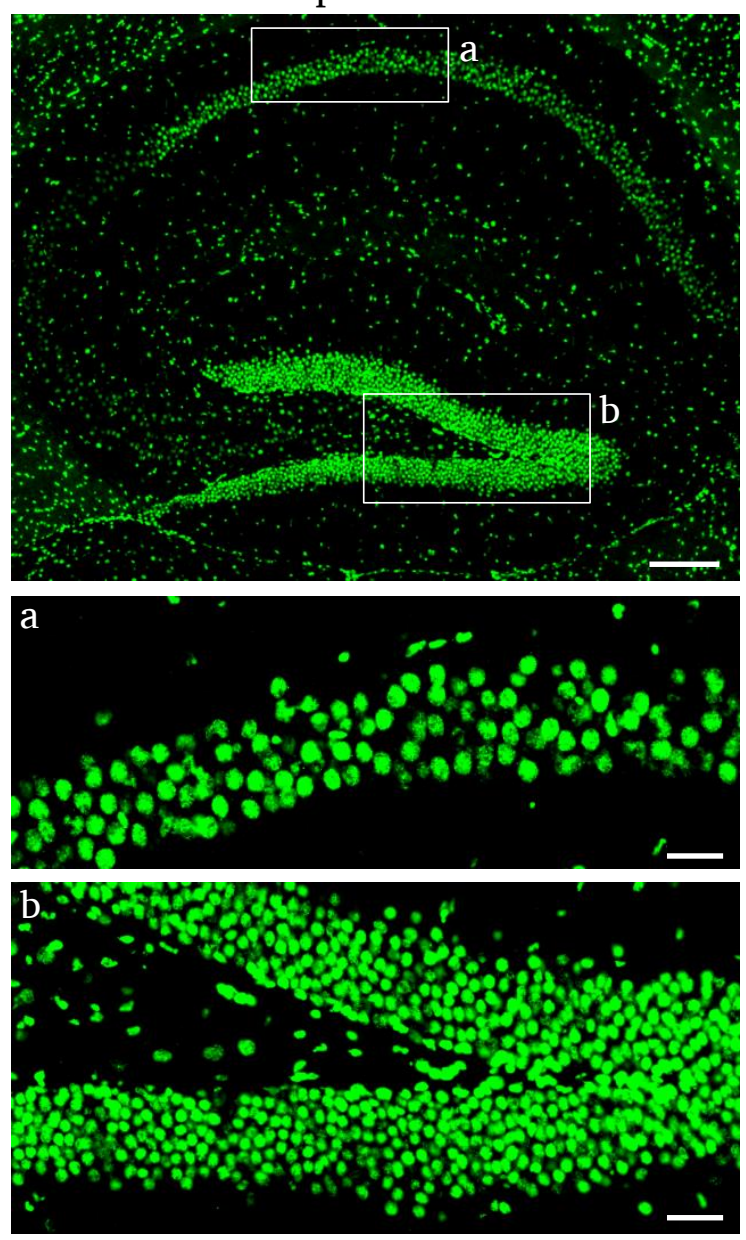

CaMKCre Tip60
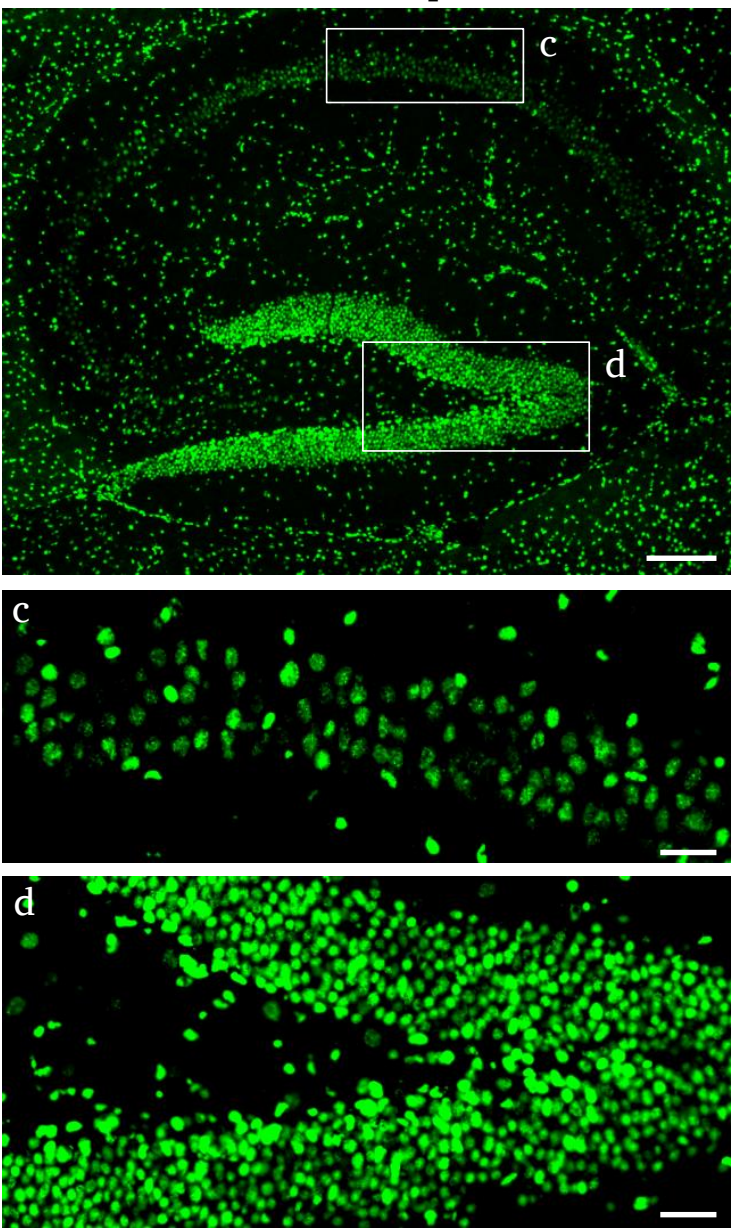

Figure 3.48: Acetylation of MECP2 is decreased in the hippocampus CaMKCre Tip60 ${ }^{\mathrm{f} / \mathrm{f}} \mathrm{mice}$. Overview images of MECP2 $2^{\mathrm{K} 464 \mathrm{c}}$ immunoreactivity in the hippocampus of Tip60 ${ }^{\mathrm{f} / \mathrm{f}}$ control and CaMKCre Tip60 $0^{\mathrm{fff}}$ mice at $5 x$ magnification. Inserts of the CA1 region (a, c) and dentate gyrus (b, d) at 20x magnification showing a mosaic of brighter and darker cells in the TIP60-deficient tissue (c, d). $10 \mu \mathrm{m}$ sagittal sections, $\mathrm{n}=3$ per genotype, 4 sections per animal. Scale bars represent $250 \mu \mathrm{m}$ for $5 \mathrm{x}$ and $50 \mu \mathrm{m}$ for $20 \mathrm{x}$ magnifications. 
$\operatorname{Tip} 60^{\mathrm{f} / \mathrm{f}}$
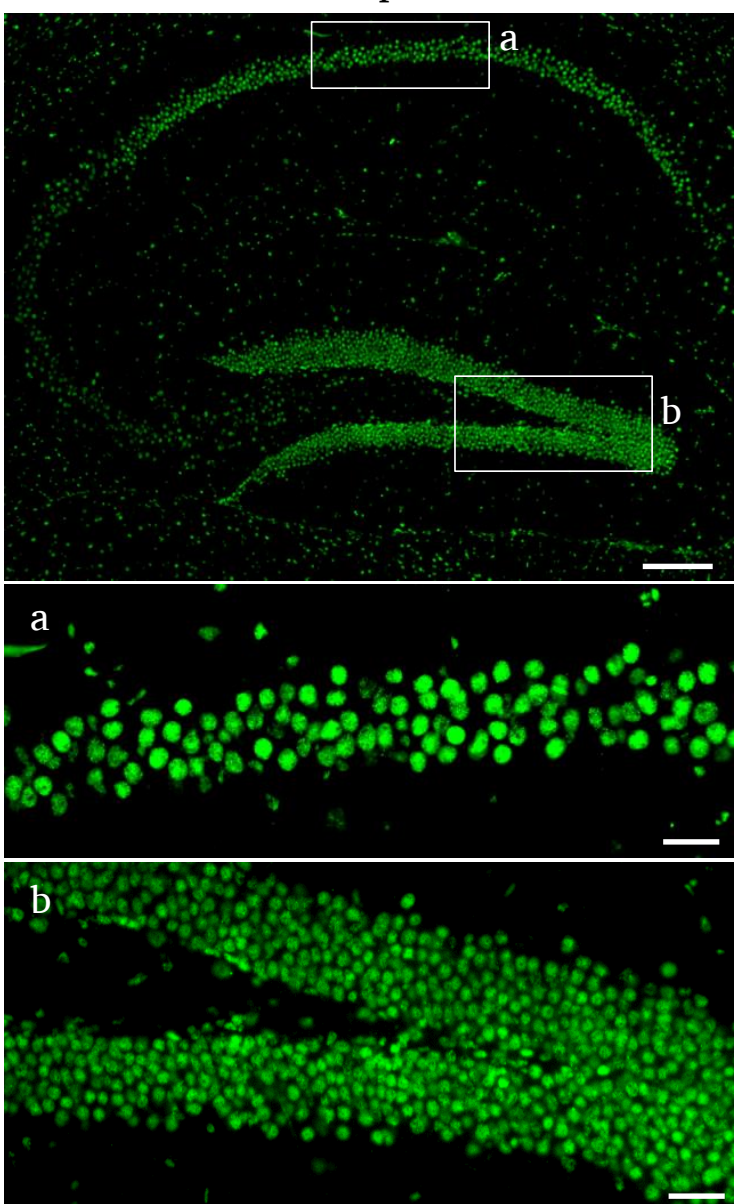

CaMKCreER $^{\mathrm{T} 2} \operatorname{Tip}^{\mathrm{f} / \mathrm{f}}$
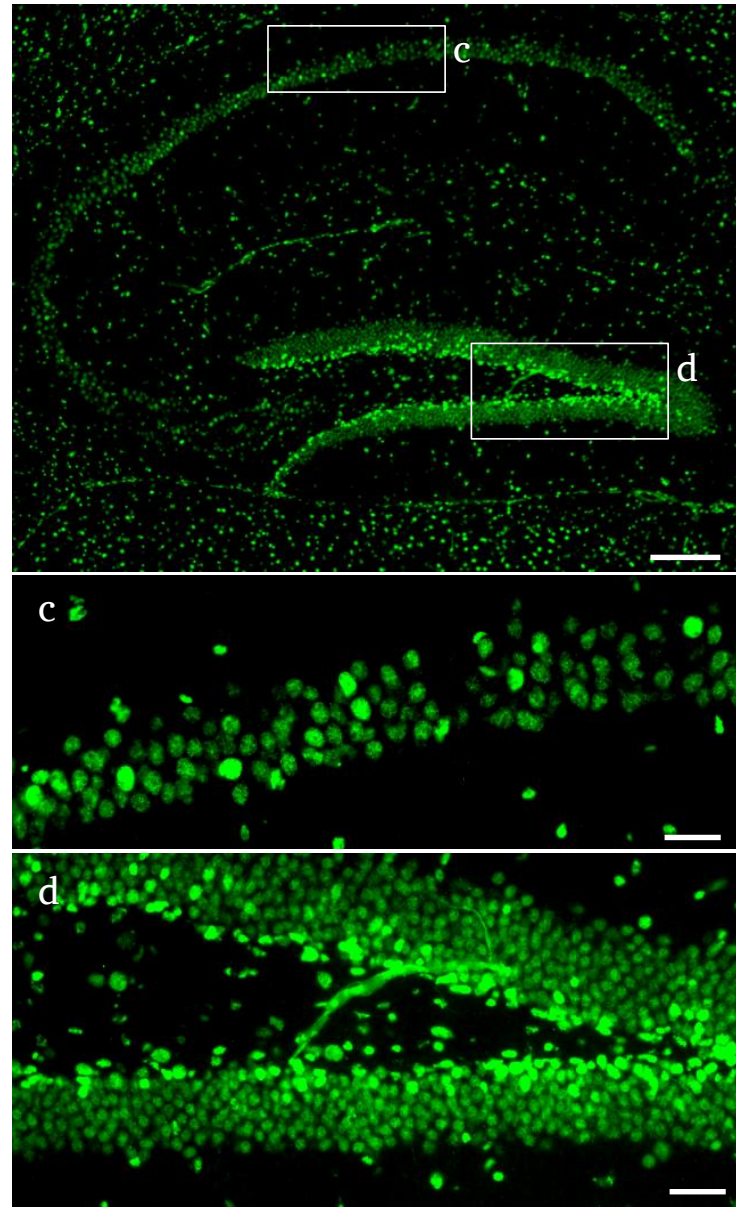

is decreased in the hippocampus of CaMK-

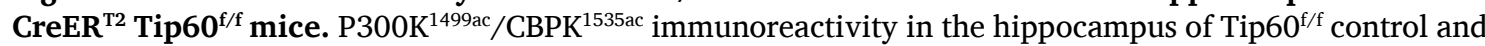
$\mathrm{CaMKCreER}^{\mathrm{T2}} \mathrm{Tip}^{\mathrm{f} / \mathrm{f}}$ mice at $5 \mathrm{x}$ magnification. Inserts of the CA1 region (a, c) and dentate gyrus (b, d) at 20x magnification showing a mosaic of brighter and darker cells in the TIP60-deficient tissue (c, d). $10 \mu \mathrm{m}$ sagittal sections, $\mathrm{n}=4$ per genotype, 4 sections per animal. Scale bars represent $250 \mu \mathrm{m}$ for $5 \mathrm{x}$ and $50 \mu \mathrm{m}$ for 20x magnifications.

$\operatorname{Tip} 60^{\mathrm{f} / \mathrm{f}}$

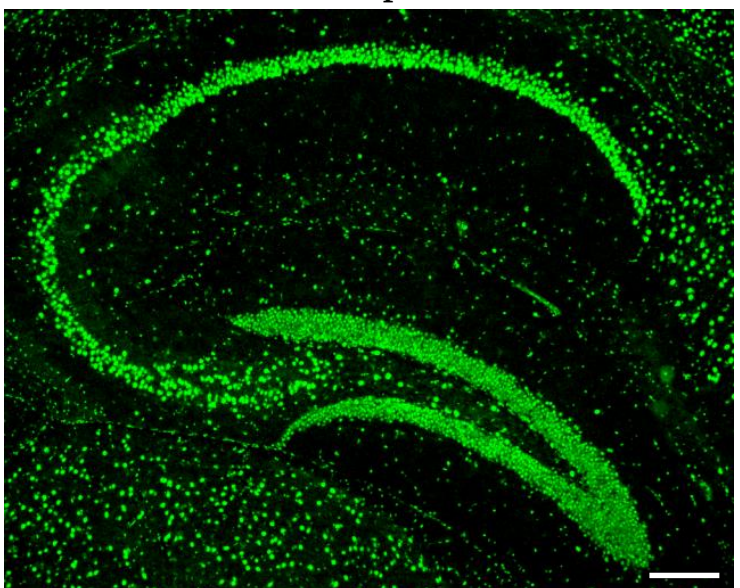

CaMKCreER $^{\mathrm{T} 2} \mathrm{Tip}^{\mathrm{f} / \mathrm{f}}$

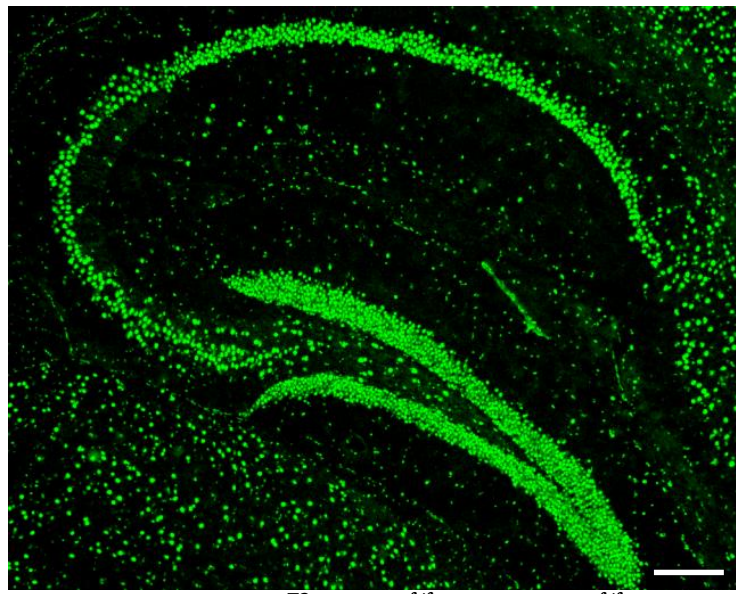

Figure 3.50: Pan P300 levels are comparable between CaMKCreER ${ }^{\mathrm{T} 2} \mathrm{Tip}^{\mathrm{t} / \mathrm{t}}$ and $\mathrm{Tip}^{\mathrm{f}} \mathrm{O}^{\mathrm{f} / \mathrm{c}}$ control mice. P300 immunoreactivity in sections of the hippocampus of Tip60 $0^{\mathrm{f} / \mathrm{f}}$ and CaMKCreER $\mathrm{R}^{\mathrm{T} 2} \mathrm{Tip60} 0^{\mathrm{f} / \mathrm{f}}$ animals. $10 \mu \mathrm{m}$ sagittal sections, $\mathrm{n}=4$ per genotype, 4 sections per animal. Scale bars represent $250 \mu \mathrm{m}$. 
$\operatorname{Tip}^{\mathrm{f} / \mathrm{f}}$
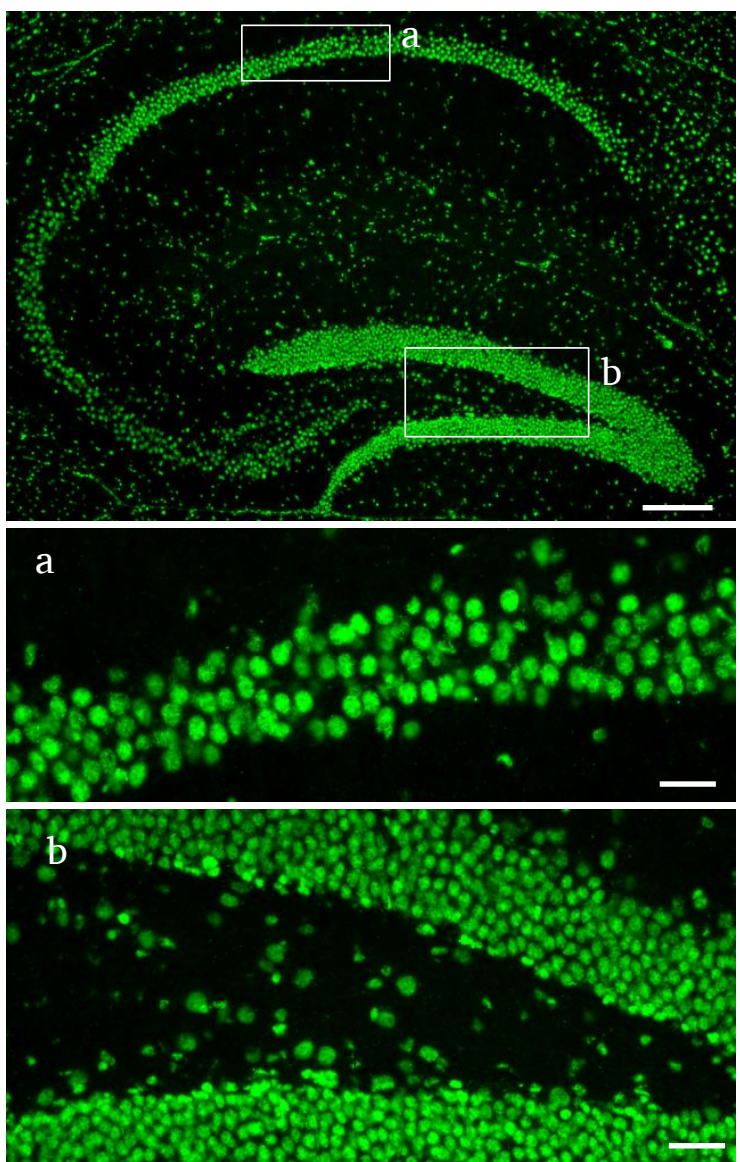

Figure 3.51: Immunoreactivity of ${\mathrm{P} 300^{\mathrm{K} 1499 \mathrm{ac}} / \mathrm{CBP}^{\mathrm{K} 1535 a c} \text { is decreased in CaMKCre Tip60 }}^{\mathrm{f} / \mathrm{f}}$ mice. P300 ${ }^{\mathrm{K} 1499 a \mathrm{c}} / \mathrm{CBPK}^{1535 \mathrm{ac}}$ immunoreactivity in the hippocampus of Tip60 $0^{\mathrm{f} / \mathrm{f}}$ control and CaMKCre Tip60 $0^{\mathrm{f} / \mathrm{f}}$ mice at $5 x$ magnification. Inserts of the CA1 region $(a, c)$ and dentate gyrus (b, d) are shown at 20x magnification showing a mosaic of brighter and darker cells in the TIP60-deficient tissue (c, d). $10 \mu \mathrm{m}$ sagittal sections, $\mathrm{n}=3$ per genotype, 4 sections per animal. Scale bars represent $250 \mu \mathrm{m}$ for $5 \mathrm{x}$ and $50 \mu \mathrm{m}$ for $20 \mathrm{x}$ magnifications.
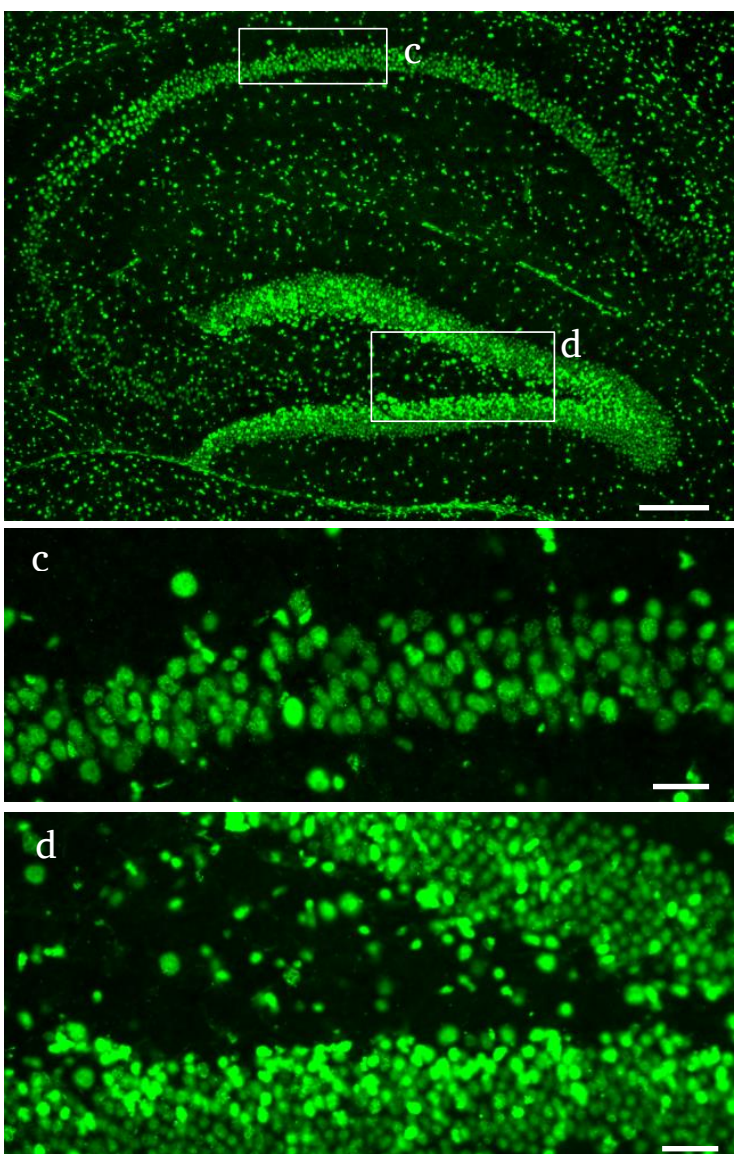



\section{Discussion}

While the presence of Tip60 mRNA in the brain was reported already over a decade ago (McAllister et al., 2002), its function in this organ had not been examined until now. Directing Tip60 deletion to excitatory hippocampal neurons the biochemical and behavioral analyses conducted in the course of this thesis project have given first insights on the consequences of TIP60-deficiency, amongst them genome-wide dysregulation of gene expression in the CA1 region. Moreover, potential new TIP60 in vivo substrates have been identified, which in the case of MECP2 and P300/CBP regulate transcription, thus underlining the broad activity of TIP60 in the regulation of the cellular machinery. In this section, the presented data will be critically reviewed also in the context of recent literature on TIP60.

\subsection{Phenotypes of the TIP60-deficient Mouse Models}

Conventional Tip60 knockout mice do not exist due to early embryonic lethality (Hu et al., 2010). That is why two conditional Tip60 knockout mouse models were established to elucidate TIP60 function in the adult hippocampus. In contrast to conventional knockout mice, conditional knockouts are expected to provide highly local and temporal control of gene deletion. To achieve this, CRE activity is controlled by the regulatory elements of a gene that shows the desired temporal and spatial specificity. For this reason, constitutive CaMKII $\alpha$-CRE driver mice were used for over a decade to achieve efficient, postnatal gene deletion in the forebrain, including the hippocampus. However, when this CRE driver was used to delete Tip60 from the hippocampus, the created Tip60 conditional knockout mice showed compromised health, and eventually lethality often already between 8 - 10 weeks post-partum. Analysis of embryonic stages using LacZ staining showed strong CRE activity both in- and outside the target regions, demonstrating that the constitutive CRE driver is in fact both spatially and temporally quite unspecific. In order to exclude data misinterpretation by possible off-target effects and to allow for a behavioral analysis of TIP60-deficient mice, an inducible CaMKII $\alpha$-CRE driver line $\left(\right.$ CaMKCreER $^{\mathrm{T} 2}$ ) was therefore obtained. 


\subsubsection{Phenotype of the Constitutive Mouse Model (CaMKCre Tip60 ${ }^{\mathrm{f} / \mathrm{f}}$ )}

CaMKCre Tip $60^{\mathrm{f} / \mathrm{f}}$ mice displayed a multitude of abnormalities including decreased body size and early lethality. This made it impossible to analyze effects of TIP60-deficiency on learning and memory in behavioral paradigms with this mouse line. In contrast to reports that the CRE driver's activity is forebrain-specific and mainly confined to postnatal stages (Minichiello et al., 1999) the detection of LacZ staining in the neocortex and spinal cord of E12.5 embryos demonstrated that it is both temporally and spatially unspecific. While intensive LacZ staining was seen in the above mentioned regions it is important to emphasize that the detection CaMKCre activity - as visualized by LacZ staining with the reporter mouse line (Figure 3.1) - is not per se equivalent to gene deletion in the CaMKCre Tip60 ${ }^{\mathrm{f} / \mathrm{f}}$ mice. In fact, while the observed CRE activity strongly implies that Tip60 would be excised in the identified regions during embryonic stages this has not been directly investigated in this work. It has to be further taken into account that the LacZ staining may lead to an overestimation of the actual degree of embryonic TIP60 deletion. First of all, the efficiency of gene excision between different floxed loci differs dependent on the length of the genomic sequence flanked by the LoxP sites and the genomic environment (Zheng et al., 2000; Coppoolse et al., 2005). Generally, a shorter distance between the LoxP sites - as in the case of the floxed stop codon in the ROSA26 reporter mice - allows for easier recombination. Furthermore, the animals used for LacZ analysis only had one ROSA26 allele and the excision of the single stop cassette is sufficient for LacZ staining to occur. However, excision of just one allele is not sufficient to significantly downregulate TIP60 protein levels since heterozygous Tip60 ${ }^{+/}$mice do not show reduced TIP60 protein levels (own data, not shown; Squatrito et al., 2006; Gao et al., 2014). The reason for the unspecific activity of the CaMKCre driver probably lies in the comparably short regulatory sequence taken from the CaMKIIa gene. While the BAC vector used for the inducible CaMKCreER ${ }^{\mathrm{T} 2}$ driver line contains the CaMKIIa gene locus with a $43 \mathrm{~kb} 5$ ' upstream and a $100 \mathrm{~kb} 3$ ' downstream region from the mouse genome project (Erdmann et al., 2007), the CaMKCre line only contains the $8.5 \mathrm{~kb}$ CaMKII $\alpha$ promoter as a regulatory element (Minichiello et al., 1999). Presumably, a regulatory region with inhibiting function is not included in the CaMKCre construct, leading to aberrant activity. Summing up, developmental defects as well as off-target effects are very likely to occur in the CaMKCre Tip60 $0^{\mathrm{f} / \mathrm{f}}$ mice and most 
probably led to most of the abnormalities observed. It is unlikely that the decreased body size and short life-span are caused solely by TIP60-deficiency in the brain. Despite the activity during embryonic stages, the LacZ staining conducted with sections of adult brain showed forebrain-specific driver activity as described previously (Minichiello et al., 1999). This indicated that TIP60 function in the hippocampus can be studied with this line and the RNA-Seq results, which showed a large overlap of significantly changed genes with the inducible line confirmed this.

\subsubsection{Phenotype of the Inducible Mouse Model (CaMKCreER ${ }^{\top 2}$ Tip60}

Most of the results presented in this thesis were obtained using the inducible CaMKCre$\mathrm{ER}^{\mathrm{T} 2} \mathrm{Tip} 60^{\mathrm{f} / \mathrm{f}}$ mouse model. In contrast to the constitutive mouse line, the use of CaMK$\mathrm{CreER}^{\mathrm{T} 2} \mathrm{Tip}^{\mathrm{f} / \mathrm{f}}$ mice allowed to perform molecular analysis with tissue of overtly healthy animals and also to analyze the consequences of TIP60-deficiency on cognitive functions. CaMKCreER ${ }^{\mathrm{T} 2} \mathrm{Tip}^{\mathrm{f} / \mathrm{f}}$ mice did not reveal any abnormalities in the first one to two months after tamoxifen injections, which was the time of tissue harvest for the molecular analyses. Unexpectedly, after about two to three months after gene deletion, also this mouse model began to display abnormalities, including nervous behavior, seizures, obesity as well as limb clasping. The fact that the phenotypes were observed as late as months after tamoxifen injections and temporally coincided indicated that TIP60deficiency had progressive effects on neuronal function and circuitry. There appeared to be a threshold-like effect, upon which normal regulation of the affected behaviors was destabilized. Since in addition to the hippocampus other forebrain-specific regions were affected by TIP60-deficiency, the observed phenotypes could not be reliably assigned to their causative areas. However, one possible explanation of both the obesity and the nervous behavior might be an altered regulation of the hypothalamic-pituitary adrenal axis (HPA) in CaMKCreER ${ }^{\mathrm{T} 2} \mathrm{Tip}^{\mathrm{f} / \mathrm{f}}$ mice. The HPA controls stress response and regulates many processes including mood, emotions, and energy homeostasis (Dallman et al., 1995). It is activated by the amygdala while the hippocampus provides negative feedback (Brown et al., 1999; Jacobson et al., 1991). Since TIP60 is deficient in the main regions of the HPA, namely the hypothalamus, the amygdala, and the hippocampus (Figure 3.4 and Figure 3.5A), this possibly altered the response to stress in the animals. While the obesity could also be due to direct effects of the TIP60-deficiency in the hypothalamus, a region with a well-established role in energy homeostasis and feeding 
behavior, increased stress has also been reported to increase feeding behavior in rodents (Levine et al., 1981). Another, possibly complementing explanation for the nervous behavior in the CaMKCreER ${ }^{\mathrm{T} 2} \mathrm{Tip}^{\mathrm{f} / \mathrm{f}}$ mice may involve an imbalance between excitatory and inhibitory transmission in these mice. This is also a possible cause of the observed seizures and will be discussed in more detail in section 4.3.

The observed limb clasping indicated motor dysfunction in the CaMKCreER ${ }^{\mathrm{T} 2} \mathrm{Tip}^{\mathrm{f} / \mathrm{f}}$ mice. Since CRE activity was absent from the cerebellum, it is not clear what caused the abnormal limb postures.

\subsubsection{Tip60 Function in Learning and Memory}

The behavioral tests performed with the CAMKCreER ${ }^{\mathrm{T} 2} \mathrm{Tip} 60^{\mathrm{f} / \mathrm{f}}$ mouse line did not reveal any major impairments in cognitive function despite a rather efficient deletion of TIP60 in the hippocampus. The strongest phenotype was observed in the elevated plus maze, where CaMKCreER ${ }^{\mathrm{T} 2} \mathrm{Tip}^{\mathrm{f} / \mathrm{f}}$ mice showed significantly decreased anxiety compared to Tip60 ${ }^{\mathrm{f} / \mathrm{f}}$ controls. The observed phenotypes were most likely due to changes in the amygdala or ventral hippocampus, which are involved in anxiety behavior (Fanselow et al., 2010; McHugh et al., 2004; Kjelstrup et al., 2002). The novel object recognition (NOR) test showed a mild impairment in short-term and long-term memory. However, the contribution of the hippocampus to this form of memory remains controversial since data of lesion studies have been ambiguous (Good et al., 2007; Fortin et al., 2002; Barker et al., 2011). Recently, the role of the hippocampus, as well as perirhinal and medial prefrontal cortex in different variations of NOR has been reanalyzed (Barker et al., 2011). The data indicate that the NOR task as performed in this thesis is probably not hippocampus-dependent but depends more on the perirhinal cortex.

Associative memory was tested by contextual fear conditioning and was comparable between CaMKCreER ${ }^{\mathrm{T} 2} \mathrm{Tip}^{\mathrm{f} / \mathrm{f}}$ and Tip60 $0^{\mathrm{f} / \mathrm{f}}$ control mice. As this is a test known to be hippocampus-dependent, the result indicated that TIP60 does not have an essential function in this form of learning (Rudy et al., 2004). However, the strength of associative memory formation in this test correlates with the strength of the given foot shock. Since the foot shock was relatively strong in the chosen setup it might have masked a milder impairment of associative memory caused by TIP60-deficiency. To test this, the fear conditioning could be repeated using a less intense foot shock. 
Apart from associative learning also the spatial working memory of CaMKCreER ${ }^{\mathrm{T} 2}$ Tip60 ${ }^{\mathrm{f} / \mathrm{f}}$ mice - as tested by the cross maze - was unchanged. Apparently, the observed molecular changes in the hippocampus, including upregulated IEG expression, did not significantly interfere with these learning tasks.

The influences of TIP60-deficiency on hippocampal learning will be further analyzed by performing the Morris water maze (MWM). Previous results were not reliable due to the onset of obesity in CaMKCreER ${ }^{\mathrm{T} 2} \mathrm{Tip}^{\mathrm{f} / \mathrm{f}}$ mice, which caused a significant decrease in swim speed. In MWM spatial learning is tested, which is especially dependent on the dorsal CA1 region (Moser et al., 1995; Bannerman et al., 2002; Fanselow et al., 2010). This experiment will therefore determine whether the marked changes identified in the transcriptome of the CA1 region have a significant effect on spatial learning and memory.

\subsection{TIP60 Substrates}

TIP60 is best studied as an enzyme, which transfers an acetyl group to the $\varepsilon$-amino group of a protein's lysine residue. In the case of histones, acetylation is correlated with active gene transcription (Clayton et al., 2006), while effects on TIP60 non-histone substrates can lead to different protein stability as well as protein activity (Li et al., 2013; Gavaravarapu et al., 2000). Additionally, TIP60 can act both as a transcriptional coactivator or co-repressor (Xiao et al., 2003; Baek et al., 2002), further broadening its range of impact on cellular processes. In this section, results in regard to TIP60 enzymatic activity on potential histone and non-histone proteins will be discussed.

\subsubsection{TIP60 Histone Substrates}

Histone modifications in CaMKCreER ${ }^{\mathrm{T} 2} \mathrm{Tip}^{\mathrm{f} / \mathrm{f}}$ mice were analyzed in whole hippocampus tissue samples by Western blot and in the principal cell layer of the dorsal CA1 region by IHC. Western blot results showed a significant downregulation of H4K5 acetylation levels. Other $\mathrm{H} 4$ specific sites also showed a trend towards lower acetylation levels but these changes did not reach significance. The rather subtle changes in $\mathrm{H} 4$ histone acetylation were probably the consequence of incomplete deletion of TIP60 in the hippocampal samples due to restriction of CaMKCreER ${ }^{\mathrm{T} 2}$ driver activity to excitatory neurons. In contrast to the decreased histone H4 acetylation levels, the H3K14 results showed a strong trend towards increased acetylation. This could be caused by compensatory actions by other KATs or altered KDAC activity. 
In an attempt to obtain more precise data on the actual downregulation of histone $\mathrm{H} 4$ acetylation, IHC double labeling was performed in the pyramidal layer of the CA1 region of CaMKCreER ${ }^{\mathrm{T} 2} \mathrm{Tip60}^{\mathrm{f} / \mathrm{f}}$ mice using TIP60P4 and panH4 acetyl (panH4ac) antibodies. In contrast to the analysis by Western blot, this approach excluded cells not targeted by the CRE driver. These quantifications showed a significant, yet rather modest decrease of $\mathrm{H} 4$ acetylation. The actual degree of downregulation found was less than was expected based on the trends provided by the Western blot data. Generally, fully accurate quantification of a desired histone acetylation is severely hampered in either Western blot or IHC due to the bias that has been observed in target recognition of antibodies against specific histone modifications. Despite the frequent usage of these antibodies and the regular tests performed on their specificity by dot blot analysis or peptide blocking, the combinatorial modifications generally present on histone proteins pose a complex challenge for assessing antibody specificity. In fact, modification-specific histone antibodies have been shown to possess different specificity to their target depending on neighboring histone modifications. This was demonstrated by Rothbart et al. (2012), who identified that $\mathrm{H} 4$ site-specific acetyl antibodies show preference towards polyacetylated histone substrates. Therefore, it is not clear whether the antibodies used had bias towards certain combinations of histone $\mathrm{H} 4$ modifications, thereby skewing the reduction of histone $\mathrm{H} 4$ acetylations. Still, the IHC data was highly significant, convincingly demonstrating downregulation of panH4 acetylation in the dorsal CA1 region.

Another point worth mentioning in respect to TIP60's potential role in histone acetylation in the hippocampus of CaMKCreER ${ }^{\mathrm{T} 2} \mathrm{Tip}^{\mathrm{f} / \mathrm{f}}$ mice is the possible involvement of P300/CBP in any of the observed changes (Section 4.2.2). In fact, it cannot be excluded that the observed changes in histone acetylation are - at least partially - not a direct effect of TIP60-deficiency but may be caused by the TIP60-dependent hypoacetylation and thus decreased enzymatic activity of P300/CBP.

\subsubsection{Potential TIP60 Non-Histone Substrates}

TIP60 and P300/CBP are closely linked proteins with many common substrates (Xiao et al., 2014; Fu et al., 2000; Gaughan et al., 2002). Interestingly, P300/CBP have also been shown to directly interact with TIP60 and to be able to acetylate TIP60 within its zinc finger domain (Col et al., 2005). Immunohistochemical analyses conducted in this thesis project revealed that P300/CBP are hypoacetylated at lysine 1499 and 1535 of P300 and CBP respectively in both TIP60-deficiency mouse models. 
Acetylation of P300 at K1499 has been demonstrated to be critical for its HAT activity and affects a wide variety of signaling events (Thompson et al., 2004). Thompson et al. (2004) detected a total of 13 acetylation sites within the HAT domain of P300 using mass spectrometry. They further showed that P300 was able to autoacetylate these lysines and that $\mathrm{P} 300^{\mathrm{K} 1499}$ was one of four catalytically important sites within the HAT domain. Despite the demonstrated self-catalyzed acetylation in P300, it cannot be excluded that other lysine acetyltransferases could also modulate the activity of P300/CBP. Thus, based on the downregulation of P300/CBP acetylation in both TIP60deficiency models, TIP60 is a potential modulator of the P300 acetylation status. Of note, any of the 12 other acetylation sites within the P300 HAT domain might potentially also be affected in the TIP60-deficient hippocampus but there were no site-specific antibodies available to test this. The change in acetylation status in at least one catalytically critical lysine may not only have impact on P300 HAT function but may also have profound impact on its many protein-protein interactions. It is not clear how exactly the hypoacetylation of P300/CBP affects their activity in vivo but their state of hypoacetylation at lysines 1499/1535 likely broadens the spectrum of effects in the TIP60-deficient animals.

Apart from P300/CBP, also MECP2 was found to be hypoacetylated in both TIP60-deficiency mouse lines. In a mass spectrometry screen, a single acetylation site was detected in this protein (Choudhary et al., 2009), which corresponds to K464 on the mouse isoform 1 of MECP2. This isoform is the predominant of the two isoforms found in the brain (Kaddoum et al., 2013). Possibly, MECP2 is not a direct TIP60 target since P300 and to a lesser degree also CBP have been shown to shown to acetylate MECP2 (Zocchi, 2012). Except for the inhibition of Bdnf exon IV expression no other function of MECP2 acetylated at K464 has been identified so far (Zocchi, 2012).

\subsection{Implications of TIP60 Function in Neuronal Homeo- static Plasticity}

The destabilizing effects of synaptic plasticity-induced changes have to be counteracted in order to maintain overall network activity. One important mechanism for this is the balancing of excitation and inhibition within neuronal networks (Maffei et al., 2004; Gonzalez-Islas et al., 2006). Seizures are caused by an imbalance between excitatory and inhibitory transmission in brain circuits (Žiburkus et al., 2013) and were observed 
in the inducible TIP60-deficiency mouse line. Their occurrence indicated that TIP60 function is directly or indirectly important for neuronal homeostasis. Although the brain regions possibly responsible for the seizures in CaMKCreER ${ }^{\mathrm{T} 2} \mathrm{Tip}^{\mathrm{f} / \mathrm{f}}$ mice are not known, the time course of changes in both seizures and nervous behavior (which can also be caused by the same imbalances as seizures) is interesting and might indicate an involvement of the dentate gyrus. The dentate gyrus is very susceptible to seizures, its granule cells being thought to play a key role in the pathogenesis of temporal lobe epilepsy (Sloviter et al., 2010; Kobayashi et al., 2003; Scharfman, 2006). Adult neurogenesis takes place in the subgranular zone (SGZ) of the dentate gyrus during an animal's lifetime. In the inducible TIP60 mouse line the CRE driver was only active as long as the metabolized tamoxifen of the last injection was available in the brain. This means that neurons born after this time window kept both their Tip60 alleles and integrated into the otherwise TIP60-deficient granular cell layer (GCL) of the dentate gyrus. Analysis of pCREB expression showed a significant upregulation of pCREB positive cells in the SGZ of CaMKCreER ${ }^{\mathrm{T} 2} \mathrm{Tip}^{\mathrm{f} / \mathrm{f}}$ mice and indicated a possible feedback signaling from the TIP60-deficient GCL to the immature neurons. pCREB is expressed in virtually all immature neurons in the SGZ and has been implicated to modulate their maturation (Fujioka et al., 2004; Nakagawa et al., 2002).

Furthermore, there was a significant upregulation of c-FOS and ARC positive cells in the TIP60-deficient GCL, pointing to changes in circuit activity. Interestingly, ARC has recently been suggested to be involved in synaptic scaling (Shepherd et al., 2006; Rial Verde et al., 2006), which is a plasticity mechanism involved in maintaining network stability despite changing input activity (Feldman, 2002).

An additional strong implication for changed homeostatic plasticity in the TIP60-deficient hippocampus was the identified downregulation of presynaptic marker Synaptoporin in the mossy fibers. This downregulation was also confirmed for the constitutive TIP60-deficiency mouse model. Synaptoporin has recently been reported to be both necessary and sufficient for homeostatic plasticity in the hippocampus (Lee et al., 2013).

Furthermore, Bdnf was found to be chronically upregulated in both the dentate gyrus and CA1 region of the TIP60-deficiency models. While BDNF function in synaptic plasticity is well-established, it has recently also been implicated in homeostatic plasticity (Reimers et al., 2014; Turrigiano, 1999). It is required for the terminal differentiation 
of newly generated neurons (Chan et al., 2008) and its overexpression in the dentate gyrus was shown to increase dendrite complexity (Tolwani et al., 2002).

Apart from the observed changes in the dentate gyrus, also the constitutive upregulation of Npas 4 in the CA1 region of CaMKCreER ${ }^{\mathrm{T} 2} \mathrm{Tip}^{\mathrm{f} / \mathrm{f}}$ mice could play a role in the seizures and nervous behavior observed. There is strong evidence that NPAS4 plays a role in inhibitory synapse development (Lin et al., 2008), which suggests that this gene also participates in the regulation of the balance between excitatory and inhibitory transmission (Coutellier et al., 2012). Interestingly, seizures and changed anxiety levels have been reported in Npas4 knockout mice (Coutellier et al., 2012).

Despite similar changes on the molecular level concerning IEG expression and downregulation of Synaptoporin in the mossy fibers the constitutive TIP60-deficiency mouse line rarely showed seizures. However, stressed behavior was regularly observed. Possibly, the TIP60-deficient hippocampal network in the constitutive mouse line has a comparable latency for seizure development as the inducible mouse model and the mice died prior to reaching this stage. Another interesting aspect is the implications of different CRE driver activity for the circuitry in the dentate gyrus of the two mouse models. In contrast to the inducible mouse line the CRE driver in the constitutive model was continuously active, deleting TIP60 in newborn neurons as soon as they begin to express CaMKIIa. Consequently, the repopulation by TIP60 wild type cells was not possible. These differences in the addition of newly-generated neurons between the two mouse models suggest that there existed marked differences in neuronal circuitry of the dentate gyrus, which might had an influence on the development of seizures.

In conclusion, several indications were found for a role of TIP60 in the regulation of homeostatic plasticity. The progressive phenotype of CaMKCreER ${ }^{\mathrm{T} 2} \mathrm{Tip}^{\mathrm{f} / \mathrm{f}}$ mice may indicate an accumulation of aberrant effects that eventually lead to neuronal network instability.

\subsection{Widespread Changes in Gene Transcription in the CA1 Region}

\subsubsection{Aberrant Regulation of Immediate-Early Genes}

Several immediate early genes (IEGs) were specifically upregulated in the CA1 region upon TIP60 deletion. In the case of c-FOS, this upregulation occurred soon after TIP60 
deletion and persisted until at least 3-4 months after deletion. Later time points could not be analyzed by the end of this thesis project. The upregulation of Npas4 pointed to increased $\mathrm{Ca}^{2+}$ levels in the CA1 region, since this gene is exclusively activated by depolarization (Ramamoorthi et al., 2011). Ramamoorthi et al. (2011) suggested that NPAS4 might be upstream of a hierarchical genetic program regulating several other activity-regulated genes. They could show that when Npas4 is selectively deleted from the CA3 region $c$-Fos is not expressed in a fear conditioning paradigm, which normally does induce $c$-Fos expression in the CA3 region. Upon rescue by injecting Npas4-AAV into the CA3 region c-Fos was normally expressed in the fear conditioning paradigm. Presumably, NPAS4 indirectly enhances and/or sustains IEG expression by recruiting RNA Pol II to the respective genes (Ramamoorthi et al., 2011). NPAS4 has further been shown to be responsible for inhibitory synapse formation in vitro (Lin et al., 2008). Along this line, Bloodgood et al. (2013) have recently shown that when NPAS4 is expressed in response to an enriched environment, it coordinates the redistribution of inhibitory synapses onto CA1 pyramidal neurons in the mouse hippocampus. They found that NPAS4 increased the number of inhibitory synapses on the pyramidal cell body while decreasing their number on the apical dendrites, thereby rearranging the inhibition. This appears to be partly accomplished by the NPAS4 target gene Bdnf, which is specifically responsible for the regulation of somatic inhibition. NPAS4 is virtually absent from the brain of naïve mice and its expression was induced by exposing mice to a novel environment in the study of Bloodgood et al. (2013). In contrast, NPAS4 was constitutively upregulated in the CA1 region of naïve CaMKCreER ${ }^{\mathrm{T} 2} \mathrm{Tip}^{\mathrm{f} / \mathrm{f}}$ mice. This indicates that the distribution of inhibitory synapses is altered in the TIP60-deficient CA1 region. However, despite the constitutive upregulation of Npas4 and also other IEGs in the CA1 region of $\mathrm{CaMKCreER} \mathrm{R}^{\mathrm{T} 2} \mathrm{Tip}^{\mathrm{f}} \mathrm{f}^{\mathrm{f} / \mathrm{f}}$ mice, the induction of gene expression upon exposure to a novel environment was comparable to Tip60 ${ }^{\mathrm{f} / \mathrm{f}}$ controls. This implies that the neuronal response was not impaired by the aberrant IEG regulation at basal levels.

\subsubsection{TIP60 and Neuronal Gene Regulation}

In order to assess transcriptional changes in the absence of TIP60 in an unbiased manner, next generation sequencing was performed with dorsal CA1 tissue both from the constitutive and the inducible mouse line. Significantly changed genes showed a broad overlap between the two mouse lines, thereby providing a highly reliable list of TIP60affected candidate genes for downstream analysis. 
Constitutive upregulation of IEG expression was identified in this thesis by analyzing whole hippocampus tissue of TIP60-deficient and control mice by qPCR. The RNA-Seq analysis confirmed these data and showed a significant upregulation of c-Fos and Npas4 expression in the dorsal CA1 region. While upregulation of other IEGs analyzed in whole hippocampus samples was also confirmed for the inducible mouse line, some of these genes (e.g. Arc and Homer1) were significantly downregulated in RNA-Seq results of the constitutive line. This discrepancy between the two mouse models could be explained by the differences in latency of Tip60 deletion or by indirect effects on the expression of these genes due to the health status of the mice.

GO term analysis revealed a significant downregulation of genes involved in several processes associated with neuronal plasticity, including ion channel activity and synaptic vesicle. These findings indicate an important role of TIP60 in synaptic transmission and are in good agreement with the proposed effects on homeostatic plasticity (Section 4.3). While TIP60 HAT activity has recently been shown to be required for neuronal gene control as well as synaptic plasticity in Drosophila (Lorbeck et al., 2011; Sarthi et al., 2011) this is the first study to identify TIP60 in synaptic processes in the mammalian brain.

Both the identified upregulated GO terms as well as KEGG pathway analysis confirmed the well-established role of TIP60 in DNA damage. However, in how far these changes might have contributed to the observed neuronal changes is unclear. NeuN staining showed no overt neuronal loss in CAMKCreER ${ }^{\mathrm{T} 2} \mathrm{Tip}^{\mathrm{f} / \mathrm{f}}$ mice, thus effects on neuronal viability at the time point of analysis can be excluded.

A possible direct TIP60 candidate gene identified in the RNA-Seq analysis is Lin7b, which is in involved in cell polarity and NMDAR subunit transport. Its expression was significantly downregulated in both TIP60-deficiency mouse lines and ISH analysis revealed that this downregulation existed in all hippocampal subregions of TIP60-deficient mice. LIN7b acts as a scaffolding protein and is localized to the postsynaptic density (Butz et al., 1998; Jo et al., 1999). It is involved in both the transport and anchoring of the NMDAR subunit NR2B (Setou, 2000; Jo et al., 1999). Interestingly, both TIP60 and LIN7b were identified in our lab as interaction partners of CRY1 in a same yeasttwo-hybrid interaction screen (unpublished data). This indicates a close connection between TIP60, CRY and LIN7B and a possible direct effect of TIP60-deficiency on Lin7b expression levels. 
In order to further elucidate the role of TIP60 in the hippocampus, the genes directly regulated by TIP60 have to be identified. While an antibody that can detect endogenous levels of TIP60 has successfully been produced during this thesis project, its performance in ChIP has yet to be validated. Alternatively, two transgenic mouse models have recently been created in our lab in order to analyze direct binding of TIP60. One of them harbors a BAC encompassing the Tip60 gene modified with a 3x-FLAG epitope upstream of the stop codon. The other bears an additional floxed stop cassette upstream of the Tip60 start codon and can be crossed to CRE driver lines for tissue specific expression of tagged TIP60. These models are currently being validated. Both ChIP-Seq as well as coimmunoprecipitation experiments are planned in order to identify TIP60 binding sites and to shed further light on its direct targets. 


\section{Conclusion and Outlook}

The here presented analyses focusing on the hippocampus of two different TIP60-deficiency mouse models have established an important role of TIP60 in neuronal gene regulation. Remarkably, a chronic upregulation of IEGs was identified in the CA1 region, pointing to changes in neuronal homeostasis and calcium signaling. Together with the seizures observed in the inducible mouse model these data suggest that the TIP60-deficient hippocampus is malfunctioning.

Future work will address important questions related to these results. Calcium imaging on organotypical hippocampal slices of CaMKCreER ${ }^{\mathrm{T} 2} \mathrm{Tip}^{\mathrm{f} / \mathrm{f}}$ and $\mathrm{Tip} 60^{\mathrm{f} / \mathrm{f}}$ mice will be performed in order to analyze possible changes in calcium levels due to TIP60-deficiency. Electrophysiological measurements will be conducted to analyze the origin of IEG dysregulation in TIP60-deficient mice. These can be performed on hippocampal slices and aid in localizing changes in synaptic transmission. In addition, hippocampal neuron culture using Tip60 ${ }^{\mathrm{f} / \mathrm{f}}$ neurons treated with lentiviral CRE could help to understand in what way the properties of TIP60-deficient neurons are changed.

In addition to the marked differences in gene expression in the CA1 region, also changes in the dentate gyrus have been observed, indicating a change in the circuitry of the granular cell layer. There was an interesting correlation between the regeneration in the dentate gyrus and a reduction in the number of seizures in longer periods after tamoxifen treatment. This possible link between pathophysiology and regeneration can be further corroborated with additional mouse cohorts. Using the produced TIP60P4 antibody the repopulation of the dentate gyrus with newborn wild type cells can be both visualized and quantified.

In order to more precisely analyze the role of TIP60 in hippocampal learning, stereotactic injections of AAV-Cre into the dorsal CA1 region of Tip60 $60^{\mathrm{f} / \mathrm{f}}$ mice will be performed. This way, the effects of TIP60-deficiency specifically directed to the CA1 region can be analyzed and directly related to a possible behavioral phenotype. 


\section{Appendix}




\subsection{KEGG Pathway Maps}
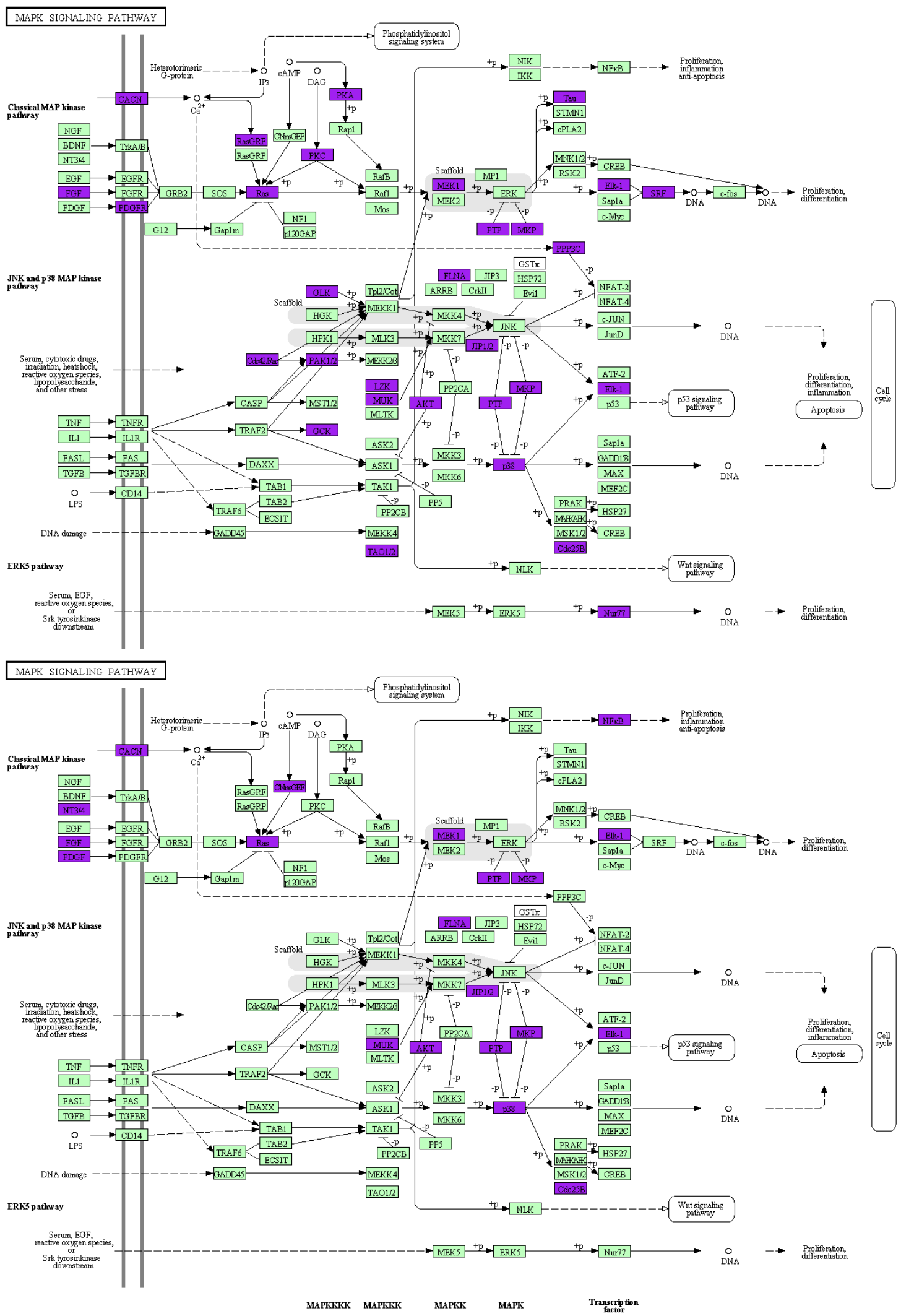

Figure 6.1 Map of the MAPK signaling pathway in constitutive (top) and inducible (bottom) TIP60deficiency mouse lines. Significantly changed genes are shown in purple. Source: KEGG PATHWAY database. 


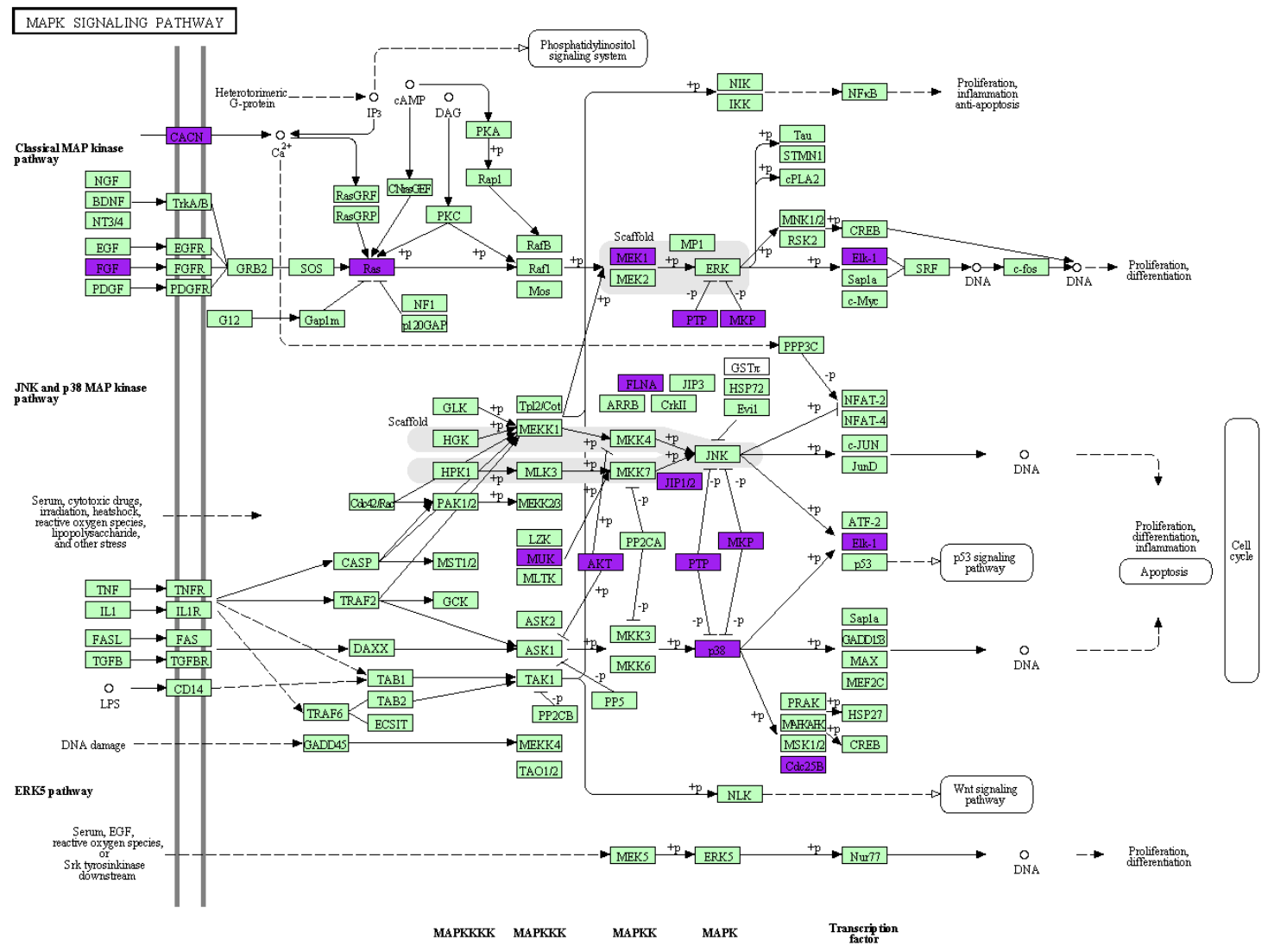

Figure 6.2: Combined map of MAPK signaling in the constitutive and the inducible TIP60-deficiency mouse lines. Genes with significantly changed expression in both mouse lines are shown in purple. Source: KEGG PATHWAY database. 


\subsection{Chemicals and Solutions}

\subsubsection{Antibodies}

\section{Primary Antibodies}

\begin{tabular}{|c|c|c|c|}
\hline Name & Dilution & Company & $\begin{array}{l}\text { Catalogue } \\
\text { No. }\end{array}$ \\
\hline NeuN (chicken polyclonal) & $1: 100$ & Synaptic Systems & 266006 \\
\hline Gfap (chicken polyclonal) & $1: 500$ & Abcam & 173002 \\
\hline Tip60P4 (rabbit polyclonal) & $1: 20$ & custom & - \\
\hline Tip60A (rabbit polyclonal) & $1: 100$ & custom, B. Amati & - \\
\hline c-Fos (rabbit polyclonal) & $1: 1000$ & Synaptic Systems & 226003 \\
\hline c-Fos (guinea pig polyclonal) & $1: 1000$ & Synaptic Systems & 226004 \\
\hline Npas4 (rabbit polyclonal) & $1: 200$ & custom, Yamada & - \\
\hline $\begin{array}{l}\text { Synaptophysin1 (guinea pig polyclo- } \\
\text { nal) }\end{array}$ & $1: 500$ & Synaptic Systems & 101004 \\
\hline MAP2 (guinea pig polyclonal) & $1: 500$ & Synaptic Systems & 188004 \\
\hline Synaptoporin (rabbit polyclonal) & $1: 500$ & Synaptic Systems & 102002 \\
\hline H4K16ac (rabbit polyclonal) & $1: 1000$ & Active Motif & 39167 \\
\hline H4K12ac (rabbit polyclonal) & $1: 1000$ & Active Motif & 39165 \\
\hline H4K8ac (rabbit polyclonal) & $1: 1000$ & Millipore & 39171 \\
\hline H4K5ac (rabbit polyclonal) & $1: 1000$ & Active Motif & 39169 \\
\hline panH4ac (mouse monoclonal) & $1: 1000$ & Active Motif & 39967 \\
\hline H3K14ac (rabbit polyclonal) & $1: 1000$ & Millipore & 06-911 \\
\hline Gapdh-HRP & $1: 20000$ & Abcam & 9482 \\
\hline Actin-HRP & $1: 2000$ & Santa Cruz & sc-1616 HRP \\
\hline Arc (rabbit polyclonal) & $1: 2000$ & Synaptic Systems & $156-003$ \\
\hline Arc (guinea pig polyclonal) & $1: 2000$ & Synaptic Systems & $156-005$ \\
\hline pCreb (Ser133) (87G3) & $1: 100$ & Cell Signaling & 9198 \\
\hline pCreb Alexa488 & $1: 100$ & Cell Signaling & 9187 \\
\hline MeCP2 XP (rabbit monoclonal) & $1: 100$ & Cell Signaling & 3456 \\
\hline $\mathrm{MeCP}^{\mathrm{K} 464 \mathrm{ac}}$ (rabbit polyclonal) & $1: 100$ & Millipore & ABE28 \\
\hline P300 (rabbit polyclonal) & $1: 100$ & Santa Cruz & sc-585 \\
\hline $\mathrm{P} 00^{\mathrm{K} 1499 \mathrm{ac}}$ (rabbit polyclonal) & $1: 100$ & Cell Signaling & 4771 \\
\hline
\end{tabular}

Secondary Antibodies

\begin{tabular}{l|l|l|l}
\multicolumn{1}{c|}{ Name } & Dilution & \multicolumn{1}{c|}{ Company } & \multicolumn{1}{c}{$\begin{array}{c}\text { Catalogue } \\
\text { No. }\end{array}$} \\
\hline Alexa Fluor 488 goat anti-rabbit & $1: 500$ & Invitrogen & A11008 \\
\hline Alexa Fluor 555 goat anti-rabbit & $1: 500$ & Invitrogen & A21428 \\
\hline Alexa Fluor 647 goat anti-rabbit & $1: 500$ & Invitrogen & A21244 \\
\hline Alexa Fluor 488 goat anti-guinea pig & $1: 500$ & Invitrogen & A-11073 \\
\hline Alexa Fluor 555 goat anti-guinea pig & $1: 500$ & Invitrogen & A21435 \\
\hline Alexa Fluor 488 goat anti-chicken & $1: 500$ & Invitrogen & A11039 \\
\hline Anti-rabbit HRP conjugated & $1: 1000$ & NEB & 7074 S
\end{tabular}




\subsubsection{Buffers/Solutions}

\subsubsection{Genotyping}

PBND-Lysis-Puffer

$50 \mathrm{mM} \mathrm{KCl}$

10mM Tris (pH 8.3)

$2.5 \mathrm{mM} \mathrm{MgCl} 2$

$0.1 \mathrm{mg} / \mathrm{ml}$ Gelatine

$0.45 \%(\mathrm{v} / \mathrm{v}) \mathrm{NP} 40$

$0.45 \%(\mathrm{v} / \mathrm{v})$ Tween 20

TAE (50x, 1 L)

$242 \mathrm{~g}$ Tris-Base

$57.1 \mathrm{ml}$ acetic acid

$100 \mathrm{ml} 0.5$ M EDTA (pH 8.0)

\subsubsection{LacZ}

1x PBS:

$150 \mathrm{mM}$ sodium chloride

$10 \mathrm{mM}$ sodium phosphate

pH 7.4

Solution A: $5 \mathrm{mM}$ EGTA, $2 \mathrm{mM} \mathrm{MgCl}_{2}$ in $100 \mathrm{mM}$ potassium phosphate buffer, $\mathrm{pH} 7.4$

Solution B: $0.2 \%$ Glutaraldehyde in solution A

Solution C: $0.01 \%$ sodiumdesoxycholate, $0.02 \%$ NP40 solution A

Staining Solution D: $1 \mathrm{mg} / \mathrm{ml} \mathrm{X-Gal;} 5$ mM KFe(CN) $)_{6 I I I} 5$ mM KFe(CN) $)_{6}$ II in Solution C

\subsubsection{Southern Blot}

DNA Lysis Buffer

0.1 M Tris, $\mathrm{pH} 8.0$

$0.2 \mathrm{M} \mathrm{NaCl}$

5 mM EDTA

$0.2 \%(\mathrm{w} / \mathrm{v}) \mathrm{SDS}$

SSC Buffer (20x)

$3 \mathrm{M} \mathrm{NaCl}$

$0.3 \mathrm{M}$ sodium citrate 
Depurination Buffer

$0.125 \mathrm{M} \mathrm{HCl}$

Alkaline Transfer Buffer

$1.5 \mathrm{M} \mathrm{NaCl}$

0.5 M Tris- $\mathrm{HCl}$ (pH 7.2)

Neutralization Buffer

0.5 M Tris-Cl pH 7.2

Modified Church Buffer

10 mM EDTA

$0.5 \mathrm{M}$ phosphate buffer $\mathrm{pH} 7.2$

$7 \%(w / v)$ SDS

\subsubsection{IHC}

1x PBS (cf. 6.2.2.2)

Blocking reagent

$5 \%$ BSA

$5 \%$ Normal Goat Serum (Vector)

In 1x PBS

\subsubsection{ISH}

see (Eichele et al., 2011)

\subsubsection{Western Blot}

\section{Laemmli Buffer}

62.5 mM Tris-HCl pH 6.8

$2 \%(\mathrm{w} / \mathrm{v})$ SDS

5\% (v/v) 2-mercaptoethanol

$10 \%(\mathrm{v} / \mathrm{v})$ glycerol

$0.001 \%$ bromphenol blue

10x Gel electrophoresis Buffer

$25 \mathrm{mM}$ Tris

$192 \mathrm{mM}$ glycine

$0.1 \%$ SDS, pH 8.3 



\section{Abbreviations}

aa

AAV

ANOVA

APP

A.U.

BAC

bp

CA

ChIP

Chromodomain

CNS

Cre

DAPI

DG

DNA

dNTP

EC

EDTA

EtOH

FC

FDR

GCL amino acids

adeno-associated virus

analysis of variance

amyloid precursor protein

arbitrary units

bacterial artificial chromosome

base pairs

cornu ammonis

chromatin immunoprecipitation

chromatin organization modifier

central nervous system

Cre recombinase

4',6-diamidino-2-phenylindole

dentate gyrus

deoxyribonucleic acid

deoxynucleotide triphosphate

entorhinal cortex

ethylenediaminetetraacetic acid

ethanol

fold change

false discovery rate

granular cell layer 
GO

HAT

HB

Hip

HPA

IEG

IHC

ISH

KAT

KDAC

KEGG

LoxP

LTM

LTP

MWM

NGS

NMDAR

NOR

O.C.T.

PBND

PBS

PCR

PFA

PKA

qPCR

RPKM gene ontology

histone acetyltransferase

hindbrain

hippocampus

hypothalamic-pituitary adrenal axis

immediate-early gene

immunohistochemistry

in situ hybridization

lysine acetyltransferase

lysine deacetylase

Kyoto Encyclopedia of Genes and Genomes

locus of X-over P1

long-term memory

long-term potentiation

Morris water maze

next generation sequencing

N-methyl-D-aspartate receptor

novel object recognition

Optimal Cutting Temperature

pcr buffer with nonionic detergents

phosphate buffered saline

polymerase chain reaction

paraformaldehyde

protein kinase $\mathrm{A}$

quantitative PCR

reads per kilo base per million 
rounds per minute

RNA

ribonucleic acid

RNA Pol II

RNA Polymerase II

RNA-Seq

RNA sequencing

RT

room temperature

SDS

sodium dodecyl sulfate

SEM

standard error of the mean

SGZ

subgranular zone

STM

short-term memory

TAE

tris-acetate-EDTA

TE

thorny excrescence

Tip60

Tat-interactive protein $60 \mathrm{kDa}$ 



\section{List of Figures}

Figure 1.1: The trisynaptic circuit of the hippocampus. ......................................... 3

Figure 1.2: Schematic presentation of TIP60 $\alpha$ and its functional domains. ............... 11

Figure 2.1: Overview of Tip60 alleles. ................................................................ 14

Figure 2.2 Genotyping results for Tip60, CaMKCreER ${ }^{\mathrm{T} 2}$, and CaMKCre..................... 17

Figure 2.3: Schematic overview of image processing for c-FOS quantification in the CA1

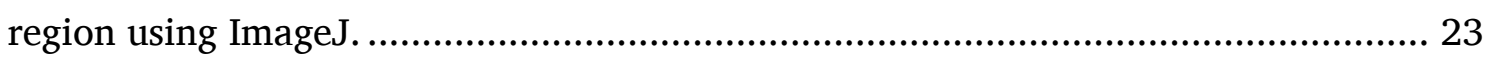

Figure 2.4 Experimental setup for the novel environment paradigm........................ 33

Figure 3.1: LacZ staining of brain sections of CaMKCre ROSA26 mice....................... 39

Figure 3.2: The constitutive CaMKCre driver lacks temporal and spatial specificity... 39

Figure 3.3: Tip60 deletion on DNA, mRNA, and protein levels.

Figure 3.4: The CaMKCreER ${ }^{\mathrm{T} 2}$ driver is specific to forebrain regions and only active after tamoxifen induction. 44

Figure 3.5 Tip60 deletion on DNA and mRNA levels. 44

Figure 3.6: TIP60 protein levels are efficiently reduced in the dorsal hippocampus of

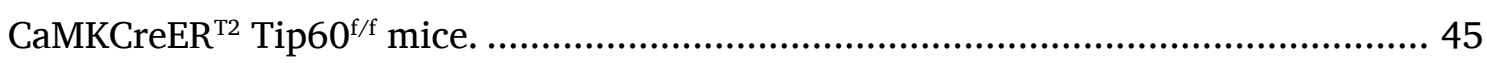

Figure 3.7: Epitope mapping strategy for TIP60 antibody production...................... 47

Figure 3.8: Comparison of immunoreactivity of TIP60 antibodies TIP60A and TIP60P4.

Figure 3.9: CaMKCre Tip60 ${ }^{\mathrm{f} / \mathrm{f}}$ mice show decreased body size and weight, as well as a crouching body posture. 50

Figure 3.10: Inducible CaMKCreER ${ }^{\mathrm{T} 2} \mathrm{Tip}^{\mathrm{f} / \mathrm{f}}$ mice become obese and show limb clasping.

Figure 3.11: CaMKCreER ${ }^{\mathrm{T} 2} \mathrm{Tip}^{\mathrm{f} / \mathrm{f}}$ mice show comparable levels of basal anxiety in the open field test. 53

Figure 3.12: Deficits in novel object recognition in CaMKCreER ${ }^{\mathrm{T} 2} \mathrm{Tip}^{\mathrm{f} / \mathrm{f}}$ mice. 54

Figure 3.13: No changes in working memory but in the elevated plus maze in CaMKCreER $^{\mathrm{T} 2} \mathrm{Tip}^{\mathrm{f} / \mathrm{f}}$ mice. 55

Figure 3.14: Fear conditioning results show no impairment of associative memory in TIP60-deficient mice. 56

Figure 3.15: c-Fos expression is highly upregulated in CaMKCreER ${ }^{\mathrm{T} 2} \mathrm{Tip}^{\mathrm{f} / \mathrm{f}}$ mice.... 58 
Figure 3.16: Arc expression is higher in CaMKCreER ${ }^{\mathrm{T} 2} \mathrm{Tip}^{\mathrm{f} / \mathrm{f}}$ mice after a novel environment exposure compared to controls. 59

Figure 3.17: Npas4 expression is highly upregulated in CaMKCreER ${ }^{\mathrm{T} 2} \mathrm{Tip}^{\mathrm{f} / \mathrm{f}}$ mice... 60 Figure 3.18: Bdnf exon I expression is significantly upregulated in CaMKCreER ${ }^{\mathrm{T} 2} \mathrm{Tip}^{\mathrm{f} / \mathrm{f}}$ mice. 62

Figure 3.19: Bdnf exon IV expression is significantly upregulated in CaMKCreER ${ }^{\mathrm{T} 2}$ Tip60 $60^{\mathrm{f} / \mathrm{f}}$ mice. 63

Figure 3.20: Basal Zif268 expression levels are significantly increased in CaMKCreER ${ }^{\mathrm{T} 2}$ Tip60 ${ }^{\mathrm{f} / \mathrm{f}}$ mice after novelty exposure. 64

Figure 3.21: Homer1 expression is significantly upregulated in CaMKCreER ${ }^{\mathrm{T} 2} \mathrm{Tip}^{\mathrm{f} / \mathrm{f}}$ animals. 65

Figure 3.22: c-Jun expression is not significantly changed in CaMKCreER ${ }^{\mathrm{T} 2} \mathrm{Tip}^{\mathrm{f} / \mathrm{f}} \mathrm{mice}$ 66 Figure 3.23: Nr4a1 is significantly upregulated in CaMKCreER ${ }^{\mathrm{T} 2} \mathrm{Tip}^{\mathrm{f} / \mathrm{f}}$ animals under home cage conditions...... 67

Figure 3.24: IEG expression in the constitutive CaMKCre Tip60 ${ }^{\mathrm{f} / \mathrm{f}}$ mouse line. 68 Figure 3.25: The number of c-FOS positive cells is significantly upregulated in the CA1 region of CaMKCreER ${ }^{\mathrm{T} 2} \mathrm{Tip}^{\mathrm{f} / \mathrm{f}}$ mice. 70

Figure 3.26: c-FOS positive cells in the CA1 region of CaMKCreER ${ }^{\mathrm{T} 2} \mathrm{Tip}^{\mathrm{f} / \mathrm{f}}$ mice are negative for TIP60. 71

Figure 3.27: Npas4 mRNA is upregulated in the CA1 region of CaMKCreER ${ }^{\mathrm{T} 2} \mathrm{Tip}^{\mathrm{f} / \mathrm{f}}$ mice.

Figure 3.28: NPAS4 protein is upregulated in the CA1 region of CaMKCreER ${ }^{\mathrm{T} 2} \mathrm{Tip}^{\mathrm{f} / \mathrm{f}}$ mice. 73

Figure 3.29: Bdnf exon $I X$ is upregulated in CaMKCreER ${ }^{\mathrm{T} 2} \mathrm{Tip}^{\mathrm{f} / \mathrm{f}}$ mice...... 74

Figure 3.30: Comparison of several general markers in the hippocampus of CaMKCreER $^{\mathrm{T} 2} \mathrm{Tip}^{\mathrm{f} / \mathrm{f}}$ and Tip60 ${ }^{\mathrm{f} / \mathrm{f}}$ control mice. 76

Figure 3.31: Presynaptic marker Synaptoporin (SPO) is reduced in the mossy fibers of the TIP60-deficient hippocampus. 78

Figure 3.32: GFAP immunoreactivity is increased in the hippocampus of CaMKCre Tip60 $60^{\mathrm{f} / \mathrm{f}}$ mice. 80

Figure 3.33: The number of pCREB positive cells is increased in the dentate gyrus of CaMKCreER $^{\mathrm{T2}} \mathrm{Tip}^{\mathrm{f} / \mathrm{f}}$ mice. 82 
Figure 3.34: The number of ARC and c-FOS positive cells is increased in the TIP60deficient dentate gyrus. 84

Figure 3.35: ARC-positive cells in the TIP60-deficient dentate gyrus are TIP60-negative. 85

Figure 3.36: Heatmap and Venn diagram of RNA-Seq results from dorsal CA1 region.

Figure 3.37: Histograms of $\log _{2}$-transformed fold changes in gene expression. 88

Figure 3.38: Esr1 is strongly upregulated in the hippocampus of CaMKCreER ${ }^{\mathrm{T} 2} \mathrm{Tip}^{\mathrm{f} / \mathrm{f}}$ mice.

Figure 3.39: Lin7b is downregulated in the hippocampus and cortex of CaMKCreER ${ }^{\mathrm{T2}}$ Tip60 $0^{\mathrm{f} / \mathrm{f}}$ mice.

Figure 3.40: Syt7 and Syt10 mRNA levels are significantly changed in the hippocampus of CaMKCreER ${ }^{\mathrm{T} 2} \mathrm{Tip}^{\mathrm{f} / \mathrm{f}}$ mice.

Figure 3.41: Cacng8 is significantly downregulated in all hippocampal subregions of CaMKCreER $^{\mathrm{T2}} \mathrm{Tip}^{\mathrm{f} / \mathrm{f}}$ mice 95

Figure 3.42 GO terms identified for the significantly overlapping genes of both TIP60deficiency mouse lines.

Figure 3.43: Histone acetylation levels in CaMKCreER ${ }^{\mathrm{T} 2} \mathrm{Tip}^{\mathrm{f} / \mathrm{f}}$ hippocampus samples.

Figure 3.44: PanH4 acetylation is downregulated in TIP60-deficient cells the CA1 region.

Figure 3.45: Binding of MECP2 $2^{\mathrm{K} 464 \mathrm{ac}}$ at $B d n f$ exon $I V$ is comparable between CaMKCreER ${ }^{\mathrm{T} 2}$ $\mathrm{Tip}^{\mathrm{f} / \mathrm{f}}$ and $\mathrm{Tip}^{\mathrm{f} / \mathrm{f}}$ mice. 105

Figure 3.46: Acetylation of MECP2 is decreased in the hippocampus of CaMKCreER ${ }^{\mathrm{T} 2}$ Tip60 6 mice. 106

Figure 3.47: MECP2 staining intensities are comparable between CaMKCreER ${ }^{\mathrm{T} 2} \mathrm{Tip}^{\mathrm{f} / \mathrm{f}}$ and Tip60 ${ }^{\mathrm{f} / \mathrm{f}}$ control mice. 106

Figure 3.48: Acetylation of MECP2 is decreased in the hippocampus CaMKCre Tip60 ${ }^{\mathrm{f} / \mathrm{f}}$ mice.

Figure 3.49: Immunoreactivity of $\mathrm{P} 300^{\mathrm{K} 1499 \mathrm{ac}} / \mathrm{CBP}^{\mathrm{K} 1535 \mathrm{ac}}$ is decreased in the hippocampus of CaMKCreER ${ }^{\mathrm{T} 2} \mathrm{Tip}^{\mathrm{f} / \mathrm{f}}$ mice. 108

Figure 3.50: Pan P300 levels are comparable between CaMKCreER ${ }^{\mathrm{T} 2} \mathrm{Tip}^{\mathrm{f} / \mathrm{f}}$ and $\mathrm{Tip}^{\mathrm{f} / \mathrm{f}}$ control mice. 
Figure 3.51: Immunoreactivity of $\mathrm{P} 300^{\mathrm{K} 1499 \mathrm{ac}} / \mathrm{CBP}^{\mathrm{K} 1535 \mathrm{ac}}$ is decreased in CaMKCre Tip60 ${ }^{\mathrm{f} / \mathrm{f}}$ mice. 109 Figure 6.1 Map of the MAPK signaling pathway in constitutive (top) and inducible (bottom) TIP60-deficiency mouse lines. 126 Figure 6.2: Combined map of MAPK signaling in the constitutive and the inducible TIP60-deficiency mouse lines. 127 


\section{List of Tables}

Table 2.1: PCR reactions and program used for genotyping. ................................ 17

Table 2.2: Primers used for genotyping............................................................. 17

Table 2.3: Options set for the watershed algorithm................................................ 23

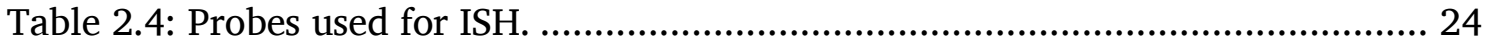

Table 2.5: Digestion reaction for Southern blot....................................................... 25

Table 2.6: Primer sequences for the Southern blot probe (817 bp).......................... 26

Table 2.7: PCR reaction for probe amplification for Southern blot............................ 26

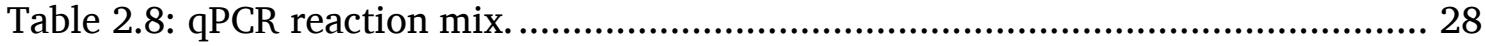

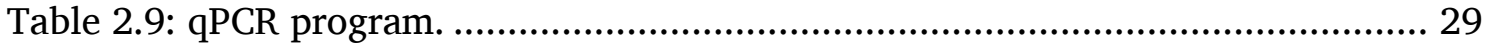

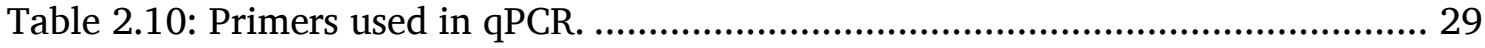

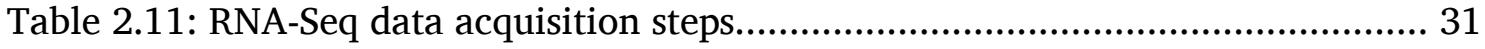

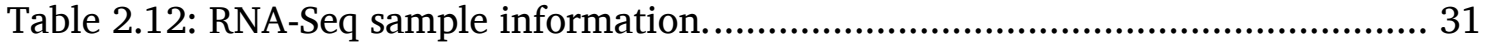

Table 3.1 List of commercial TIP60 antibodies tested, that did not detect endogenous

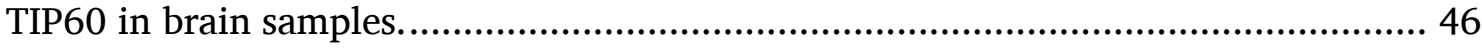

Table 3.2: Peptides used for TIP60 custom antibody productions. .............................. 46

Table 3.3 Bonferroni multiple comparison results for $c$-Fos expression. ..................... 58

Table 3.4: Bonferroni multiple comparison results for Arc expression........................ 59

Table 3.5: Bonferroni multiple comparison results for Npas4 expression................... 60

Table 3.6: Bonferroni multiple comparison results for Bdnf exon I expression............ 62

Table 3.7: Bonferroni multiple comparison results for Bdnf exon IV ......................... 63

Table 3.8: Bonferroni multiple comparison results for Zif268 expression. ................... 64

Table 3.9: Bonferroni multiple comparison results for Homer1 expression. ................ 65

Table 3.10: Bonferroni multiple comparison results for c-Jun. ............................... 66

Table 3.11: Bonferroni multiple comparison results for Nr4a1 expression. ................ 67

Table 3.12: RNA-Seq results for selected genes validated in Section 3.8.1 ................ 90

Table 3.13: Validation of RNA-Seq fold changes by qPCR...................................... 90

Table 3.14: GO-Term and KEGG analysis for the overlapping genes of the inducible and the constitutive TIP60-deficiency mouse line.

Table 3.15: GO-Term and KEGG analysis for the constitutive CaMKCre Tip60 ${ }^{\mathrm{f} / \mathrm{f}}$ mouse line. 
Table 3.16: GO-Term and KEGG-Pathway analysis of the inducible CaMKCreER ${ }^{\mathrm{T} 2}$ TIP60-

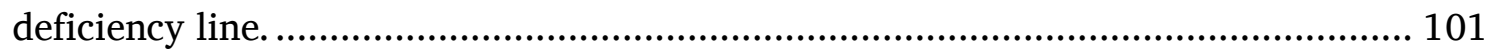




\section{References}

Alberts, B., Johnson, A., Lewis, J., Raff, M., Roberts, K. and Walter, P., 2002. Molecular Biology of the Cell 4th ed., Garland Science.

Allis, C.D., Berger, S.L., Cote, J., Dent, S., Jenuwien, T., Kouzarides, T., Pillus, L., Reinberg, D., Shi, Y., Shiekhattar, R., Shilatifard, A., Workman, J. and Zhang, Y., 2007. New Nomenclature for Chromatin-Modifying Enzymes. Cell, 131(4), pp.633-636.

Almendral, J.M., Sommer, D., Macdonald-Bravo, H., Burckhardt, J., Perera, J. and Bravo, R., 1988. Complexity of the early genetic response to growth factors in mouse fibroblasts. Molecular and Cellular Biology, 8(5), pp.2140-8.

Amaral, D., Andersen, P., Morris, R., Bliss, T. and O'Keefe, J., 2006. The Hippocampus Book 1st ed., Oxford University Press.

Amaral, D.G. and Dent, J. a, 1981. Development of the mossy fibers of the dentate gyrus: I. A light and electron microscopic study of the mossy fibers and their expansions. The Journal of Comparative Neurology, 195(1), pp.51-86.

Anders, S. and Huber, W., 2010. Differential expression analysis for sequence count data. Genome Biology, 11(10).

Angel, P. and Karin, M., 1991. The role of Jun, Fos and the AP-1 complex in cellproliferation and transformation. Biochimica et Biophysica Acta, 1072(2-3), pp.129-157.

Araque, A. and Navarrete, M., 2010. Glial cells in neuronal network function. Philosophical Transactions of the Royal Society of London. Series B, Biological Sciences, 365(1551), pp.2375-81.

Van Attikum, H. and Gasser, S.M., 2005. The histone code at DNA breaks: a guide to repair? Nature Reviews. Molecular Cell Biology, 6(10), pp.757-765.

Avvakumov, N. and Côté, J., 2007. The MYST family of histone acetyltransferases and their intimate links to cancer. Oncogene, 26(37), pp.5395-407.

Babity, J.M., Armstrong, J.N., Plumier, J.C., Currie, R.W. and Robertson, H.A., 1997. A novel seizure-induced synaptotagmin gene identified by differential display. Proceedings of the National Academy of Sciences of the United States of America, 94(6), pp.2638-41.

Babraham-Bioinformatics, 2012. FastQC A Quality Control tool for High Throughput Sequence Data. http://www.bioinformatics.babraham.ac.uk/projects/fastqc/ 
Bading, H., Ginty, D.D. and Greenberg, M.E., 1993. Regulation of gene expression in hippocampal neurons by distinct calcium signaling pathways. Science (New York, N.Y.), 260(5105), pp.181-6.

Baek, S.H., Ohgi, K. a, Rose, D.W., Koo, E.H., Glass, C.K. and Rosenfeld, M.G., 2002. Exchange of N-CoR corepressor and Tip60 coactivator complexes links gene expression by NF-kappaB and beta-amyloid precursor protein. Cell, 110(1), pp.55-67.

Bannerman, D.M., Deacon, R.M.J., Offen, S., Friswell, J., Grubb, M. and Rawlins, J.N.P., 2002. Double dissociation of function within the hippocampus: Spatial memory and hyponeophagia. Behavioral Neuroscience, 116(5), pp.884-901.

Barker, G.R.I. and Warburton, E.C., 2011. When is the hippocampus involved in recognition memory? The Journal of Neuroscience, 31(29), pp.10721-31.

Bean, L. a, Ianov, L. and Foster, T.C., 2014. Estrogen Receptors, the Hippocampus, and Memory. The Neuroscientist, pp.1-12.

Bird, A., 2010. Redefining the Function of the Rett Syndrome Protein. Rett Syndrome Research Trust. https://rettsyndrome.wordpress.com/2010/02/25/redefining-thefunction-of-the-rett-syndrome-protein/

Bliss, T. and Lømo, T., 1973. Long-lasting potentiation of synaptic transmission in the dentate area of the anaesthetized rabbit following stimulation of the perforant path. The Journal of physiology, pp.331-356.

Bloodgood, B.L., Sharma, N., Browne, H.A., Trepman, A.Z. and Greenberg, M.E., 2013. The activity-dependent transcription factor NPAS4 regulates domain-specific inhibition. Nature, 503(7474), pp.121-5.

Bouras, T., Fu, M., Sauve, A. a., Wang, F., Quong, A. a., Perkins, N.D., Hay, R.T., Gu, W. and Pestell, R.G., 2005. SIRT1 deacetylation and repression of p300 involves lysine residues 1020/1024 within the cell cycle regulatory domain 1. Journal of Biological Chemistry, 280(11), pp.10264-10276.

Brandt, M.D., Maass, A., Kempermann, G. and Storch, A., 2010. Physical exercise increases Notch activity, proliferation and cell cycle exit of type-3 progenitor cells in adult hippocampal neurogenesis. The European Journal of Neuroscience, 32(8), pp.1256-64.

Brown, E.S., Rush, a J. and McEwen, B.S., 1999. Hippocampal remodeling and damage by corticosteroids: implications for mood disorders. Neuropsychopharmacology, 21(4), pp.474-84.

Butz, S., Okamoto, M. and Südhof, T.C., 1998. A tripartite protein complex with the potential to couple synaptic vesicle exocytosis to cell adhesion in brain. Cell, 94(6), pp.773-82. 
Cao, X. and Südhof, T.C., 2004. Dissection of amyloid-beta precursor proteindependent transcriptional transactivation. The Journal of Biological Chemistry, 279(23), pp.24601-11.

Chahrour, M., Jung, S.Y., Shaw, C., Zhou, X., Wong, S.T.C., Qin, J. and Zoghbi, H.Y., 2008. MeCP2, a key contributor to neurological disease, activates and represses transcription. Science, 320(5880), pp.1224-9.

Chan, J., Cordeira, J. and Calderon, G., 2008. Depletion of central BDNF in mice impedes terminal differentiation of new granule neurons in the adult hippocampus. Molecular and Cellular Biology, 39(3), pp.372-383.

Chen, D., Wu, C.F., Shi, B. and Xu, Y.M., 2002. Tamoxifen and toremifene cause impairment of learning and memory function in mice. Pharmacology, Biochemistry, and Behavior, 71(1-2), pp.269-76.

Choudhary, C., Kumar, C., Gnad, F., Nielsen, M.L., Rehman, M., Walther, T.C., Olsen, J. V and Mann, M., 2009. Lysine acetylation targets protein complexes and coregulates major cellular functions. Science, 325(5942), pp.834-40.

Clayton, A.L., Hazzalin, C. a and Mahadevan, L.C., 2006. Enhanced histone acetylation and transcription: a dynamic perspective. Molecular Cell, 23(3), pp.289-96.

Col, E., Caron, C., Chable-Bessia, C., Legube, G., Gazzeri, S., Komatsu, Y., Yoshida, M., Benkirane, M., Trouche, D. and Khochbin, S., 2005. HIV-1 Tat targets Tip60 to impair the apoptotic cell response to genotoxic stresses. The EMBO Journal, 24(14), pp.2634-45.

Coppoolse, E.R., de Vroomen, M.J., van Gennip, F., Hersmus, B.J.M. and van Haaren, M.J.J., 2005. Size does matter: cre-mediated somatic deletion efficiency depends on the distance between the target lox-sites. Plant Molecular Biology, 58(5), pp.687-98.

Coutellier, L., Beraki, S., Ardestani, P.M., Saw, N.L. and Shamloo, M., 2012. Npas4: a neuronal transcription factor with a key role in social and cognitive functions relevant to developmental disorders. PloS One, 7(9).

Dallman, M. and Akana, S., 1995. The neural network that regulates energy balance is responsive to glucocorticoids and insulin and also regulates HPA axis responsivity at a site proximal to CRF neurons. Annals of the New York Academy of Sciences, 771, pp.730-42.

Davis, I.J., Hazel, T.G., Chen, R.H., Blenis, J. and Lau, L.F., 1993. Functional domains and phosphorylation of the orphan receptor Nur77. Molecular Endocrinology, 7(8), pp.953-964.

Deng, W., Aimone, J.B. and Gage, F.H., 2010. New neurons and new memories: how does adult hippocampal neurogenesis affect learning and memory? Nature Reviews. Neuroscience, 11(5), pp.339-50. 
Dennis, G., Sherman, B.T., Hosack, D. a, Yang, J., Gao, W., Lane, H.C. and Lempicki, R. a, 2003. DAVID: Database for Annotation, Visualization, and Integrated Discovery. Genome Biology, 4(5).

Doyon, Y., Selleck, W., Lane, W.S., Tan, S. and Co, J., 2004. Structural and Functional Conservation of the NuA4 Histone Acetyltransferase Complex from Yeast to Humans. Molecular and Cellular Biology, 24(5), pp.1884-1896.

Eichele, G. and Diez-Roux, G., 2011. High-throughput analysis of gene expression on tissue sections by in situ hybridization. Methods, 53(4), pp.417-23.

Elmér, E., Kokaia, Z., Kokaia, M., Carnahan, J., Nawa, H. and Lindvall, O., 1998. Dynamic changes of brain-derived neurotrophic factor protein levels in the rat forebrain after single and recurring kindling-induced seizures. Neuroscience, 83(2), pp.351-62.

Ennaceur, a and Delacour, J., 1988. A new one-trial test for neurobiological studies of memory in rats. 1: Behavioral data. Behavioural Brain Research, 31(1), pp.47-59.

Erdmann, G., Schütz, G. and Berger, S., 2007. Inducible gene inactivation in neurons of the adult mouse forebrain. BMC Neuroscience, 8(63).

Eriksson, P.S., Perfilieva, E., Björk-Eriksson, T., Alborn, a M., Nordborg, C., Peterson, D. a and Gage, F.H., 1998. Neurogenesis in the adult human hippocampus. Nature Medicine, 4(11), pp.1313-1317.

Fanselow, M.S. and Dong, H.-W., 2010. Are the dorsal and ventral hippocampus functionally distinct structures? Neuron, 65(1), pp.7-19.

Feil, R., Wagner, J., Metzger, D. and Chambon, P., 1997. Regulation of Cre recombinase activity by mutated estrogen receptor ligand-binding domains. Biochemical and Biophysical Research Communications, 237(3), pp.752-7.

Feldman, D.E., 2002. Synapses, scaling and homeostasis in vivo. Nature Neuroscience, 5(8), pp.712-714.

Fortin, N.J., Agster, K.L. and Eichenbaum, H.B., 2002. Critical role of the hippocampus in memory for sequences of events. Nature Neuroscience, 5(5), pp.458-62.

Frank, S.R., Parisi, T., Taubert, S., Fernandez, P., Fuchs, M., Chan, H.-M., Livingston, D.M. and Amati, B., 2003. MYC recruits the TIP60 histone acetyltransferase complex to chromatin. EMBO reports, 4(6), pp.575-80.

Fu, M., Wang, C., Reutens, A.T., Wang, J., Angeletti, R.H., Siconolfi-Baez, L., Ogryzko, V., Avantaggiati, M.L. and Pestell, R.G., 2000. p300 and p300/cAMP-response element-binding protein-associated factor acetylate the androgen receptor at sites governing hormone-dependent transactivation. Journal of Biological Chemistry, 275(27), pp.20853-20860. 
Fujioka, T., Fujioka, A. and Duman, R.S., 2004. Activation of cAMP signaling facilitates the morphological maturation of newborn neurons in adult hippocampus. The Journal of Neuroscience, 24(2), pp.319-28.

Fykse, E. and Takei, K., 1993. Relative properties and localizations of synaptic vesicle protein isoforms: the case of the synaptophysins. The Journal of Neuroscience, 13(11).

Gao, Y., Hamers, N., Rakhshandehroo, M., Berger, R., Lough, J. and Kalkhoven, E., 2014. Allele compensation in tip60+/- mice rescues white adipose tissue function in vivo. PlOS One, 9(5).

Gaughan, L., Brady, M.E., Cook, S., Neal, D.E. and Robson, C.N., 2001. Tip60 Is a Coactivator Specific for Class I Nuclear Hormone Receptors. Journal of Biological Chemistry, 276(50), pp.46841-46848.

Gaughan, L., Logan, I.R., Cook, S., Neal, D.E. and Robson, C.N., 2002. Tip60 and histone deacetylase 1 regulate androgen receptor activity through changes to the acetylation status of the receptor. The Journal of biological chemistry, 277(29), pp.25904-13.

Gavaravarapu, S. and Kamine, J., 2000. Tip60 inhibits activation of CREB protein by protein kinase A. Biochemical and Biophysical Research Communications, 269(3), pp.758-66.

Geerts, S., 2008. Nutrition management of children with Rett syndrome: An update. Nutrition, 23(6), pp.293-297.

Gleichmann, M., Chow, V.W. and Mattson, M.P., 2011. Homeostatic disinhibition in the aging brain and Alzheimer's disease. Journal of Alzheimer's Disease, 24(1), pp.15-24.

Glozak, M. a, Sengupta, N., Zhang, X. and Seto, E., 2005. Acetylation and deacetylation of non-histone proteins. Gene, 363, pp.15-23.

Gonzalez-Islas, C. and Wenner, P., 2006. Spontaneous network activity in the embryonic spinal cord regulates AMPAergic and GABAergic synaptic strength. Neuron, 49(4), pp.563-75.

Good, M. a, Barnes, P., Staal, V., McGregor, A. and Honey, R.C., 2007. Context- but not familiarity-dependent forms of object recognition are impaired following excitotoxic hippocampal lesions in rats. Behavioral Neuroscience, 121(1), pp.21823.

Grabs, D., Bergmann, M., Schuster, T., Fox, P. a, Brich, M. and Gratz, M., 1994. Differential expression of synaptophysin and synaptoporin during pre- and postnatal development of the rat hippocampal network. The European Journal of Neuroscience, 6(11), pp.1765-71. 
Greenberg, M. and Ziff, E., 1984. Stimulation of 3T3 cells induces transcription of the c-fos proto-oncogene. Nature, 311, pp.433 - 438.

Greenberg, M.E., Xu, B., Lu, B. and Hempstead, B.L., 2009. New insights in the biology of BDNF synthesis and release: implications in CNS function. The Journal of Neuroscience, 29(41), pp.12764-7.

$\mathrm{Gu}, \mathrm{W}$. and Roeder, R., 1997. Activation of p53 sequence-specific DNA binding by acetylation of the p53 C-terminal domain. Cell, 90(4), pp.595-606.

Guy, J., Cheval, H., Selfridge, J. and Bird, A., 2011. The role of MeCP2 in the brain. Annual Review of Cell and Developmental Biology, 27, pp.631-52.

Guzowski, J.F., 2002. Insights into immediate-early gene function in hippocampal memory consolidation using antisense oligonucleotide and fluorescent imaging approaches. Hippocampus, 12(1), pp.86-104.

Guzowski, J.F., McNaughton, B.L., Barnes, C. a and Worley, P.F., 1999. Environmentspecific expression of the immediate-early gene Arc in hippocampal neuronal ensembles. Nature Neuroscience, 2(12), pp.1120-1124.

Hagihara, H., Toyama, K., Yamasaki, N. and Miyakawa, T., 2009. Dissection of hippocampal dentate gyrus from adult mouse. Journal of Visualized Experiments: JoVE, 3000(33), pp.1-6.

Han, X., Aenlle, K.K., Bean, L. a, Rani, A., Semple-Rowland, S.L., Kumar, A. and Foster, T.C., 2013. Role of estrogen receptor $\alpha$ and $\beta$ in preserving hippocampal function during aging. The Journal of Neuroscience, 33(6), pp.2671-83.

Hansson, E. and Rönnbäck, L., 2003. Glial neuronal signaling in the central nervous system. FASEB Journal, 17(3), pp.341-8.

Hebb, D.O., 1949. The Organization of Behavior: A Neuropsychological Theory, New York: Wiley and Sons.

Hebbes, T.R., Thorne, A.W. and Crane-Robinson, C., 1988. A direct link between core histone acetylation and transcriptionally active chromatin. The EMBO Journal, 7(5), pp.1395-1402.

Hess, U.S., Lynch, G. and Gall, C.M., 1995. Regional patterns of c-fos mRNA expression in rat hippocampus following exploration of a novel environment versus performance of a well-learned discrimination. The Journal of Neuroscience, 15(12), pp.7796-7809.

Hlubek, F., Löhberg, C., Meiler, J., Jung, A., Kirchner, T. and Brabletz, T., 2001. Tip60 is a cell-type-specific transcriptional regulator. Journal of Biochemistry, 129(4), pp.635-41.

Hong, L., Schroth, G.P., Matthews, H.R., Yau, P. and Bradburys, E.M., 1993. Studies of the DNA Binding Properties of Histone H4 Amino Terminus. , 268(1), pp.305-14. 
Hu, Y., Fisher, J.B., Koprowski, S., Mcallister, D. and Kim, M., 2010. Homozygous Disruption of the Tip60 Gene Causes Early Embryonic Lethality. Developmental Dynamics, 238(11), pp.2912-2921.

Ikura, T., Ogryzko, V. V, Grigoriev, M., Groisman, R., Wang, J., Horikoshi, M., Scully, R., Qin, J. and Nakatani, Y., 2000. Involvement of the TIP60 histone acetylase complex in DNA repair and apoptosis. Cell, 102(4), pp.463-473.

Imayoshi, I., Sakamoto, M., Ohtsuka, T., Takao, K., Miyakawa, T., Yamaguchi, M., Mori, K., Ikeda, T., Itohara, S. and Kageyama, R., 2008. Roles of continuous neurogenesis in the structural and functional integrity of the adult forebrain. Nature Neuroscience, 11(10), pp.1153-61.

Jacobson, L. and Sapolsky, R., 1991. The role of the hippocampus in feedback regulation of the hypothalamic-pituitary-adrenocortical axis. Endocrine Reviews, 12(2), pp.118-34.

Jenuwein, T. and Allis, C.D., 2001. Translating the histone code. Science, 293(5532), pp.1074-1080.

Jeong, K.W., Kim, K., Situ, A.J., Ulmer, T.S., An, W. and Stallcup, M.R., 2011. Recognition of enhancer element-specific histone methylation by TIP60 in transcriptional activation. Nature Structural \& Molecular Biology, 18(12), pp.135865.

Jo, K., Derin, R., Li, M. and Bredt, D.S., 1999. Characterization of MALS/Velis-1, -2, and -3: a family of mammalian LIN-7 homologs enriched at brain synapses in association with the postsynaptic density-95/NMDA receptor postsynaptic complex. The Journal of Neuroscience, 19(11), pp.4189-99.

Johnson, A. a, Sarthi, J., Pirooznia, S.K., Reube, W. and Elefant, F., 2013. Increasing Tip60 HAT levels rescues axonal transport defects and associated behavioral phenotypes in a Drosophila Alzheimer's disease model. The Journal of Neuroscience, 33(17), pp.7535-47.

Jones, T.R., Kang, I.H., Wheeler, D.B., Lindquist, R. a, Papallo, A., Sabatini, D.M., Golland, P. and Carpenter, A.E., 2008. CellProfiler Analyst: data exploration and analysis software for complex image-based screens. BMC Bioinformatics, 9, p.482.

Kaczmarek, L., Siedlecki, J.A. and Danysz, W., 1988. Proto-oncogene cfos induction in rat hippocampus. Brain Research, 427(2), pp.183-6.

Kaddoum, L., Panayotis, N., Mazarguil, H., Giglia-Mari, G., Roux, J.C. and Joly, E., 2013. Isoform-specific anti-MeCP2 antibodies confirm that expression of the e1 isoform strongly predominates in the brain. F1000Research.

Kamine, J., Elangovan, B., Subramanian, T., Coleman, D. and Chinnadurai, G., 1996. Identification of a cellular protein that specifically interacts with the essential cysteine region of the HIV-1 Tat transactivator. Virology, 216(2), pp.357-66. 
Kimura, A. and Horikoshi, M., 1998. Tip60 acetylates six lysines of a specific class in core histones in vitro. Genes to Cells, 3(12), pp.789-800.

Kjelstrup, K.G., Tuvnes, F. a, Steffenach, H.-A., Murison, R., Moser, E.I. and Moser, M.B., 2002. Reduced fear expression after lesions of the ventral hippocampus. Proceedings of the National Academy of Sciences of the United States of America, 99(16), pp.10825-30.

Kobayashi, M. and Buckmaster, P.S., 2003. Reduced inhibition of dentate granule cells in a model of temporal lobe epilepsy. The Journal of Neuroscience, 23(6), pp.244052.

Kouzarides, T., 2000. Acetylation: a regulatory modification to rival phosphorylation? The EMBO Journal, 19(6), pp.1176-1179.

Kruijer, W., Cooper, J., Hunter, T. and Verma, I., 1983. Platelet-derived growth factor induces rapid but transient expression of the c-fos gene and protein. Nature, 312, pp.711-716.

Lanahan, A. and Worley, P., 1998. Immediate-early genes and synaptic function. Neurobiology of Learning and Memory, 70, pp.37-43.

Lee, D.Y., Hayes, J.J., Pruss, D. and Wolffe, A.P., 1993. A positive role for histone acetylation in transcription factor access to nucleosomal DNA. Cell, 72(1), pp.7384.

Lee, K.J., Queenan, B.N., Rozeboom, A.M., Bellmore, R., Lim, S.T., Vicini, S. and Pak, D.T.S., 2013. Mossy fiber-CA3 synapses mediate homeostatic plasticity in mature hippocampal neurons. Neuron, 77(1), pp.99-114.

Lee, K.K. and Workman, J.L., 2007. Histone acetyltransferase complexes: one size doesn't fit all. Nature Reviews. Molecular Cell Biology, 8(4), pp.284-95.

Legube, G. and Trouche, D., 2003. Identification of a larger form of the histone acetyl transferase Tip60. Gene, 310, pp.161-168.

Lehner, B., Crombie, C., Tischler, J., Fortunato, A. and Fraser, A.G., 2006. Systematic mapping of genetic interactions in Caenorhabditis elegans identifies common modifiers of diverse signaling pathways. Nature Genetics, 38(8), pp.896-903.

Levenson, J.M., O'Riordan, K.J., Brown, K.D., Trinh, M. a., Molfese, D.L. and Sweatt, J.D., 2004. Regulation of histone acetylation during memory formation in the hippocampus. Journal of Biological Chemistry, 279(39), pp.40545-40559.

Levine, a S. and Morley, J.E., 1981. Stress-induced eating in rats. The American Journal of Physiology, 241(1), pp.R72-6.

Li, Y., Tsun, A., Gao, Z., Han, Z., Gao, Y., Li, Z., Lin, F., Wang, Y., Wei, G., Yao, Z. and Li, B., 2013. 60-kDa Tat-interactive protein (TIP60) positively regulates Th- 
inducing POK (ThPOK)-mediated repression of eomesodermin in human CD4 + T cells. Journal of Biological Chemistry, 288(22), pp.15537-15546.

Lin, Y., Bloodgood, B.L., Hauser, J.L., Lapan, A.D., Koon, A.C., Kim, T.-K., Hu, L.S., Malik, A.N. and Greenberg, M.E., 2008. Activity-dependent regulation of inhibitory synapse development by Npas4. Nature, 455(7217), pp.1198-204.

Livak, K.J. and Schmittgen, T.D., 2001. Analysis of relative gene expression data using real-time quantitative PCR and the 2(-Delta Delta C(T)) Method. Methods, 25(4), pp.402-408.

Lømo, T., 1966. Frequency potentiation of excitatory synaptic activity in dentate area of hippocampal formation. Acta Physiologica Scandinavica, 68, p.277.

Lorbeck, M., Pirooznia, K., Sarthi, J., Zhu, X. and Elefant, F., 2011. Microarray analysis uncovers a role for tip60 in nervous system function and general metabolism. PloS One, 6(4).

Luger, K., Mäder, a W., Richmond, R.K., Sargent, D.F. and Richmond, T.J., 1997. Crystal structure of the nucleosome core particle at 2.8 A resolution. Nature, 389(6648), pp.251-260.

Maffei, A., Nelson, S.B. and Turrigiano, G.G., 2004. Selective reconfiguration of layer 4 visual cortical circuitry by visual deprivation. Nature Neuroscience, 7(12), pp.1353-9.

McAllister, D., Merlo, X. and Lough, J., 2002. Characterization and expression of the mouse tat interactive protein $60 \mathrm{kD}$ (TIP60) gene. Gene, 289(1-2), pp.169-76.

McClelland, J.L., McClelland, J.L., McNaughton, B.L., McNaughton, B.L., O'Reilly, R.C. and O'Reilly, R.C., 1995. Why there are complementary learning systems in the hippocampus and neocortex: Insights from the Successes and Failures of Connectionist Models of Learning and Memory. Psychological review, 102(3), pp.419-57.

McHugh, S.B., Deacon, R.M.J., Rawlins, J.N.P. and Bannerman, D.M., 2004. Amygdala and ventral hippocampus contribute differentially to mechanisms of fear and anxiety. Behavioral Neuroscience, 118(1), pp.63-78.

Metzger, D. and Chambon, P., 2001. Site- and time-specific gene targeting in the mouse. Methods, 24(1), pp.71-80.

Milner, B., 1962. Les troubles de la mémoire accompagnant des lésions hippocampiques bilatérales. Physiologic de l'Hippocampe, pp.257-272.

Ming, G.-L. and Song, H., 2011. Adult neurogenesis in the mammalian brain: significant answers and significant questions. Neuron, 70(4), pp.687-702.

Minichiello, L., Korte, M., Wolfer, D. and Kühn, R., 1999. Essential role for TrkB receptors in hippocampus-mediated learning. Neuron, 24, pp.401-414. 
Morgan, J.I., Cohen, D.R., Hempstead, J.L. and Curran, T., 1987. Mapping patterns of c-fos expression in the central nervous system after seizure. Science, 237(4811), pp.192-197.

Moser, M. and Moser, E., 1995. Spatial learning with a minislab in the dorsal hippocampus. Proceedings of the National Academy of Sciences of the United States of America, 92, pp.9697-9701.

Musselman, C.A., Lalonde, M.-E., Côté, J. and Kutateladze, T.G., 2012. Perceiving the epigenetic landscape through histone readers. Nature Structural \& Molecular Biology, 19(12), pp.1218-1227.

Nakagawa, S., Kim, J.-E., Lee, R., Chen, J., Fujioka, T., Malberg, J., Tsuji, S. and Duman, R.S., 2002. Localization of phosphorylated cAMP response elementbinding protein in immature neurons of adult hippocampus. The Journal of Neuroscience, 22(22), pp.9868-76.

Oberman, L. and Pascual-Leone, A., 2013. Changes in Plasticity Across the Lifespan: Cause of Disease and Target for Intervention 1st ed., Elsevier B.V.

Ogryzko, V. V., Schiltz, R.L., Russanova, V., Howard, B.H. and Nakatani, Y., 1996. The transcriptional coactivators p300 and CBP are histone acetyltransferases. Cell, 87(5), pp.953-959.

Okuno, H., 2011. Regulation and function of immediate-early genes in the brain: beyond neuronal activity markers. Neuroscience Research, 69(3), pp.175-86.

Olson, A.K., Eadie, B.D., Ernst, C. and Christie, B.R., 2006. Environmental enrichment and voluntary exercise massively increase neurogenesis in the adult hippocampus via dissociable pathways. Hippocampus, 16(3), pp.250-60.

Parpura, V., Heneka, M.T., Montana, V., Oliet, S.H.R., Schousboe, A., Haydon, P.G., Stout, R.F., Spray, D.C., Reichenbach, A., Pannicke, T., Pekny, M., Pekna, M., Zorec, R. and Verkhratsky, A., 2012. Glial cells in (patho)physiology. Journal of Neurochemistry, 121(1), pp.4-27.

Patel, J., Du, Y. and Ard, P., 2004. The c-MYC oncoprotein is a substrate of the acetyltransferases hGCN5/PCAF and TIP60. Molecular and Cellular Biology.

Peleg, S., Sananbenesi, F., Zovoilis, A., Burkhardt, S., Bahari-Javan, S., Agis-Balboa, R.C., Cota, P., Wittnam, J.L., Gogol-Doering, A., Opitz, L., Salinas-Riester, G., Dettenhofer, M., Kang, H., Farinelli, L., Chen, W. and Fischer, A., 2010. Altered histone acetylation is associated with age-dependent memory impairment in mice. Science, 328(5979), pp.753-6.

Ploski, J.E., Monsey, M.S., Nguyen, T., Dileone, R.J. and Schafe, G.E., 2011. The Neuronal PAS Domain Protein 4 (Npas4) Is Required for New and Reactivated Fear Memories. PloS One, 6(8), p.e23760. 
Pruunsild, P., Kazantseva, A., Aid, T., Palm, K. and Timmusk, T., 2007. Dissecting the human BDNF locus: bidirectional transcription, complex splicing, and multiple promoters. Genomics, 90(3), pp.397-406.

Quinlan, A. and Hall, I., 2010. BEDTools: a flexible suite of utilities for comparing genomic features. Bioinformatics, pp.1-2.

Ramamoorthi, K., Fropf, R., Belfort, G.M., Fitzmaurice, H.L., McKinney, R.M., Neve, R.L., Otto, T. and Lin, Y., 2011. Npas4 Regulates a Transcriptional Program in CA3 Required for Contextual Memory Formation. Science, 334(6063), pp.16691675.

Ramirez, S., Liu, X., Lin, P. -a., Suh, J., Pignatelli, M., Redondo, R.L., Ryan, T.J. and Tonegawa, S., 2013. Creating a False Memory in the Hippocampus. Science, 341(6144), pp.387-391.

Ran, Q. and Pereira-Smith, O.M., 2000. Identification of an alternatively spliced form of the Tat interactive protein (Tip60), Tip60(beta). Gene, 258, pp.141-6.

Reimers, J.M., Loweth, J. a and Wolf, M.E., 2014. BDNF contributes to both rapid and homeostatic alterations in AMPA receptor surface expression in nucleus accumbens medium spiny neurons. The European Journal of Neuroscience, 39(7), pp.1159-69.

Rial Verde, E.M., Lee-Osbourne, J., Worley, P.F., Malinow, R. and Cline, H.T., 2006. Increased expression of the immediate-early gene arc/arg3.1 reduces AMPA receptor-mediated synaptic transmission. Neuron, 52(3), pp.461-74.

Riccio, A., 2010. Dynamic epigenetic regulation in neurons: enzymes, stimuli and signaling pathways. Nature Neuroscience, 13(11), pp.1330-7.

Robinson, J. and Thorvaldsdóttir, H., 2011. Integrative genomics viewer. Nature Biotechnology, 29(1), pp.24-26.

Rothbart, S.B., Lin, S., Britton, L.-M., Krajewski, K., Keogh, M.-C., Garcia, B. a and Strahl, B.D., 2012. Poly-acetylated chromatin signatures are preferred epitopes for site-specific histone H4 acetyl antibodies. Scientific Reports, 2, p.489.

Rudy, J.W., Huff, N.C. and Matus-Amat, P., 2004. Understanding contextual fear conditioning: insights from a two-process model. Neuroscience and Biobehavioral Reviews, 28(7), pp.675-85.

Sager, C., Tapken, D., Kott, S. and Hollmann, M., 2009. Functional modulation of AMPA receptors by transmembrane AMPA receptor regulatory proteins. Neuroscience, 158(1), pp.45-54.

Saha, R.N., Wissink, E.M., Bailey, E.R., Zhao, M., Fargo, D.C., Hwang, J.-Y., Daigle, K.R., Fenn, J.D., Adelman, K. and Dudek, S.M., 2011. Rapid activity-induced transcription of Arc and other IEGs relies on poised RNA polymerase II. Nature Neuroscience, 14(7), pp.848-56. 
Sapountzi, V., Logan, I.R. and Robson, C.N., 2006. Cellular functions of TIP60. The International Journal of Biochemistry \& Cell Biology, 38(9), pp.1496-509.

Sarthi, J. and Elefant, F., 2011. dTip60 HAT activity controls synaptic bouton expansion at the Drosophila neuromuscular junction. PloS One, 6(10).

Scharfman, H.E., 2006. Seizure-Induced Neurogenesis in the Dentate Gyrus and its Dependence on Growth Factors and Cytokines. In Growth Factors and Epilepsy. pp. $1-40$.

Scoville, W. and Milner, B., 1957. Loss of recent memory after bilateral hippocampal lesions. Journal of Neurology, Neurosurgery and Psychiatry, 20(11).

Semon, R., 1920. Die Mneme, Leipzig: Engelmann.

Setou, M., 2000. Kinesin Superfamily Motor Protein KIF17 and mLin-10 in NMDA Receptor-Containing Vesicle Transport. Science, 288(5472), pp.1796-1802.

Sharma, S.K., 2010. Protein acetylation in synaptic plasticity and memory. Neuroscience and Biobehavioral Reviews, 34(8), pp.1234-1240.

Shaywitz, A.J. and Greenberg, M.E., 1999. CREB: a stimulus-induced transcription factor activated by a diverse array of extracellular signals. Annual Review of Biochemistry, 68, pp.821-861.

Sheng, M. and Greenberg, M.E., 1990. The regulation and function of c-fos and other immediate early genes in the nervous system. Neuron, 4(4), pp.477-85.

Shepherd, J., Rumbaugh, G. and Wu, J., 2006. Arc/Arg3. 1 mediates homeostatic synaptic scaling of AMPA receptors. Neuron, 52(3), pp.475-484.

Sheridan, A.M., Force, T., Yoon, H.J., O’Leary, E., Choukroun, G., Taheri, M.R. and Bonventre, J. V, 2001. PLIP, a novel splice variant of Tip60, interacts with group IV cytosolic phospholipase A(2), induces apoptosis, and potentiates prostaglandin production. Molecular and Cellular Biology, 21(14), pp.4470-4481.

Skene, P., 2010. Global analysis of the methyl-CpG binding protein MeCP2.

Skene, P.J., Illingworth, R.S., Webb, S., Kerr, A.R.W., James, K.D., Turner, D.J., Andrews, R. and Bird, A.P., 2010. Neuronal MeCP2 is expressed at near histoneoctamer levels and globally alters the chromatin state. Molecular Cell, 37(4), pp.457-68.

Sloviter, R. and Bumanglag, A., 2010. Abnormal dentate gyrus network circuitry in temporal lobe epilepsy. Jasper's Basic Mechanisms of the Epilepsies, pp.1-20.

Soriano, P., 1999. Generalized lacZ expression with the ROSA26 Cre reporter strain. Nature Genetics, 21(1), pp.70-1. 
Squatrito, M., Gorrini, C. and Amati, B., 2006. Tip60 in DNA damage response and growth control: many tricks in one HAT. Trends in Cell Biology, 16(9), pp.433-42.

Squire, L.R., 2004. Memory systems of the brain: A brief history and current perspective. Neurobiology of Learning and Memory, 82(3), pp.171-177.

Squire, L.R. and Bayley, P.J., 2007. The neuroscience of remote memory. Current Opinion in Neurobiology, 17(2), pp.185-196.

Strahl, B.D. and Allis, C.D., 2000. The language of covalent histone modifications. Nature, 403(6765), pp.41-5.

Sun, Y., Jiang, X., Xu, Y., Ayrapetov, M.K., Moreau, L. a, Whetstine, J.R. and Price, B.D., 2009. Histone H3 methylation links DNA damage detection to activation of the tumour suppressor Tip60. Nature Cell Biology, 11(11), pp.1376-82.

Sun, Y., Xu, Y., Roy, K. and Price, B.D., 2007. DNA damage-induced acetylation of lysine 3016 of ATM activates ATM kinase activity. Molecular and Cellular Biology, 27(24), pp.8502-9.

Sykes, S.M., Mellert, H.S., Holbert, M. a, Li, K., Marmorstein, R., Lane, W.S. and McMahon, S.B., 2006. Acetylation of the p53 DNA-binding domain regulates apoptosis induction. Molecular Cell, 24(6), pp.841-51.

Tang, Y., Luo, J., Zhang, W. and Gu, W., 2006. Tip60-dependent acetylation of p53 modulates the decision between cell-cycle arrest and apoptosis. Molecular Cell, 24(6), pp.827-39.

Taverna, S.D., Li, H., Ruthenburg, A.J., Allis, C.D. and Patel, D.J., 2007. How chromatin-binding modules interpret histone modifications: lessons from professional pocket pickers. Nature Structural \& Molecular Biology, 14(11), pp.1025-40.

Thompson, P.R., Wang, D., Wang, L., Fulco, M., Pediconi, N., Zhang, D., An, W., Ge, Q., Roeder, R.G., Wong, J., Levrero, M., Sartorelli, V., Cotter, R.J. and Cole, P.A., 2004. Regulation of the p300 HAT domain via a novel activation loop. Nature Structural \& Molecular Biology, 11(4), pp.308-15.

Tischmeyer, W. and Grimm, R., 1999. Activation of immediate early genes and memory formation. Cellular and molecular life sciences: CMLS, 55(4), pp.564-574.

Tolwani, R.J., Buckmaster, P.S., Varma, S., Cosgaya, J.M., Wu, Y., Suri, C. and Shooter, E.M., 2002. BDNF overexpression increases dendrite complexity in hippocampal dentate gyrus. Neuroscience, 114(3), pp.795-805.

Trapnell, C., Pachter, L. and Salzberg, S.L., 2009. TopHat: discovering splice junctions with RNA-Seq. Bioinformatics, 25(9), pp.1105-11.

Tsien, J.Z., 2000. Linking Hebb's coincidence-detection to memory formation. Current Opinion in Neurobiology, 10(2), pp.266-273. 
Turlo, K. a, Gallaher, S.D., Vora, R., Laski, F. a and Iruela-Arispe, M.L., 2010. When Cre-mediated recombination in mice does not result in protein loss. Genetics, 186(3), pp.959-67.

Turrigiano, G., 2012. Homeostatic synaptic plasticity: local and global mechanisms for stabilizing neuronal function. Cold Spring Harbor Perspectives in Biology, 4(1).

Turrigiano, G., 2008. The self-tuning neuron: synaptic scaling of excitatory synapses. Cell, 135(3), pp.422-435.

Turrigiano, G.G., 1999. Homeostatic plasticity in neuronal networks: the more things change, the more they stay the same. Trends in Neurosciences, 22(5), pp.221-7.

VanElzakker, M., Fevurly, R.D., Breindel, T. and Spencer, R.L., 2008. Environmental novelty is associated with a selective increase in Fos expression in the output elements of the hippocampal formation and the perirhinal cortex. Learning \& Memory, 15(12), pp.899-908.

Vazdarjanova, A., Ramirez-amaya, V., Insel, N., Plummer, T.K., Rosi, S., Chowdhury, S., Mikhael, D., Worley, P.F. and Guzowski, J.F., 2006. Spatial Exploration Induces ARC , a Only in Calcium / Calmodulin-Dependent Protein Kinase IIPositive Principal Excitatory and Inhibitory Neurons of the Rat Forebrain. The Journal of Comparative Neurology, 329(October 2005), pp.317-329.

Vogt, M. a, Chourbaji, S., Brandwein, C., Dormann, C., Sprengel, R. and Gass, P., 2008. Suitability of tamoxifen-induced mutagenesis for behavioral phenotyping. Experimental Neurology, 211(1), pp.25-33.

Walf, A. a and Frye, C. a, 2006. A review and update of mechanisms of estrogen in the hippocampus and amygdala for anxiety and depression behavior.

Neuropsychopharmacology, 31(6), pp.1097-111.

Wang, J. and Chen, J., 2010. SIRT1 regulates autoacetylation and histone acetyltransferase activity of TIP60. The Journal of Biological Chemistry, 285(15), pp.11458-64.

Watson, R. and Clements, J., 1980. A herpes simplex virus type 1 function continuously required for early and late virus RNA synthesis. Nature, 285, pp.329 -330 .

West, A.E. and Greenberg, M.E., 2011. Neuronal activity-regulated gene transcription in synapse development and cognitive function. Cold Spring Harbor Perspectives in Biology, 3(6).

Wondolowski, J. and Dickman, D., 2013. Emerging links between homeostatic synaptic plasticity and neurological disease. Frontiers in Cellular Neuroscience, 7, p.223.

Xiao, H., Chung, J., Kao, H.-Y. and Yang, Y.-C., 2003. Tip60 is a co-repressor for STAT3. The Journal of Biological Chemistry, 278(13), pp.11197-204. 
Xiao, Y., Nagai, Y., Deng, G., Ohtani, T., Zhu, Z., Zhou, Z., Zhang, H., Ji, M.Q., Lough, J.W., Samanta, A., Hancock, W.W. and Greene, M.I., 2014. Dynamic Interactions between TIP60 and p300 Regulate FOXP3 Function through a Structural Switch Defined by a Single Lysine on TIP60. Cell Reports, 3, pp.1-10.

Yamamoto, T. and Horikoshi, M., 1997. Novel substrate specificity of the histone acetyltransferase activity of HIV-1-Tat interactive protein Tip60. Journal of Biological Chemistry.

Yi, S.S., Hwang, I.K., Yoo, K.-Y., Park, O.K., Yu, J., Yan, B., Kim, I.Y., Kim, Y.N., Pai, T., Song, W., Lee, I.S., Won, M.-H., Seong, J.K. and Yoon, Y.S., 2009. Effects of treadmill exercise on cell proliferation and differentiation in the subgranular zone of the dentate gyrus in a rat model of type II diabetes. Neurochemical Research, 34(6), pp.1039-46.

Yun, M., Wu, J., Workman, J.L. and Li, B., 2011. Readers of histone modifications. Cell Research, 21(4), pp.564-578.

Zheng, B. and Sage, M., 2000. Engineering mouse chromosomes with Cre-loxP: range, efficiency, and somatic applications. Molecular and Cellular Biology, 20(2).

Žiburkus, J., Cressman, J.R. and Schiff, S.J., 2013. Seizures as imbalanced up states: excitatory and inhibitory conductances during seizure-like events. Journal of Neurophysiology, 109(5), pp.1296-306.

Zocchi, L.. S.-C.P., 2012. SIRT1-mediated deacetylation of MeCP2 contributes to BDNF expression. Epigenetics, 7(7), pp.695-700.

Zola-Morgan, S., Squire, L.R. and Amaral, D.G., 1986. Human amnesia and the medial temporal region: enduring memory impairment following a bilateral lesion limited to field CA1 of the hippocampus. The Journal of Neuroscience, 6(10), pp.2950-67. 